\title{
ReiDoCrea
}

ISSN: 2254-5883

Revista electrónica de investigación y Docencia Creativa Volumen 2 - 2013

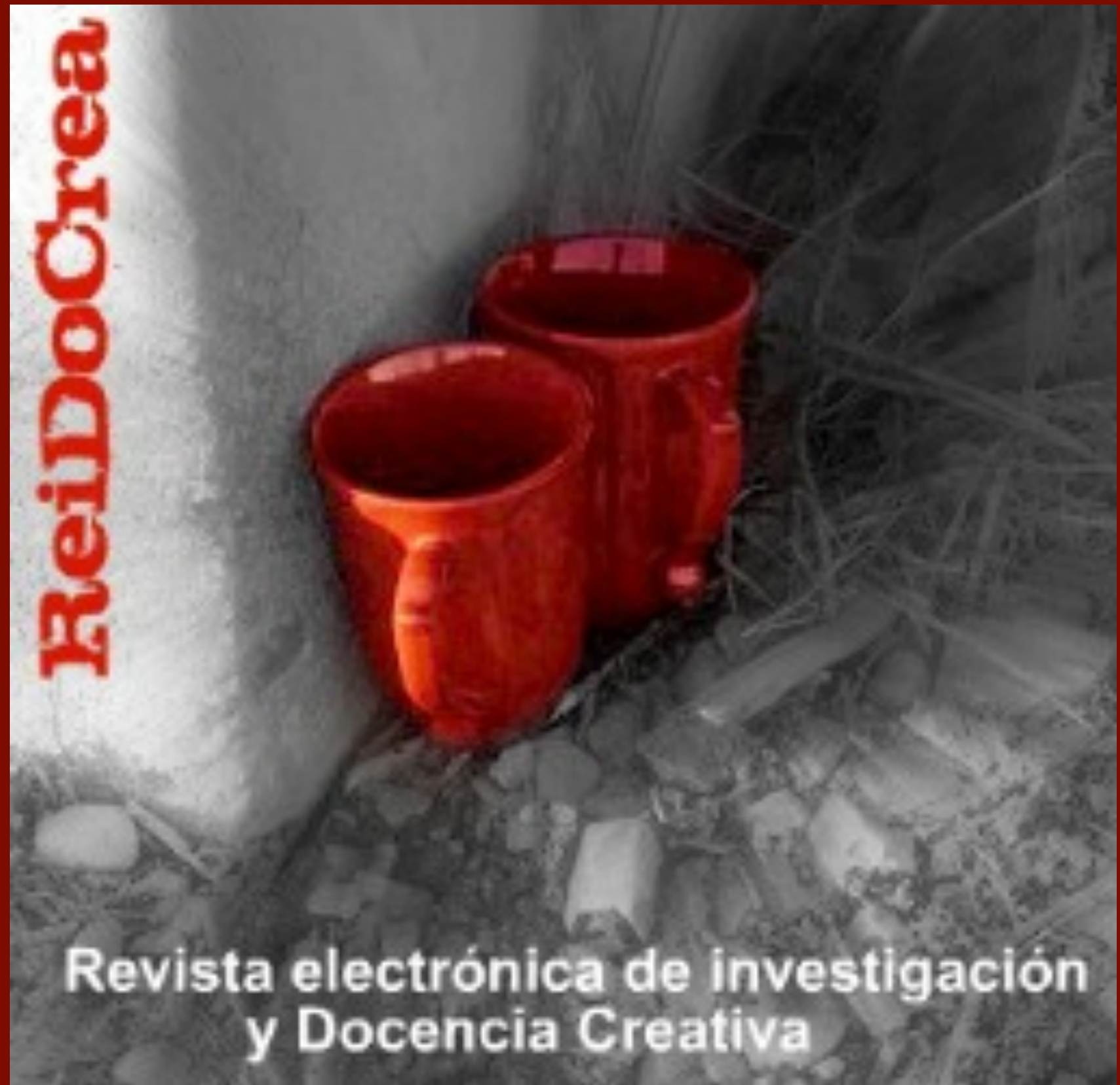

Facultad de Ciencias de la Educación Universidad de Granada http://www.ugr.es/ reidocrea/ 
Volumen 2 - año 2013

ReiDoCrea | Revista electrónica de investigación y Docencia Creativa

\section{ISSN: 2254-5883}

Facultad de Ciencias de la Educación. Universidad de Granada

Campus Universitario de Cartuja, s/n

18071 Granada

Correo-e: reidocrea@ugr.es | Skype: reidocrea

http://www.ugr.es/ reidocrea/

DIRECCIÓN-EDITORAL. Universidad de Granada

GARCÍA RAMÍREZ, JOSÉ MIGUEL

CONSEJO EDITORIAL-CIENTÍFICO

AGUILAR LUZÓN, MARÍA DEL CARMEN

ALARCÓN NAVÍO, ESPERANZA

BAJARDI, ALICE

CARRANZA DOMÍNGUEZ, DIANA

CASARES GARCÍA, PILAR

EL HOMRANI, MOHAMMED

FERNÁNDEZ ALMENARA, MARIANO G

GARCÍA MARTÍNEZ, J. MIGUEL ANGEL

GONZÁLEZ GIJÓN, GRACIA

JIMÉNEZ MOYA, GLORIA

JIMÉNEZ RÍOS, FRANCISCO JAVIER

LEMUS MARTÍN, SOLEDAD DE

LUENGO NAVAS, JULIÁN JESÚS

MARTÍNEZ RODRÍGUEZ, FRANCISCO MIGUEL

MIÑÁN ESPIGARES, ANTONIO

MONTEOLIVA SÁNCHEZ, ADELAIDA

PORRAS CHAVARINO, CARMEN

RODRIGUEZ FERNÁNDEZ, SONIA

RUIZ JIMENEZ, FRANCISCO JOSE

RUIZ ROMERO, JOSEFA

SALMERÓN VÍLCHEZ, PURIFICACIÓN

SÁNCHEZ SANTA-BÁRBARA, EMILIO

SANTOS GÓMEZ, MARCOS

SAURA CASANOVA, GEO

VALOR SEGURA, INMACULADA

ESTUDIANTES. Universidad de Granada

CONDE LACÁRCEL, ALFONSO

FRUTOS MORALES, ERICA GETSEMANÍ

JIMÉNEZ ARIZA, MARÍA DEL CARMEN

JIMÉNEZ MAÑAS, M DEL MAR

JUSTICIA DE LA TORRE, MARÍA DEL CONSUELO

MARTÍN GÓMEZ, MARI CARMEN

PEREZ FERNANDEZ, JOSE ANGEL

QUIRANTE CARRERO, M ${ }^{a}$ ROSA

RODRíGUEZ DE MEDINA QUEVEDO, ISABEL

SÁNCHEZ ARCO, DIANA V.

VALERA VIVO, TANIA
PERSONAL DE ADMINISTRACIÓN Y SERVICIOS. Universidad de Granada

COSTELA SERRANO, JUAN ANTONIO

GÁMEZ LÓPEZ, ROGELIO

GARCÍA GARCÍA, JOSÉ CARLOS

LOPEZ RODRIGUEZ, SLAVA

LEULMI TRABSI, YASMINE

PEREZ OSORIO, INES

SÁNCHEZ PUERTOLLANO, MARÍA SONIA

\section{EVALUADORES/AS EXTERNOS/AS}

ANCHETA ARRABAL, ANA

BAÑOS MILÁN, PEDRO

CAROZO MARTIIN, VALENTÍN

DE LA OLIVA GONZÁLEZ, Ma DEL MAR

DÍAZ GONZÁLEZ, Ma CARMEN

FERNÁNDEZ ESCAÑO, MARÍA DE LAS MERCEDES

FIORINI, MARZIA

GARCIA MCMULLIN, SOFIA

GUTIÉRREZ PASTOR, ISABEL

HERNANDEZ MATIZ, PAOLA ANDREA

HERNANDEZ PRADOS, MARIA DE LOS ANGELES

HERVÁS TORRES, MIRIAN

HIRSCH Y ADLER, ANA CECILIA

LEVEL, EMMA

MARIN MATAIX, VICTOR MANUEL

MARTOS ORTEGA, JOSÉ MANUEL

MATEOS BLANCO, TANIA

MCMULLIN, KAREN

MÍNGUEZ VALLEJOS, RAMÓN

MOLINERO MORALES, ROBERTO

MONTEOLIVA SANCHEZ, ENCARNACION

NAVARRO SOLANO, MARÍA DEL ROSARIO

PAILLACAR MUTIZÁBAL, TANIA VALENTINA

PAILLACAR SILVA, JOSE ALBERTO

RODRÍGUEZ ENTRENA, MARÍA JESÚS

SAGARRA MARTÍN, CATALINA

SAMPEDRO ROMÁN, FRANCISCO

SÁNCHEZ MARTÍN, MICAELA

SMITH BYRNE, KARL

VÍLCHEZ VÍLCHEZ, JOSÉ FRANCISCO 
Volumen 2 - año 2013

Índice

Título | Autores/as | Adscripción

Páginas

Artículo ReiDoCrea un proyecto de construcción y divulgación del conocimiento

Editorial José Miguel García. Universidad de Granada

1. Ansiedad y motivación de logro en estudiantes universitarios: un estudio correlacional

Pablo Aguilar, Roció Mudarra, Sarai Perelló, Cristian Rojas. Universidad de Granada

2. Factores que influyen en el rendimiento académico

M. Garrido, N. Jiménez, A. Landa, E. Páez, M. Ruiz. Universidad de Granada

3. Motivación y rendimiento académico: ¿Cumple sus objetivos el Plan de Bolonia?

Laura Fernández, José Mancebo, María Jiménez, T. Ardanaz, N. Fernández, A. Montano. Universidad de Granada

$1-10$

$17-25$

Relación entre las dimensiones del síndrome de Burnout y los factores de satisfacción laboral

David García-Fernández, María Peña, Emilio León, Beatriz Camacho, Alicia Mateos. Universidad de Granada

26-32

¿Influye el tipo de liderazgo de los profesores en la satisfacción estudiantil?

Lucia Salas, Nuria Palomero, Gema Pozo, Antonio Rosa. Universidad de Granada

$33-40$

Satisfacción de los alumnos con la institución universitaria y el rendimiento académico

6. Satisfacción de los alumnos con la institución universitaria y el rendimiento académico
Sofíceres, Emilio Jiménez, Victoria Moraleda, Belén Romero. Universidad de Granada

7. $\quad$ Auto-eficacia docente, motivación intrínseca y expectativa de resultado de alumnado

Joel Revelli, P. Gutiérrez, F. del Castillo, M. Centeno, A. Vinuesa, B. Balcaid, M. Andrade. Universidad de Granada

El síndrome del quemado en el personal sanitario y la satisfacción del paciente

8. El síndrome del quemado en el personal sanitario y la satisfacción del paciente
Roció Cano, Zoraida Ciruela, Irene Gómez, Ángel Mata, Carolina Montalvo, Héctor O Om

9. Efectos de la crisis económica sobre la salud mental en la población española

Agar Marín, Lucia Gil, Vanesa Román, Luca Farella. Universidad de Granada

10. Relación entre engagement y las creencias de autoeficacia en los trabajadores

María Fajardo, Marianela Iroz, Debla López, Seima Mirón. Universidad de Granada

11. ¿Líderes sexistas? Un estudio sobre la influencia del sexismo en los estilos de liderazgo

Carolina Garzón, D. Jiménez, I. Juan, C. Luque, R. Navío, M. Pacheco, M. Pérez. Universidad de Granada

12. TDAH y su relación con la motivación en el contexto educativo

Isabel Gómez, Verónica Morán, Macarena Pereda, Eloísa Pazos. Universidad de Huelva

13. La motivación en los diferentes contextos educativos en alumnado de Educación Secundaria

Mirian Ceciliano, Laura Feria, Jenny González, Soroya Orta. Universidad de Huelva

$54-62$

Discriminación racial dentro del ámbito universitario

Gracia Nacarí Lara-Guardia. Universidad de Granada

$63-70$

El papel de la mujer en el franquismo y en la democracia: análisis comparativo entre épocas

María del Pilar Garrido-Cárdenas, María Lina Higueras-Rodríguez. Universidad de Granada

$71-78$

Estudio correlacional entre la imaginación creativa y las habilidades sociales

Lucía González-Rodríguez, Lorena Marín-Polo, Ángela Ruiz-Velasco. Universidad de Granada

Homosexualidad, ¿Qué actitud tienen los universitarios al respecto?

Daniel Baena-Pérez, María del Rocio Calvente-Pérez, Marina Díaz-Sánchez. Universidad de Granada

18. Autoconcepto: factores e influencias

Ignacio Casado-Lozano, Alberto Hernández-Sande, Elena Manzano-Bazagaz. Universidad de Huelva

La dependencia emocional en las relaciones interpersonales

Isabel Rodríguez de Medina-Quevedo. Universidad de Granada

20. Un centro lúdico como refuerzo educativo en período vacacional

Alba Marín-Santaolaya, José María Romero-Rodríguez. Universidad de Granada

Voluntariado: perspectivas de los estudiantes de desarrollo internacional

Jory Bolton. Trent University (Canadá)

22. Motivación de logro y motivación hacia la práctica de la actividad físico-deportiva

María Almudena Carrasco-Mantero, Rosario Lepe-Pavón. Universidad de Huelva

23. La influencia del autoconcepto en el rendimiento académico: una revisión teórica

Bella Aguilar, Ana Navarro, Roció Rodríguez, Virginia de la Cinta Trillo. Universidad de Huelva

$130-137$

Incidencia de los factores psicosociales en el trabajo: un estudio en docentes universitarios

Sonia Ortega-Domínguez, Carmen Sánchez-Díaz. Universidad de Huelva

$157-162$

Relación entre el autoconcepto y el rendimiento académico en adolescentes

Marina Agapito, Ana Calderón, Blanca Cobo, Laura Rodríguez. Universidad de Huelva

$163-168$

Aplicaciones de la inteligencia emocional

Christian Platero-lbáñez. Universidad de Granada

27. Propuestas de mejora de trabajo en casos de absentismo escolar en educación primaria

Raquel Coronel Garrido, Melody Díaz García, Patricia Moreno Leal. Universidad de Huelva

28. La importancia de la creatividad en las aulas del primer ciclo de la Enseñanza Secundaria

V. Carreño, I. Castillo, C. Falcón, M.L. Romero, S. Rico. Universidad de Huelva

29. Acoso escolar: sensibilización y percepción de los alumnos de psicología

F. Cabello, C. Gregorio, M. Monge, G. Suárez. Universidad de Huelva

$169-173$

$174-180$

La inteligencia emocional aplicada al mundo laboral

Álvaro Moreno-Lucena. Universidad de Granada

Estilos de enseñanza y las nuevas tecnologías en la educación

D.M. García, M. Joaquín, P. Torres, I. R. Vázquez. Universidad de Huelva

$212-218$

La gestión del centro educativo ante situaciones de acoso escolar

M. Boumadan-Hamed, A. Vega-Galiano. Universidad de Granada

33. Percepción de la inclusión educativa entre el profesorado

Alfonso Conde-Lacárcel. Universidad de Granada

219-225

Comprendiendo la amenaza del estereotipo

Sofía Furrer. Universidad de Granada 


\title{
ReiDoCrea un proyecto de construcción y divulgación del conocimiento
}

\author{
ReiDoCrea a Project of Knowledge Building and Dissemination \\ José Miguel García Ramírez. Universidad de Granada \\ Fecha de recepción: 30 de mayo de 2013 | Fecha de aceptación y publicación: 12 de junio de 2013
}

\section{Resumen}

ReiDoCrea es un proyecto de innovación que consolida la primera revista electrónica de investigación en la que los estudiantes pueden construir y divulgar el conocimiento aprendido mientras estudian. El proyecto utiliza los principios de Investigación-Acción. Durante el curso académico 2011-12 participaron 145 estudiantes ( $M=26,52$, $S D=5,23)$. Se publicaron 21 artículos de 39 presentados. Las categorías emergentes significativas fueron: Motivación con un $92 \%$ de frecuencia y Dificultad con un $89 \%$ de frecuencia (Atla.ti).

Palabras clave: Educación | Creatividad | Innovación | Empatía | Motivación

\begin{abstract}
ReiDoCrea is an innovation project that consolidates the first electronic research journal in which students can build and disseminate knowledge learned while studying. The project uses the principles of action research. During the academic year 2011-12 145 students participated $(M=26.52, S D=5.23)$. Of the 39 articles presented, 21 were published. Significant emerging categories were: Motivation with $92 \%$ frequency and difficulty with $89 \%$ frequency (Atla.ti).
\end{abstract}

Keywords: Education | Creativity | Innovation | Empathy | Motivation

La innovación y la creatividad son claves en el desarrollo de la Educación Superior. En este sentido, el pensamiento creativo es necesario tanto en el alumnado como en el profesorado para favorecer e incrementar la eficiencia y la satisfacción en el proceso educativo. Además, la sociedad reclama una enseñanza renovada, creativa, interdisciplinar y contextualizada (Fiorini y Garcia-Ramirez, 2013; Garcia-Ramirez, Garcia-Sempere y Fiorini, 2012; Garcia-Ramirez, 2012).

A través del uso de las Tecnologías de la Información y la Comunicación, TIC, se implementa el proyecto de innovación docente ReiDoCrea, consolidándose como revista electrónica de investigación en la que los estudiantes pueden construir y divulgar el conocimiento aprendido durante el curso académico. Por lo tanto, para consolidar el proyecto se utilizan los principios de Investigación-Acción, para generar un cambio de actitud y comportamiento, promocionar el aprendizaje social y cooperativo, y potenciar el desarrollo personal de identidad sociocultural (GarciaRamirez, 2012). Esto posibilita el cumplimiento de los objetivos marcados por el proyecto: Mejorar la docencia, como proceso de enseñanza-aprendizaje; Incrementar la satisfacción y la motivación en docentes y estudiantes; Aumentar la motivación en la educación universitaria; Desarrollar un nuevo instrumento de evaluación del rendimiento académico; y divulgar el conocimiento adquirido por el alumnado. 
La Universidad de Granada, para cumplir con una educación con garantía de la calidad, evalúa anualmente la docencia a través de un cuestionario aprobado por su Consejo de Gobierno. La valoración media en Facultad de Ciencias de la Educación es de aproximadamente 4,00 sobre 5,00 . Aunque el rendimiento y la eficacia de la docencia son altos, se puede mejorar motivando a los estudiantes a publicar sus trabajos para divulgarlos en la sociedad. (García-Ramírez, 2012)

\section{Método}

\section{Participantes}

Participaron 145 estudiantes, 113 mujeres y 32 hombres, con edades comprendidas entre 20 y 61 años $(M=26,52$, $S D=5,23)$. Los participantes participaron voluntariamente y eran estudiantes de las titulaciones o grado de Psicopedagogía $(46 \%)$, Pedagogía (5\%), Primaria (5\%), Educación Social (18\%), Educación Infantil (5\%) Psicología (15\%) y Logopedia (6\%).

\section{Instrumentos y procedimiento}

Elaborar un estudio de investigación relacionado con unas asignatura que estaban cursando en ese momento y siguiendo las normas publicadas en la revista ReiDoCrea. Después el alumnado participante tenía que completar un cuestionario de una pregunta abierta en el que se le pedía a los/as participantes que describiera su experiencia, expresando como se sintió durante todo el proceso de elaboración, revisión y publicación de su trabajo.

Se aplicó la valoración de logro; entendiendo como logro la publicación de su trabajo académico el cual había sido evaluado por pasos de manera estrictamente sistemática:

- La primera corresponde al profesorado participante que evalúa los trabajos realizados por el alumnado. Pero previamente el profesorado había incorporado, en el contenido de la guía docente, los criterios de evaluación que aseguran que el alumnado adquiera los conceptos básicos, la capacidad de análisis de la realidad, el sentido crítico y dominio de las claves epistemológicas y teóricas de la materia.

- La segunda valoración de los trabajos es realizada por los miembros del consejo o evaluadores externos.

- La tercera valoración de los trabajos es realizada por un comité de iguales, estudiantes del grado participantes en el proyecto.

- La cuarta valoración es una autoevaluación, a través de un relato breve (máximo de 200 palabras), para explicar su experiencia en esta actividad. Los datos obtenidos se analizan a través del programa Atla.ti para codificar el material y describir las categorías emergentes

\section{Resultados}

Los/as 145 participantes presentaron 39 artículos valorados positivamente por su profesorado. Todos los/as estudiantes participantes superaron las asignaturas, el $52 \%$ de los/as participantes obtuvieron sobresaliente y el $26 \%$ notable.

Posteriormente los trabajos fueron enviados a la revista para su segunda valoración y posible publicación en la revista. De los 39 artículos presentados fueron evaluados positivamente y publicados 21 artículos elaborados por 61 participantes, equivale al $41 \%$ de los 145 participantes. 
La tercera valoración se hizo entre iguales para conocer los puntos fuertes, débiles y posibilidades de mejora; se exponen en la siguiente tabla:

\begin{tabular}{lll} 
PUNTOS FUERTES & PUNTOS DÉBILES & POSIBILIDADES DE MEJORA \\
\hline Motivación. & & \\
\hline $\begin{array}{l}\text { Revista electrónica de investigación } \\
\text { gratuita y de carácter público. }\end{array}$ & Redactar un artículo. & $\begin{array}{l}\text { Curso específicos para } \\
\text { elaborar artículos académicos } \\
\text { Depositada en el Digibug. }\end{array}$ \\
\hline Satisfacción. & & \\
\hline $\begin{array}{l}\text { Publicación de los trabajos } \\
\text { elaborados por los estudiantes. }\end{array}$ & Tiempo de revisión. \\
\hline
\end{tabular}

La última valoración corresponde al cuestionario de una pregunta abierta en el que se le pedía a la persona participantes que describiera su experiencia, expresando como se sintió durante todo el proceso de elaboración, revisión y publicación de su trabajo. Los participantes entregaron el cuestionario completado después de que se les informara si sus trabajos habían sido aceptados no para su publicación. Participaron el $100 \%$ de los participantes. Las categorías emergentes significativas fueron: Motivación con un $92 \%$ de frecuencia y Dificultad con un $89 \%$ de frecuencia (Atla.ti). La dificultad se debe principalmente a la inseguridad y falta de apoyo en el momento de elaborar un artículo académico, principalmente, porque no tuvieron formación previa de cómo elaborar un artículo.

A continuación se detallan la información básica de los artículos aceptados: Título, autores/as, resumen y palabras clave:

Proyecto innovación y buenas prácticas docentes, ReiDoCrea (García-Ramírez, 2013). Resumen: Docencia-Creativa es un proyecto de innovación docente de la Universidad de Granada con la misión de publicar los trabajos que realiza el alumnado durante el curso académico. Supone una mejora global en el proceso de enseñanzaaprendizaje, porque implica la participación activa y creativa de ambas partes del proceso educativo, docentes y estudiantes. Palabras clave: Educación; Creatividad; Innovación; Empatía; Motivación.

El efecto del burnout en la antigüedad en el puesto de trabajo: Análisis mediacional de la ansiedad (Sagripanti, Gonzalez, Messi, Romero y Khlie, 2012). Resumen: Cada vez en mayor medida se hace patente que el síndrome de burnout es una realidad social. Esta disfunción psicológica está relacionada directamente con el ámbito laboral, que afecta especialmente a la profesión sanitaria, caracterizada por una continua relación de ayuda indispensable hacia otras personas, que a su vez dependen del citado personal. La muestra de estudio es de 70 trabajadores de un mismo centro del sector sanitario de atención de mayores de la ciudad de Granada. Los resultados muestran que la ansiedad se relacionará positivamente tanto con el burnout como con la antigüedad en el puesto, mientras que predecimos que a menor realización personal en presencia de mayor antigüedad los valores en ansiedad también serán más altos. También se comprueba que la ansiedad estado tiene efectos mediadores sobre la realización personal, puesto que puede causar mayor alteración de este estado que la propia antigüedad. Palabras Clave: Síndrome de estar quemado; Antigüedad; Realización personal; Sanidad; Estrés.

Cualificación y satisfacción laboral: Un estudio sobre los empleos para los que hemos sido formados previamente (Asenjo, Dios y Banqueri, (2012). Resumen: Esta investigación, que ha contado con 80 sujetos, explora la relación entre las diferentes dimensiones de la satisfacción laboral y la cualificación del trabajo (relacionado o no con 
los currículos académicos previos). Se ha realizado utilizando Cuestionario de Satisfacción Laboral S20/23. Los resultados han sido significativos, confirmándose la hipótesis: hemos encontrado mayor satisfacción laboral en los sujetos que desarrollan trabajos cualificados y menor satisfacción en los que desarrollan trabajos no cualificados. Palabras clave: Cualificación; Satisfacción laboral; Formación previa.

Efectos de la turnicidad sobre la ansiedad y la salud psicológica en profesionales sanitarios de centros hospitalarios (Lizarte, Montero, Peral y Postigo, 2012). Resumen: El objetivo de este estudio correlacional es analizar el efecto que tiene el turno rotatorio sobre la ansiedad y la salud psicológica autopercibida del personal sanitario de enfermería, frente a aquellos profesionales de la misma categoría que tienen un turno fijo. Para ello se administraron dos cuestionarios que recogían las variables de interés, a una muestra de 140 profesionales de enfermería que trabajan en los hospitales de la provincia de Granada. Los resultados han mostrado que no hay evidencia significativa entre la ansiedad y la salud psicológica autopercibida sobre la turnicidad, sin diferencias relevantes con el turno fijo. Se concluye que hay una tendencia a padecer más trastornos de ansiedad entre aquellos profesionales sanitarios que llevan más años en la profesión. Palabras clave: Turnicidad; Ansiedad; Salud percibida; Enfermería.

\begin{abstract}
¿Depende la satisfacción estudiantil de la calidad real de la facultad 0 de la percepción individual de esta? Análisis comparativo entre facultades privadas y públicas (Pérez, López, Couto y Navarro, 2012). Resumen: El objetivo de este estudio es conocer la satisfacción estudiantil en relación a las universidades públicas y privadas. Es un estudio correlacional, realizado en la Universidad de Granada en la escuela universitaria de magisterio La Inmaculada y en la de facultad de ciencias de la educación. Participaron 111 alumnos entre ambas facultades que completaron un cuestionario sobre satisfacción estudiantil. Los principales resultados exponen que a pesar de no obtener diferencias significativas en la satisfacción global, sí lo hacen en distintos aspectos, obteniendo mayor satisfacción los estudiantes de la Facultad privada, en competencias profesionales y servicio administrativo, en comparación con los de la pública que obtienen mayores puntuaciones en satisfacción con el ambiente en la facultad y la biblioteca. Palabras Clave: Satisfacción estudiantil; Universidad Pública; Universidad Privada.
\end{abstract}

Las habitaciones de la Dislalia (Moreno y Ramírez, 2012). Resumen: La primera parte de este artículo la hemos dedicado a exponer algunos aspectos que consideramos básicos para conocer en qué consiste la dislalia. Hemos desarrollado con más profundidad la dislalia funcional porque es uno de los trastornos de habla que actualmente está aumentando su porcentaje de aparición en los colegios. El resto del artículo está dedicado a concienciar sobre la importancia que tiene el entorno familiar en el desarrollo lingüístico del/a niño/a y a ofrecer algunas orientaciones y ejercicios que permita a la familia estimular este desarrollo utilizando el tiempo que emplean para realizar actividades de su vida cotidiana. Palabras clave: Desarrollo del lenguaje; Trastorno del habla; Familia; Dislalia.

Guía de intervención para un alumno con Hipoacusia Neurosensorial (Segura Azor (Universidad de Granada). Resumen: Este estudio de caso se centra en un niño con hipoacusia neurosensorial. Se detalla cómo se detectó y qué pasos se siguieron en su tratamiento. En el equipo reintervención, contamos con una maestra de Pedagogía Terapéutica (PT) y dos profesionales de Audición y Lenguaje ( $\mathrm{AL}$ ). El sujeto ha tenido una evolución muy adecuada, a partir de los objetivos y actividades propuestas por el equipo a lo largo de su etapa escolar, las cuales se describen en el presente trabajo. Este estudio de caso pretende servir de guía a futuros maestros y maestras que trabajen ante una problemática similar. Palabras clave: Estudio de caso; Sordera; Educación de sordos; Lenguaje de signos.

El síndrome de Dandy Walker y su intervención en la infancia (García, 2012). Resumen: El Síndrome de Dandy Walker es una anomalía congénita del cerebelo y del IV ventrículo, que aparece normalmente en la infancia y recibe múltiples nominaciones. 
Su característica más común es la hidrocefalia y en la mayoría de los casos, las causas se desconocen. El artículo se centra en gran parte en el análisis de un caso práctico de un niño de cinco años, con dificultades en la movilidad debido al retraso psicomotor y sin habla, cuyo tratamiento está basado en el control de los movimientos, en la estimulación del balbuceo y en el aprendizaje de un sistema alternativo de comunicación. Palabras clave: Síndrome de Dandy Walker; Infancia; Lengua; Necesidades educacionales; Técnicas de comunicación.

Trabajando de forma cooperativa en la escuela: abriendo la puerta a las familias (García, 2012). Resumen: Este estudio pretende mostrar la importancia del trabajo cooperativo en la escuela, en especial del relacionado con la participación de los padres y la familia de los alumnos con el profesorado y el centro educativo. Por otro lado, se propondrán variadas acciones y actividades educativas prácticas que se pueden llevar a cabo en el mismo para conseguir la relación cooperativa familia-escuela y alcanzar así el clima óptimo para el desarrollo integral del alumno y una educación de calidad que serán los principales objetivos perseguidos. Todo ello se hará en el marco del respeto y la integración de todos los sujetos implicados. Palabras clave: Relación padres-escuela; Familia; Participación de los padres; Enseñanza en equipo; Cooperación educacional.

El uso de técnicas de animación sociocultural en la Universidad mejora las relaciones interpersonales entre profesores y estudiantes en la universidad (López, Platero, Aguilar y Rubia, 2012). Resumen: La relación existente entre el profesor y los alumnos puede depender de muchas circunstancias. De entre ellas, este estudio se centra en confirmar que el uso de técnicas de animación sociocultural en el aula hace que se vean mejoradas las relaciones interpersonales entre estos agentes educativos. El procedimiento metodológico seguido se centra en un enfoque interpretativo-descriptivo mediante el uso de unos cuestionarios como técnicas de recogida de datos. Los resultados encontrados confirman nuestra hipótesis inicial y a la vez nos abren las puertas hacia futuras líneas de investigación. Palabras clave: Animación sociocultural; Relaciones interpersonales; Innovación educativa; Comunicación interpersonal; Grupos.

La educación diferenciada en Primaria, ¿se puede llamar coeducación? (Sánchez, 2012). Resumen: En este trabajo se tiene como referencia el aprendizaje diferenciado en la etapa de Primaria, y tras tener en cuenta diversas teorías tanto a favor como en contra de la misma, podemos realizar un análisis exhaustivo de si realmente dicho aprendizaje logra la coeducación o no, en el aula. Como conclusión podemos sostener que existen pocos estudios que abalen dicha manera de entender la educación, además como hemos podido observar se tiende a generalizar en la enseñanza de niñas y de niños como un todo, sin tener en cuenta las características esenciales de cada persona. Palabras clave: Educación; Diferenciación; Sexos; Métodos; Posibilidades.

Consumo de sustancias adictivas y efectos en las relaciones intergrupales y personales en estudiantes universitarios (Pastrana, Manrubia y Muñoz, 2012). Resumen: Tras una primera revisión bibliográfica se llega a la conclusión de que, en el ámbito del estudiante universitario español, no se han realizado estudios acerca de las consecuencias del consumo de sustancias adictivas en relación a las relaciones interpersonales. Nuestro objetivo es analizar los efectos del consumo de sustancias adictivas dentro de las relaciones intergrupales en el ámbito universitario para que, posteriormente, esta investigación pueda ser llevada a cabo en otros ámbitos. La muestra empleada, que ha sido seleccionada de manera aleatoria, queda organizada en 50 estudiantes, a los cuales se les ha pasado un cuestionario relacionado con el tema investigado. Nuestros resultados apoyan el efecto que causa el consumo de sustancias adictivas, a través de las diferentes variables estudiadas, en la población universitaria. Palabras claves: Sustancias adictivas; Consumo; Consecuencia; Relaciones intergrupales de género; Concienciación.

Las redes sociales influyen en el comportamiento de los universitarios (Jabalera, Morey, Rodríguez y Sánchez, 2012). Resumen: Las redes sociales son un medio muy utilizado hoy en día por el colectivo universitario, de este modo nos centramos en 
investigar su influencia en el comportamiento de éstos, para comprobar hasta qué punto se dejan de lado las relaciones interpersonales por la utilización de éstas, así como las actividades más utilizadas en las mismas, y las que se dejan de realizar por su utilización. Nos centramos en un colectivo de la universidad de Granada. Palabras clave: Redes sociales; Relaciones interpersonales; Comunicación; Influencia social; Disonancia cognitiva.

Las mujeres viven la relación romántica diferente al hombre (García, Garnica, González, Márquez, Martín, Pérez y Vico, 2012). Resumen: Desde hace unas décadas, han emergido una serie de teorías que estudian las relaciones románticas y los estilos de amor. En base a estas teorías, nos ha parecido interesante estudiar las relaciones románticas de 120 estudiantes de la Facultad de Ciencias de la Educación de la Universidad de Granada y confirmar si existe relación con la diferencia de género, comprobando si difieren en la importancia que otorgan a los diferentes estilos de amor. Para ello, se administró la Escala de Actitudes sobre el Amor (LAS). Los resultados indican que entre las mujeres el estilo de amor más aceptado es Eros mientras que en los hombres es Ludus. En los estilos Ágape y Manía se muestra una clara diferencia entre mujeres y hombres, ya que estos obtienen mayor puntuación de la esperada. Se muestra una indiferencia, sin distinción de género, en los estilos de amor Pragma y Storge. Se analizan y discuten los resultados. Palabras claves: Relación romántica; Estilos de amor; Género.

La medida de la empatia en el alumnado de la facultad de ciencias de la educación de Granada (Artacho, López, Molina, Ortiz, Rosado, Ruiz y Sillero, 2012). Resumen: El objetivo principal de este trabajo de investigación ha sido analizar la capacidad empática de 100 universitarios de la Facultad de Ciencias de la Educación de Granada. Para ello hemos utilizado el "Interpersonal Reactivity Index" (IRI), que es uno de los cuestionarios más utilizados para evaluar esta capacidad. Este instrumento incluye dos subescalas dedicadas a factores cognitivos, la toma de perspectiva (PT) y la fantasía (FS) y otras dos a factores emocionales, la preocupación empática (EC) y el malestar personal (PD). Palabras Clave: Empatía; Toma de perspectiva; Fantasía; Preocupación empática; Malestar personal.

Las tic en la educación superior como vía de formación y desarrollo competencial en la sociedad del conocimiento (Molina, 2012). Resumen: La sociedad del conocimiento, nos pone a prueba en relación a las destrezas, conocimientos y habilidades que adquirimos. El ámbito educativo ha de avanzar al compás de esta sociedad desde la primera de las etapas hasta el final de ellas, valiéndose de las TIC. A través del presente trabajo se pretende analizar la interacción comunicativa establecida entre docentes y discentes a través de los espacios virtuales en la Educación Superior, profundizando en sus posibilidades y destacando la necesidad de flexibilizar la educación. A la vez, se muestran una serie de experiencias renovadoras y unas vías de continuidad en el futuro. Palabras clave: Tutor virtual; Espacio virtual; Aprendizaje virtual; TIC; Educación Superior.

Percepción de la inclusión educativa en el contexto universitario: un estudio aproximativo en la Facultad de Ciencias de la Educación de la Universidad de Granada (Conde, 2012). Resumen: El presente artículo pretende realizar un análisis aproximativo respecto al grado de aplicación de la inclusión educativa en la Facultad de Ciencias de la Educación de la ciudad de Granada. ¿Es consciente el alumnado y el profesorado de esta corriente que se está desarrollando desde hace tiempo en el sistema educativo de otros países y también en el nuestro; En qué grado conciben la comunidad universitaria que está llevándose a cabo? Primera parte, de un estudio aproximativo centrado en la percepción del alumnado, que posteriormente se complementará con la percepción del profesorado. Palabras clave: Educación universal; Acceso a la educación; Inclusión educativa; Enseñanza Superior.

Calidad educativa y espacios de trabajo universitarios (Fernández, Gámiz, García, Moraga, Peña y Porras, 2012). Resumen: La sociedad actual avanza a pasos 
agigantados, circunstancia que exige de nuestro modelo educativo un cambio paralelo a dichos avances. La educación es uno de los motores de cambio y como tal debe dar respuesta a las exigencias que se le planteen. Es mucha la bibliografía que podemos encontrar acerca de la calidad educativa, pero muy poca de ésta se centra en la evaluación de la calidad de los espacios educativos como tales. Desde este estudio se pretende analizar los puntos de vista y exigencias de los estudiantes de la Facultad de Ciencias de la Educación de la Universidad de Granada respecto a dichos espacios educativos. Palabras clave: Universidad; Calidad educativa; Espacios educativos; Ambiente educativo.

EI Mindfulness como método para la mejora de las relaciones interpersonales (Rodríguez de Medina, 2012). Resumen: Muchos de los problemas sociales se remontan a las dificultades de comunicación interpersonal. Este ensayo examina el potencial de la relación entre los estados de la mente, su anatomía y las interacciones sociales seguido por la eficacia de los programas Mindfulness para la mejora de los males sociales. Palabras claves: Relaciones interpersonales; Mindfulness; Emoción; Neurobiología; Apego.

La interacción comunicativa en el proceso de enseñanza-aprendizaje (Márquez, 2012). Resumen: Tomando como referencia el proceso de interacción comunicativa, que alude al sistema de transmisión de mensajes o información entre personas, y teniendo en cuenta los tipos de lenguajes implicados en el proceso comunicativo, en este trabajo se abordarán las diferentes formas de interacción comunicativa -formal y espontáneoque pueden llegar a darse en el aula entre profesorado y alumnado, tanto de forma interpersonal como grupal, así como sus implicaciones didácticas. De igual modo, se realizará un breve recorrido sobre los estilos de profesorado y por consiguiente, los estilos de comunicación didáctica que favorecen un tipo u otro de interacción entre el profesorado y el alumnado. Palabras clave: Comunicación; Interacción; Enseñanza; Aprendizaje.

Universidad y empredimiento: Un caso de estudio en la Facultad de Ciencias Económicas y Empresariales de la Universidad de Granada (Ruiz, Cabeza y Briano, 2012). Resumen: Con el objetivo de fomentar una cultura emprendedora dentro del ámbito educativo, se desarrollaron prácticas en las cuales los estudiantes de la licenciatura en administración y dirección de empresas, debían realizar las distintas etapas del plan de empresa que el emprendedor tiene en cuenta en el momento de poner en marcha su negocio. En este trabajo, analizamos esta experiencia en emprendimiento, destacando el importante desafío que tienen las instituciones educativas en desarrollar programas, en los cuales, los estudiantes puedan contar con herramientas que les sirvan a la hora de emprender su propio negocio en un mercado laboral competitivo. Con el fin de contribuir al desarrollo económico y social del país. Observamos que antes de esta practica, la mayoría de los alumnos no habían tenido una experiencia de emprendimiento es su carrera universitaria. Además, al finalizar dicha práctica más de la mitad de los estudiantes desean continuar con su proyecto de empresa. Palabras clave: Emprendimiento; Mercado laboral; Universidad.

La competencia comunicativa en personas que presentan parálisis cerebral (Rosado, 2012). Resumen: A pesar de los numerosos intentos por definir universalmente la Parálisis Cerebral, todavía no se ha conseguido una definición que una todas las opiniones acerca de ésta, aunque sí existen puntos en común en la mayoría de ellas. Todas las personas, para poder desenvolverse en su contexto social, deben desarrollar su capacidad de comunicación, especialmente las personas con parálisis cerebral. Esta capacidad se debe potenciar, desde el desarrollo de la lengua por parte de los centros educativos, a través del desarrollo de la competencia comunicativa ya sea a través del lenguaje oral o a través de los sistemas alternativos/aumentativos de comunicación. Palabras clave: discapacidad, persona con discapacidad, comunicación, comunicación alternativa, competencia comunicativa. 


\section{Qué supone el proyecto para la mejora del aprendizaje}

Este proyecto supone una mejora global en el proceso de enseñanza-aprendizaje, porque implica de una forma participativa y creativa a ambas partes del proceso educativo, docentes y estudiantes. El profesorado orienta y guía al alumnado durante el proceso de aprendizaje de los contenidos necesarios para que adquiera las competencias necesarias de la propia área del conocimiento; pero el profesorado, también, es responsable garantizar la mayor calidad en los trabajos académicos. La publicación de un trabajo académico es un reconocimiento público a los autores; pero este proyecto también conlleva una mejora en eficiencia y satisfacción, porque el estudiante puede sentir que su rendimiento es útil. También forma parte de un proceso de enseñanza-aprendizaje sociocultural consciente de la importancia de la difusión del conocimiento.

\section{Conclusiones}

Los resultados obtenidos justifican la necesidad de potenciar la comunicación entre docentes y estudiantes para construir el conocimiento de manera social o colaborativa. Esto se puede implementar desde la simpatía como proceso de escucha que supone ponerse en el lugar del otro y considerarlo un igual aunque los roles de docente y estudiante sean diferentes. Por lo tanto, en la Educación Superior reconocer los trabajos que realizan los/as estudiantes está significativamente relacionado con la motivación y el pensamiento creativo. (García-Ramírez, 2012)

La divulgación del conocimiento adquirido responde a la demanda social; además de ser un vehículo de reconocimiento y eficiencia de una Educación de Excelencia Visible. Por lo tanto, se plantea la creación de ReiDoCrea, Revista electrónica de investigación y Docencia Creativa, partiendo de los recursos existentes. (Fiorini, García Ramírez, 2013)

Para finalizar todas las publicaciones en la revista están sujetas a la licencia Creative Commons Attribution 4.0 International, se adhiere a los principios y procedimientos dictados por el Committee on Publication Ethics "COPE", deposita todos los artículos en el Repositorio de la Universidad de Granada "Digibug" y ha sido indexada en el catálogo de Latindex y en el Google Académico.

\section{Referencias}

Artacho Castilla, F.; et al. (2012). La medida de la empatía en el alumnado de la Facultad de Ciencias de la Educación de Granada. ReiDoCrea, 1, 101-105. http://hdl.handle.net/10481/21968

Asenjo Fenoy, A.; Banqueri López, M.; De Dios Chacón, M. (2012). Cualificación y satisfacción laboral: un estudio sobre los empleos para los que hemos sido formado previamente. ReiDoCrea, 1, 4-11. http://hdl.handle.net/10481/21938 
Conde Lacárcel, A. (2012). Percepción de la inclusión educativa en el contexto universitario: un estudio aproximativo en la FCEE de Granada. ReiDoCrea, 1, 115-125. http://hdl.handle.net/10481/20634

Fernández Pérez, R.; et al. (2012). Calidad educativa y espacios de trabajo universitarios. ReiDoCrea, 1, 126-131. http://hdl.handle.net/10481/21986

Fiorini, M.; Garcia-Ramirez, JM. (2013). Cap. 5: Técnicas de grupo y creatividad aplicadas en el ámbito universitario,117-147. En Villena Martinez, MD.; Muñoz Garcia, A. (2013). Recursos para la tutoría en el aula universitaria. Granada: Editorial Universidad de Granada.

Gallardo Pastrana, M.E.; Manrubia Prados, C.M.; Muñoz Palomino, R. (2012). Consumo de sustancias adictivas y efectos en las relaciones intergrupales y personales en estudiantes universitarios. ReiDoCrea, 1, 80-87. http://hdl.handle.net/10481/21975

García Caballero, I.M. (2012). El síndrome de Dandy Walker y su intervención en la infancia. ReiDoCrea, 1, 52-58. http://hdl.handle.net/10481/21943

García Carmona, M. (2010). Trabajando de forma cooperativa en la escuela: abriendo la puerta a las familias. ReiDoCrea, 1, 59-66. http://hdl.handle.net/10481/21944

García Palma, M.E.; et al. (2012). Las mujeres viven la relación romántica diferente al hombre. ReiDoCrea, 1, 95-100. http://hdl.handle.net/10481/21967

Garcia-Ramirez, J.M. (2011). Una reconsideración de la excelencia visible en la educación superior: la escucha empática. Andaluciaeduca, 66, 84. http://www.andaluciaeduca.com/hemeroteca/ae digital66.pdf

García-Ramírez, J.M. (2012). Docencia-Creativa: una estrategia de motivación a través de la difusión del conocimiento. Reidocrea, 1, 1-3. http://hdl.handle.net/10481/33571

García-Ramírez, J.M. (2012). La comunicación, clave de excelencia visible en la Educación Superior. Journal for Educators, Teachers and Trainers, 3, 25-36. http://hdl.handle.net/10481/22300

Garcia-Ramirez, J.M. (2012). Las Tecnologías de la Información y la Comunicación, TIC, en la educación universitaria. Andaluciaeduca, 76, 77. http://www.andaluciaeduca.com/hemeroteca/ae_digital76.pdf

García-Ramírez, J.M. (ed.). (2012). ReiDoCrea: volumen 1. Granada: Universidad de Granada. http://hdl.handle.net/10481/33702

García-Ramírez, J.M.; García-Sempere, P.J.; Fiorini, M. (coords.). (2012). Docencia universitaria y creatividad. Granada: Universidad de Granada. http://hdl.handle.net/10481/33193

Garcia-Ramirez, J.M.; Perez-Villen, MP. (2003). Educación y convivencia, 555-557. En Alvaraz-Rodriguez, J.; Casares-Garcia, P.; Luengo-Navas, J. (2003). Participación, Convivencia y Ciudadanía. Granada: Ediciones Osuna. ISBN 13: 978-84-95805-18-8 
Herrero Márquez, P. (2012). La interacción comunicativa en el proceso de enseñanzaaprendizaje. ReiDoCrea, 1, 138-143. http://hdl.handle.net/10481/21983

Jabalera Sierra, P.M.; Morey Amer, M.M.; Rodríguez Bonachera, A.; Sánchez Molina, A.B. (2012). Las redes sociales influyen en el comportamiento de los universitarios. ReiDoCrea, 1, 88-94. http://hdl.handle.net/10481/21966

Lizarte Castillo, M.; Montero Madej, A.; Peral Bueno, N.; Postigo Higueras, E. (2012). Efectos de la turnicidad sobre la ansiedad y salud psicológica en profesionales sanitarios de centros hospitalarios. ReiDoCrea, 1, 21- 28. http://hdl.handle.net/10481/21939

López Serrano, C.J.; et al. (2012). El uso de técnicas de animación sociocultural en la Universidad mejora las relaciones interpersonales entre profesores y estudiantes en la Universidad. ReiDoCrea, 1, 67-75. http://hdl.handle.net/10481/21945

Molina Ramírez, A.M. (2012). Las TIC en la educación superior como vía de formación y desarrollo competencial en la sociedad del conocimiento. ReiDoCrea, 1, 106114. http://hdl.handle.net/10481/21977

Moreno González, R.; Ramírez Villegas, M.A. (2012). Las habitaciones de la dislalia. ReiDoCrea, 1, 38-45. http://hdl.handle.net/10481/21941

Pérez Zamora, L.A.; López López, M.C.; Couto Olivares, J.M.; Navarro Luque, G. (2012). ¿Depende la satisfacción estudiantil de la calidad real de la facultad o de la percepción individual de ésta? Análisis comparativo entre facultades privadas y públicas. ReiDoCrea, 1, 29-37. http://hdl.handle.net/10481/21940

Rodríguez de Medina Quevedo, I. (2012). El Mindfulness como método para la mejora de las relaciones interpersonales. ReiDoCrea, 1, 132-137. http://hdl.handle.net/10481/21978

Rosada Ayala, J.I. (2012). La competencia comunicativa en personas que presentan parálisis cerebral. ReiDoCrea, 1, 158-163. http://hdl.handle.net/10481/21996

Ruiz Jiménez, J.M.; Cabeza Pullés, D.; Briano Turrent, G.C. (2012). Universidad y empredimiento: un caso de estudio en la Facultad de Ciencias Económicas y Empresariales de la UGR. ReiDoCrea, 1, 144-157. http://hdl.handle.net/10481/21988

Sagripanti Mazuquin, O.G.; et al. (2012). El efecto del burnout en la antigüedad en el puesto de trabajo: análisis mediacional de la ansiedad. ReiDoCrea, 1, 4-11. http://hdl.handle.net/10481/21909

Sánchez Arco, D.V. (2012). La educación diferenciada en Primaria, ¿se puede llamar coeducación? ReiDoCrea, 1, 76-79. http://hdl.handle.net/10481/21965

Segura Azor, E.A. (2012). Guía de intervención para un alumno con hipoacusia neurosensorial. ReiDoCrea, 1, 46-51. http://hdl.handle.net/10481/21942 


\section{ANSIEDAD Y MOTIVACIÓN DE LOGRO EN ESTUDIANTES UNIVERSITARIOS: UN ESTUDIO CORRELACIONAL}

\section{ANXIETY AND ACHIEVEMENT MOTIVATION IN UNIVERSITY STUDENTS: A CORRELATIONAL STUDY}

Pablo Aguilar de Tena, Rocío Mudarra Fernández, Sarai Perelló Alberola y Cristian Rojas González, Universidad de Granada

\section{Resumen}

El propósito de este estudio fue evaluar si existían diferencias entre estudiantes de diferentes titulaciones universitarias y el nivel de ansiedad y motivación de logro autopercibido, frente a su próxima incorporación al mundo laboral. Se utilizó una muestra española (112 mujeres y 48 hombres). Se obtuvieron respuestas en cuatro facultades de la capital granadina y se compararon los resultados obtenidos en las cuatro muestras. Se observó si los datos se adecuaban a los postulados psicológicos que sostienen que el nivel de ansiedad y la motivación de logro pueden estar relacionados. Se llegó a la conclusión de que esto era cierto y se propusieron diferentes estrategias de intervención psicológica temprana en el ámbito educativo universitario.

Palabras clave: Motivación de logro, ansiedad-estado, estudio correlacional, estudiantes universitarios, futuro profesional.

Abstract

The purpose of this study was to evaluate if there were differences between students from different university degrees and the level of anxiety and self-perceived achievement motivation against its future incorporation into the workplace. Was used a Spanish sample (112 women and 48 men). Responses were obtained in four faculties of the city of Granada and compared the results obtained in the four samples. We was observed if the data were aligned with the psychological principles argue that the anxiety and achievement motivation may be related. They concluded that this was true and propose strategies early psychological intervention in education degree.

Keywords: Achievement motivation, anxiety state, correlational study, college students, professional future.

\section{Introducción}

Debido a los continuos cambios acontecidos en los últimos años, donde tener un trabajo se ha convertido en un privilegio y perder el empleo genera un estado de frustración e incertidumbre insoslayable para el ciudadano. Es en este panorama de desolación donde el estudiante universitario no ve, al final de su trayectoria profesional, un empleo digno relacionado con lo estudiado, sino más bien a una 
persona cabizbaja en la cola de la oficina del INEM. Es en esta situación de desesperanza donde creemos que los niveles de ansiedad constituyen un papel clave en la motivación de logro y en el afán de superación.

Según Spielberger, Pollans y Worden (1884) el estado de ansiedad se define como una reacción emocional que consiste en sentimientos de tensión, aprensión, nerviosismo y preocupación, así como activación o descarga del sistema nervioso autónomo. Spielberger defiende que existen dos tipos de ansiedad en función de la temporalidad, la ansiedad-rasgo (más estable y relacionada con factores de personalidad) y la ansiedad-estado.

Esta última esta conceptualizada como un estado o condición emocional transitoria del organismo humano, que se caracteriza por sentimientos subjetivos, conscientemente percibidos de tensión y aprensión, así como por una hiperactividad del sistema nervioso autonómico. Puede variar con el tiempo y fluctuar en intensidad. El cuestionario STAI ha demostrado ser óptimo para medir este constructo, así su subescala, ansiedad-estado (A/E), puede ser utilizada para determinar los niveles contemporáneos de la ansiedad en los participantes (Spielberger, 2004).

Por otro lado, Atkinson (en Ruiz, 2005) define la motivación de logro como la disposición relativamente estable de buscar el éxito o el logro. Mientras que McClelland (en Ruiz, 2005) la entiende como la tendencia a alcanzar el éxito en situaciones que suponen la evaluación del desempeño de una persona, en relación con estándares de excelencia. Morales (2006) la define en términos de búsqueda del éxito, competitividad, aceptación de riesgos, constancia, organización en el trabajo y el proponerse objetivos a largo plazo. Esta última definición fue la empleada para construir los cuestionarios ML-1 y ML-2 utilizados.

La ansiedad, al igual que cualquier otra emoción, implica al menos tres componentes o sistemas de respuesta: cognitivo, fisiológico y conductual (Sandín y Chorot, 2011). La activación de estos componentes en la ansiedad, sobre todo el cognitivo y el conductual, puede provocar una mayor tasa de error o bloquear nuestro desempeño, haciendo que se deteriore significativamente nuestra motivación de logro, y que recurramos a tareas más fáciles y asequibles, o provocando una respuesta de escape o evitación de la situación de riesgo, que pudiera llegar a afectarnos, sobre todo, a nivel psicológico (e.g. la autoestima).

Enmarcando una posible relación entre ambos conceptos, nos pareció interesante ver cómo afecta la ansiedad-estado a la motivación de logro de estudiantes universitarios. Con este fin, suministramos la subescala (A/E) del cuestionario de ansiedad STAI (Spielberger, 2004) y el test de motivación de logro ML-1 y ML-2 (Morales, 2006) a estudiantes universitarios en su penúltimo o último año de estudios, ya que a priori, son los que deberían ver el terreno laboral más cercano, todo ello, con el fin de comprobar si existe una posible relación entre ambos constructos psicológicos.

Además de desencadenar ansiedad, la situación contemporánea ejerce la presión de un arma de doble filo, ya que otorga las escasas plazas de que dispone el mercado laboral solo a los más cualificados y sobresalientes, desechando al resto de estudiantes a la migración, la baja remuneración o la desolación. Creemos que este clima de incertidumbre está ejerciendo una presión desmesurada sobre los 
estudiantes, sometiendo al alumnado a una situación de indefensión, de la que algunos serían incapaces de salir. Creemos que este estudio puede arrojar luz al psicólogo, otorgándole un papel preventivo que ayude a detectar las expectativas de futuro de los estudiantes para intervenir antes de que sus ideales caigan en saco roto.

\section{Método}

\section{Participantes}

Los datos fueron recabados de una muestra de 160 estudiantes de último curso de Licenciatura de la Universidad de Granada, repartidos entre las diferentes titulaciones de Farmacia, Derecho, Económicas y Filología Inglesa. De los cuales 112 eran mujeres y 48 hombres.

\section{Diseño}

El presente estudio utiliza un diseño correlacional en el que se busca una asociación entre el la ansiedad y el grado de motivación de logro entre estudiantes universitarios.

\section{Instrumentos}

Para la recogida de datos se utilizaron tres instrumentos de medida: Para medir la motivación de logro de los participantes se pasó una adaptación de las escalas Mehrabian (1968, reproducidas en Brown, Cherrington y Cohen, 1975). La "Escala de motivación de logro (ML-1)" y la "Escala de motivación de logro (ML-2)" (Morales, 2006). Ambas escalas se complementan midiendo diferentes características de este constructo, de ahí que se optara por pasar ambas escalas para una mayor denominación de motivación de logro. Para medir la ansiedad se utilizó la "Escala de Ansiedad Estado/Rasgo (STAI)", aunque dado que nuestro interés estaba en obtener la información acerca de la ansiedad estado, se utilizaron únicamente los ítems pertenecientes a ese constructo. Como datos adicionales se les pidió a los participantes que informaran de sus planes de futuro tras acabar la carrera (seguir estudiando, buscar trabajo u otras alternativas a especificar) así como su edad, titulación universitaria y sexo.

\section{Procedimiento}

La recogida de datos se realizó en las respectivas facultades de los participantes en horario de clase. Se les administró la escala ML-1, seguida de la escala ML-2 y finalmente el STAI, cuya duración no sobrepasó los 15 minutos. Para una mejor administración de las pruebas y que todos los estudiantes estuvieran en igualdad de condiciones, previo a la prueba se les puso en situación; se les propició que reflexionaran sobre su futuro próximo tras la finalización de la carrera. Se enfatizó que el cuestionario era confidencial y anónimo, y se dejó la libre elección de su contribución a la investigación.

\section{Hipótesis}

$>$ Se prevé una correlación negativa entre motivación de logro y ansiedad, significando esto que, a mayor motivación de logro menores niveles de ansiedad y viceversa. 
$>$ Se prevé que existan diferencias estadísticamente significativas entre las diferentes facultades de la muestra.

$>$ Se prevé que existan diferencias estadísticamente significativas en niveles de ansiedad entre sexos.

\section{Resultados}

Se realizaron diferentes análisis estadísticos: descriptivos, correlaciones (Pearson) y prueba $\mathrm{T}$ para muestras independientes. Los análisis de datos se efectuaron con el programa estadístico SPSS.

Con el objetivo de estudiar el tipo de correlación existente entre la motivación de logro y la ansiedad de manera global hemos realizado el análisis de correlaciones bivariadas. La puntuación obtenida por el coeficiente de correlación de Pearson nos muestra que existe una correlación inversa entre las dos variables $(T=-.171 ; p=.031)$; por lo que se confirma la hipótesis principal, a mayor motivación de logro menor ansiedad-estado y viceversa.

\section{Tabla 1}

Correlaciones entre ansiedad-estado y motivación de logro

\section{STAI}

\begin{tabular}{ll}
\hline & STAI \\
\hline Motivación Logro & $-.17^{*}$
\end{tabular}

Nota: ${ }^{*} p<.05$

En cuanto al análisis descriptivo de la motivación de logro por facultades, se observa que en todas ellas la media de motivación de logro entre sus alumnos es aproximadamente la misma. Así, tras el análisis de varianza, no se aprecian diferencias significativas de motivación de logro entre titulaciones $(p=.390)$.

Tabla 2

Análisis de varianza (ANOVA) de motivación de logro entre titulaciones

\begin{tabular}{lccccc}
\hline & Suma de cuadrados & gl & media cuadrática & F & Sig \\
\hline Inter-grupos & 79,284 & 3 & 26,428 & 1,011 &, 390 \\
Intra-grupos & 4051,323 & 155 & 26,138 & & \\
Total & 4130,607 & 158 & & & \\
\hline
\end{tabular}

En lo referente al análisis de varianza del inventario de ansiedad-estado (STAI) tampoco se aprecian diferencias significativas entre las distintas titulaciones $(p=.718)$. 
Tabla 3

Análisis de varianza (ANOVA) de ansiedad-estado entre titulaciones

\begin{tabular}{lcrccc}
\hline & Suma de cuadrados & gl & media cuadrática & F & Sig \\
\hline Inter-grupos & 157,512 & 3 & 52,504 &, 449 &, 718 \\
Intra-grupos & 18225,863 & 156 & 116,832 & & \\
Total & 18383,375 & 159 & & & \\
& & & & & \\
\hline
\end{tabular}

Al realizar el análisis de resultados por sexos con la prueba $\mathrm{T}$ para muestras independientes no se observan diferencias estadísticamente significativas en la motivación de logro ni en la ansiedad-estado entre hombres y mujeres.

\section{Discusión y Conclusiones}

Tras el análisis de los resultados, hemos encontrado una correlación negativa entre ansiedad y motivación de logro, por lo tanto, los estudiantes universitarios con unos mayores niveles de ansiedad, tendrán unas expectativas de logro menores, y viceversa.

En cuanto a las diferentes titulaciones no se han encontrado diferencias significativas entre ellas en relación a las variables medidas. Creemos que puede ser debido a que las muestres no sean lo suficientemente representativas del grupo de titulaciones universitarias que tienen más y menos salidas laborales. Sería interesante replicar el estudio con las titulaciones que representen los extremos de la demanda laboral; según datos del Instituto Nacional de Estadística, estas serían Ingeniería Industrial y Administración y Dirección de Empresas siendo las que más, e Historia y Filología las de menor perspectiva de futuro (Randstad Professionals, 2012).

En lo referente a las diferencias entre sexos no hemos encontrado resultados concluyentes, tal vez si se hubiera optado por una muestra mayor y más equitativa, podríamos haber encontrado diferencias, principalmente en ansiedad.

Tomando como referencia los resultados obtenidos en esta investigación, tal vez sería interesante la posible incorporación de la figura del psicólogo al ámbito universitario, otorgándole un papel de ayuda y orientación, de cara a mejorar las expectativas de futuro profesional, así como reducir los niveles de ansiedad y aumentar la percepción de motivación de logro. Pues, en un ambiente donde principalmente se demandan actitudes emprendedoras y creativas, resulta imprescindible un profesional que pueda aportar estabilidad, seguridad y confianza, a estudiantes mermados por los contratiempos que se ciñen sobre sus espaldas.

Por todo ello, sería muy interesante desarrollar más líneas de investigación futuras que tomen en cuenta las necesidades del estudiante, así como los factores que directa o indirectamente le afectan a su desempeño y salud mental. 
Sin más preámbulos, concluimos nuestro artículo recalcando una vez más la importancia que tiene los niveles de ansiedad en la motivación de logro, basándonos en esta premisa, sería necesario buscar soluciones efectivas que ayuden al estudiante en su afán de superación, para que no vea un mundo laboral turbulento, donde él apenas tiene cabida, sino un horizonte lleno de posibilidades.

Tal vez el papel del psicólogo en el ámbito educativo tiene mucho que decir, ya sea en colegios o universidades, el profesional de la salud mental puede ofrecer un diálogo con el aprendiz que consiga un cambio de perspectiva y una reducción de los niveles de ansiedad.

\section{Referencias}

Brown, G., Cherrington, D. H., and Cohen, L. (1975), Experiments in the Social Science, London: Harper and Row.

Mehrabian, A. (1968). "Male and Female Scales of the Tendency to Achieve", Educational and Psychological Measurement, 28, 493-502.

Morales, P. (2006). Medición de actitudes en Psicología y Educación; construcción de escalas y problemas metodológicos. Madrid: Universidad Pontificia Comillas (Anexo VII, pp. 569-572).

Randstad professionals.(2012). Retrieved 05/29, 2013.

Ruiz, F. (2005). Relación entre la motivación de logro académico, la autoeficacia y la disposición para la realización de una tesis. Revista de la Facultad de Psicología de la Universidad de Lima. $N^{\circ}$ 8, p. 221. Lima. Fondo Editorial Universidad de Lima.

Sandín, B. y Chorot, P. (2011). Concepto y categorización de los trastornos de ansiedad. En Belloch, A., Sandín, B., \& Ramos, F. (2011). Manual de psicopatología. Madrid: McGraw-Hill.

Spielberger, C. D. (2004). STAl: Cuestionario de ansiedad estado-rasgo: Manual (6 ${ }^{a}$ ed.). Madrid: Tea.

Spielberger. C. D.; Pollans, C. H., y Worden, T. J. (1984). Anxiety disorders. En S.M. Turner y M. Hersen (ds). Adult psychopathology and diagnosis (pp. 263-303). Nueva York: Wiley. 


\section{FACTORES QUE INFLUYEN EN EL RENDIMIENTO ACADÉMICO: LA MOTIVACIÓN COMO PAPEL MEDIADOR EN LAS ESTRATEGIAS DE APRENDIZAJE Y CLIMA ESCOLAR}

\section{FACTORS INFLUENCING ACADEMIC ACHIEVEMENT: THE MEDIATING ROLE OF MOTIVATION IN LEARNING STRATEGIES AND SCHOOL CLIMATE}

Garrido Macías, M., Jiménez Luque, N., Landa Sánchez, A., Páez Espinar, E. y Ruiz Barranco, M. Universidad de Granada

\section{RESUMEN}

El objetivo principal de esta investigación consiste en analizar la relación existente entre estrategias de aprendizaje, motivación, clima escolar y el rendimiento académico y establecer cuáles son los mejores predoctores de este rendimiento. Para ello hemos utilizado una muestra de 101 alumnos de $4^{\circ}$ ESO de centros de Granada y Málaga, a los que se les administró el CEAM II, para medir estrategias de aprendizaje y motivación; y el CECSCE para medir el clima escolar. Los resultados indican que altas puntuaciones en estrategias de aprendizaje, una mayor motivación y un mejor clima escolar se relacionan con un mejor rendimiento académico. A su vez, los resultados muestran que los factores que mejor predicen el rendimiento académico son la valoración de la tarea y percepción de autoeficacia (motivación), organización y esfuerzo (estrategias de aprendizaje) y percepción del centro (clima escolar). Por último, se observa que la motivación tiene un papel mediador entre las estrategias de aprendizaje y el clima escolar sobre el rendimiento académico.

PALABRAS CLAVE: motivación; estrategias de aprendizaje; clima escolar; rendimiento académico; secundaria.

\section{ABSTRACT}

The main objective of this research is to analyze the relationship between learning strategies, motivation, school climate and academic performance and establish which are the best predictors of this performance. We have used a sample of 101 students of $4^{\circ}$ ESO center of Granada and Malaga, who were administered the CEAM II, to measure learning strategies and motivation, and the CECSCE to measure school climate. Results indicate that high scores on learning strategies, increased motivation and improved school climate are related to better academic performance. In turn, results show that the factors that predict academic performance are the assessment of the task and self-efficacy (motivation), organization and effort (learning strategies) and perception of school (school climate). Finally, we observe that motivation has a mediating role between learning strategies and school climate on student achievement.

KEY WORDS: motivation; learning strategies; school climate; academic achievement; Secondary.

\section{INTRODUCCIÓN}

Durante los años 60 y 70 comienzan a coexistir dos líneas investigadoras -cognitiva y motivacional- avanzado por caminos separados. Sin embargo, posteriormente se han ido afianzando determinadas corrientes que recalcan la necesidad de conjugar ambos componentes para lograr la mejora del aprendizaje y el rendimiento (González y Tourón, 1992). 
Aunque la literatura que trata sobre el tema de la motivación ofrece una amplia variedad de conceptos y teorías vinculadas con este constructo, en este estudio tomaremos en cuenta la clasificación de Pintrich, Smith, García y Mc-keachie (1991), que establece que la motivación es un constructo multidimensional formado por la motivación intrínseca o extrínseca, la valoración de las tareas, los sentimientos de autoeficacia, las creencias de control y la ansiedad.

Por su parte, el término estrategias de aprendizaje también hace referencia a un constructo multidimensional. Gargallo (1999) se refiere a ellas como las capacidades procedimentales que se usan para aprender cualquier información, contenido, concepto e incluso los mismos procedimientos. Dichas estrategias serían la capacidad de elaboración, de concentración, de solicitar ayuda de otros, organización, esfuerzo y metacognición.

En las décadas de los 80 y 90, se han realizado numerosos estudios empíricos sobre las relaciones entre motivación, estrategias de aprendizaje y rendimiento académico (Bouffard-Bouchard, Parent y Larivée, 1991; Pokay y Blumenfeld, 1990; Pintrich, DeGroot y García, 1992). Estas investigaciones dejan claro que el uso que los estudiantes hacen de sus estrategias de aprendizaje está íntimamente relacionado con sus características motivacionales (González y Tourón, 1992).

Una de las investigaciones más importantes que confirman esta relación entre motivación, estrategias de aprendizaje y rendimiento académico es la llevada a cabo por Pintrich et al., (1991), haciendo uso de MSLQ (Motivation Strategies for Learning Questionnaire), donde asumen que la motivación y estrategias de aprendizaje no son algo estático sino que se pueden cambiar y aprender.

Además, diversos estudios sugieren que la motivación y el uso de estrategias no influyen sólo de forma aislada en el rendimiento académico, sino que la interacción entre ambas tienen también un importante papel. Por ejemplo, Pintrich y DeGroot (1992) afirman que los componentes motivacionales están correlacionados con las estrategias de aprendizaje, puesto que el estudiante activa sus estrategias de aprendizaje con la motivación. De este modo, es posible que la motivación tenga un papel mediador entre el aprendizaje y el rendimiento académico.

Pero no sólo la motivación y las estrategias de aprendizaje se relacionan con el rendimiento. El clima escolar, entendido como la percepción favorable que tienen los alumnos de la clase y los lazos mutuos de apoyo, aceptación, reconocimiento y afecto (Infante et al., 2003) también juega un papel muy importante.

En el trabajo de Trianes, Blanca, De la Morena, Infante y Raya (2006) se establece que el clima escolar esta formado por dos variables: Clima Social del Centro Escolar (referido a la capacidad de ayuda, seguridad y respeto en el centro educativo percibidos por el alumno) y Clima referente al Profesorado (referido a la percepción de los alumnos sobre el trato de los profesores).

Un adecuado clima escolar favorece la convivencia pacífica, potencia el aprendizaje de los estudiantes (Ma, 2008), los motiva por actividades educativas (Anderson, Christenson, Sinclair y Lehr, 2004) y modera sus problemas psicológicos (Westling, 2002). Pero no solo eso, sino que también está relacionado con el rendimiento académico del alumno (Giraldo, 2000).

Partiendo del marco teórico expuesto, la presente investigación se centra en el estudio de 3 objetivos básicos: (1) Comprobar la relación existente entre motivación, 
estrategias de aprendizaje y clima escolar y el rendimiento académico; (2) determinar qué variables de motivación, estrategias de aprendizaje y clima escolar predicen mejor el rendimiento académico; y (3) examinar el papel mediador de la motivación en la relación estrategias de aprendizaje y el rendimiento y entre el clima escolar y el rendimiento.

\section{MÉTODO}

\section{Participantes}

Para llevar a cabo la investigación se seleccionó una muestra aleatoria de 101 alumnos de $4^{\circ}$ E.S.O., compuesta por 52 hombres y 49 mujeres, con edades comprendidas entre los 15 y 19 años $(M=15.74$ y $D T=.83)$. Los alumnos pertenecían a tres centros diferentes: 50 al I.E.S. Santo Domingo (Granada), 21 al Colegio Ntra. Sra. de la Consolación (Granada) y 30 al I.E.S. Luis Barahona de Soto (Málaga).

\section{Diseño y Procedimiento}

Se trata de un estudio correlacional donde se pretende ver la relación existente entre la motivación del alumnado (VI1), sus estrategias de aprendizaje (VI2) y la su percepción del clima escolar (VI3) con el rendimiento académico (VD).

Para llevar a cabo nuestra investigación, seleccionamos aleatoriamente los tres centros en los que aplicar el cuestionario. Los alumnos colaboraron de forma voluntaria y anónima. A cada alumno se le entregó un cuestionario que fue realizado en su misma aula y de forma individual, conforme a las instrucciones previamente establecidas.

Los datos obtenidos han sido analizados con el paquete estadístico SPSS versión 20.0., con el que han realizado tres análisis: análisis correlacional, análisis de regresión (para determinar qué factores, pertenecientes a las VIs, predicen mejor el rendimiento académico (VD)) y análisis de mediación (para comprobar el papel mediador de la motivación entre las estrategias de aprendizaje y el rendimiento académico, y entre el clima escolar y el rendimiento académico).

\section{Materiales}

Para la recogida de datos necesarios para nuestra investigación, los sujetos realizaron el siguiente cuestionario:

-Datos Sociodemográficos: edad, sexo y colegio/instituto.

-Nota media del trimestre anterior, utilizada como indicador del rendimiento académico.

-EI CEAM II (Cuestionario de Estrategias de Aprendizaje y Motivación) (Roces, Tourón y González, 1995) es el resultado de la traducción y adaptación al castellano del MSLQ (Pintrich et al., 1991) y se refiere a la motivación y estrategias de aprendizaje que utiliza el alumno en el conjunto de las asignaturas de un curso académico, a diferencia del instrumento original, que se refería a una asignatura concreta. Consta de 81 ítems: 31 de motivación y 50 de estrategias de aprendizaje y se responde en una escala likert de 7 puntos (1= no, nunca; $7=$ sí, siempre). La subescala de motivación presenta un índice de consistencia interna de 0.88 y está formada por 6 factores: motivación intrínseca, motivación extrínseca, valoración de la tarea, 
creencias de autoeficacia, creencias de control y ansiedad. Por su parte, las estrategias de aprendizaje presentan un índice de consistencia interna de 0.89 e incluyen 6 factores: elaboración, concentración y tiempo, ayuda, organización, esfuerzo y metacognición.

-EI CECSCE (Trianes et al., 2006) construido a partir de los ítems del California School Climate and Safety Survey (Furlong y Morrison, 1995; Rosenblatt y Furlong, 1997). Es un instrumento de autorregistro que evalúa dos dimensiones del clima escolar: el Clima escolar del Centro y el Clima escolar referente al Profesorado. El formato de respuestas ofrece alternativas del 1 al 5 . A mayor puntuación, mayor es la percepción de un adecuado clima social.

\section{RESULTADOS}

\section{Relación entre rendimiento académico y otras variables}

Con el objetivo de analizar las relaciones existentes entre el rendimiento académico de los alumnos y el resto de variables de nuestra investigación (motivación, estrategias de aprendizaje y clima social escolar), se llevó a cabo un análisis de correlación mediante el coeficiente de correlación de Pearson, utilizando las puntuaciones medias de las variables que se presentan en la Tabla 1.

\begin{tabular}{|c|c|c|c|c|c|}
\hline & $M$ & $S D$ & Motivación & Estrategias & Clima \\
\hline Motivación & 4.93 & .72 & --- & & \\
\hline Estrategias & 4.52 & .68 & $.66^{* *}$ & --- & \\
\hline Clima & 3.59 & .62 & $.49^{* * *}$ & $.32^{* * *}$ & --- \\
\hline Rendimiento & 6.90 & 1.32 & $.41^{* * *}$ & $.37^{* * *}$ & $.35^{* * *}$ \\
\hline
\end{tabular}

Nota. ${ }^{*} p<.05^{* *} p<.01{ }^{* * *} p<.001$

Los resultados muestran que el rendimiento académico correlaciona significativamente de forma positiva con la motivación, las estrategias de aprendizaje y el clima social escolar (ver Tabla 1).

\section{Análisis de regresión múltiple para variables predictoras de rendimiento académico}

Con el objetivo de analizar las variables que predicen el rendimiento académico se realizó un análisis de regresión lineal en el que las variables predoctoras fueron las diferentes motivaciones y como variable criterio el rendimiento académico evaluado mediante la nota media del participante.

Como se observa en la Tabla 2 , los mejores predictores del rendimiento académico fueron la valoración de la tarea y la percepción de autoeficacia.

Del mismo modo, se realizó otro análisis de regresión lineal y como variables predictoras en este caso fueron las diferentes estrategias de aprendizaje. 
Observando la Tabla 2, encontramos que, del conjunto de factores que componen las estrategias de aprendizaje, las que mejor predicen el rendimiento del alumnado son: las estrategias de organización y las estrategias de esfuerzo. Por último, el factor del clima social escolar que mejor predice la nota media del alumnado es el clima del centro, con una relación positiva.

Tabla 2. Análisis de regresión lineal de las motivaciones, estrategias de aprendizaje y clima escolar en el rendimiento escolar

$$
\begin{aligned}
& \text { Rendimiento académico } \\
& \beta \quad t \quad p
\end{aligned}
$$

\section{Motivaciones}

Intrínseca

$\begin{array}{lll}.08 & .66 & .508\end{array}$

Extrínseca

$\begin{array}{lll}-.12 & -1.05 & .297\end{array}$

Tarea

$\begin{array}{lll}.31 & 2.27 & .030\end{array}$

Autoeficacia

$\begin{array}{lll}.33 & 2.89 & .005\end{array}$

Control

$\begin{array}{lll}-.01 & -.13 & .900\end{array}$

Ansiedad

$\begin{array}{lll}-.11 & -1.1 & .274\end{array}$

Estrategias de Aprendizaje

$\begin{array}{lrrr}\text { Elaboración } & .05 & .39 & .700 \\ \text { Concentración } & .11 & 1.21 & .227 \\ \text { Ayuda } & .05 & .49 & .621 \\ \text { Organización } & -.28 & -2.26 & .026 \\ \text { Esfuerzo } & .38 & 3.22 & .002 \\ \text { Metacognición } & .24 & 1.66 & .099\end{array}$

Clima Escolar

$\begin{array}{lrrr}\text { Centro } & .26 & 2.01 & .047 \\ \text { Profesorado } & .12 & .95 & .367\end{array}$

\section{El efecto mediador de la motivación entre las estrategias de aprendiza y el rendimiento académico}

Para analizar el posible papel mediador de la motivación, se deben cumplir tres condiciones (Baron y Kenny, 1986). En primer lugar, que la variable independiente (estrategias de aprendizaje) influya en la variable mediadora (motivación). Segundo, que la variable mediadora se relacione con la variable dependiente (rendimiento académico). Y, en tercer lugar, que exista una relación significativa entre la variable independiente y la dependiente, y que, una vez introducida la variable mediador, esta relación pierda, parcial o totalmente, su efecto.

Tal y como se observa en la Figura 1, los resultados mostraron que la motivación influye significativamente en el rendimiento académico. Igualmente, se observó una relación significativa entre la motivación y las estrategias de aprendizaje y entre las estrategias de aprendizaje y el rendimiento. Además, en 
el paso tres de la regresión, se observa que las estrategias de aprendizaje pierden totalmente su efecto sobre el rendimiento académico cuando se introduce la variable motivación. Para examinar si la reducción del efecto de las estrategias de aprendizaje sobre la variable dependiente era significativa se realizó el test de Sobel (Sobel, 1982) que indicó que el descenso fue significativo $(z=2.32, p<.05)$. Por lo tanto, de los análisis se desprende que la motivación media totalmente la relación entre las estrategias de aprendizaje y el rendimiento académico.

Figura 1. El papel mediador de la motivación en las estrategias de aprendizaje y el rendimiento académico

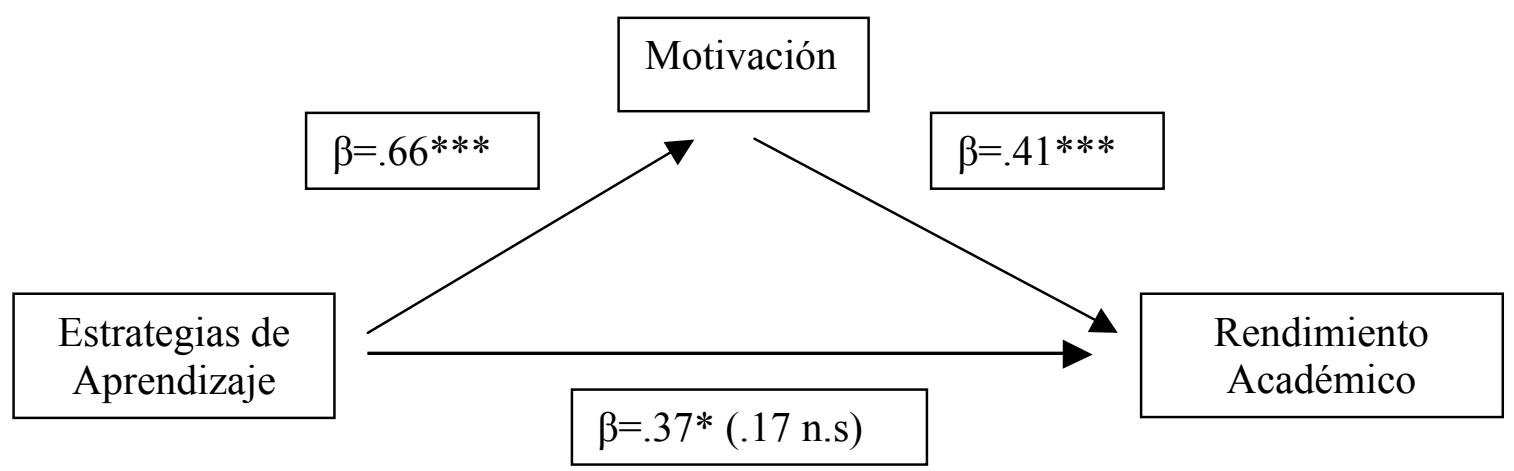

Nota. ${ }^{*} p<.05^{* *} p<.01^{* * *} p<.001$

Este mismo análisis se llevó a cabo utilizando como VI el clima escolar, para comprobar si existe ese papel mediador de la motivación entre el clima escolar y rendimiento académico. Tal y como se observa en la Figura 2, los resultados mostraron una relación significativa entre la motivación y el clima escolar y entre el clima escolar y el rendimiento. En el paso tres de la regresión también se observa que el clima escolar pierde totalmente su efecto sobre el rendimiento académico cuando se introduce la variable motivación. Para examinar si la reducción del efecto del clima escolar sobre la variable dependiente era significativa se realizó el test de Sobel (Sobel, 1982) que indicó que el descenso fue significativo $(z=2.36, p<.05)$. Por lo tanto, de los análisis se desprende que la motivación media totalmente la relación entre el clima escolar y el rendimiento académico.

Figura 2. El papel mediador de la motivación en el clima escolar y el rendimiento académico

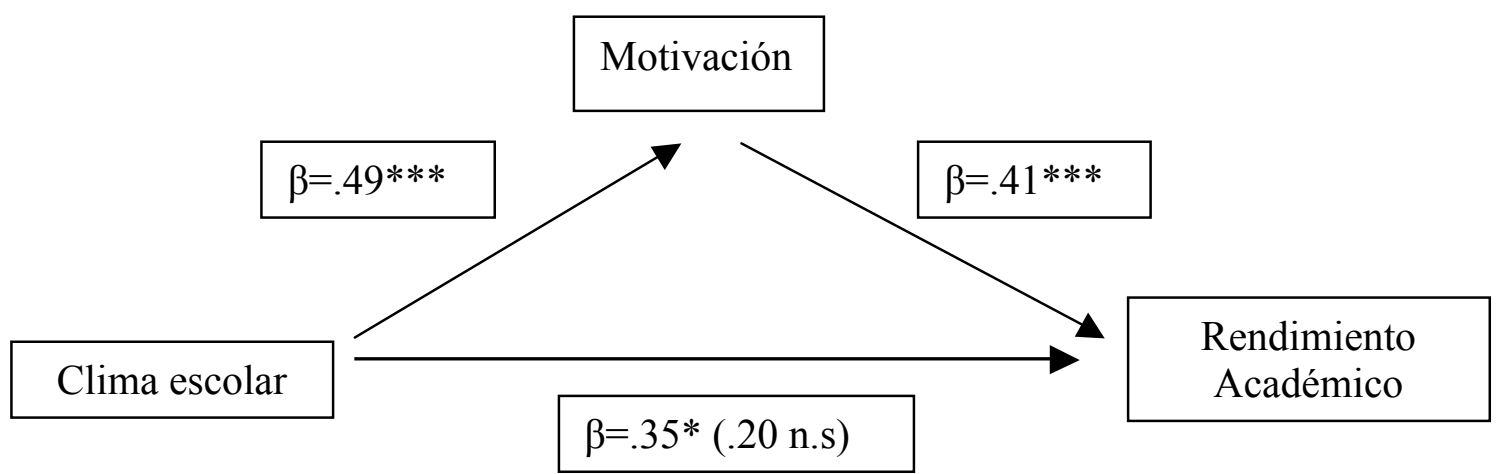

Nota. ${ }^{*} p<.05{ }^{* *} p<.01{ }^{* *} p<.001$ 


\section{DISCUSIÓN}

Los resultados de la presente investigación han mostrado que la motivación, las estrategias de aprendizaje y el clima escolar están relacionados con el rendimiento académico, corroborando los resultados obtenidos en estudios previos (Pintrich et al., 1992; Giraldo, 2000). Además, esta relación es positiva, por lo que, a más motivación del sujeto, más estrategias utilizadas y mejor percepción del clima escolar, mayor será su rendimiento académico.

Al realizar el análisis de regresión, hemos encontrado que existen factores que predicen mejor el rendimiento académico. Dentro de la motivación, la valoración de la tarea y la percepción de autoeficacia son las que más se relacionan con dicho rendimiento. Esta relación es positiva, lo que significa que a mayor puntuación en estos factores, mayor rendimiento académico obtendrá el alumno. Con respecto a las estrategias de aprendizaje, el esfuerzo es el que mejor predice positivamente el rendimiento (a mayor esfuerzo, mejor calificación), mientras que la organización es el que mejor lo predice negativamente. La existencia de esta relación negativa nos indica que a mayor organización menor calificación, lo que puede explicarse por diversas razones. Dicho resultado no era el esperado en nuestra investigación, aunque reflexionando sobre ello, podemos llegar a la conclusión de que es posible que esa organización reste tiempo de estudio, que piense que con organizarse es suficiente para obtener un buen resultado, o que la propia organización no sea la adecuada. Por último, el factor del clima escolar que mejor predice el rendimiento académico es la percepción del centro, de forma que una mejor percepción del centro por parte del alumno contribuye a un mejor resultado académico de éste.

Finalmente, el análisis de mediación nos muestra que la motivación ejerce un papel mediador en la relación entre estrategias de aprendizaje y rendimiento y clima escolar y rendimiento. De esta forma, las estrategias se relacionan con el rendimiento siempre que exista motivación, en caso contrario, esa relación se anularía. Del mismo modo, el clima escolar correlaciona con el rendimiento siempre que haya motivación, y en ausencia de ésta, de nuevo se anularía esta relación.

Los resultados de esta investigación nos sugieren que las variables con las que hemos trabajado ejercen una influencia importante en el rendimiento. Por tanto, como propuesta de aplicación práctica en la escuela de estos resultados, sería interesante focalizar a los alumnos en la mejora de estos factores. De esta manera, los profesores y profesional de apoyo del centro escolar deberían centrarse en fomentar la motivación del alumno, asó como proporcionar diferentes estrategias de aprendizaje que puedan resultar útiles en una mejora del rendimiento académico del alumno. Por último, un clima escolar adecuado, potenciado por todos los miembros que componen el centro escolar, mejorará el rendimiento académico. 


\section{REFERENCIAS BIBLIOGRÁFICAS}

Anderson, A.R., Christenson, S.L., Sinclair, M.F., y Lehr, C.A. (2004). Check and connect: The importance of relationships for promoting engagement with school. Journal of School Psychology, 42, 95-113.

Baron, R. M. y Kenny, D. A. (1986). The moderator-mediator variable distinction in social psychological research: Conceptual, strategic and statistical considerations. Journal of Personality and Social Psychology, 51, 1173- 1182.

Bouffard-Bouchard, T., Parent, S. y Larivée, S. (1991). Influence of Self-Efficacy on Self-Regulation and Performance among Junior and Senior High-School Age Students. International Journal of Behavioral Development, 14(2), 153-164.

Furlong, M.J. y Morrison, R.L. (1995). Status update of research related to National Education Goal Seven: school violence content area. En Proceedings of National Education Goals Panel/National Alliance of Pupil Service Organization Safe School, Safe Students Conference. Educational Research Information Centre, Chapel Hill, NC.

Giraldo, L. y Mera, R. (2000). Clima social escolar: percepción del estudiante. Revista Colombia Médica, 31(1), 23-27.

Gargallo, I. S. (1999). Lingüística aplicada a la enseñaza-aprendizaje del español como lengua extranjera. Madrid: Arco libros.

González, M.C, y Tourón, J. (1992). Autoconcepto y Rendimiento Escolar: Sus Implicaciones en la Motivación y en la Autorregulación del Aprendizaje, Pamplona: EUNSA.

Infante, L., Hierrezuelo, L., García, B., Sánchez, A., De la Morena, M.L., Muñoz, A., y Trianes, M.V. (2003). Evaluación de actitudes violentas y clima escolar en situaciones de agresividad en alumnado de Secundaria. Psicología, Saúde \& Doenças, 4(2), 277-286.

Ma, L. (2008). The development of academic competence among adolescents who bully and who are bullied. Dissertation Abstracts International: Section B: The Sciences and Engineering, 68 (7-B), 4866.

Pintrich, P.R., DeGroot, E. y García, T. (1992). Student Motivation and SelfRegulated Learning In Different Classroom Contexts. Paper presented at the International Congress of Psychology, Bruselas.

Pintrich, P.R., Smith, DA.F., García, T. y Mc-keachie W.J. (1991). A Manual for the Use of the Motivated Strategies for Learning Questionnaire, (MSLQ). Ann Arbor, MI: National Center for Research to Improve Postsecondary Teaching and Learning, The University of Michigan. 
Pokay, P. y Blumenfeld, P. C. (1990). Predicting Achievement Early and Late in the Semester: The Role of Motivation and Use of Learning Strategies. Journal of Educational Psychology, 82(1), 41-50.

Trianes, M.V., Blanca, M.J., De la Morena, L., Infante, L., y Raya, S. (2006). Un cuestionario para evaluar el clima social del centro escolar. Psicothema, 18(2), 272-277.

Roces, C., Tourón, J. y González, M. C. (1995). Validación preliminar del CEAM II (cuestionario de estrategias de aprendizaje y motivación II). Psicológica, 16(3), 347-366.

Rosenblatt, J. y Furlong, M.J. (1997). Assessing the reliability and validity of student self-reports of campus violence. Journal of Youth and Adolescence, 26(2), 187-201.

Westling, M. (2002). A two level analysis of classroom climate in relation to social context, group composition and organization of special support. Learning Enviromments Research, 5, 253-274. 
ReiDoCrea

\title{
MOTIVACIÓN Y RENDIMIENTO ACADÉMICO: ¿CUMPLE SUS OBJETIVOS EL PLAN BOLONIA?
}

\section{MOTIVATION AND ACADEMIC ACHIEVEMENT: DOES BOLOGNA PLAN FULFILL ITS OBJECTIVES?}

Laura Fernandez García, José Antonio Mancebo Quirante, María Pilar Jiménez Álvarez, Teresa Ardanaz Sánchez, Noelia Fernández Sánchez y Alba María Montano de la Hoz. Universidad de Granada

\section{RESUMEN}

Diversos estudios han establecido que existe una relación directa entre la motivación y el rendimiento académico. La confluencia de estos dos factores resulta relevante en la formación del alumnado universitario, por esta razón, se decidió implantar en 2010 el Plan Bolonia, cuyo fin es aumentar la eficacia y calidad de la enseñanza, sustituyendo al Plan 2000. Este estudio tiene como objetivo, comprobar si estas mejoras son realmente eficaces, suponiendo un avance con respecto al plan 2000. Para esta investigación, se ha seleccionado a 103 estudiantes universitarios elegidos al azar, de ambos planes de estudios. Los resultados obtenidos han desmitificado los objetivos del Plan Bolonia,obteniendo una media de 5.01 en Motivación frente al 5.08 de Motivación del Plan 2000. Esto conlleva a que el Rendimiento académico sea más elevado en el Plan 2000, consiguiendo una media de 7.16 respecto al 6.71 del Plan Bolonia.

Palabras clave: Plan de estudios, Motivación, Rendimiento académico.

\begin{abstract}
Several studies have established that exists a direct relationship between Motivation and Academic Achievement. The confluence of these two factors is eminent in the university students' education. For this reason, in 2010, the Bologna Plan is deployed as purpose to increase the efficiency and the quality of education, by replacing Plan 2000 . This study aims to verify if those improvements are really effectives, assuming an advance with regard to Plan 2000. For this investigation, 103 university students have been selected at random, of both curriculums. The results obtained have demystified the Bologna Plan's objectives, obtaining an average of 5.01 in Motivation against 5.08 of Plan 2000's Motivation. All of these mean that Academic achievement is higher in Plan 2000, getting an average of 7.16 , in respect of 6.71 of Bologna Plan's Academic achievement.
\end{abstract}

Key words: Curriculum, Motivation, Academic achievement.

\section{INTRODUCCIÓN}

Está demostrado que existen dos aspectos importantes en la vida académica y que estos son la motivación y el rendimiento académico. Ambos conceptos están incluidos en la escuela, colegio, instituto y universidad. En el siguiente estudio nos centraremos en la relación entre la motivación y el rendimiento académico, concretamente en el ambiente 
universitario. Nuestra intención es conocer, en primer lugar, si existe relación entre estos dos conceptos; y después saber qué plan de estudios de los dos actuales que existen en el sistema universitario de España es más efectivo y favorable teniendo en cuenta estas dos variables, en concreto el Plan 2000, incluyendo licenciaturas y diplomaturas, y el Plan Bolonia dedicado sólo a estudiantes de grado.

Empezaremos explicando el rendimiento académico, que es un indicador de eficacia y calidad educativa. Las variables que intervienen en él son: factores contextuales, donde se incluyen variables socioculturales (clima educativo y familiar, origen sociocultural), institucionales (tipo y tamaño del centro) y pedagógicas (expectativas y actitudes del profesor). $\mathrm{Y}$ hay que tener también en cuenta factores personales, dentro de los que se incluyen variables demográficas (sexo, edad), cognitivas (aptitudes intelectuales y motivación) y actitudinales (satisfacción, autoconcepto); Todos estos factores son, a su vez, los principales indicadores de riesgo de fracaso académico.

En relación a la diversidad de variables vinculadas con un rendimiento académico eficaz, hemos orientado nuestra investigación hacia el estudio de la relación existente entre éste y la motivación. Según Kleinginna y Kleinginnna (1981), la motivación es una fuerza interna que mueve al organismo para llevar a cabo un determinado comportamiento. El término motivación dentro de la psicología ha sido empleado para definir el inicio, la dirección, la intensidad y la persistencia de una conducta (Geen, 1995). Los componentes de la motivación son cuatro: activación (fuerza o energía que justifica que un comportamiento llegue a producirse), persistencia (se asume que el grado de ésta es un índice del nivel de motivación de un individuo ante una situación), intensidad (a mayor intensidad mayor motivación), y dirección (mostrar preferencia por una alternativa frente a otra).

Diversos estudios han afirmado correlaciones positivas entre estas dos variables, entre ellos figura el trabajo de Celorrio (1999), Hidalgo (1987) y García Llamas (1985). Hidalgo (1987) afirma que la motivación general, la motivación específica y el rendimiento académico están asociados significativamente. Por otro lado, Llamas encontró que los motivos de elección de una carrera son un predictor significativo del rendimiento académico.

A partir de estas dos variables se han elaborado distintos planes de estudio. Uno de ellos es el Plan 2000 que se encuentra en proceso de extinción, y que busca la especialización en los distintos ámbitos de conocimiento con el fin de conseguir una preparación para asumir las exigencias del mercado laboral. Está dividido en dos ciclos; el primero más dirigido a la teoría y los conocimientos generales y el segundo, hacia la profundización y puesta en práctica de los conocimientos adquiridos. Además de los créditos troncales y optativos, el estudiante debe de obtener créditos de libre configuración obtenidos en materias que pueden elegirse en la propia facultad o en centros especializados. La carga lectiva oscila entre 20 y 30 horas semanales siendo el total del curso entre 60 y 90 créditos por año académico.

Más nuevo e innovador es el Plan Bolonia, elaborado para una mayor eficacia del alumnado y para mejorar con respecto a los planes anteriores. Busca la diversificación curricular permitiendo que la universidad aproveche su capacidad de innovación, sus fortalezas y oportunidades. También incluye créditos europeos (ECTS) como unidad de 
medida que refleja los resultados del aprendizaje y volumen de trabajo realizado por el estudiante para alcanzar los objetivos establecidos en el plan de estudio, poniendo en valor la motivación y el esfuerzo del estudiante para aprender.

Los objetivos planteados que pretendemos abordar en este estudio son: comprobar si existe correlación entre la motivación y el rendimiento académico orientada a la formación universitaria y también conocer si las bases de mejora que se proponen conseguir con el Plan Bolonia se han alcanzado.

A continuación se presentan las hipótesis que vamos a utilizar como base para esta investigación:

Hipótesis 1: Una mayor motivación en los estudios universitarios provoca un mayor rendimiento académico.

Hipótesis 2: Existe una mayor motivación y un mayor rendimiento académico en Grado que en el Plan 2000.

\section{MÉTODO}

\section{Participantes}

La muestra está formada por estudiantes universitarios entre 18 y 47 años, siendo representativa de ambos sexos. La edad media es de 21.8 años ( $S D=2.86)$. Todos ellos estudian diferentes titulaciones en universidades públicas españolas con distinta ubicación geográfica, por lo que su nivel educativo es medio-alto.

La muestra total se compone de 103 sujetos seleccionados al azar. A partir de esta muestra, se han establecido dos grupos en función de su pertenencia al Plan 2000 (más comúnmente denominado Licenciatura) o al Sistema de Transferencia de Créditos Europeos o Grado. Según esta variable, la muestra se compone de 50 participantes pertenecientes a Licenciatura y 53 a Grado.

\section{Instrumentos}

Para la obtención de los datos necesarios se construyó un cuestionario que incluía las siguientes medidas:

- Datos socio-demográficos: edad, sexo, estudios y facultad, si trabajaba además de estudiar y si realizaba un Grado o una Licenciatura.

- Cuestionario de Estrategias de Aprendizaje y Motivos de Estudio (CEAM) (Roces, Tourón, González-Torres, 1995), del cual se han utilizado los ítems correspondientes a la evaluación de la motivación (parte A del cuestionario, 31 ítems). Los sujetos indicaban su respuesta en una escala Likert con 7 opciones de respuesta, siendo el 1 "No me describe en absoluto" y el 7 "Me describe totalmente". 
- Rendimiento académico que se ha evaluado utilizando la nota media del expediente académico (sobre 10) hasta la fecha en que desarrolló el estudio. Se empleó esta medida ya que es la que mejor refleja en forma numérica esta variable.

Este cuestionario se ha administrado en formato papel y vía online, a partir de la herramienta de creación de encuestas de Google.

Los materiales utilizados fueron un ordenador, en caso de ser necesaria la consulta del expediente académico o como forma de cumplimentar el cuestionario y bolígrafos para rellenar los cuestionarios. Para el análisis estadístico de los datos obtenidos se utilizó el programa SPSS 20.0 de IBM.

\section{Procedimiento}

El experimento se inició con la administración del cuestionario a diferentes universitarios de España mediante una encuesta online o pasándolo con cuestionarios en papel. El motivo de hacerlo online fue el de captar a la mayor cantidad posible de sujetos de diferentes universidades y facultades, no solo de Granada. En todo momento se aseguró el anonimato a los participantes.

\section{ANÁLISIS DE LOS RESULTADOS}

Los resultados se presentan en primer lugar haciendo referencia a la relación entre la motivación y el rendimiento académico; y en segundo lugar se comprueba si existe mayor motivación y rendimiento académico en Grado que en el Plan 2000.

\section{- Motivación y rendimiento académico}

Los resultados obtenidos en el análisis de los datos en cuanto a la motivación, señalan una media $=156,35(S D=18.15)$; y en el rendimiento académico se ha obtenido una media correspondiente a $6.80(S D=1.32)$.

Para analizar si existe correlación entre motivación y rendimiento académico se ha utilizado la correlación de Pearson, y teniendo en cuenta que $(p<.05)$ se ha obtenido una correlación significativa, $r=.23$.

\section{TABLA 1. RELACIÓN ENTRE MOTIVACIÓN Y RENDIMIENTO ACADÉMICO}

\begin{tabular}{llll}
\hline Media & $\begin{array}{l}\text { Desviación } \\
\text { típica }\end{array}$ & $\begin{array}{l}\text { Coeficiente de } \\
\text { correlación de } \\
\text { Pearson }\end{array}$ & $\begin{array}{l}\text { Significación } \\
\text { Pilal }\end{array}$ \\
\hline
\end{tabular}

\begin{tabular}{lll}
\hline Motivación & 153.35 & 18.15
\end{tabular}

$\begin{array}{lll}\text { Rendimiento académico } \quad 6.804 & 1.32\end{array}$ 


\section{- Mayor motivación y rendimiento académico en Grado que en el Plan 2000}

Para llevar a cabo este análisis de resultado se han realizado las medias y desviaciones típicas de ambos planes de estudio y las correlaciones existentes entre motivación y rendimiento académico de cada plan, utilizando la correlación de Pearson, teniendo en cuenta que $(p<.05)$.

En primer lugar en Grado se han obtenido las siguientes medias y desviaciones típicas: en motivación $(M=5.01 ; S D=.55) ; y$ en rendimiento académico $(M=6.71 ; S D=.96)$. En cuanto a si existe correlación entre motivación y rendimiento académico en Grado, el resultado obtenido es de .065 por tanto, no es significativa.

En cuanto al Plan 2000 se han obtenido las siguientes medias y desviaciones típicas: en motivación $(M=5.08 ; S D=.63)$; y en rendimiento académico $(M=7,16 ; S D=.72)$, sin embargo sí existe correlación significativa entre motivación y rendimiento académico en estos estudiantes, siendo de .318 .

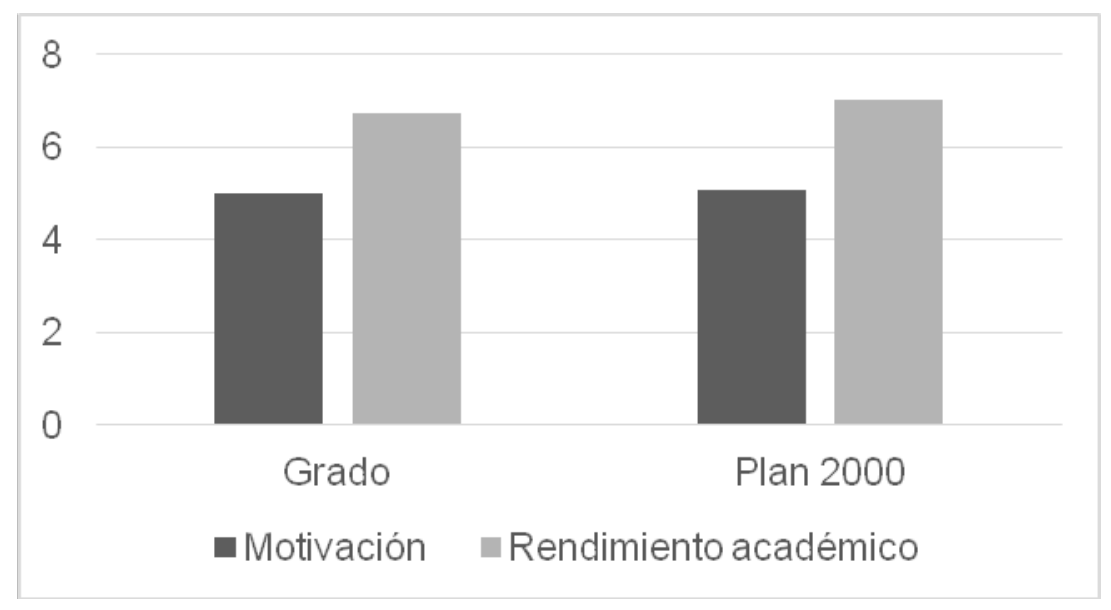

TABLA 2. RESULTADOS DE DIFERENCIACIÓN ENTRE GRADO Y LICENCIATURA

\begin{tabular}{llcccc}
\hline & Media & $\begin{array}{l}\text { Desviación } \\
\text { típica }\end{array}$ & $\begin{array}{l}\text { Coeficiente } \\
\text { de } \\
\text { correlación } \\
\text { de Pearson }\end{array}$ & $\begin{array}{l}\text { Significación } \\
\text { bilateral }\end{array}$ \\
\hline Grado & Motivación & 5.01 & .55 & .065 & .642 \\
& $\begin{array}{l}\text { Rendimiento } \\
\text { académico }\end{array}$ & 6.71 & .96 & & $.318^{*}$ \\
2000 & $\begin{array}{l}\text { Motivación } \\
\text { Plan }\end{array}$ & 5.08 & .63 & & .024 \\
& $\begin{array}{l}\text { Rendimiento } \\
\text { académico }\end{array}$ & 7.16 & .73 & & \\
\hline
\end{tabular}




\section{DISCUSIÓN}

La hipótesis 1, una mayor motivación en los estudios universitarios provoca un mayor rendimiento académico, se cumple. Es decir, existe una correlación positiva, por tanto a mayor motivación mayor rendimiento académico. Esto se puede deber a que cuando un estudiante comienza una carrera universitaria es porque está motivado a tener un futuro mejor con lo que estudia o bien porque adquiere un conocimiento sobre un área concreta sobre la que le gusta aprender. Esta motivación lleva al alumno a prepararse e interesarse más por lo que aprende y sacar buenas notas en los exámenes lo que repercute en su rendimiento académico.

Por otra parte, la hipótesis 2, existe una mayor motivación y un mayor rendimiento académico en Grado que en el Plan 2000, no se cumple ya que existe una puntuación significativa en cuanto a motivación y rendimiento académico en los alumnos del plan 2000 que no se ha encontrado en los alumnos del plan Bolonia. Y en comparación entre las medias se observa un mayor rendimiento académico entre los estudiantes del Plan 2000 que en los de Grado. Una de las razones que pueden justificar este resultado es la urgencia de los estudiantes del plan 2000 a la hora de terminar sus estudios por la extinción de este plan. Esta situación puede dar lugar a que la motivación por aprobar las asignaturas sea mayor en estos estudiantes y esto afecte al rendimiento académico.

Otra razón puede ser que las premisas del Plan Bolonia no se lleven a cabo de una manera adecuada en la práctica y lo único que se haya hecho es seguir con lo anterior pero haciendo todas las asignaturas cuatrimestrales llevando a que lo único que se quiera sea aprobar para no examinarse en septiembre disminuyendo la motivación.

Por todo esto, podemos sacar como conclusión que el Plan 2000 es más efectivo que el moderno Plan Bolonia en lo referente a la motivación, y por ello se obtiene un mayor rendimiento académico. Esto nos lleva a cuestionarnos si las manifestaciones de muchos alumnos y profesores de las diferentes universidades en contra del Plan Bolonia podrían ser fundamentadas por este motivo: la falta de efectividad a la hora de conseguir que los alumnos estén motivados con el fin de obtener un mayor rendimiento académico.

Por último, cabe citar las limitaciones que presenta este estudio entre las que se encuentran el tamaño de la muestra, la motivación por contestar al cuestionario y el no poder controlar que hacían los sujetos mientras contestaban online.

Por otra parte hay que tener en cuenta que los sujetos pueden haber mentido al responder sobre su nota media de expediente y poner una más alta de la que se tiene en realidad debido a la deseabilidad social.

Para finalizar, otro factor importante son los años que llevan los estudiantes en la carrera ya que no es lo mismo un alumno de primero que tiene mucha ilusión por estudiar lo que le gusta que un repetidor o alguien de último curso que quiere terminar. Se podría crear otra línea de investigación sobre la motivación y el rendimiento académico en estos estudiantes, para ver las diferencias existentes entre ambos. 


\section{REFERENCIAS BIBLIOGRÁFICAS}

Artunduaga Murillo, M. (2008). Variables que influyen en el rendimiento académico en la universidad.

Recuperado 22 de abril de http://www.slideshare.net/1234509876/variablesdel-rendimiento-academico-universidad

Cazorla, M.C. Una aproximación a los aspectos positivos y negativos derivados de la puesta en marcha del Plan Bolonia en la Universidad española.

Recuperado el 18 de abril de http://eciencia.urjc.es/bitstream/10115/5764/1/PDF.pdf

Colmenares, M. y Delgado, F. (2008). La correlación entre rendimiento académico y motivación de logro: elementos para la discusión y reflexión. Revista electrónica de humanidades, educación y comunicación social (REDHECS), 3 (5), 179-191.

Edel, R. (2003). El rendimiento académico: concepto, investigación y desarrollo. Revista electrónica iberoamericana sobre la calidad, eficacia y cambio en educación (REICE), 1 (2), 1-15.

España. Real Decreto 1393/2007, de 29 de octubre, del Código educativo. Boletín Oficial del Estado, 30 de octubre de 2007, núm. 260, p. 44037.

España. Real Decreto 1497/1987, de 27 de noviembre, del Código educativo. Boletín oficial del Estado, 14 de diciembre de 1987, núm. 298, p. 36639.

García Bacete, F.J. y Doménech Betoret, F. (1997). Motivación, aprendizaje y rendimiento escolar. Revista electrónica de Motivación y Emoción, 1 (0). Universidad Jaume I de Castellón.

Recuperado el 16 de abril de 2013 de http://reme.uji.es/articulos/pa0001/texto.html

González, C. (2003). Factores determinantes del bajo rendimiento académico en educación secundaria. Tesis doctoral no publicada, Universidad Complutense de Madrid, Madrid, España.

Herrera, M.E., Nieto, S., Rodriguez, M.J. y Sánchez, M.C. (1999). Factores implicados en el rendimiento académico de los alumnos. Universidad de Salamanca. Revista de Investigación Educativa, 17(2), 413-421.

Núñez, J.C. (2009). Motivación, Aprendizaje y Rendimiento Académico.X Congreso Internacional Galego-Portugués de Psicopedagogía. Universidade do Minho.

Quirós Expósito, P. Cabestrero Alonso, R. (2008). Funciones activadoras: principios básicos de la motivación y la emoción. Editorial Universitaria Ramón Areces. 


\section{RELACIÓN ENTRE LAS DIMENSIONES DEL SÍNDROME DE BURNOUT Y LOS FACTORES DE SATISFACCIÓN LABORAL}

\section{RELATIONSHIP BETWEEN THE DIMENSIONS OF BURNOUT SYNDROME AND JOB SATISFACTION}

David García Fernández, $\mathrm{M}^{\mathrm{a}}$ del Pilar Peña Trobat, Emilio León Chaparro, Beatriz Camacho y Alicia Mateos. Universidad de Granada

El objetivo de este estudio fue analizar las relaciones existentes entre el síndrome de quemarse por el trabajo (burnout) y satisfacción laboral en el Personal de Administración y Servicios de la universidad de Granada. La muestra estuvo formada por 87 trabajadores del PAS de manera no aleatoria. El diseño del estudio fue transversal y no aleatorio. Los análisis correlaciónales mostraron una relación muy significativa entre las dimensiones del síndrome burnout y la satisfacción laboral. También se observó que estas dimensiones mantenían correlaciones específicas con cada uno de los factores de satisfacción laboral.

Palabras clave: Satisfacción laboral, burnout y dimensiones del burnout.

The purpose of this study was to examine the relationship between burnout and job satisfaction among Administration and Services Staff. The sample consisted of 87 Administration and Services Staff of Granada's University. The study was crosssectional study, and not randomized. Correlational analyzes showed a significant relationship between the dimensions of burnout syndrome and job satisfaction. It was also maintained that these dimensions specifics correlations with eat of the factors of job satisfaction.

Key word: job satisfaction, burnout \& burnout's dimensions.

Para toda empresa o servicio es vital que los trabajadores se encuentren en las mejores condiciones posibles. Esto es así, ya que el rendimiento de cualquier trabajador se ve muy influido tanto por las condiciones de su trabajo como por su estado psíquico. De tal manera, suelen rendir más en su trabajo aquellas personas que se encuentran satisfechas laboralmente. Por otro lado, el hecho de trabajar en situaciones crónicamente estresantes puede hacer aparecer problemas como el síndrome de quemarse en el trabajo o burnout, el cual implica un agotamiento emocional y una despersonalización del trabajador respecto a sus compañeros o a las personas atendidas, además de aparecer conductas negativas como absentismo o irritabilidad. Este síndrome puede dar lugar a largo plazo a la aparición de problemas de salud, como fatiga crónica, trastornos del sueño, úlceras y tensión muscular entre otros.

En España se han producido cambios importantes en las últimas décadas que han afectado al sistema universitario. Para la adaptación al Espacio Europeo de Educación Superior las enseñanzas universitarias están sometidas a cambios que son resultado, además, de las políticas de convergencia europea, de las profundas transformaciones sociales, culturales y políticas a las que estamos asistiendo, consecuencia, a su vez, de la globalización, la sociedad del conocimiento y la fuerte presencia de las tecnologías en nuestras vidas (Michevila y Calvo, 2000; UNESCO, 1998). Dichos cambios afectan a la figura del Personal de Administración y Servicios universitarios, por ejemplo el cambio de los procesos de gestión del conocimiento, mediante la introducción de las TICS que implican cambios en la política de formación y algunas 
de las funciones de todos los profesionales implicados (Secretarías, bibliotecas y conserjerías). Estos cambios, además afectan a la forma de interacción social que se establecen entre dichos profesionales y el resto de usuarios. Puede decirse que la situación actual del PAS apunta hacia un aumento de las demandas del trabajo y una perdida de control al no disponer de recursos suficientes o tener que enfrentarse a situaciones aun novedosas. Esto configura una situación idónea para la aparición de problemas asociados al estrés, como puede ser el Síndrome de Burnout.

El objetivo de este estudio no es elaborar una formula para solucionar los problemas de insatisfacción laboral, propósito realmente ambicioso y utópico. Sin embargo, se pretende llevar a cabo con la intención de encontrar cual puede ser el mejor indicador a la hora de prevenir dichos problemas. Para poder entender esto le explicaremos los dos constructos de los que partimos a continuación.

Dentro de la psicología organizacional se entiende por satisfacción laboral una actitud circunscrita al ámbito laboral, que se ha definido como el grado de afecto positivo hacia el trabajo o sus componentes (Adams y Bond, 2000), o el grado en el que a los individuos les gusta su trabajo (Price y Mueller, 1986). Locke (1976) la describió como un estado emocional agradable y positivo resultante de la valoración del trabajo personal o de las experiencias laborales.

Por otra parte, el síndrome de quemarse en el trabajo consiste en una respuesta prolongada a los estresores crónicos de naturaleza emocional e interpersonal (GrauAlberola, Gil-Monte, García-Juesas y Figueiredo-Ferraz, 2010). Este síndrome psicológico se caracteriza por síntomas de apatía y no poder dar más de sí mismo en el ámbito emocional y afectivo (agotamiento emocional), desarrollo de sentimientos y actitudes de cinismo $\mathrm{y}$, en general, de carácter negativo hacia las personas destinatarias del trabajo (despersonalización), además de la tendencia a evaluarse negativamente, de manera especial con relación a la habilidad para realizar el trabajo y para relacionarse profesionalmente con las personas a las que atienden (baja realización personal en el trabajo) (Maslach, Schaufeli y Leiter, 2001). De este modo podemos ver tres dimensiones dentro de este síndrome: agotamiento emocional, despersonalización y falta de realización profesional.

Es más que imaginable, después de la presentación de los dos constructos, que la relación entre ambos es negativa. También se puede ver claramente que la satisfacción laboral es un buen indicador del bienestar del trabajador y su buen desempeño en su puesto de trabajo. Sin embargo la relación entre satisfacción laboral y cada una de las dimensiones del síndrome de quemarse en el trabajo no son tan claras. Existen estudios donde se obtiene que la satisfacción laboral está negativamente relacionada con los niveles de agotamiento emocional $y$ despersonalización, y positivamente con la realización personal en el trabajo (Alimoglu y Donmez, 2005; Michinov, 2005). Algunos estudios concluyen que la relación más intensa se establece entre agotamiento emocional y satisfacción laboral (Doest, Maes y Gebhardt, 2006), mientras que otros obtienen que la relación más intensa se da entre realización personal en el trabajo y satisfacción laboral (Iverson, Olekalns y Erwin, 1998). Ante esta situación, este estudio pretende analizar las relaciones existentes entre la satisfacción laboral y el síndrome de quemarse por el trabajo (burnout). Como entre satisfacción laboral y burnout existe una relación significativa esperamos que esta relación se mantenga con las tres dimensiones del burnout. Sin embargo es probable que existan relaciones específicas entre los factores de la satisfacción laboral y las dimensiones del burnout. 
En primer lugar, se pretenden analizar la correlación entre satisfacción laboral y las dimensiones del burnout. De tal manera, se espera que las correlaciones entre satisfacción laboral y cada una de las dimensiones de burnout sean significativas.

Por último, pretendemos averiguar si existen correlaciones con diferentes niveles de fuerza entre factores de satisfacción laboral y dimensiones de burnout. De esta manera esperamos que existan correlaciones con niveles de significatividad diferentes entre factores de la satisfacción laboral y dimensiones del burnout. Esto resulta interesante a la hora de estudiar los factores de satisfacción laboral como predictores del burnout por sí mismos.

\section{MÉTODO}

\section{Participantes}

La muestra de sujetos que participó en el estudio estaba formada por 87 trabajadores del Personal de Administración y Servicio (PAS) provenientes de las facultades de Ciencias, Relaciones Laborales, Derecho, Medicina, Enfermería, Psicología, Ciencias de la educación, Empresariales, Filosofía y Letras de la Universidad de Granada durante curso académico 2012-2013. De los 87 participantes 37 eran hombres y 50 mujeres con una edad entre 22 y 65 años y una antigüedad en su puesto de trabajo entre 1 y 39 años.

\section{Instrumentos}

Los instrumentos usados en esta investigación fueron los siguientes:

Cuestionario de Satisfacción S20/23 (Meliá y Peiró, 1989).

Los ítems se responden con una escala de 5 puntos que valora el grado de satisfacción que el trabajador tiene con diferentes aspectos del trabajo como: satisfacción con la supervisión ( 6 ítems: relaciones con supervisor y con la supervisión recibida), satisfacción con el ambiente físico de trabajo (5 ítems: limpieza y espacio disponible), satisfacción con las prestaciones (5 ítems: salario, promoción y formación), satisfacción intrínseca (4 ítems: hacer lo que le gusta y objetivos que debe alcanzar) y satisfacción con la participación (3 ítems: capacidad para decidir y participación en decisiones del departamento). La escala permite obtener una puntuación global en satisfacción laboral resultado del promedio de las puntuaciones de los ítems que la forman. Altas puntuaciones indican mayor satisfacción laboral.

Maslach Burnout Inventory (Maslach y Jackson, 1986)

Se trata de una escala para medir el síndrome burnout. Está adaptada para muestras españolas (Gil-Monte y Peiró, 1999). Este instrumento se compone de 22 ítems y consta de tres subescalas destinadas a medir los síntomas del síndrome burnout: Realización Personal en el trabajo (8 ítems; v.g., Siento que mediante mi trabajo estoy influyendo positivamente en la vida de otros), Agotamiento emocional (9 ítems; v.g., Debido a mi trabajo me siento emocionalmente agotada/o) y Despersonalización (5 ítems; v.g., Creo que trato a algunos pacientes como si fueran objetos). Esta escala de frecuencia tiene 5 grados que van desde 1 ("Nunca") a 5 ("Diariamente"). Las puntuaciones bajas en Realización personal en el trabajo junto a altas puntuaciones en Agotamiento emocional y en Despersonalización se corresponden con altos niveles del síndrome burnout. 


\section{Diseño y Procedimiento}

Nuestra investigación se trata de un estudio transversal, en cuanto a la participación de personas de diferentes edades y con una antigüedad laboral diferente cada una. Se trata, también, de un estudio con una sola medida donde la satisfacción laboral se mide con el cuestionario de Satisfacción S20/23 (Meliá y Peiró, 1989) y el síndrome de quemarse en el trabajo o Burnout con el Inventario de Burnout de Maslach (Maslach y Jackson, 1986). Por otra parte, la selección de la muestra se realizó de manera no aleatoria y su participación en el estudio fue voluntaria y anónima. Los responsables del estudio acudieron personalmente a las distintas facultades entregando el cuestionario en mano a los sujetos que estaban presentes en el lugar de trabajo. El cuestionario incluía una introducción en la que se explicaba el procedimiento de respuesta de los ítems además de un apartado donde indicar la edad, el sexo y la antigüedad en el puesto de trabajo, pero no se presentaba información alguna de la investigación.

\section{Análisis}

Los datos se han analizado con el programa estadístico SPSS 15. Para contrastar la primera hipótesis se ha realizado una correlación entre la satisfacción laboral y las dimensiones de burnout (agotamiento emocional, despersonalización y realización personal). Para la segunda hipótesis, se ha realizado una correlación entre las dimensiones de satisfacción laboral (satisfacción con la supervisión, satisfacción con el ambiente físico de trabajo, satisfacción con las prestaciones, satisfacción intrínseca y satisfacción con la participación).

\section{RESULTADO}

En la siguiente tabla presentamos las variables con la que hemos trabajado y sus características:

Tabla 1: Estadístico descriptivos

\begin{tabular}{lccccc}
\hline & $\mathbf{N}$ & Mínimo & Máximo & Media & Desv. típ. \\
EDAD & 87 & 22 & 65 & 46.78 & 8.77 \\
SEXO & 87 & 1 & 2 & 1.57 & .49 \\
ANTIGÜEDAD & 87 & 1 & 39 & 15.47 & 8.77 \\
AGOTAMIENTO & 87 & 9 & 37 & 18.63 & 6.34 \\
EMOCIONAL & 87 & 5 & 21 & 8.56 & 3.75 \\
DESPERSONACIZACIÓN & 87 & 9 & 34 & 17.54 & 5.39 \\
DESMOTIVACIÓN & 87 & 25 & 115 & 77.46 & 17.32 \\
SASTISFACCIÓN & 87 & & & & \\
LABORAL & & & &
\end{tabular}

Para analizar los resultados hemos realizado diferentes análisis de correlaciones entre las variables del estudio (tabla 1). De dichos análisis obtenemos relaciones entre la edad, el sexo, la antigüedad en la empresa y la variable satisfacción laboral con las dimensiones de Burnout. 
Tabla 2: Análisis correlacional de las variables

\begin{tabular}{lcccc}
\hline & EDAD & SEXO & ANTIGÜEDAD & $\begin{array}{c}\text { SASTISFACCIÓN } \\
\text { LABORAL }\end{array}$ \\
SASTISFACCIÓN & -.01 & -.13 & .02 & - \\
LABORAL & & & & $-.64^{* * *}$ \\
$\begin{array}{l}\text { AGOTAMIENTO } \\
\text { EMOCIONAL }\end{array}$ & .07 & .153 & .02 & $-.31^{* *}$ \\
$\begin{array}{l}\text { DESPERSONALIZ } \\
\text { ACIÓN }\end{array}$ & .03 & -.05 & -.08 & $-.33^{* *}$ \\
DESMOTIVACIÓN & .07 & .01 & -.02 & \\
\hline
\end{tabular}

Nota: ${ }^{* *} p<.001^{* *} p<.01$

En el análisis de los resultados (Tabla 2) se puede ver que las variables edad, género y antigüedad en la empresa no mantienen correlaciones significativas ni con la variable satisfacción laboral ni con las dimensiones del síndrome burnout. En cambio, hemos obtenido que la satisfacción laboral correlaciona con el agotamiento emocional significativamente y de manera negativa $(r=-, 636 ; p<0,01)$, al igual que ocurre con la dimensión despersonalización $(r=-, 307 ; p<0,01)$, y la desmotivación personal $(r=-$ ,329; $p<0,01)$.

Para analizar la segunda hipótesis que presentamos en el estudio, se realizó otro análisis correlacional entre los cinco factores de la Satisfacción Laboral y las tres dimensiones del Síndrome Burnout, en el que obtenemos como todos los factores de satisfacción laboral correlacionan con al menos una dimensión de Burnout (véase la tabla 3).

Tabla 3: Análisis de correlación entre las variables de satisfacción personal y las dimensiones de Burnout.

\begin{tabular}{|c|c|c|c|c|c|c|}
\hline & EDAD & SEXO & ANTIGÜEDAD & $\begin{array}{l}\text { AGOTAMIENTO } \\
\text { EMOCIONAL }\end{array}$ & DESPERSONALIZACIÓN & DESMOTIVACIÓN \\
\hline $\begin{array}{l}\text { SATISFACCIÓN } \\
\text { INTRÍNSECA }\end{array}$ & .14 & -.09 & .12 & $-.49^{\star \star \star}$ & $-.21^{*}$ & $-.313^{\star *}$ \\
\hline $\begin{array}{l}\text { SATISFACIÓN CON } \\
\text { LAS } \\
\text { PRESTACIONES }\end{array}$ & .03 & -.03 & .02 & $-.45^{\star \star \star}$ & -.19 & $-.32^{\star \star}$ \\
\hline $\begin{array}{l}\text { SATISFACIÓN CON } \\
\text { EL AMBIENTE }\end{array}$ & .07 & -.17 & .12 & $-.44^{\star \star \star}$ & $-.20^{*}$ & -.18 \\
\hline $\begin{array}{l}\text { SATISFACCIÓN } \\
\text { CON LA } \\
\text { SUPERVISIÓN }\end{array}$ & -.08 & -.07 & -.11 & $-.59^{\star \star \star}$ & $-.34^{* * *}$ & $-.23^{*}$ \\
\hline $\begin{array}{l}\text { SATISFACCIÓN } \\
\text { CON LA } \\
\text { PARTICIPACIÓN }\end{array}$ & -.18 & -.15 & -.03 & $-.49^{\star * *}$ & $-.22^{*}$ & $-.30^{* *}$ \\
\hline
\end{tabular}

Nota: ${ }^{* *} p<.001{ }^{* *} p<.01{ }^{*} p<.05$

En esta tabla encontramos que la dimensión de agotamiento emocional mantiene una correlación negativa significativa con todos factores de la satisfacción laboral. La dimensión de despersonalización correlaciona significativamente y negativamente con la satisfacción de supervisión y mantiene otra correlación negativa con la satisfacción de participación. La dimensión de desmotivación muestra una correlación positiva significativa con los factores de satisfacción intrínseca, con las prestaciones y con la supervisión, además mantiene una correlación significativa con la satisfacción de supervisión. 


\section{DISCUSIÓN Y CONCLUSIÓN}

En nuestra primera hipótesis se esperaba que entre satisfacción laboral y las tres dimensiones de burnout existiesen correlaciones significativas. Por lo que se podría afirmar que la satisfacción laboral mantiene una relación con los tres tipos de dimensiones del burnout (agotamiento emocional, despersonalización y realización persona). Ante esto, podemos decir que nuestra hipótesis inicial se ha cumplido. La segunda de nuestras hipótesis pretendía encontrar si existían relaciones específicas entre los factores de satisfacción laboral y las dimensiones del burnout. En el análisis correlacional se obtuvo que las relaciones entre factores de satisfacción laboral y dimensiones de burnout fueron diferentes unas de otras, surgiendo correlaciones muy significativas, ligeramente significativas o no significativas. Este hecho hace que nuestra segunda hipótesis se confirme, lo cual nos permite afirmar la existencia de relaciones específicas entre los factores de satisfacción laboral y las dimensiones del síndrome burnout.

Según otros autores, existen unas relaciones entre satisfacción laboral y las dimensiones de burnout que son más intensas que otras. Sin embargo, los resultados de dichas investigaciones no coinciden. De este modo podemos encontrar estudios donde se establece una relación más intensa entre satisfacción laboral y realización personal (Iverson, Olekalns y Erwin, 1998) mientras otros establecen una relación más intensa de la satisfacción laboral con el agotamiento emocional y la despersonalización (Doest, Maes y Gebhardt, 2006) o, como en este caso, donde se establece una relación igual de intensa entre satisfacción y cada una de las dimensiones. Sin embargo, estas investigaciones sólo han trabajado sobre el constructo general de satisfacción laboral y no sobre los factores que lo componen, lo cual supone un nivel de análisis inapropiado o poco profundo para establecer dichas relaciones. De tal modo una persona puede puntuar como insatisfecha en determinados factores mientras se muestra satisfecha en el resto, mostrando una puntuación que no refleje dichos défits factoriales del constructo. Por lo cual a la hora de estudiar las relaciones entre la satisfacción laboral y síndrome burnout, pueden surgir casos donde haya una buena satisfacción laboral y se muestre alguna dimensión del síndrome burnout, es por eso que el nivel de análisis no sería apropiado.

El hecho de que existan diferentes grados de relación significativa nos muestra que algunos de estos factores de la satisfacción laboral podrían actuar como predictores de alguna de las dimensiones del burnout. De este modo podríamos esperar que el factor de supervisión nos indicase problemas de agotamiento emocional y/o de despersonalización, de tal manera que aquellas personas que puntúen bajo en satisfacción con la supervisión muestren problemas de agotamiento emocional o de despersonalización, o bien de los dos. Esta propuesta resulta interesante de estudiar ya que podría ser importante en el ámbito de la intervención y prevención de problemas laborales como es el síndrome de burnout, pues si los factores de satisfacción pudiesen predecir aquellos problemas derivados de las dimensiones del burnout facilitaría la identificación y el tratamiento de estos mejorando posiblemente tanto el rendimiento del empleado como su bienestar.

Debemos ser conscientes de que este estudio posee algunas limitaciones. Entre estas limitaciones encontramos que la muestra se obtenido de manera no aleatoria por lo cual es probable que no sea equilibrada por lo que no representaría bien a la población. Los datos recogidos se consiguieron mediante cuestionarios, esto hace que los datos dependan en última instancia del criterio de sinceridad de respuesta del participante. Sin embargo estas limitaciones no invalidan los resultados obtenidos en este estudio ni su comparación con otras investigaciones. 


\section{Referencias:}

Adams, A., y Bond, S. (2000). Hospital nurses job satisfaction, individual and organizational characteristics. Journal of Advanced Nursing, 32, 536-543.

Alimoglu, M.K., y Donmez, L. (2005). Daylight exposure and the other predictors of burnout among nurses in a University Hospital. International Journal of Nursing Studies, 42, 549-555

Burisch, M. (2002). A longitudinal study of burnout: The relative importance of dispositions and experiences. Work and Stress, 16, 1-17.

Doest, L., Maes, S., y Gebhardt, W.A. (2006). Personal goal facilitation through work: Implications for employee satisfaction and well-being. Applied Psychology: An International Review, 55, 192-219.

Figueiredo-Ferraz1, H., Grau-Alberola2, E., Gil-Monte1, P. R., y García-Juesas, J. A. (2012). Síndrome de quemarse por el trabajo y satisfacción laboral en profesionales de enfermería. Psicothema, 24, 271-276.

Grau-Alberola, E., Gil-Monte, P.R., García-Juesas. J.A., y Figueiredo-Ferraz, H. (2010). Incidence of burnout in Spanish nursing professionals: A longitudinal study. International Journal of Nursing Studies, 47, 1013-1020.

Iverson, D.R., Olekalns, M., y Erwin, J.P. (1998). Affectivity, organizational stressors and absenteeism: A causal model of burnout and its consequences. Journal of Vocational Behavior, 52, 1-23.

Kalliath, T.J., y Morris, R. (2002). Job satisfaction among nurses: A predictor of burnout levels. Journal of Nursing Administration, 32, 648-654.

Lee, H., Hwang, S., Kim, J., y Daly, B. (2004). Predictors of life satisfaction of Korean nurses. Journal of Advanced Nursing, 48, 632-641.

Locke, E.A. (1976). The nature and causes of job satisfaction. En M.R. Dunnette (Ed.), Handbook of industrial and organizational psychology (pp. 1297-1349). Chicago, IL: Rand McNally College Publishing Co.

Maslach, C., y Jackson, S.E. (1986). Maslach Burnout Inventory Manual. (2a ed.). Palo Alto, California: Consulting Psychologists Press.

Maslach, C., Schaufeli, W.B., y Leiter, M.P. (2001). Job burnout. Annual Review of Psychology, 52, 397-422.

Meliá, J.L., y Peiró, J.M. (1989). La medida de la satisfacción laboral en contextos organizacionales: El Cuestionario de Satisfacción S20/23. Psicologemas, 5, 59-74.

Michinov, N. (2005). Social comparison, perceived control and occupational burnout. Applied Psychology: An International Review, 54, 99-118.

Navarro, M. L. A. (2010). Esters laboral y síndrome burnout en la Universidad: Analisis descriptivo de la situación actual y revisión de las principales líneas de investigación. Anuario de psicología clínica y de la salud, 6, pp 73-78. 
Price, J.L., y Mueller, C.W. (1986). Absenteeism and turnover among hospital employees. Greenwich, CT: JAI Press.

Soler Sánchez, M.I. (2008). La evaluación de los factores de riesgo psicosocialdel trabajo en el sector hortofrutícola: el cuestionario FAPSIHOS. (Tesis doctoral). 


\section{¿INFLUYE EL TIPO DE LIDERAZGO DE LOS PROFESORES EN LA SATISFACCIÓN ESTUDIANTIL? ESTUDIO COMPARATIVO ENTRE LOS DISTINTOS DEPARTAMENTOS DE LA FACULTAD DE PSICOLOGÍA DE LA UNIVERSIDAD DE GRANADA.}

\section{DOES IT INFLUENCE THE TYPE OF TEACHERS LEADERSHIP IN STUDENT SATISFACTION? COMPARATIVE STUDY BETWEEN DEPARTAMENTS OF PSYCHOLOGY FACULTY OF THE UNIVERSITY OF GRANADA.}

Salas Alba, L., Palomero Fernández, N., Pozo Arenas, G. y Rosa Bares, A. Universidad de Granada

\section{RESUMEN}

El presente estudio pretende medir el nivel de satisfacción, percibido por los alumnos de la facultad de psicología de Granada, en relación a los diferentes estilos de liderazgo presentes en cada uno de los departamentos de dicha facultad. Por ello, se mide el estilo de liderazgo y la satisfacción a través de dos tests realizados por los alumnos. Así pues, se busca la correlación entre ambas variables. Los resultados obtenidos muestran, en general, que en todos los departamentos predomina un estilo de liderazgo democrático y a su vez una satisfacción relativamente alta. Finalmente, se observa que tan solo existe una correlación significativa en el Departamento de Psicobiología, en el cual el estilo de liderazgo correlaciona positivamente con la satisfacción de los estudiantes.

Palabras Clave: Satisfacción Estudiantil; Liderazgo Percibido; Departamentos.

\section{ABSTRACT}

This study aims to measure the level of satisfaction perceived by students of the Psychology Faculty of Granada in relation to different leadership styles present in each departments of this faculty. For this reason, the leadership's style and satisfaction is measured with two tests performed by the students. This study aims to know if there is correlation between both variables. The results show, in general, that a democratic leadership style predominates in all departments and there is a relatively high satisfaction too. Finally, it is observed that there is only a significant correlation in the Psychobiology Department, in which leadership style correlates positively with student's satisfaction.

Key Words: Student Satisfaction; Perceived Leadership; Departments.

\section{INTRODUCCIÓN}

El liderazgo y la satisfacción en el trabajo han sido temas que han despertado gran interés entre los investigadores desde hace mucho tiempo, interés que no ha decaído en los tiempos actuales. Los investigadores han enfocado su estudio en formas muy distintas, de donde han emanado una serie de teorías que han tratado de explicar los factores que intervienen en la emergencia del liderazgo y satisfacción en el trabajo (Aldalpe, A. Et al., 2011).

Liderazgo: La conceptualización más común de liderazgo ha sido enfocarse en un solo líder y sus características (Teoría del Gran Hombre). Desde los tiempos de la Grecia 
antigua y el Imperio Romano, Herodoto, Tácito y otros historiadores se concentraron en hombres sobresalientes que contribuyeron en forma significativa al acontecer de los eventos principales de su tiempo, (Aldape, 2003). En la actualidad, todavía se conserva este enfoque.

Satisfacción: Por muchos años los investigadores han estado interesados en la relación entre desempeño y satisfacción en el trabajo de los empleados. Los pioneros en este tópico (Lawler y Porter, 1967) sugirieron que la satisfacción en el trabajo aumentaba el desempeño. Este tema sigue estudiándose por varias razones: ausentismo, rotación, efectividad organizacional, clima organizacional (Ross y Zander, 1957 ) y más recientemente, el creciente interés en la calidad de vida laboral.

En base a lo anteriormente expuesto: si el desempeño depende de la satisfacción y ésta depende en parte del estilo de liderazgo de los directivos, cabría esperar que estudiantes cuyos profesores tengan un estilo autoritario presenten menor satisfacción. Esto incluiría una menor motivación, mayor absentismo al aula, menor efectividad, etc. En definitiva, un peor desempeño.

Los estudios realizados muestran que los comportamientos de liderazgo percibidos por los alumnos son predictores razonables de la satisfacción. Además el estilo democrático tiene un impacto positivo en la satisfacción, al contrario del estilo autocrático (Pinto, 1997).

Otro estudio desarrollado en la Universidad Pública de Mongolia muestra evidencia de que la satisfacción en el trabajo de los profesores está íntimamente relacionada con el estilo de liderazgo de sus jefes. Esperan que los jefes posean un liderazgo profesional, buena comunicación, habilidades de organización, ser justos y respetuosos con ellos. Además de tomar decisiones críticas después de recibir las aportaciones de la facultad. Esto se relaciona con un estilo de liderazgo democrático (Mclnerney et al., 2007).

Con este estudio pretendemos comprobar si la intervención del profesor tiene un impacto en el desempeño y satisfacción de los alumnos (Antunes et. al., 1999). Además de cómo esta relación afecta a los distintos departamentos de la Facultad de Psicología de la Universidad de Granada.

Creemos que es importante llevar a cabo este tipo de estudios, ya que, factores que impactan en la satisfacción en el trabajo también lo hacen en el clima organizacional y la calidad de vida en el ámbito estudiantil, así como, el desempeño.

Por esta razón es imprescindible monitorear continuamente la satisfacción en el trabajo puesto que esto permitirá al líder que tome decisiones sobre si su estilo de liderazgo es adecuado o no.

Con los grandes cambios ocasionados por la globalización, hoy más que nunca se requiere de buenos líderes, preparados no solo para entender los cambios sino para generarlos y que permitan a sus organizaciones competir exitosamente (Aldalpe, 2011). 


\section{METODOLOGÍA}

\section{Selección de participantes}

Para poder comprobar nuestra hipótesis hemos seleccionado una muestra de 300 sujetos. Todos ellos de la Licenciatura y Grado de Psicología de la Universidad de Granada. Para este estudio no hemos tenido en cuenta datos sociodemográficos como edad, sexos, curso, etc ya que, ningunas de las variables que componen nuestra hipótesis se ven influenciados por estos datos. Únicamente se ha necesitado que los estudiantes hayan cursado alguna asignatura en los distintos departamentos que componen titulación de Psicología.

\section{Instrumentos}

En el proceso de investigación se aplicaron los siguientes instrumentos:

- Test de Liderazgo (Lewin y Lippitt, 1938) que evalúa tres tipos de liderazgo: autoritario, democrático y laissez faire (dejar hacer).

- Cuestionario de Satisfacción Estudiantil (Jiménez, Terriquez y Robles, 2011) que mide la satisfacción que tienen los estudiantes con respecto a su ámbito de estudio.

Para conocer más información de ambos instrumentos, a continuación, se hace una detallada explicación de cada uno de ellos.

El Test de Liderazgo de Kurt Lewin es un cuestionario que está indicado para conocer el tipo de liderazgo que posee un individuo en base a su personalidad, ideologías, creencias, etc. Consta de 33 ítems donde se muestra una acción que llevaría a cabo una persona como líder, y es el sujeto el que deberá responder si está de acuerdo o en desacuerdo en función de la afirmación que hace cada uno de los ítems.

La dinámica que nuestro equipo ha llevado a cabo, consiste en rellenar el cuestionario de liderazgo adoptando la posición del profesor evaluado. Para saber qué estilo predomina en la persona es suficiente contabilizar las respuestas de "acuerdo". A través de este cuestionario se obtiene tres puntuaciones que oscilan entre $1=$ liderazgo autoritario, 2= liderazgo democrático y 3 = liderazgo "laissez faire" (dejar hacer).

En lo que se refiere al Cuestionario de Satisfacción Estudiantil hay que señalar que mide la satisfacción que tienen los estudiantes con respecto a la asignatura (en nuestro caso se evaluarán departamentos) que se evalúa. Está compuesto por 35 preguntas que se dividen en dos secciones: 5 para ver el nivel de importancia que le otorgan los estudiantes y 30 para conocer el grado de satisfacción respecto a los aspectos comprendidos en el plan de estudios que están cursando.

La segunda sección de este cuestionario, que es la que hemos aplicado, consta de preguntas que evalúan el desempeño de los aspectos relacionados con la experiencia escolar agrupada en cinco aspectos: contenido de la unidad de aprendizaje (desarrollo de la unidad de aprendizaje, claridad y cumplimiento de los objetivos de la misma), metodología (actividades y materiales didácticos que ayuden a entender el contenido de la unidad de aprendizaje), infraestructura disponible (instalaciones, equipos y mantenimiento de aulas, laboratorios, baños), desempeño del profesor (conocimiento y dominio de tema, solución de tareas y exámenes, motivación, puntualidad, dinámicas de grupo, comportamiento) y desempeño del estudiante (participación, motivación, cumplimiento con tareas y trabajos, tiempo de dedicación). 
Las respuestas que los participantes pueden dan a los distintos ítems se basan en una escala tipo Likert de 1 a 5, donde: (1) "Muy insatisfecho", (2) "Insatisfecho", (3 "Poco satisfecho", (4) "Satisfecho" y (5) "Muy satisfecho" (Jiménez et al., 2011)

\section{Procedimiento}

Como ya se ha indicado, nuestro objetivo primordial es demostrar que hay una relación entre el liderazgo predominante de cada departamento yla satisfacción estudiantil. Por ello, comenzamos con una búsqueda de información sobre los diversos departamentos, asignaturas y profesores que integraban tanto el grado como la licenciatura de Psicología en la Universidad de Granada.

Recopilada esta información hicimos una selección aleatoria de profesorado (5 miembros de cada departamento), y se pusieron junto al nombre de todas las asignaturas en unas instrucciones que se adjuntaron en los cuestionarios.

A continuación, tras pasar los cuestionarios se procedió a la corrección e interpretación de los mismos.

\section{Diseño}

Esta investigación es de corte transversal correlacional donde se pretende ver si el tipo de liderazgo percibido correlaciona con la satisfacción estudiantil.

Las variables utilizadas son las siguientes: estilo de liderazgo (VI) y satisfacción estudiantil (VD).

\section{Análisis}

Para el análisis de los resultados se realizó el estudio de descriptivos básicos, comparación de medias a través de un ANOVA, prueba de Levenne, comparaciones múltiples a través de la prueba de Tukey y Correlación de Pearson. Para ello, se ha utilizado el software IBM SPSS Statistics 19.0.

\section{RESULTADOS}

Una primera aproximación a la población del estudio nos lleva a estadísticos descriptivos básicos (Tabla I y Gráfico 1), que muestran los valores medios de liderazgo y satisfacción obtenidos tras la evaluación de los distintos departamentos. Se observa cómo todos los departamentos tienen un valor similar en liderazgo, donde la tendencia es al estilo democrático (puntuación igual a 2). El dpto. de Personalidad obtuvo los valores más altos en satisfacción estudiantil (media $=3,83$ ), seguido de los dptos. Evolutiva $(3,59)$, Psicobiología $(3,50)$, Experimental y Social $(3,42)$. Los resultados más bajos en satisfacción fueron obtenidos por el dpto. de Metodología $(2,69)$. 


\begin{tabular}{|lll}
\hline & Liderazgo & Satisfacción \\
\hline Dpto. Psicobiologia & 1.82 & 3.50 \\
\hline Dpto. Evolutiva & 1.98 & 3.59 \\
\hline Dpto. Personalidad & 2.04 & 3.83 \\
\hline Dpto. Experimental & 1.96 & 3.42 \\
\hline Dpto. Social & 2.02 & 3.42 \\
\hline Dpto. Metodologia & 1.96 & 2.69 \\
\hline
\end{tabular}

Tabla I. Valores medios de liderazgo y satisfacción por departamentos. Liderazgo (Autoritario=1, Democrático $=2$, "Laissez faire" $=3$ ). Satisfacción (Muy insatisfecho $=1$. Insatisfecho $=2$. Poco Satisfecho $=3$. Satisfecho $=4$ y Muy Satisfecho $=5$ ).

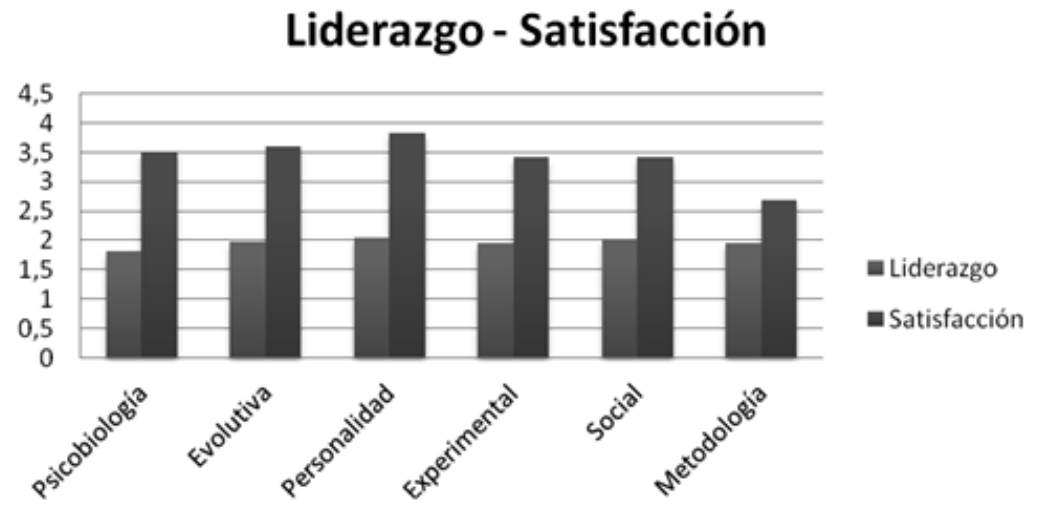

Gráfico 1. Valores medios de liderazgo y satisfacción por departamentos

La Tabla II muestra el análisis de varianza entre el estilo de liderazgo y la satisfacción por departamentos. En los departamentos de Evolutiva $(p=0,246)$, Experimental $(p=0,86)$, Metodología $(p=0,724)$, Personalidad $(p=0,712)$ y Social $(p=0,766)$ concluiremos que las poblaciones definidas por la variable liderazgo poseen la misma satisfacción. En cambio, en el Departamento de Psicobiología $(p<0,001)$ concluiremos que las poblaciones definidas por la variable liderazgo no poseen la misma satisfacción.

\begin{tabular}{lcc}
\hline & $\mathrm{F}$ & $\mathrm{p}$ \\
\hline Evolutiva & 1.445 & 0.246 \\
\hline Experimental & 0.142 & 0.86 \\
\hline Metodología & 0.325 & 0.724 \\
\hline Personalidad & 0.138 & 0.712 \\
\hline Psicobiología & 8.430 & 0.001 \\
\hline Social & 0.090 & 0.766
\end{tabular}

Tabla II. ANOVA entre el estilo de liderazgo y satisfacción en los distintos departamentos

La Tabla III muestra, dentro del Departamento de Psicobiología, cómo los promedios comparados Autoritario-Democrático $(p<0,001)$, Autoritario-Laissez Faire $(p=0,023)$ difieren significativamente. El estilo autoritario obtiene una menor satisfacción que el democrático y laissez faire. 


\begin{tabular}{|c|c|c|c|c|c|c|}
\hline (I) Liderazgo & (J) Liderazgo & $\begin{array}{l}\text { Diferencias } \\
\text { de medias (I- } \\
\mathrm{J} \text { ) }\end{array}$ & Error Típico & Sig. & $\begin{array}{c}\text { Límite } \\
\text { inferior (IC } \\
95 \% \text { ) }\end{array}$ & $\begin{array}{c}\text { Límite } \\
\text { superior (IC } \\
95 \%)\end{array}$ \\
\hline Autoritario & $\begin{array}{l}\text { Democrático } \\
\text { Laissez Faire }\end{array}$ & $\begin{array}{l}-0.55661 \\
-0.63381\end{array}$ & $\begin{array}{l}0.14258 \\
0.23068\end{array}$ & $\begin{array}{l}0.001 \\
0.023\end{array}$ & $\begin{array}{l}-0.9017 \\
-1.1921\end{array}$ & $\begin{array}{l}-0.2116 \\
-0.0755\end{array}$ \\
\hline Democrático & $\begin{array}{c}\text { Autoritario } \\
\text { Laissez Faire }\end{array}$ & $\begin{array}{c}0.55661 \\
-0.07720\end{array}$ & $\begin{array}{l}0.14258 \\
0.21339\end{array}$ & $\begin{array}{l}0.001 \\
0.930\end{array}$ & $\begin{array}{r}0.2116 \\
-0.5936\end{array}$ & $\begin{array}{l}0.9017 \\
0.4392\end{array}$ \\
\hline $\begin{array}{l}\text { Laissez } \\
\text { Faire }\end{array}$ & $\begin{array}{c}\text { Autoritario } \\
\text { Democrático }\end{array}$ & $\begin{array}{l}0.63381 \\
0.07720\end{array}$ & $\begin{array}{l}0.23068 \\
0.21339\end{array}$ & $\begin{array}{l}0.023 \\
0.930\end{array}$ & $\begin{array}{r}0.0755 \\
-0.4392\end{array}$ & $\begin{array}{l}1.1921 \\
0.5936\end{array}$ \\
\hline
\end{tabular}

La tabla IV ofrece una clasificación de los grupos basada en el grado de parecido existente entre sus medias. Así, en el subgrupo 1, está incluido un solo grupo (autoritario) que difiere de los dos posteriores y que, obviamente no difiere de sí mismo (significación $=1$ ), y en el subgrupo 2 están incluidos dos grupos (democrático y laissez faire) cuyas medias no difieren significativamente (significación $=, 921$ ).

Subgrupo 1 Subgrupo 2

\begin{tabular}{ccc}
\hline Autoritario & 3.0929 & \\
\hline Democrático & & 3.6495 \\
\hline Laissez Faire & & 3.7267 \\
\hline p & 1 & 0.921 \\
\hline
\end{tabular}

Tabla IV. Subgrupos homogéneos del procedimiento ANOVA de un factor.

La tabla $\mathrm{V}$ muestra cómo solo existe correlación significativa entre el estilo de liderazgo y la satisfacción en el Departamento de Psicobiología $(p<0,001)$. Observándose una correlación positiva moderada entre estos valores. Cuanto más tendencia haya hacia el estilo Laissez Faire más satisfacción estudiantil habrá.

\begin{tabular}{llll} 
& \multicolumn{1}{c}{$\begin{array}{c}\text { Correlación de } \\
\text { Pearson }\end{array}$} & $\mathrm{P}$ \\
\hline Evolutiva & 0.235 & 0.101 \\
Experimental & 0.072 & 0.618 \\
Metodología & 0.088 & 0.545 \\
Personalidad & -0.053 & 0.712 \\
Psicobiología & 0.465 & 0.001 \\
Social & 0.043 & 0.076
\end{tabular}

Tabla V. Correlación entre estilo de liderazgo (Autoritario $=1$, Democrático $=2$, Laissez Faire $=3$ ) y satisfacción estudiantil por departamentos

\section{CONCLUSIONES}

En este estudio podemos observar que en todos los departamentos predomina un estilo de liderazgo democrático. Además, la satisfacción es bastante alta en cada uno, exceptuando el de metodología en el que la puntuación es menor.

Basándonos en nuestra hipótesis de partida: "El estilo de liderazgo correlaciona positivamente con la satisfacción de los estudiantes", concluimos que solo se cumple en el Departamento de Psicobiología. En el resto, se puede decir que no obtenemos resultados significativos para esta correlación (Véase tabla 2). 
Centrándonos en el Departamento de Psicobiología obtenemos que existe una correlación positiva moderada entre el estilo de liderazgo Laissez-Faire y la satisfacción estudiantil.

Al no obtener los resultados que esperábamos encontrar en base a las investigaciones previas, nos planteamos una prospectiva de futuro. Sería interesante una mayor muestra de sujetos por departamento. Aunque nuestra muestra es representativa, mayor número de sujetos elevaría la representatividad. Otro aspecto sería contar con instrumentos más precisos. El cuestionario que se ha pasado sobre liderazgo está más orientado a empresas que a personal docente, lo cual puede haber sido una variable extraña de cara a los resultados. En cuanto al diseño, se alcanzaría un entendimiento más profundo de la realidad si se hiciesen investigaciones de carácter longitudinal, observando cohortes a lo largo del tiempo. Mediante éste se iría viendo cada año, desde que un grupo de estudiantes comienza en primero hasta que termina su formación, cómo varía esta relación.

Finalmente, creemos que puede haber influido la nota media de cada uno, en las respuestas que han dado tanto para liderazgo como para satisfacción. Es por ello que sería interesante relacionar la nota de expediente con la satisfacción de cada estudiante.

\section{REFERENCIAS BIBLIOGRÁFICAS}

Aldalpe, A., Pedrozo, J., Castillo Pérez, L. y Moguel Liévano, M.J. (2011). Liderazgo y satisfacción en el trabajo ¿Vale la pena estudiarlos? Revista de economía, finanzas y negocios, 2(1), 1-8.

Aldalpe, Alfonso A. (2003). Liderazgo: Su Impacto en la Satisfacción en el Trabajo y la Productividad. Tesis Doctoral. Publicada por la División de Estudios de Posgrado e Investigación del Instituto Tecnológico de Cd. Juárez, Chich., Mex.2003.

Antunes, I., Sidónio, S., y Carita, I. (1998). Liderazgo y satisfacción en la educación física. Revista de psicología del deporte, 8(1), 147-164.

Jiménez, A, Terriquez, B. y Robles, F.J. (2011). Evaluación de la satisfacción académica de los estudiantes de la Universidad Autónoma de Nayarit, 3 (6), 46-56.

Lawler III, E, E., y Porter, L.W. (1967a.) The effect of Performance in Job Satisfaction. Industrial Relations, 7, 20-28.

Lewin, K. y Lippitt, R. (1938). An experimental approach to the study of autocracy and democracy: a preliminary note. Sociometry, 1, 292-300.

Mclerney, W.D., Hirth, M.A., Knupfer, A.M., y Greenan, J.P. (2007). Perceived Presidential Leadership Styles and Faculty Job Satisfaction At Mongolian Universities. Tesis doctoral sin publicar. Universidad de Mongolia.

Pinto, T.M.M. (1997). Comportamientos de liderazgo de los profesores y satisfacción de los alumnos. Tesis de máster. Lisboa: Facultad de Motricidad Humana, UTL (trabajo no publicado).

Ross, I.C., y Zander, (1957). A. Need Satisfaction and Employee Turnover. Personnel Psychology, 10, 327-338. 


\title{
SATISFACCIÓN DE LOS ALUMNOS CON LA INSTITUCIÓN UNIVERSITARIA Y EL RENDIMIENTO ACADÉMICO
}

\section{SATISFACTION OF STUDENTS WITH UNIVERSITY INSTITUTION AND ACADEMIC PERFORMANCE}

Abarca Franco, S. Cáceres Galera, S., Jiménez Ortiz, E., Moraleda Borja, V. y Romero Durán, B. Universidad de Granada

\section{Resumen}

En el presente artículo, se ha investigado la relación existente entre el rendimiento académico y la satisfacción con la institución educativa en alumnos universitarios. Nuestra hipótesis de partida era que se hallaría una correlación positiva entre ambas variables. Para ello, se utilizó una muestra de 101 estudiantes de Licenciatura en Psicología de la Universidad de Granada. El instrumento de evaluación que se ha utilizado es el SEUE (Satisfacción de los Estudiantes Universitarios con su Educación) de Gento y Vivas (2003). Este instrumento incluye una serie de subdimensiones acerca del constructo estudiado que hemos tenido en cuenta en el análisis estadístico. Tras el análisis de los resultados hemos comprobado que no se ha confirmado la hipótesis, ya que no se observa una correlación significativa entre las variables estudiadas. Junto con la discusión de los resultados, incluimos una serie de limitaciones a tener en cuenta para futuras investigaciones.

Palabras Claves: Rendimiento académico, Satisfacción, Universidad.

\begin{abstract}
In the present article, we have investigated the relationship between academic performance and satisfaction with the educational institution in university students.

Our hypothesis was that we would be found a positive correlation between both variables. For this, we used a sample of 101 students of degree in psychology at the University of Granada. The assessment tool that has been used is the SEUE (Satisfacción de los Estudiantes Universitarios con su Educación) of Gento and Vivas (2003). This instrument includes some subdimensions about studied construct which we have taken into account in the statistical analysis. After the analysis of the results we have verified that not been confirmed the hypothesis, since there isn't a significant correlation between the variables studied. Along with the discussion of the results, we have included a series of limitations to keep in mind for future research.
\end{abstract}

Keywords: Academic performance, Satisfaction, University.

\section{Introducción}

La satisfacción es el resultado de un proceso que se da en el sujeto, por lo que se trata de un fenómeno esencialmente subjetivo. Es un concepto que se refiere a algo o alguien, que tiene que ver, con lo que el sujeto desea y con el resultado que espera. Para lograr la satisfacción, como algo sentido en un sujeto, debe haber al menos una intención por parte de otro sujeto o institución de realizar una acción determinada que provoque un resultado, el cual será valorado como positivo o no (Zas, 2002).

El aumento de la calidad de la institución académica, constituye actualmente uno de los principales retos a los que se enfrenta la Universidad española. En este sentido, en 
las últimas dos décadas las universidades de nuestro país han puesto en marcha metodologías de evaluación de la calidad orientadas a la mejora institucional. Para ello es importante realizar evaluaciones sobre la satisfacción de los estudiantes con el centro como propuso Pereira (2011).

La satisfacción ha sido estudiada en el ámbito de las instituciones educativas para ver cómo se relaciona con diferentes variables relativas a los estudiantes. Algunas de estas variables han sido burnout, absentismo escolar, compromiso, autoeficacia, rendimiento académico, etc. (Caballero, Abello y Palacio, 2007). Otros estudios se han centrado en la relación existente entre los resultados académicos y la satisfacción de los estudiantes con la enseñanza recibida en todo su proceso, es decir, hasta la comprobación de conocimientos (Fernández, Fernández, Álvarez y Martínez, 2007). Así mismo, en el estudio de Cabrera y Galán (2002) uno de los objetivos principales era probar que las expectativas positivas que posee el alumno sobre la universidad, se asocian a un alto rendimiento académico. Según el estudio de Jiménez, Terriquez y Robles (2011), la satisfacción del estudiante refleja la eficiencia de los servicios académicos y administrativos. Por ello es importante conocer la satisfacción de los estudiantes respecto a las unidades de aprendizaje, las interacciones con profesores y compañeros de clase, así como con las instalaciones y el equipamiento.

Los hallazgos de Caballero et al., (2007) muestran que el buen funcionamiento académico correlaciona positivamente con la satisfacción y viceversa. Sin embargo, otros estudios como el de Hon, Raslin y Thean (2011) encontraron que los alumnos más satisfechos eran los que obtenían calificaciones más bajas. De acuerdo con Garbanzo (2007), en el rendimiento académico del estudiante universitario intervienen diversos factores: personales, sociales e institucionales. Entre los factores institucionales se encuentran el ambiente estudiantil, las condiciones institucionales, los servicios institucionales de apoyo, las relaciones profesor-estudiante, etc.

Montero, Villalobos y Valverde (2007) han estudiado la relación entre factores institucionales, pedagógicos, psicosociales y sociodemográficos con el rendimiento académico, encontrando entre otros resultados, que hay una relación positiva entre la satisfacción del alumno con el docente y el rendimiento académico.

Se considera que es importante identificar los obstáculos y facilitadores que los estudiantes encuentran en el ámbito académico, y la relación de estos con el bienestar psicológico y desempeño académico (Soria, Martínez, Bresó, Llorens y Grau, 2005).

Con el fin de evaluar la satisfacción de los estudiantes con la institución escolar, Hussain y Bhamani (2012) han creado el instrumento de medida Student University Satisfaction Scale (SUSS). En su estudio, el instrumento demostró su fiabilidad y validez, obteniendo un coeficiente alfa de Cronbach de 0.91. Dado que este instrumento está desarrollado para población pakistaní, en este estudio utilizaremos el cuestionario Satisfacción de los Estudiantes Universitarios con su Educación (SEUE), de Gento y Vivas (2003), validado para la población española, y que presenta un coeficiente alfa de Cronbach de 0,93.

De acuerdo con los estudios revisados, consideramos importante profundizar en el estudio de la relación entre variables relativas a la actuación del estudiante y a la evaluación de este sobre el centro de estudios.

En el presente estudio se pretende investigar si existe relación entre la satisfacción de los alumnos con el centro universitario en el que estudian y su rendimiento académico. En concreto, nuestra hipótesis de investigación es la siguiente:

Existe una relación positiva entre la satisfacción con el centro y el rendimiento académico, de modo que a mayor satisfacción del estudiante con el centro, mayor será el rendimiento académico obtenido. 


\section{Método}

\section{Participantes}

La muestra está compuesta por 101 alumnos (25 hombres y 76 mujeres) de la Universidad de Granada, de la Facultad de Psicología, con edades comprendidas entre 19 y 30 años, la media de edad fue de 22.26 (DT=1.95).

\section{Materiales y procedimiento}

A los participantes se les entregó el cuadernillo en el cuál aparecían las instrucciones que debían seguir, y que además se explicaron oralmente por si tenían alguna duda.

El cuadernillo estaba formado por:

- Datos personales referentes a la edad, sexo y nota media del expediente académico.

- Un cuestionario de Gento y Vivas (2003), Satisfacción de los Estudiantes Universitarios con su Educación (SEUE). Este instrumento consta de las siguientes dimensiones: Condiciones básicas de infraestructura $(\mathrm{Cl})$, Servicios de la Institución (SI), Condiciones de seguridad (S), Consideración a su situación económica (CS), Seguridad emocional por el trato afectuoso (SE), Sentido de pertenencia a la Institución y al grupo de clase por la aceptación (PE), Proceso de enseñanza y aprendizaje (EA), Logros personales (LP), Reconocimiento del éxito personal (RE) y Autorrealización (AU). La consistencia interna de la escala calculada mediante el coeficiente alfa de Cronbach es de 0.93.

El cuadernillo se pasó a lo largo de un día, en tres grupos de clase, de la asignatura de Psicología de los Grupos y las Organizaciones de $4^{\circ}$ curso de Licenciatura en Psicología. También se pasó dicho cuadernillo a alumnos de otros cursos que se encontraban en la biblioteca de la facultad en ese día.

\section{Resultados}

Tras la recogida de datos se han llevado a cabo análisis correlacionales entre la nota media y la satisfacción (global y subdimensiones), además de estadísticos descriptivos (media y desviación típica). En las siguientes tablas se muestran los resultados obtenidos en dichos análisis.

Tabla 1. Descriptivos de las dimensiones de la satisfacción

\begin{tabular}{lcc}
\hline & $\mathrm{M}$ & $\mathrm{DT}$ \\
\hline Nota expediente & 7.43 & 0.76 \\
$\mathrm{CI}$ & 39.99 & 7.07 \\
$S I$ & 43.56 & 8.72 \\
$S$ & 18.85 & 4.86 \\
$C S$ & 18.07 & 5.10 \\
$S E$ & 25.83 & 5.03 \\
$P E$ & 31.66 & 6.57 \\
$E A$ & 51.46 & 13.13 \\
LP & 20.02 & 4.64 \\
$R E$ & 15.02 & 3.80 \\
$A U$ & 18.80 & 5.17 \\
$S T$ & 282.87 & 45.57 \\
\hline
\end{tabular}


Tabla 2. Correlación entre las dimensiones de la satisfacción y el rendimiento

\begin{tabular}{|c|c|c|c|c|c|c|c|c|c|c|c|}
\hline & $\mathrm{Cl}$ & $S I$ & $S$ & CS & SE & $P E$ & $E A$ & $L P$ & $R E$ & $A U$ & $S T$ \\
\hline Nota & $.085^{*}$ & $-.092^{*}$ & $-.127^{*}$ & $-.07^{*}$ & $-.118^{*}$ & $-.066^{*}$ & .018 & $.063^{*}$ & .015 & $-.067^{*}$ & .047 \\
\hline Expediente & & & & & & & & & & & \\
\hline
\end{tabular}

Nota: ${ }^{*} \mathrm{p}<.05$; $\mathrm{Cl}$ : Condiciones básicas de Infraestructura; SI: Servicio de la Institución; S: Condiciones de Seguridad; CS: Consideración de la Situación Económica; SE: Seguridad Emocional; PE: Sentido de Pertenencia; EA: Proceso de Enseñanza aprendizaje; LP: Logro Personal; RE: Reconocimiento del Éxito Personal; AU: Autorrealización; ST: Satisfacción Total.

No se obtiene una correlación significativa entre la Satisfacción Total (ST) y la nota media del expediente académico de los universitarios.

Sin embargo, la nota media del expediente académico correlaciona positivamente con las dimensiones: Condiciones básicas de Infraestructura (Cl) y Logro Personal (LP). Por otro lado, esta correlaciona negativamente con las dimensiones: Servicio de la Institución (SI), Condiciones de Seguridad (S), Consideración de la Situación Económica (CS), Seguridad Emocional (SE), Sentido de Pertenencia (PE), Autorrealización (AU).

Tabla 3. Correlaciones entre las subdimensiones de la escala

\begin{tabular}{|c|c|c|c|c|c|c|c|c|c|}
\hline & $\mathrm{SI}$ & $S$ & CS & SE & $P$ & EA & LP & $\mathrm{RE}$ & AU \\
\hline$\overline{\mathrm{Cl}}$ & $.508^{\star \star}$ & $.544^{\star \star}$ & $.415^{\star \star}$ & $.400^{\star \star}$ & $.369^{* *}$ & $.475^{\star \star}$ & $.288^{\star \star}$ & .191 & $.344^{* *}$ \\
\hline SI & & $.560^{* *}$ & $.504^{* *}$ & $.428^{* *}$ & $.402^{* *}$ & $.366^{* *}$ & $.314^{* \star}$ & $.277^{* \star}$ & $.375^{* *}$ \\
\hline$S$ & & & $.523^{* *}$ & $.538^{\star *}$ & $.453^{* *}$ & $.401^{* *}$ & $.394^{\star \star}$ & $.263^{\star \star}$ & $.338^{* *}$ \\
\hline CS & & & & $.489^{\star *}$ & $.490^{* *}$ & $.345^{* *}$ & .177 & $.276^{* \star}$ & $.297^{* *}$ \\
\hline SE & & & & & $.699^{* *}$ & $.612^{* *}$ & $.347^{\star \star}$ & $.469^{* *}$ & $.339^{* *}$ \\
\hline$P$ & & & & & & $.639^{* *}$ & $.379^{\star \star}$ & $.549^{\star \star}$ & $.450^{* *}$ \\
\hline EA & & & & & & & $.525^{\star \star}$ & $.520^{\star \star}$ & $.628^{* *}$ \\
\hline LP & & & & & & & & $.475^{\star \star}$ & $.643^{* *}$ \\
\hline RE & & & & & & & & & $.407^{* *}$ \\
\hline
\end{tabular}

Nota: ${ }^{* *}$ p<.001; Cl: Condiciones básicas de Infraestructura; SI: Servicio de la Institución; S: Condiciones de Seguridad; CS: Consideración de la Situación Económica; SE: Seguridad Emocional; PE: Sentido de Pertenencia; EA: Proceso de Enseñanza aprendizaje; LP: Logro Personal; RE: Reconocimiento del Éxito Personal; AU: Autorrealización; ST: Satisfacción Total.

Como se puede observar en la Tabla 3, las diferentes su dimensiones que componen la escala SEUE correlacionan de manera positiva entre sí, siendo las correlaciones estadísticamente significativas.

\section{Discusión}

Tras la revisión de la literatura acerca de la satisfacción de los universitarios con el centro de estudios, hemos podido comprobar que esta variable se ha relacionado con diversos factores. Por ejemplo Caballero et al., (2007), encontraron que se relacionaba 
con el burnout, absentismo escolar, compromiso, autoeficacia, rendimiento académico, etc.

De todas las variables implicadas, nos hemos centrado en la revisión de estudios que relacionan la satisfacción con el rendimiento académico. Algunos autores que han estudiado esta temática han sido Cabrera y Galán (2002) y Caballero et al. (2007) cuyos hallazgos muestran que el buen funcionamiento académico correlaciona positivamente con la satisfacción y viceversa.

Partiendo de esta base, nuestro objetivo ha sido investigar la relación entre la satisfacción de los alumnos con el centro universitario en el que estudian y su rendimiento académico. Nuestra hipótesis de partida era que se daría una correlación positiva entre ambas.

Sin embargo, a la luz de los hallazgos obtenidos, debemos rechazar la hipótesis ya que no hemos encontrado una correlación estadísticamente significativa. Por tanto, nuestros resultados no coinciden con las investigaciones citadas.

Por otra parte, para profundizar más en el constructo de satisfacción con el centro, hemos tenido en cuenta diferentes subdimensiones que recoge el instrumento SEUE de Gento y Vivas (2002). Una de estas subdimensiones es la de satisfacción con el proceso de enseñanza-aprendizaje, la cual fue estudiada por Fernández et al. (2007), obteniendo una correlación positiva con el rendimiento. En cambio, la correlación obtenida para esta subdimensión en nuestro estudio no es significativa.

Aunque la mayoría de datos obtenidos en la literatura aportan correlaciones positivas entre ambas variables, algunos estudios muestran resultados contrarios. Un ejemplo sería la investigación de Hon et al. (2011), en la cual encontraron que los alumnos más satisfechos eran los que obtenían calificaciones más bajas. A pesar de que la satisfacción global obtenida en nuestra investigación no correlaciona significativamente con el rendimiento, algunas de las subdimensiones que componen la escala muestran una correlación negativa con el rendimiento, en la línea de los resultados de Hon et al. (2011).

A continuación comentaremos algunas críticas que se deberían considerar de cara a futuras investigaciones sobre el tema. Los resultados hallados, que refutan nuestra hipótesis de partida, pueden estar influidos por diversos factores, entre ellos destacamos:

- Una muestra insuficiente, ya que si hubiésemos reunido un mayor número de participantes, los efectos observados podrían haberse visto modificados.

- El momento económico actual, que puede conllevar a una insatisfacción debida a los recortes en educación. Los alumnos que conforman nuestra muestra pueden encontrarse insatisfechos con ciertas desventajas que están sufriendo un gran número de estudiantes españoles, como pueden ser la disminución del número y la cuantía de becas y ayudas para el estudio, aumento del porcentaje de créditos superados exigidos para poder acceder a dichas ayudas, problemas en la gestión del personal docente (demora de la incorporación de los profesores a su puesto de trabajo una vez comenzado el año escolar).

- El cambio de plan de estudio de Licenciatura a Grado es posible que genere cierta incertidumbre. Algunos ejemplos son la extinción de asignaturas año tras año, viéndose obligados a cursar asignaturas que no son de su interés, el uso de métodos de instrucción y evaluación de los estudios de Grado para alumnos de Licenciatura, problemas con las plazas para realizar las prácticas, etc. 


\section{Referencias bibliográficas}

Caballero, C.C., Abello, R., y Palacio, J. (2007). Relación del burnout y el rendimiento académico con la satisfacción frente a los estudios en estudiantes universitarios. Avances en Psicología Latinoamericana, 25(2), 98-111.

Cabrera, P y Galán, E. (2002). Satisfacción escolar y Rendimiento académico. Revista de Psicodidáctica, 14, 86-98.

Fernández, J. E., Fernández, S., Álvarez, A. y Martínez, P. (2007). Éxito académico y satisfacción de los estudiantes con la enseñanza universitaria. RELIEVE, 13, (2), 203214.

Garbanzo, G.M. (2007). Factores asociados al rendimiento académico en estudiantes universitarios, una reflexión desde la calidad de la educación superior pública. Revista Educación, 31(1), 43-63.

Gento, S. y Vivas, M. (2003). EI SEUE: un instrumento para conocer la satisfacción de los estudiantes universitarios con su educación. Acción Pedagógica, 12(2), 16- 27.

Hon, Raslin y Thean (2011). Student satisfaction and academic performance: a discriminant analysis approach. Interdisciplinary journal of contemporary research in business, 3(2), 1401-1407.

Hussain, N., y Bhamani, S. (2012). Development of the Student University Satisfaction Scale: Reliabiliy and validity. Interdisciplinary Journal of Contemporary Research in Business, 4 (3). 332-342.

Jiménez, A., Terriquez, B., y Robles, F. J. (2011). Evaluación de la satisfacción académica de los estudiantes de la Universidad Autónoma de Nayarit. Revista Fuente, 3(6), 46-56.

Montero, E., Villalobos, J. y Valverde, A. (2007). Factores institucionales, pedagógicos, psicosociales y sociodemográficos asociados al rendimiento académico en la universidad de Costa Rica: un análisis multinivel. RELIEVE, 13(2), 215-234.

Pereira, M. (2011). Nuevas tendencias en la evaluación de la calidad de las universidades: los índices de calidad percibida y satisfacción de los egresados (con modelos de ecuaciones estructurales). Aula Abierta, 39(3), 73-84.

Salanova, M., Martínez, I.M., Bresó, E., Llorens, S., y Grau R. (2005). Bienestar psicológico en estudiantes universitarios: facilitadores y obstaculizadores del desempeño académico. Anales de Psicología, 21(1), 170-180.

Zas, B. (2002). La satisfacción como indicador de excelencia en la calidad de los servicios de salud. Revista Electrónica Psicología Científica. Recuperado de http://psicologiacientifica.com. 


\title{
AUTO-EFICACIA DOCENTE, MOTIVACIÓN INTRÍNSECA Y EXPECTATIVA DE RESULTADO DEL ALUMNADO
}

\section{PROFESSORIAL SELF-EFFICACY, INTRINSIC MOTIVATION, AND PERFORMANCE EXPECTATION OF STUDENTS}

Joel Andrés Revelli Galarza, Pablo Gutiérrez Sedeño, Federico del Castillo Fernández, María Centeno Mudarra, Alejandro Vinuesa González, Basma Belcaid y María Teresa Andrade Robles. Universidad de Granada

\section{RESUMEN}

La Teoría Social-Cognitiva de Bandura da gran importancia a la auto-eficacia como método regulador del aprendizaje y sus diferentes elementos, como la motivación y la expectativa de resultado. Por ello, el objetivo de este estudio es determinar en qué grado se relacionan ambos constructos en un contexto universitario y como la motivación intrínseca afecta la expectativa de resultado en alumnos. Para ello se han pasado cuestionarios de auto-eficacia a tres profesores, y cuestionarios de motivación intrínseca sus respectivos alumnos. No se han podido concretar los resultados esperados en la mayoría de las comparaciones en cuanto a relación autoeficaciamotivación, pero sí se ha visto una relación observable entre motivación y expectativa de resultado del alumnado. Se puede concluir que la alta auto-eficacia docente es un factor decisivo en el aprendizaje.

Palabras clave: motivación, papel del docente, interés (aprendizaje), rendimiento de la educación; eficacia del docente.

\begin{abstract}
Bandura's Social Cognitive Theory gives great importance to self-efficacy as regulator for learning and its different elements, like motivation and performance expectations. And so, the goal of this work is to determine the degree of connection between both constructs in a university context and how intrinsic motivation influences performance expectations in students. For this purpose, self-efficacy tests have been used for three professors and an intrinsic motivation test for their respective alumni. The hypothesized results eluded the investigation in most of the comparisons concerning self-efficacy and motivation, but this work did yield the expected results in an observable relationship between motivation and performance expectations of alumni. It can be ascertained that high professorial self-efficacy is a decisive factor in learning.
\end{abstract}

Key words: motivation, teacher role, interest (learning), educational output; teacher effectiveness.

\section{Introducción}

Auto-eficacia: La forma en la que los profesores consideran sus propias capacidades y limitaciones tiene un efecto importante en cómo se desenvolverán en su trabajo y cómo afectarán a sus alumnos. Estudiar esta relación es vital si hemos de entender cómo la relación entre profesor y alumno afecta a estos últimos, y nos da una visión mucho más dinámica de factores interpersonales a tomar en cuenta en el proceso de aprendizaje. 
Dentro del constructo teórico cognitivo-social de Albert Bandura se le da mucha importancia a los procesos auto-reflexivos y auto-regulativos. Bandura se aleja del concepto de persona reactiva y dependiente de las circunstancias (1986), siendo la auto-eficacia uno de los núcleos de su teoría reivindicativa de la importancia de cogniciones mediadoras. Define este concepto como las creencias de la gente sobre sus capacidades para producir niveles designados de rendimiento que ejerciten influencia sobre eventos que afectan a sus vidas (Bandura, 1994). Los trabajos de Bandura han defendido reiteradamente que la auto-eficacia influye en nuestra conducta e incluso nuestro éxito o fracaso, así como los trabajos de Pajares (1997), de Pintrich y Schunk (1996) y Gónzalez (2010).

Muchos estudios y artículos se han hecho para verificar los efectos de la auto-eficacia. Nosotros nos centraremos en los aspectos educacionales del constructo, concretamente su relación con los educadores y sus implicaciones en clase. Por ejemplo, se observó que la auto-eficacia percibida por profesores determina sus conductas particulares de enseñanza (Woolfolk y Hoy, 1990) y correlacionan positivamente con la satisfacción de su trabajo, mostrando más compromiso (Trentham et al. 1985). Así mismo, maestros con alta auto-eficacia tienden a persistir ante situaciones de fracaso en la enseñanza y a innovar en métodos de instrucción (Gibson y Dembo, 1984).

Todas las consecuencias de la auto-eficacia descritas arriba tienen efectos sobre la clase en su conjunto. La auto-eficacia del profesor no solo influencia sus creencias y motivación, sino que también tiene un rol fundamental en la educación de los alumnos. Parece ser que una buena auto-eficacia en el profesor promueve un mejor rendimiento académico estudiantil (Ashton y Webb, 1986; Moore y Esselman, 1992), y mejora la percepción de su propia auto-eficacia (Anderson et al. 1988; Midgely et al. 1989). La confianza del profesor en sus capacidades también promueve la confianza hacia las capacidades de sus alumnos: menos alumnos serán recomendados para educación especial si su profesor es auto-eficaz, y recibirán más ayuda y menos crítica cuando fallan (Gibson y Dembo, 1984). También parece que alumnos con profesores de alta auto-eficacia son incitados más a menudo a completar tareas de mayor dificultad y a desarrollar un entendimiento más profundo sobre la tarea, gracias a que el profesor tiene más recursos cognitivos y emocionales disponibles, quizá por temerle menos al conflicto con estudiantes y a tomar mayores riesgos intelectuales e interpersonales (Woolfolk Hoy y Davis, 2005). Las tasas de suspensiones y abandonos del alumnado también son menores si el profesorado suele tener alta auto-eficacia (Goddard, 2001). Estos son solo algunos de los muchos estudios llevados a cabo que indican grandes beneficios de una buena auto-eficacia en los educadores, beneficios que se extienden a los alumnos. De estos, el que nos interesa discutir es el efecto que tiene sobre la motivación estudiantil, que consideramos es la raíz de los cambios positivos en ellos.

Motivación: Muchos autores coinciden en que la motivación se define como un conjunto de procesos implicados en la activación, dirección y persistencia de la conducta (Beltrán, 1993; Bueno, 1995; McClelland, 1989). Este constructo se compone de la motivación extrínseca, que es estimulada por incentivos externos ya sean auto-administrados o administrados por otros, y la motivación intrínseca, que es estimulada por la tarea en sí y carente de incentivos externos (Ryan y Deci, 2002), de las cuales nos centraremos en esta última.

La motivación intrínseca es importantísima en el estudiante. Afrontar una tarea por el hecho de aprender en sí, y no por una "recompensa", libera al estudiante de las presiones de la competencia entre pares y del "conservadurismo académico", o sea, ir a lo seguro y a lo fácil con tal de sacar buena nota y no arriesgarse o ampliar e ir más allá de lo requerido (Elliot, 1999; Pajares, Britner y Valiente, 1996). Trabajar 
intrínsecamente motivado posibilita incrementar, capacidades, competencias y el disfrute de uno en la tarea, y por ende, su rendimiento académico (Dweck y Elliot, 1883; Deci y Ryan, 1985; Alonso Tapia, 1997), logrando superar aburrimiento y ansiedad (Csikszentmihalyi, 1975), y buscando soluciones y ayuda por uno mismo (Jagacinsky, 1992). Plantearse una tarea como un proyecto personal es una consecuencia de la motivación intrínseca que genera efectos muy positivos en la forma en la que el estudiante afronta la tarea y a su educación.

El papel del profesor tiene un efecto positivo sobre el rendimiento del alumno asociado a la motivación intrínseca (Boza Carreño y Toscano Cruz, 2012). Dada la estrecha concordancia teórica que tiene la auto-eficacia percibida del profesor con la motivación y rendimiento del estudiante, demostrada en numerosos estudios que relacionan la auto-eficacia del educador con varios y diversos factores componentes o consecuentes del constructo de la motivación, nuestra hipótesis se basa en el efecto de la auto-eficacia percibida del profesor por parte del alumno sobre la motivación intrínseca de este en particular, y se operativiza de la siguiente forma: La auto-eficacia percibida por los profesores se relacionará positivamente con la motivación intrínseca de sus estudiantes.

También queremos comprobar que una alta motivación intrínseca mejora la expectativa de nota, que es un componente de la auto-eficacia del alumno en esa asignatura.

\section{Método}

\section{Participantes}

El número total de participantes en este estudio ha sido de 101,3 profesores universitarios de Psicología y 98 de sus alumnos. 45 son alumnos de $2^{\circ}$ de grado, 31 alumnos de $3^{\circ}$ de grado y 21 alumnos de $4^{\circ}$ de licenciatura.

\section{Instrumentos}

Auto-eficacia de los profesores: Para medir la auto-eficacia se ha utilizado una adaptación al español de la Teacher's sense of efficacy Scale elaborado por Tshannen-Moran y Woolfolk (2001). El test consta de 44 items que se pueden subdividir en 3 escalas más la escala global de auto-eficacia. (a) eficacia percibida para optimizar la propia instrucción, (b) eficacia percibida para gestionar el aula y (c) eficacia para implicar al estudiante en el aprendizaje. La escala de Tshannen-Moran y Woolfolk ha mostrado validez y una gran fiabilidad tanto de la escala global como de las tres subescalas (Klassen et al., 2009). En el presente trabajo utilizaremos únicamente la escala global.

Motivación intrínseca de alumnos: Para la motivación hemos utilizado el test psicométrico de motivación intrínseca (Vilchez, 2008) que consta de 40 items validados por un grupo de expertos.

\section{Procedimiento}

Los datos han sido recogidos en la facultad de Psicología de Granada. Tanto la escala de auto-eficacia a los profesores como el test de motivación fueron realizados en el horario de clases habitual 


\section{Resultados}

En la tabla 1 se presentan los datos descriptivos de los grupos de alumnos con profesor de alta auto-eficacia (grupo alta auto-eficacia), con profesor de auto-eficacia media (grupo media auto-eficacia) y con profesor de baja auto-eficacia (grupo baja auto-eficacia).

\begin{tabular}{lllll}
\hline & Grupo auto-eficacia & $\mathrm{N}$ & Media & DT \\
\hline \multirow{2}{*}{ MOTIVACION } & Alta & 45 & 3.76 & .36 \\
& Media & 31 & 3.56 & .39 \\
& Baja & 21 & 3.53 & .34 \\
\hline
\end{tabular}

Hipótesis 1: Con el objetivo de analizar si existían diferencias en la motivación y en la nota esperada en los participantes en función del grupo de alta eficacia, media eficacia y baja se han realizado diferentes pruebas $t$ de student para muestras independientes (véase gráficas 1 y 2 )

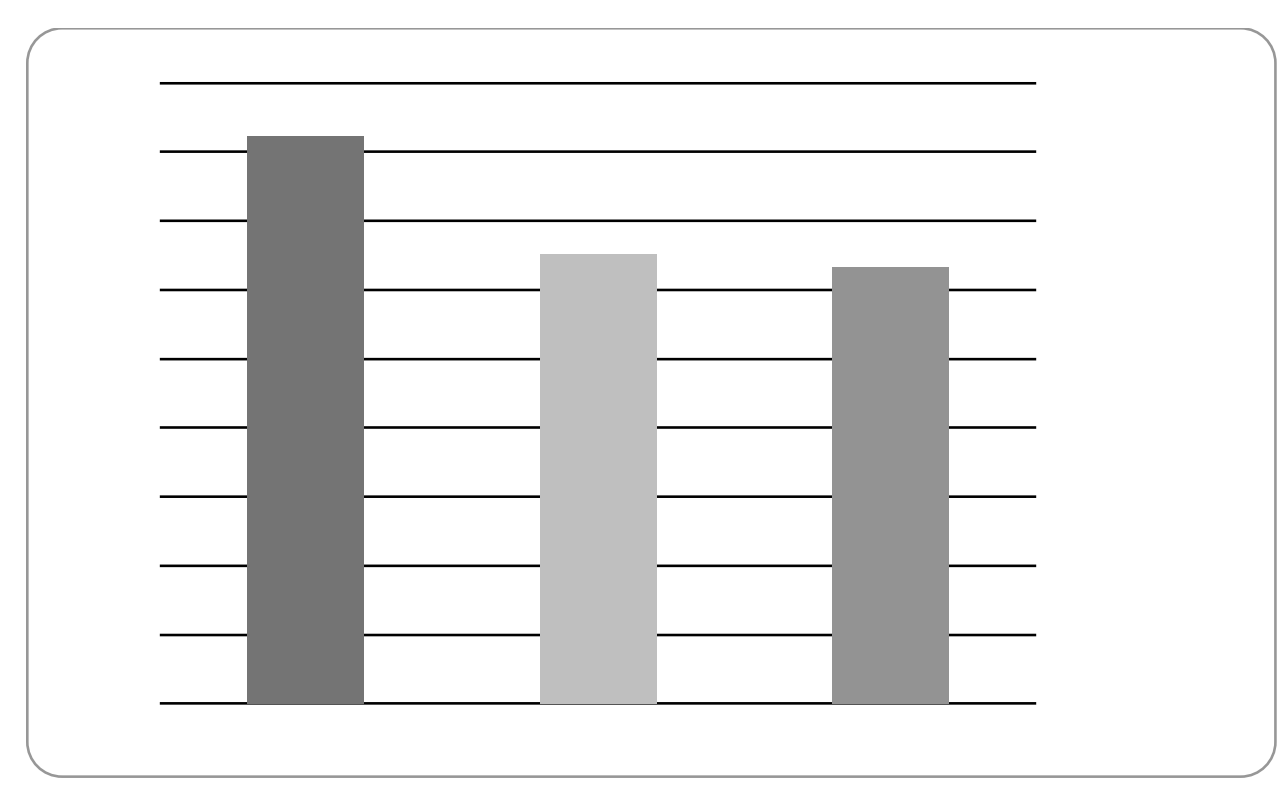

Gráfica 1. Puntuaciones obtenidas por los participantes en la nota esperada en función de la alta, media y baja autoeficacia del profesor 


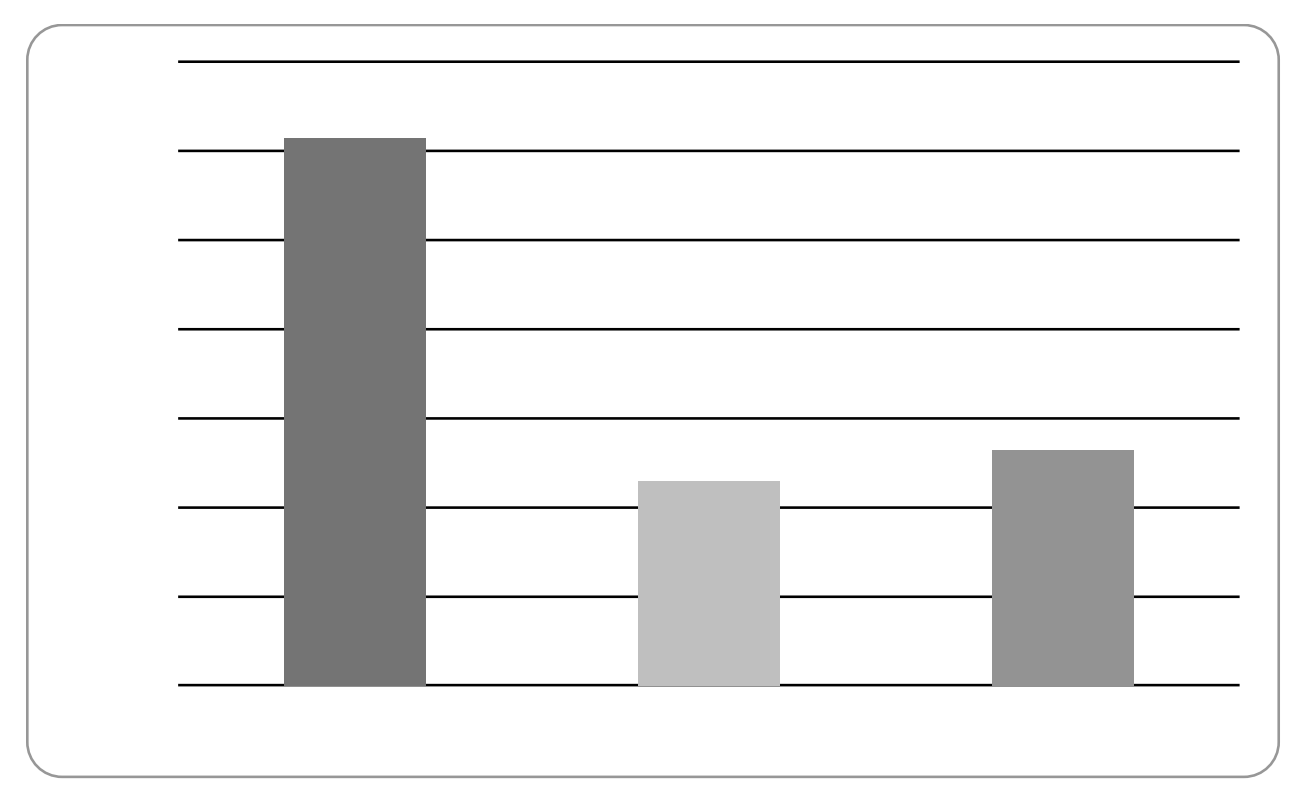

Gráfica 2. Puntuaciones obtenidas por los participantes en la motivación en función de la alta, media y baja autoeficacia del profesor

Tras comparar los grupos se encontraron diferencias significativas al estudiar el grupo de Alta Autoeficacia (Grupo1) con el grupo de Media Autoeficacia (Grupo 2) tanto en motivación $\mathrm{t}(73)=2.18, \mathrm{p}<.05$ como en la nota esperada $\mathrm{t}(73)=5.91, \mathrm{p}<.05$.

Hipótesis 2: Con el objetivo de analizar las relaciones existentes entre la motivación y la expectativa de la nota (NParcial) en los distintos grupos (alta eficacia, media eficacia y baja eficacia), se llevó a cabo un análisis de correlación mediante el coeficiente de correlación de Pearson (veáse Tabla 2).

Tabla 2. Correlaciones bivariadas entre las diferentes variables

$$
\text { Nota }
$$

Alta Eficacia $\quad$ Media Eficacia $\quad$ Baja Eficacia

$\begin{array}{llll}\text { Motivación } & .416^{* *} & .165 & -.696^{* *}\end{array}$

Nota: ${ }^{*} p<.05^{* *} p<.01^{* * *} p<.001$

Como se puede observar, existe una correlación significativa y positiva entre la motivación y la nota en los grupos de alta autoeficacia, de modo que a mayor motivación, una mayor motivación. Los resultados también mostraron una correlación significativa negativa en el grupo de baja eficacia, de modo que en el grupo de profesores con baja eficacia, una mayor motivación se relaciona con una menor nota esperada. Para el grupo de media eficacia, no existe una relación significativa entre la motivación y el rendimiento esperado. 


\section{Discusión}

Primero de todo, hay que aclarar: ¿Por qué nos concentramos en la motivación intrínseca y no en la extrínseca, o en ambas? La razón es que la auto-eficacia del profesor no puede definirse como una "meta" o recompensa externa. Su eficacia funciona como un medio de apoyo al estudiante y no como un fin. Pues, aunque un profesor eficaz sí logre mejorar la motivación extrínseca en el alumno, el efecto no sería puro ya que, además de la auto-eficacia percibida en el educador, también se requeriría de un incentivo externo para argumentar causalidad en el cambio del alumno, causalidad que sería compartida (entre la auto-eficacia percibida del profesor y la influencia del incentivo) y posiblemente sesgada, cosas que no discutiremos en este trabajo. La motivación intrínseca no tiene este problema y se puede medir el efecto sobre el alumno de la auto-eficacia profesoral percibida de forma más directa, sin tanta contaminación metodológica.

En este trabajo se ha pretendido encontrar una relación positiva entre la auto-eficacia percibida del profesor y la motivación intrínseca de sus estudiantes. Aunque existe una tendencia de la motivación intrínseca a desarrollarse cuanto mayor sea la auto-eficacia del educador, los resultados no indican que esta diferencia sea suficientemente significativa en los grupos de media y baja auto-eficacia. Hay dos razones principales por las que creemos que obtuvimos esta baja significación: la primera es la poca diferencia en la puntuación de auto-eficacia de los profesores, es decir, no diferían lo suficiente como para reflejarse en las puntuaciones de motivación estudiantil. La segunda razón es la falta de control en las variables situacionales externas que afectan a la motivación, como puede ser la dificultad dispar entre asignaturas impartidas. Mucho se han estudiado los efectos de la dificultad de una tarea sobre la motivación (Csikszentmihalyi, 1990). El diferente contenido de las clases puede haber afectado los resultados. Otras investigaciones con grupos más similares y profesores más dispares podrían mejorar el diseño experimental y dar resultados más significativos.

Los resultados de cada comparación particular de grupos podrían indicar que la relación entre la auto-eficacia y la motivación solo se daría en el supuesto de que el profesor tenga una alta auto-eficacia. Estos resultados se podrían relacionar con las conclusiones aportadas en otro estudio en el que se afirmaba que los profesores con una autoeficacia alta le dan más importancia a aspectos extrínsecos como el sentido del deber o disfrutar con el aprendizaje del alumno (Blas, Núñez, Rodríguez, Rosario, \& Valle, 2009). Esta relación no se observa en los grupos con profesores de media y baja auto-eficacia. Esto puede deberse a que los estudiantes de estos educadores buscan otras fuentes de motivación externas, mostrando que no deriva en efectos negativos sobre la motivación per se, y resalta los efectos positivos de una alta autoeficacia del profesorado.

Los resultados de la segunda hipótesis, no obstante, corroboran investigaciones previas que defendían la motivación como un factor determinante en las expectativas de resultado (Bandura, 1977). Sin embargo, en uno de los grupos esta correlación no aparece como significativa. Esto puede deberse a los extremos de dificultad (muy alta o muy baja) percibida de la asignatura en concreto y hace que la expectativa de nota sea independiente de la motivación del alumnado.

Ciertamente, el estudio de la auto-eficacia ha dado fruto, pero el concepto no está exento de debate. Pajares (1997) defiende que la auto-eficacia debe ser estudiada en contexto, y relacionada a conductas específicas. Por otro lado, se pone en tela de juicio la validez de las puntuaciones obtenidas en los instrumentos de medición primarios de la auto-eficacia (Coladarci \& Fink, 1995; Guskey \& Passaro, 1994). Una 
tercera vía de estudio sería entonces la revisión del constructo en su totalidad, con las posibles implicaciones que esto tendría para la teoría social-cognitiva de Bandura.

A pesar de los pormenores del diseño experimental, creemos que se observan pautas prometedoras que explotar y expandir en el futuro mediante otras investigaciones. Una línea de investigación interesante sería contrastar los efectos de los distintos tipos de auto-eficacia (cultural, emocional, cognitiva y conductual) en los diferentes tipos de motivación (de logro, de afiliación, de dominio, etc.). Otro posible estudio podría adentrarse en los factores que influencian a la auto-eficacia profesoral, como por ejemplo rendimiento logrado anteriormente, experiencia vicaria, simbolización imaginativa, persuasión verbal y activación emocional y fisiológica. También se podría relacionar la autoeficacia con las estrategias de aprendizaje ya que se ha demostrado que profesores que utilizan estrategias enfocadas en el aprendizaje influyen mñas positivamente sobre el aprendizaje de sus alumnos (Fernández March, Garfella Esteban, Gargallo López, \& Pérez Pérez, 2010). Esto abriría las puertas a un entrenamiento docente mucho más adecuado y enfocado al incremento motivacional del alumnado.

\section{BIBLIOGRAFÍA}

Alonso Tapia, J. (1997). Motivar para el aprendizaje. Teoría y Estrategias. EDEBE, Barcelona.

Ashton y Webb (1986) Making a Difference: Teacher Efficacy and Student Achievement. Monogram. White Plains, NY: Longman.

Bandura, A. (1977). Self-efficacy: toward a unifying theory behavioral change. Psychogical Review, 84(2), 191-215.

Bandura, A. (1986). The explanatory and predictive scope of self-efficacy theory. Journal of Social and Clinical Psychology, 4 (3), 359-373.

Bandura A. (1994). Self-efficacy. In V.S. Ramachandran (Ed.) Encyclopedia of human behavious (Vol.4, pp.71-81). New York: Academic Press.

Beltrán, J. (1993). Procesos, estrategias y técnicas de aprendizaje. Madrid: Síntesis. S.A.

Blas, R., Núñez, J. C., Rodríguez, S., Rosario, P., \& Valle, A. (2009). Auto-eficacia Docente, Motivación del Profesor y Estrategias de Enseñanza. Escritos de Psicología, 3(1), 1-7.

Boza Carreño, A., y Toscano Cruz, M. d. (2012). Motivos, actitudes y estrategias de aprendizaje: Aprendizaje motivado en alumnos universitarios. Profesorado , 16 (1).

Bueno, J. A. (1995): Motivación y aprendizaje. En Beltrán y Bueno: Psicología de la educación. Barcelona: Marcombo, pp. 227-255.

Coladarci, T., y Fink, D. R. (1995). Correlations among measures of teacher efficacy: Are they measuring the same thing? Paper presented at the annual meeting of the American Educational Research Association, San Francisco.

Csikszentmihalyi, M. (1975). Beyond Boredom and anxiety. Jossey Bass. San Francisco. 
Csikszentmihalyi, M. (1990). Flow: The Psychology of Optimal Experience. New York: Harper-Row.

Deci, E. L., y Ryan, R. M. (1985). Intrinsic motivation and self-determination in human behaviour. New York: Plenum.

Deci, E. L., y Ryan, R. M. (1985).The general causality orientations scale: Selfdetermination in personality. Journal of Research in Personality, 19, 109-134.

Dweck, C.S. \& Elliot, E.s. (1983). Achievement motivation. En E.M. Hetherington (ed.) Socialization, personality and social development. Wiley \& sons, N.Y.

Elliot, A. J. (1999) Approach and avoidance motivation and achievement goals, Educational Psychologist, 34, 169-189.

Fernández March, A., Garfella Esteban, P. R., Gargallo López, B., \& Pérez Pérez, C. (2010). Modelos de enseñanza y aprendizaje en la universidad. Seminario Interuniversitario de Teoría de la Educación. Madrid.

González, M. L. (2010). Autoeficacia percibida y desempeño académico en estudiantes universitarios. Acceso y Permanencia en una educacion de calidad. Buenos Aires.

Gibson, S., \& Dembo, M.H. (1984). Teacher efficacy: A construct validation. Journal of Educational Psychology, 76, 569-582.

Goddard, R. D., \& Goddard, Y. L. (2001). A multilevel analysis of the relationship between teacher and collective efficacy in urban schools. Teacher and Teacher Education, 17, 807-818.

Guskey, T., \& Passaro, P. (1994). Teacher efficacy: A study of construct dimensions. American Educational Research Journal, 31, 627-643.

Jagacinski, C.M. (1992). The effects of task involvement and ego involvement and achievement-related cognition and behaviours. En D.H. Schunk y J.L. Meece (Eds.) Students' perceptions in the classroom. (pp. 307-326) Laurens Erlbaum. Hillsdale, NJ.

Klassen, R.M., Bong, M., Usher, E.L., Chong, W.H., Huan, V.S., Wong, I.Y.F. y Georgiou, T. (2009). Exploring the validity of a teachers' self-efficacy scale in five countries. Contemporary Educational Psychology, 34, 67-76.

Midgely, C., Feldlaufer, H., \& Eccles, J.S (1989). Change in teacher efficacy and student self- and task-related beliefs in mathematics during the transition to junior high school. Journal of Educational Psychology, 81 (2), 247-258.

Pajares F. (1997). Current directions in self-efficacy research. In M. Maehr \& P.R. Pintrich (Eds.). Advances in motivation and achievement (Vol.10, pp. 1-49). Greenwich, CT: JAI Press.

Pajares, F.; Britner, S. L. y Valiente, G. (2000) Relation between achievement goals and self-beliefs of middle school students in writing and science, Contemporary Educational Psychology, 25, 406-422.

Pintrich, P. \& Schunk, D. (1996). Motivation in Education: Theory, Research \& Applications, Ch. 3. Englewood Cliffs, NJ: Prentice-Hall. 
Ryan, R. M., \& Deci, E. L. (2002). An overview of self-determination theory. In E. L. Deci \& R. M. Ryan (Eds.), Handbook of self-determination research (pp. 3-33). Rochester, NY: University of Rochester Press.

Trentham, L., Silvern, S., \& Brogdon, R., (1985). Teacher efficacy and teacher competency ratings. Psychology in the Schools, 22 (3), 343-352.

Tschannen-Moran M. y Woolfolk, A. (2001). Teacher efficacy: capturing an elusive construct. Teaching and Teacher Education, 17, 783-805.

Vilchez, A. (2008). Test psicométrico para medir el grado de motivación intrínseca. Extraído el 27-5-2013 de: http://es.scribd.com/doc/17379211/Test

Woolfolk, A. E. \& Hoy, W. K. (1990). Prospective teachers' sense of efficacy and beliefs about control. Journal of Educational Psychology, 82(1), 81-91.

Woolfolk Hoy, A., \& Davis, H. (2005). Teachers' sense of efficacy and adolescent achievement. In T. Urdan \& F. Pajares (Eds.), Adolescence and education: Vol. 5: Selfefficacy beliefs during adolescence (pp. 117-137). Greenwich, CT: Information Age. 


\section{EL SINDROME DEL QUEMADO EN EL PERSONAL SANITARIO Y LA SATISFACCIÓN DEL PACIENTE}

\section{BURNOUT SYNDROME IN HEALTH WORKERS AND PATIENT SATISFACTION}

Rocío Cano Sánchez, Zoraida Ciruela Palomino, Irene Gómez Gómez, Ángel Mata Fernández, Carolina Montalvo Vico y Héctor Olmedo Sánchez. Universidad de Granada.

\section{Resumen}

El presente estudio tiene dos objetivos, por un lado conocer e identificar el síndrome del quemado en el personal médico de tres hospitales de Granada y por otro lado conocer la satisfacción de los pacientes a la hora de ser atendidos. Para tales objetivos se ha seleccionado una muestra de un total de 57 trabajadores sanitarios a los cuales se les administró el Maslach Burnout Inventory (MBI) y 50 pacientes a los que se les administró la Encuesta de Opinión sobre la Atención Hospitalaria (SERVQHOS). Los principales resultados muestran diferencias significativas en la escala de cansancio emocional pero sólo entre enfermeros y médicos, además se han encontrado diferencias significativas en las escalas de cansancio emocional y despersonalización entre los tres hospitales, y por último en cuanto a las pacientes no se han encontrado diferencias significativas ni en sexo ni edad.

Palabras Clave: satisfacción, personal médico, paciente, síndrome de estar quemado.

\section{Abstract}

The present study has two aims, in one hand try to know and identify the burnout syndrome in medical personnel in three Granada's hospitals, on the other hand the study try to know the patients' satisfaction when they are being looked after. For this two aims we have selected a sample of 57 medical personnel who have taken Maslach Burnout Inventory (MBI) and 50 patients who have taken the Encuesta de Opinión sobre la Atención Hospitalaria (SERVQHOS). The main results showed significant differences in emotional exhaustion scale but only between nurses and doctors, in addition we have found significant differences in emotional exhaustion scale and depersonalization scale between the three hospitals, and finally related with patients we haven't found significant differences in sex and age.

Keywords: satisfaction, medical personnel, burnout syndrome, patients. 


\section{INTRODUCCIÓN}

La Ley General de Sanidad establece como principios generales la eficacia, la economía, la racionalización, la organización, la coordinación y la integración de los recursos sanitarios públicos, para hacer efectivas las prestaciones sanitarias y mantener altos niveles de calidad debidamente evaluados y controlados (Ley 14/1986, de 25 de Abril, General de Sanidad; Real Decreto $63 / 1995$, de 20 de enero, sobre ordenación de prestaciones sanitarias del Sistema Nacional de Salud).

Por ello la evaluación del sistema de organización de los servicios sanitarios se ha convertido en una tarea esencial de los sistemas de salud y se ha incorporado a los organismos encargados de evaluar tecnologías sanitarias. La satisfacción de los pacientes es clave en la mejora de la calidad asistencial y también se utiliza como medida de los resultados de los cuidados y se ha asociado con aspectos relacionados con la salud tan importantes como la adhesión al tratamiento y las recomendaciones de los profesionales, el cambio de proveedor, e incluso la mejora de la salud (Delgado, 1995; Prieto, 1999). A pesar de su reconocida importancia, la satisfacción del paciente con los servicios de salud, no es suficientemente investigada en España y, cuando se hace, son empleados métodos, enfoques e instrumentos muy heterogéneos entre sí (Clíments, 2003).

La satisfacción puede definirse como "la medida en que la atención sanitaria y el estado de salud resultante cumplen con las expectativas del usuario"(Corbella 1990). El grado de calidad de los servicios ofertados en un sistema sanitario está directamente relacionado con el nivel de satisfacción de los profesionales que trabajan en él y en su vinculación con la motivación (García, 1995; Olivar, 1999).

En un estudio sobre la satisfacción de 328 pacientes sobre la atención del personal médico del Subsistema de Urgencias en Atención Primaria de Salud (SUAPS), los elementos que más se relacionaron con la satisfacción fueron el tiempo de espera, el ambiente adecuado y el trato recibido (Chang, 1999). En el mismo se encontraron diferencias entre sexos -las mujeres manifiestan una mayor insatisfacción- y entre edades -los de mayor edad son más críticos con los servicios sanitarios-.

En las últimas dos décadas ha habido un creciente reconocimiento público de las limitaciones de la medicina (Feletti, 1986). Donabedian (1982) afirma que la satisfacción es un componente integral y esencial para la estimación de la calidad de la atención médica.

El síndrome del quemado, que se conceptualiza como una respuesta al estrés laboral crónico, parece afectar en mayor o menor medida a un colectivo profesional importante. No hay un consenso global para la explicación de este síndrome de desgaste profesional. Una de las teorías con más aceptación es la proporcionada por Maslach, en la que el síndrome estaría caracterizado por tres dimensiones interrelacionadas: el cansancio emocional, la despersonalización y la realización personal (Férnandez, 2000; Maslach, 1986). 
La relación entre satisfacción laboral y desgaste profesional es estrecha. Bajos niveles de satisfacción se asociaron con altas puntuaciones en las escalas de cansancio emocional y despersonalización, y bajas puntuaciones en realización personal (Sobrequés, 2003).

Teniendo en cuenta las argumentaciones anteriores y estudios realizados, nuestros objetivos principales han sido dos, por un lado identificar y analizar el Síndrome de quemado (Burnout) en el personal sanitario, y por otro lado, comprobar la satisfacción de los pacientes a la hora de ser atendidos, en sus distintas dimensiones, centrándonos en hospitales de Granada capital (Hospital Universitario San Cecilio, Hospital Materno Infantil Virgen de las Nieves, Hospital de Rehabilitación y Traumatología Virgen de las Nieves).

H1: Los médicos muestran menor cansancio emocional y despersonalización que los enfermeros y auxiliares.

$\mathrm{H} 2$ : Los resultados del cuestionario $\mathrm{MBI}$ estarán igualados en los tres centros hospitalarios.

H3: La satisfacción (global, objetiva y subjetiva) será menor en pacientes mujeres.

H4: La satisfacción global se relacionará inversamente con la edad.

\section{MÉTODO}

\section{Participantes}

La población que ha participado en este estudio se puede dividir en dos grupos, por un lado, personal sanitario, formado por 11 médicos, 26 enfermeros, 17 auxiliares de enfermería y 3 celadores, haciendo un total de 57 personas, de los cuales 6 son hombres y 51 mujeres. Todos ellos trabajadores de tres centros médicos de Granada (Hospital Universitario San Cecilio, Hospital Materno Infantil Virgen de las Nieves, Hospital de Rehabilitación y Traumatología Virgen de las Nieves). Por otro lado, el siguiente grupo consta de 50 pacientes ( 25 hombres y 25 mujeres) que debían cumplir el requisito de acudir o haber acudido en el último año a los centros antes mencionados. La edad de los sujetos en ambos grupos se encuentra entre 18-65 años.

\section{Materiales}

Para el primer grupo de participantes (personal sanitario) se utilizó el Maslach Burnout Inventory (MBI), que se trata de un cuestionario de 22 ítems con 7 opciones de respuesta (escala Likert de 0 a 6) y posee tres subescalas que miden el cansancio emocional (sentimiento del sujeto respecto a encontrarse saturado emocionalmente por el trabajo), despersonalización (respuesta fría e impersonal hacia los pacientes) y realización personal (sentimientos de competencia y eficacia en la realización del trabajo). Las subescalas de cansancio emocional y despersonalización indican mayor desgaste a mayor puntuación, mientras que la subescala de realización personal funciona en sentido inverso, indicando mayor desgaste las puntuaciones bajas. En el 
presente estudio se obtuvo un coeficiente de fiabilidad alfa de Cronbach de .81 en cansancio emocional, .31 en despersonalización y .41 en realización personal.

Para el segundo grupo (pacientes) se empleó la Encuesta de Opinión sobre la Calidad de la Atención Hospitalaria (SERVQHOS) que es uno de los instrumentos más utilizados en el sector servicios para evaluar el nivel de satisfacción y la calidad percibida por los clientes. Consta de 19 ítems, divididos en dos subescalas que miden la satisfacción objetiva y subjetiva. Además se evalúa el grado de satisfacción global de los pacientes. En relación a la fiabilidad, en este estudio se obtuvo un coeficiente de Cronbach de .96 en satisfacción global, .86 en satisfacción objetiva y .84 en subjetiva.

\section{Procedimiento}

Acudimos a los 3 centros hospitalarios mencionados con anterioridad para pasar el cuestionario $\mathrm{MBI}$ a la mayor parte de personal sanitario posible y dispuesto a participar, y a su vez, repartimos el cuestionario SERVQHOS a una muestra aleatoria de personas que acuden en el presente o han acudido en el último año a uno de estos centros. Una vez pasados los cuestionarios recurrimos al análisis estadístico de los datos mediante el programa SPSS.

\section{RESULTADOS}

La presentación de los resultados se dividirá en dos estudios, por un lado el referente al personal sanitario y por otro lado, el referente a los pacientes.

\section{Estudio 1}

Nuestra intención en este primer estudio es comparar las profesiones (médico, enfermero y auxiliar de enfermería), con las diferentes escalas medidas por el cuestionario $\mathrm{MBI}$ (cansancio emocional, despersonalización, y realización personal) por un lado, y por otro, comparar además estas mismas escalas, en función de la pertenencia a un centro hospitalario u otro (Materno Infantil, Clínico y Traumatología). Con respecto a la comparación entre profesiones, no se tuvo en cuenta a los celadores, ya que la muestra era escasa.

Con el objetivo de analizar si existían diferencias entre los participantes en función de su profesión en las puntuaciones obtenidas en las distintas escalas, se realizó una $t$ de student para muestras independientes.

Los resultados mostraron diferencias significativas, $t(35)=3.76 ; p<.001$ entre médicos y enfermeros, exclusivamente en la escala de cansancio emocional, siendo mayor en los últimos. No se obtuvieron diferencias significativas comparando médicos con auxiliares y enfermeros con auxiliares, en ninguna escala. 
Gráfica 1. Comparación entre las puntuaciones del MBI de los diferentes grupos del personal sanitario.

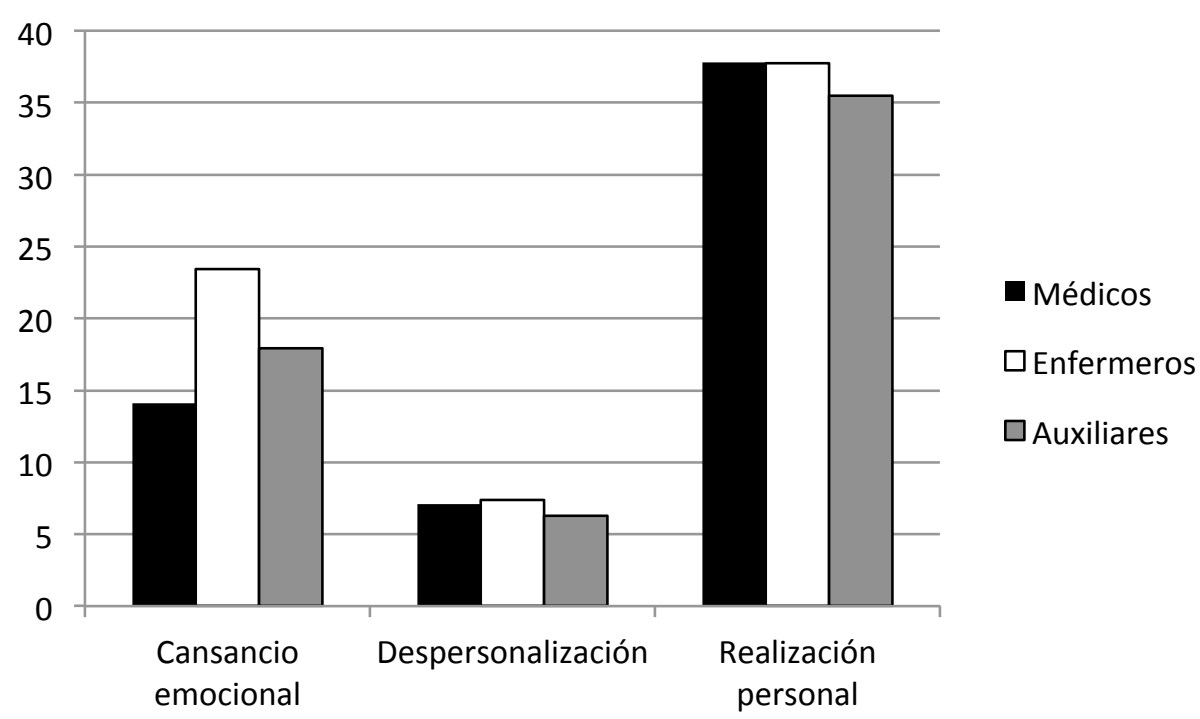

Con la finalidad de analizar si existían diferencias entre el centro hospitalario en el que trabajan y las puntuaciones obtenidas en las distintas escalas, se realizó una $t$ de student para muestras independientes.

Los resultados mostraron diferencias significativas en las escalas de cansancio emocional y despersonalización $t(42)=3,66 ; p<.001$ y $t(42)=2,87 ; p=.006$ respectivamente entre los hospitales Materno Infantil y Clínico, siendo mayores en el primero. También hubo diferencias significativas en la escala de cansancio emocional $t(36)=4.60 ; p<.001$ en los hospitales Materno Infantil y Traumatología, siendo mayor en el primero en este caso también. Con respecto a los hospitales Clínico y Traumatología se encontraron diferencias significativas en la escala de despersonalización $t(28)=2.2 ; p=.040$, siendo mayor en éste último.

Gráfica 2. Comparación entre las puntuaciones del MBI de los diferentes centros hospitalarios.

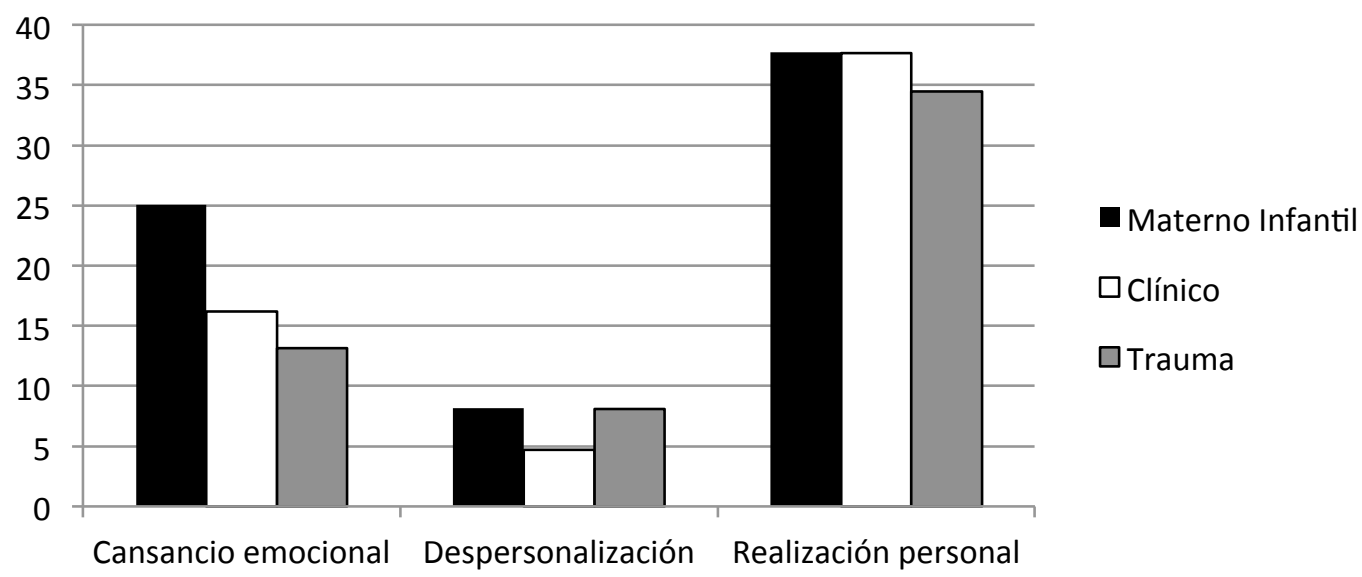




\section{Estudio 2}

En este estudio pretendemos comparar las distintas dimensiones de satisfacción (objetiva, subjetiva y global) entre el sexo de los pacientes por un lado, y su edad por otro.

Con el objetivo de analizar si existían diferencias en las puntuaciones obtenidas en las distintas dimensiones en función del sexo de los participantes, se realizó una $t$ de student para muestras independientes.

Tabla 1. Resultados t de student, media y desviación típica de cada escala en función del sexo.

\begin{tabular}{lllcl}
\hline & sexo & N & Media & DT \\
\hline \multirow{2}{*}{ satifacciónGLOBAL } & hombre & 25 & 2.84 & 0.68 \\
& mujer & 25 & 2.84 & 0.68 \\
\hline \multirow{2}{*}{ SatisfaccionSubjetiva } & hombre & 25 & 3.20 & 0.57 \\
& mujer & 25 & 3.09 & 0.67 \\
\hline \multirow{2}{*}{ SatisfaccionObjetiva } & hombre & 25 & 2.95 & 0.54 \\
& mujer & 25 & 2.95 & 0.64 \\
\hline
\end{tabular}

Los resultados han mostrado que no existen diferencias significativas en ninguna dimensión. Incluso se han encontrado puntuaciones exactamente iguales en todas las dimensiones de la encuesta, tanto en hombres como en mujeres.

Con el fin de comprobar la posible relación entre la satisfacción y la edad, se llevó a cabo un análisis de correlación de Pearson bivariado, teniendo en cuenta los distintos tipos de satisfacción.

Los resultados obtenidos muestran que la edad no está relacionada con la satisfacción. Sin embargo, correlacionan significativa y positivamente la escala de satisfacción subjetiva con la global $(r=.42 ; p<.01)$ e igualmente la escala objetiva con la global $(r=.46 ; p<.01)$.

\section{DISCUSIÓN}

El objetivo del trabajo ha sido, por un lado describir el estado de distintos trabajadores sanitarios en tres centros de la provincia de Granada, en relación al síndrome de burnout, y por otro lado describir la satisfacción de pacientes que acuden normalmente a dichos centros.

En cuanto a la primera hipótesis propuesta sólo se obtuvieron diferencias significativas en relación a médicos y enfermeros, en la escala de cansancio emocional, siendo estos últimos los que se encuentran más afectados. 
Posiblemente debido al tamaño de la muestra no se obtuvieron resultados significativos en cuanto a auxiliares.

En relación a la segunda hipótesis acerca del grado de burnout en los distintos centros, se ha encontrado que el hospital Materno Infantil presenta mayor cansancio emocional que el Clínico y Traumatología, y mayor grado de despersonalización con respecto al Clínico. Por otro lado, Traumatología presenta mayor despersonalización que el Clínico. Estas diferencias pueden deberse a la afluencia de pacientes que tiene cada hospital para determinadas consultas, o a la especialidad de los trabajadores, como por ejemplo en Oncología Infantil, presente en el hospital Materno Infantil.

La importancia de estas dos hipótesis reside en que, se puede estimar los profesionales y los hospitales en los que se presenta más desgaste profesional. Con ello, podría mejorarse la satisfacción y a su vez, el trato con el paciente. Diversos estudios, como el de Cebrià et al (2000) o el de González (1998), han analizado los factores asociados a dicho desgaste profesional pero, su relación con la satisfacción ha sido poco explorada en el ámbito nacional.

Según nuestra tercera hipótesis las mujeres pacientes deberían tener una puntuación menor en satisfacción tanto global como objetiva y subjetiva. Así lo indican otros estudios argumentando además que ellas son las que solicitan asistencia sanitaria con más frecuencia (Chang, 1999). Sin embargo según los resultados esta hipótesis no se cumple debido a que no hay diferencias significativas según la prueba $\mathrm{T}$ de student en ninguna dimensión entre sexos. Esto puede deberse a sesgos en el estudio como el tamaño de la muestra que no es demasiado extensa ( 25 hombres y 25 mujeres) por lo que en futuras investigaciones se habrá de seleccionar una muestra mayor.

En cuanto a la relación entre edad y satisfacción no se ha encontrado que exista correlación. Esto contrasta con que los grupos de 40 a 49 años son los más críticos peyorativamente hacia la sanidad (Ruiz, 1990). Si bien, si existe entre los distintos tipos de satisfacción una correlación, encontrando que a mayor satisfacción global, mayor satisfacción objetiva y subjetiva.

En futuros estudios podría resultar interesante comparar el síndrome de burnout entre hombres y mujeres sanitarios, ya que en este caso no se ha tenido en cuenta por el evidente mayor número de mujeres de nuestra muestra. Además, del mismo modo, también podrían existir diferencias entre las distintas especialidades médicas entre dicho personal sanitario. Esto es importante para el conocimiento sobre la especialidad en la que se podría comenzar a prevenir o tratar el síndrome en aras de una mejora de la satisfacción del trabajador que repercute en la calidad de la atención a los pacientes.

\section{REFERENCIAS}

Cebrià J, Segura J, Corbella S, Sos P, Comas O, García M, et al. (2000) Rasgos de personalidad y burnout en médicos de familia. Atención Primaria, 27, 459-68. 
Chang, M, Alemán, M.C., Cañizares, M. y Ibarra, A.M. (1999) Satisfacción de los pacientes con la atención médica. Revista Cubana de Medicina General Integral, 15(5), 541-547.

Clíments, G. D. y Aguirre-Jaime, A. (2003).Enfermera amable, paciente satisfecho. Validación de una nueva escala de la satisfacción de los usuarios. Enfermería clínica, 13(1), 7-15.

Corbella, A. y Saturno, P. (1990) La garantía de la calidad en atención primaria de salud. Madrid: Instituto Nacional de Salud, Secretaría General (pp 397-399).

Delgado A. (1997) Factores asociados a la satisfacción de los usuarios. Cuadernos de Gestión, 3(2):90-101.

Donabedian, A. (1997). The quality of care.Archives of pathology \& laboratory medicine 121, 11.

Feletti, G., Firman, D., ySanson-Fisher, R. (1986).Patient satisfaction with primary-care consultations. Journal of behavioral medicine, 9(4), 389-399.

Fernández M.I., Moinelo, A., Villanueva, A., Andrade, C., Rivera, M., Gómez, J.M., et al (2000). Satisfacción laboral de los profesionales de atención primaria del área 10 del Insalud de Madrid. Revista Española de Salud Pública, 74(1),139-47.

García, S. y González, J. A. (1995). Factores de motivación de los profesionales de la salud en Atención Primaria. FMC, 2, 1

González, P., Suberviola, R. y González, J.F. (1998). Prevalencia del síndrome de burnoutr o desgastge profesional en los médicos de atención primaria. Atención Primaria, 22, 580-584.

Maslach, C., y Goldberg, J. (1999). Prevention of burnout: New perspectives. applied and Preventive Psychology, 7(1), 63-74.

Mira, J.J., Aranaz, J., Rodríguez-Marín, J., Buil, J.A., Castell, M., Vitaller, J. (1998). SERVQHOS: un cuestionario para evaluar la calidad percibida de la asistencia hospitalaria. Medicina Preventiva, 1(4), 12-18.

Olivar, C., González, S. y Martínez, M.M. (1999). Factores relacionados con la satisfacción laboral y el desgaste profesional en los médicos de atención primaria de Asturias. Atención Primaria, 24, 352-359.

Prieto, M.A., March, J.C. y López F. (1999). Calidad percibida por usuarios de centros de salud y de aseguradoras privadas. Atención Primaria, 24, 259-266.

Ruiz Chávez, M. (1990) Bases para la evaluación de la calidad de la atención médica en las unidades médicas del sector salud. Salud Pública Mexicana, 32(2), 156-69.

Sobrequés, J., Cebriá, J., Segura, J., Rodríguez, C., García, M., y Juncosa, S. (2003). La satisfacción laboral y el desgaste profesional de los médicos de atención primaria. Atención Primaria, 31(4), 227-233. 


\section{EFECTOS DE LA CRISIS ECONÓNIMA SOBRE LA SALUD MENTAL EN LA POBLACIÓN ESPAÑOLA}

\section{Economic crisis effects about mental health in Spanish population}

Agar Marín Morales, Lucía Gil Domínguez, Vanesa Román Macías, Luca Farella. Universidad de Granada

El propósito del presente estudio es conocer la prevalencia de personas con problemas de salud mental a causa de la crisis económica, en concreto aquellas que se encuentren en la situación de desempleo o disminución de clase social. Se trata de un estudio transversal en el que participaron 95 sujetos. Las herramientas utilizadas han sido un instrumento de cribado de salud mental General Health Questionnaire (GHQ-28) y el Cuestionario de Ansiedad Estado/Rasgo (STAI). Se realizaron análisis correlaciónales y comparaciones de medias. Entre los resultados obtenidos podemos destacar la relación existente entre la sintomatología depresiva con respecto al descenso de la clase social y la situación laboral. Estos resultados reflejan la necesidad de crear programas preventivos y de intervención sobre dicho problema.

Palabras clave: Crisis económica,Salud Mental, Desempleo, Clase social

The purpose of this study is to know the prevalence of people with mental health problems because of the economic crisis, in particular those that are in the situation of unemployment or decline of social class. This is a cross-sectional study involving 95 subjects. The tools used have been a screening instrument in mental health General Health Questionnaire (GHQ-28) and anxiety Questionnaire State/Trait (STAI). Correlational analyzes were performed and comparisons. Among the results we can emphasize the relationship between depressive symptomatology in relation to the decline of the social class and the labor situation. These results reflect the need to create preventive programs and intervention on this issue.

Key words: Economic crisis, Mental Health, Unemployment, Social class

\section{INTRODUCCIÓN}

Desde 2008, la crisis económica ha afectado de manera considerable en multitud de aspectos individuales, sociales, económicos y culturales. Entre las consecuencias principales de esta situación se encuentran el aumento del desempleo y la bajada de ingresos (Uutela, 2010). En España, en concreto, el Instituto Nacional de Estadística (INE), muestra una tasa de paro en el primer trimestre de 2008 de 2.174 .200 personas (INE, 2008) y en el primer trimestre de 2013 de 6.202.700 personas (INE, 2013). Observando estos datos, se aprecia un considerable incremento que está teniendo graves repercusiones en un gran porcentaje de la población española.El sujeto está influenciado por el contexto en el que vive, y en la actualidad dicho contexto está 
caracterizado por acontecimientos estresantes provocados por la crisis (Uutela, 2010). El desempleo es considerado como uno de los eventos de la vida más estresantes (Buendía, 1990) y tiene un impacto negativo sobre el bienestar psicológico de los empleados (Murphy y Atlanasou, 1999). Estudios muestran que quienes pierden el empleo durante periodos de crisis pueden tener peor estado de salud general que aquellos que lo pierden en otras circunstancias (Brenner y Mooney, 1983; Carlisle, 2008). Otros estudios confirman la existencia de una relación entre el estado socioeconómico y los síntomas depresivos (Mossakowski, 2009). Los síntomas depresivos son las variables más frecuentes en personas desempleadas (Murphy y Atlanasou, 1999), que en casos extremos, y cada vez con más frecuencia, derivan en el suicidio (Uutela, 2010; Gili, Roca, Sanjay, McKee y Stuckler, 2012). El desempleo afecta de forma más acentuada en hombres que en mujeres, esto está relacionado con la cultura, la estigmatización sobre cómolos hombres deben ser los responsables del mantenimiento del hogar (Mossakowski, 2009). Existen discrepancias entre diversas investigaciones en base a la influencia del tiempo de desempleo. Uno de los estudios muestra que el deterioro de la salud mental va aumentando hasta un punto cuyo máximo se sitúa entre los tres y los seis meses, y hacia los seis meses parece estabilizarse el deterioro a medida que la situación se va haciendo más controlable y predecible (Warr, 1987). No obstante, en un estudio realizado por Del Pozo, Ruiz, Pardo y San Martin (2002), los resultados muestran que el deterioro en la salud mental aumenta entre los siete y doce meses y mejora levemente en períodos más largos de desempleo. La bajada de ingresos supone un descenso en la escala social, aunque no está claro que la presencia de trastornos de depresión y ansiedad estén relacionadas con un nivel bajo socioeconómico (Fryers, Melzer y Jenkins, 2003; Laakson en et al., 2007). Sin embargo, los problemas asociados a la bajada de ingresos, y con ello, la bajada en la clase social, son buenos predictores de la aparición de síntomas depresivos (Butterworth et al., 2009; Friedman y Thomas, 2008; Molarius et al., 2009). El estudio de Gili et al. (2012) muestran aumentos significativos respecto al periodo anterior a la crisis en el estado de ánimo, la ansiedad, los trastornos somatomorfos y los relacionados con el alcohol.

Según el marco conceptual propuesto, se considera que se trata de un fenómeno social que está teniendo graves repercusiones en la población española. Por ello, resulta de vital importancia contribuir al estudio científico en dicho tema a fin de sensibilizar a la población en general e intervenir sobre la afectada.

Nuestro estudio pretende verificar las siguientes hipótesis:

1. El estado de ansiedad es mayor en las personas que han descendido de clase social con respecto a las que se han mantenido o han ascendido.

2. En personas que han descendido de clase social, existirán mayores niveles de depresión que las personas que se mantienen.

3. Las personas desempleadas tendrán mayores niveles de depresión que las personas empleadas.

4. Entre las personas desempleadas, se presentan niveles más bajos de salud general percibida en aquellas que llevan entre 7 y 12 meses de desempleo.

5. El desempleo produce mayores niveles de ansiedad en hombres que en mujeres. 


\section{MÉTODO}

\section{Participantes}

Se ha optado por un estudio transversal en el que se ha obtenido una muestra de 95 personas, entre los cuales 44 son hombres y 51 mujeres, con edades comprendidas entre 30 y 60 años $(M=44.34, D T=8.54)$. Todos los participantes de la investigación son de nacionalidad y residencia española.

\section{Instrumentos}

Para llevar a cabo el estudio se han empleado varias herramientas. Para medir el estado de salud general se ha utilizado el General Health Questionnaire (GHQ) de Goldberg (1979) en la versión de 28 ítems (GHQ-28), del cual se ha comprobado la validez a través de varios estudios.La versión española está validada por Lobo (1981, 1986).

Dicho cuestionario se divide en cuatro subescalas: Síntomas somáticos, Ansiedad/Insomnio, Disfunción social y Depresión grave. Cada una de ellas se evalúa a través de siete ítems, contestadas a partir de una escala de tipo Likert.

Por otra parte, se ha utilizado el State-Trait Anxiety Inventory (STAI)(Cuestionario de Ansiedad Estado/Rasgo) de Spielberger, Gorsuch y Lushene (1982). Dicho cuestionario está compuesto por dos subescalas, Estado y Rasgo. Teniendo el objetivo de evaluar el nivel de ansiedad actual de la persona, solo se ha administrado la subescala Estado. Está compuesta por 20 ítems y las respuestas posibles están organizadas en una escala de tipo Likert (0-3).

Además, se han añadido varias cuestiones socioeducativas como la edad, el sexo, el nivel académico, la situación laboral y los cambios referentes a la clase social.

\section{Procedimiento}

La muestra del estudio fue seleccionada mediante muestreo no probabilístico, en concreto el de accesibilidad y el de bola de nieve.

Con el fin de obtener una muestra representativa de la situación en la población española, se ha administrado los diversos instrumentos a sujetos de diferentes comunidades autónomas, como Andalucía, Extremadura, Murcia, Madrid, País Vasco y Cataluña entre los meses de Abril y Mayo de 2013.

\section{Análisis de datos}

Para analizar los datos obtenidos, se ha utilizado el programa estadísticoinformático SPSS 20.0 (IBM SPSS).

Se han realizado análisis descriptivos, comparaciones de medias, análisis de la varianza (ANOVA) y análisis de correlaciones bivariadas. 


\section{RESULTADOS}

Con el objetivo de analizar si existían diferencias entre los participantes en función del mantenimiento o descenso de la clase social en las puntuaciones obtenidas en ansiedad y salud mental en sus diferentes dimensiones, ansiedad-insomnio, depresión grave, y se ha realizado una t de student para muestras independientes.

A continuación, se exponen los resultados más relevantes encontrados tras el análisis de datos (ver Tabla 1).

Tabla 1. Puntuaciones obtenidas por los participantes en las diferentes medidas en función de la clase social

\begin{tabular}{lcccccc}
\hline & Mantiene Clase & \multicolumn{2}{c}{ Desciende clase } & & \\
& Media & $D T$ & Media & $D T$ & $t$ & $p$ \\
\hline DEPRESIÓN GRAVE & .29 & .97 & .78 & 1.18 & -2.17 & .046 \\
\hline ANSIEDAD INSOMNIO & 1.71 & 2.42 & 2.68 & 3.06 & -1.69 & .123 \\
\hline TOTAL ANSIEDAD & 25.77 & 5.31 & 26.81 & 5.12 & -.908 & .366 \\
\hline
\end{tabular}

Como se puede observar en la Tabla 1., no hay diferencias significativas $(p>0.05)$ entre la el total de Ansiedad y el descenso o mantenimiento de la clase social. Sin embargo, sí se encuentran diferencias significativas en relación con la Depresión.

Con el objetivo de analizar la existencia de diferencias según el sexo y la situación laboral (desempleado, empleado) con respecto a los niveles de ansiedad y la sintomatología depresiva se ha realizado una prueba $t$ de student para muestras independientes.

Tabla 2. Puntuaciones obtenidas por los participantes en depresión y ansiedad en función del sexo

\begin{tabular}{lccccccc}
\hline & \multicolumn{3}{c}{ Mujer } & Hombre & & \\
& Media & $D T$ & Media & $D T$ & $t$ & $p$ \\
\hline TOTALANSIEDAD & 26,5 & 5,57 & 25,7 & 4,9 & - & 0,765 & .45 \\
\hline Total Depresón Grave &, 45 & 1,19 &, 45 &, 92 &, 016 & .99 \\
\hline
\end{tabular}

Como se observa en la Tabla 2, no hay diferencias según el sexo con respecto a los niveles de ansiedad y depresión. 
Tabla 3. Puntuaciones obtenidas por los participantes en depresión y ansiedad en función de la situación laboral

\begin{tabular}{lcccccc}
\hline & \multicolumn{2}{c}{ Empleado } & \multicolumn{2}{c}{ Desempleado } & & \\
& Media & DT & Media & $D T$ & $t$ & $p$ \\
\hline TOTALANSIEDAD & 26,5 & 5,017 & 25,45 & 5,7 & 0,91 & .36 \\
\hline Total Depresón Grave &, 26 &, 60 &, 82 & 1,6 & -1.98 & .05 \\
\hline
\end{tabular}

Como se puede observar en la Tabla 3, existen diferencias significativas con respecto a la situación laboral en los niveles de depresión, de modo que los desempleados presentan mayores niveles de depresión en comparación con los empleados. Sin embargo, no se han encontrado diferencias significativas en los niveles de ansiedad.

Con el objetivo de analizar la existencia de relación entre los meses de desempleo y la salud general y la ansiedad, se han realizado correlaciones bivariadas.

Los resultados muestran que no existe una correlación significativa entre los meses de desempleo y los niveles de Ansiedad y Salud general (depresión grave, ansiedadinsomnio, disfunción social y síntomas somáticos). Los resultados han mostrado una correlación positiva y significativa en la relación entre la salud general y la ansiedad ( $r=$ $0.399, p<001)$.

\section{DISCUSIÓN Y CONCLUSIONES}

Según los resultados obtenidos, se puede afirmar lo siguiente: La primera Hipótesis, consistente en que "El estado de ansiedad es mayor en las personas que han descendido de clase social con respecto a las que se han mantenido o han ascendido", se rechaza, ya que no se han encontrado diferencias significativas en la Ansiedad de las personas que se han mantenido en la misma clase y las que han descendido. Cabe mencionar que no se puede afirmar la ausencia de diferencias en los niveles de ansiedad en relación con sujetos que han ascendido, puesto que en nuestra investigación nadie considera que ha subido de clase social.

Con respecto a la segunda Hipótesis, la cual afirmaba que en las personas que han descendido de clase social, existirán mayores niveles de depresión que las personas que se mantienen. Se confirma, puesto que los datos son significativos, y por ello, la disminución de la clase social está relacionada con la aparición de síntomas depresivos.

La tercera Hipótesis,que consiste en“Las personas desempleadas tendrán mayores niveles de depresión que las personas empleadas", se confirma, puesto que existen diferencias significativas según la situación laboral en los niveles de depresión. 
La cuarta Hipótesis, la cual consistía en“Entre las personas desempleadas, se presentarán niveles más bajos de salud general percibida en aquellas que llevan entre 7 y 12 meses de desempleo", se rechaza, puesto que no se ha encontrado una relación significativa.

En relación a la quinta Hipótesis, basada en "El desempleo produce mayores niveles de ansiedad en hombres que en mujeres", se puede decir que se rechaza, puesto que no existen diferencias significativas en cuanto al sexo entre los desempleados y empleados en los niveles de ansiedad.

Con respecto a las limitaciones de nuestro estudio, cabe destacar las siguientes: La metodología utilizada, basada en la encuesta, ha podido producir diversos sesgos, como pueden ser la deseabilidad social, debido ala existencia de ítems demasiado comprometedores para los sujetos y han podido contestar según la norma establecida y no lo que piensen realmente, aun conociendo su anonimato.Por otro lado, ha podido influir en los resultados, el sesgo de la selección de la muestra, a pesar de que se ha intentado que los sujetos fueran representativos de la población, se considera que la muestra debería haber sido mayor y con mayor diversidad de residencia. Además, se debe mencionar la insuficiencia de pruebas para evaluar los efectos de la crisis económica y verificar nuestras hipótesis, a pesar de que la metodología utilizada tenga la ventaja de ser rápida, suponer bajo coste y evitar la fatiga del sujeto.

Como variables extrañas que han podido distorsionar el estudio, se encuentran las situaciones personales de cada individuo, dado que pueden haber reflejado puntuaciones significativas en ansiedad y depresión debido a otros factores que no se han controlado, sin relación directa con la crisis económica.

Con el fin de ampliar el conocimiento sobre los efectos de la crisis económica en la salud mental de la población, se propone llevar a cabo una investigación longitudinal para comprobar el efecto de los meses de desempleo en la salud mental de una persona de forma válida y fiable. Por otra parte, se propone estudiar otras variables relevantes que se han podido modificar a causa de la crisis, como por ejemplo locus de control, autoestima, autoeficacia, apoyo social, etc.

A pesar de la existencia de resultados no significativos, se muestra una relación entre la crisis económica y la salud mental de los sujetos, por lo que se considera conveniente crear programas de intervención para aquellas personas afectadas y programas de prevención para evitar el deterioro de salud mental en el colectivo de riesgo, es decir, aquellos que presenten alta probabilidad de sufrir estas consecuencias. 


\section{REFERENCIAS BIBLIOGRÁFICAS}

Brenner, M. Harvey and Anne Mooney.(1983). Unemployment and Health in the Context of Economic Change.Social Science Medicine, 17 (16), 1125-1138.

Buendía, J. (1990). Psicopatología del desempleo. Anales de psicología, 6(1), 21-36.

Butterworth, P., Rodgers, B., Windsor, T.D. (2009). Financial hardship, socio-economic position and depression: Results from the PATH Through the Life survey. Social Science and Medicine, 69, 229-237.

Carlisle, D. (2008). Public health in a recession.Nursing times, 104(47), 20-23.

Del Pozo, J.A., Ruiz, M.A., Pardo, A. y San Martin, R. (2002). Psicothema, 14(2), 440443.

Friedman, J. y Thomas, D. (2008). Psychological health before, during, and after an economic crisis: results from Indonesia, 1993-2000. World Bank Economic Review, 23, 57-76.

Fryers, T., Melzer, D., y Jenkins, R. (2003). Social inequalities and the common mental disorders: A systematic review of the evidence. Social psychiatric and Psychiatric Epidemiology, 38, 229-237.

Gili, M., Roca, M., Sanjay, B., McKee, y M.,Stuckler, D.(2012).The mental health risks of economic crisis in Spain: Evidence from primary care centres, 2006 and 2010. European Journal of Public Health, 23(1), 103-108.

Goldberg, D.P. y Hillier, V.F. (1979).A scaled version of the General Health Questionnaire, Psychological Medicine, 9, 139-145.

Instituto Nacional de Estadística (2008).Encuesta de Población Activa (EPA): Primer trimestre de 2008.

Recuperado dehttp://www.ine.es/daco/daco42/daco4211/epa0108.pdf

Instituto Nacional de Estadística (2013). Encuesta de Población Activa (EPA): Primer trimestre de 2013.

Recuperado dehttp://www.ine.es/daco/daco42/daco4211/epa0113.pdf

Laaksonen, E., Martikainen, P., Lahelma, E., Lallukka, T., Rahkonen, O., Head, J., et al. (2007). Socioeconomic circumstances and common mental disorders among Finnish and British public sector employees: Evidence from the Helsinki Health Study and the Whitehall II Study. International Journal of Epidemiology, 36, 776-786.

Lobo, A., Pérez-Echeverria, M.J, y Artal, J. (1986).Validity of the scaled versión of the General Health Questionnaire (GHQ-28) in a Spanish population, Psychological Medicine, 16, 135-140. 
Molarius A, Berglund K, Eriksson C, et al. (2009). Mental symptoms in relation to socioeconomic conditions and lifestyle factors: A population based study in Sweden. BMC Public Health, 9, 302.

Mossakowski, K., (2009). The Influence of Past Unemployment Duration on Symptoms of Depression Among Young Women and Men in the United States. American Journal of Public Health, 99(10), 1826-1832.

Murphy, G. y Athanasou, J. (1999). The effect of unemployment on mental health.Journal of Occupational and Organizational Psychology, 72, 83-99.

Spielberger, C.D., Gorsuch, R.L., y Lushene, R. (1982). Manual del Cuestionario de Ansiedad Estado/Rasgo (STAI). Madrid, España: TEA Ediciones.

Uutela, A. (2010). Economic crisis and mental health. CurrentOpinion in Psychiatry, 23, 127-130.

Warr, P.B. (1987). Work, Unemployment and Mental Health. England: Oxford, Scienced Publications. 


\title{
RELACIÓN ENTRE ENGAGEMENT Y LAS CREENCIAS DE AUTOEFICACIA EN LOS TRABAJADORES
}

\section{RELATIONSHIP BETWEEN ENGAGEMENT AND SELF-EFFICACY BELIEFS IN WORKERS}

María Fajardo Sarmiento, Marianela Iroz Bortolotto, Debla López Talavera, Seima Mirón Hernández. Universidad de Granada.

\section{RESUMEN}

Hoy en día, si se quiere tener una alta productividad laboral, es necesario crear un alto nivel de compromiso organizacional (work Engagement) de los empleados con la empresa. Es necesario estudiar las variables psicológicas que favorecen el "work Engagement". Según la Teoría Social Cognitiva de Bandura, la creencia de eficacia predice a largo plazo la satisfacción familiar y las conductas sanas (Bandura, 2004). En la presente investigación analizamos la autoeficacia y su relación con el Engagement organizacional, para descubrir si realmente esta variable puede ser mediadora en el Engagement. Para ello se ha medido, en 105 trabajadores de diferentes sectores, el nivel de autoeficacia percibida mediante General Self Efficacy Scale y el nivel de work engagement utilizando el Utrecht Work engagement Scale. Esperábamos obtener a mayores niveles de autoeficacia mayor nivel de engagement. Al mismo tiempo, medimos el engagement de estos trabajadores teniendo en cuenta variables como sexo, ámbito laboral y nivel de estudios.

PALABRAS CLAVE: work engagement, creencias de autoeficacia, bienestar laboral, estudio correlacional.

\begin{abstract}
Nowadays, if you want to have a high labor productivity, it is necessary to create a high level of organizational commitment (workEngagement) of employees with the company. You need to study the psychological variables which favor the "workEngagement". According to Bandura's Social Cognitive Theory, the efficacy belief predicts family satisfaction and health behaviors (Bandura, 2004). In this study we analyze the self-efficacy and its relationship to organizational Engagement, to discover if really this variable may be a mediator in the Engagement. To do this, we was measured in 105 workers from different areas, the level of self-efficacy by General Self Efficacy Scale and level of workengagement using Workengagement Utrecht Scale. We expected to have higher levels of self-efficacy to higher levels of engagement. At the same time, measure the engagement of these workers taking into account variables such as gender, workplace and educational level.
\end{abstract}

KEY WORDS: work engagement, self efficacy belief, work-related wellbeing, correlational study.

\section{INTRODUCCIÓN}

Para rendir al máximo en un mundo cada vez más competitivo, en todos los aspectos vitales en general, y en el ámbito laboral en particular, los trabajadores deben tener asegurado no sólo la preparación académica y laboral, sino también aspectos 
psicológicos individuales y sociales que los lleven a experimentar satisfacción y sentido de logro. Las empresas tienen una gran responsabilidad en este sentido, y deben esforzarse para poder potenciar al máximo las capacidades de sus trabajadores.

Actualmente nos vemos inmersos en un mundo cambiante, a nivel social, laboral y tecnológico. Vivimos a un ritmo acelerado, y para hacer frente de manera óptima a estas exigencias es preciso que los trabajadores nos sintamos capaces de nosotros mismos, que creamos que nuestras competencias personales y profesionales son adecuadas para hacer frente a las diversas circunstancias del día a día. Por ejemplo, autores como Cherniss $(1980,1993)$ señalan que en el desarrollo del burnout (desgaste en el trabajo), la falta de confianza en las propias competencias es un factor crítico.

Tradicionalmente, la psicología había venido ocupándose de aspectos negativos y patológicos de la conducta humana. Más recientemente, Seligman propuso estudiar al ser humano desde una perspectiva positiva, enfocándose en su funcionamiento óptimo (Seligman, Steen, Park y Peterson, 2005). De esta manera, la Psicología Positiva centra su objetivo en potenciar las capacidades del ser humano.

Llevando esta postura al mundo de las organizaciones, la psicología se interesa en aspectos como la creatividad, la iniciativa, la responsabilidad y el compromiso del trabajador con su empresa. La Psicología Positiva Organizacional es definida como "el estudio y aplicación de recursos y competencias humanas, que pueden ser medidas, desarrolladas y gestionadas con el objetivo de mejorar el desempeño en las organizaciones" (Salanova, Martínez y Llorens, 2006). En definitiva, se trataría de conseguir, en última instancia, el bienestar laboral y la máxima satisfacción y rendimiento del trabajador.

Para definir el bienestar laboral, se han desarrollado muchas teorías y se han estudiado diversas variables. Dos de ellas son el compromiso laboral (Work Engagement) y el estado de desgaste (Burnout) (Bakker y Oerlemans, 2011). Ambos constructos psicológicos reflejan el grado de conexión psicológica que la persona tiene con su trabajo.

El primer autor en definir el Work Engagement fue Khan en 1990, que lo describió como qué tan "enganchado" está el empleado con el trabajo que realiza. Otra definición hace referencia al grado en que los empleados se encuentran involucrados, comprometidos, entusiasmados y apasionados sobre su trabajo (Macey y Schneider, 2008). Es un indicador de motivación intrínseca por el trabajo, un estado cognitivo afectivo persistente en el tiempo. Se daría cuando los niveles de energía en el trabajo son altos, se observa una gran persistencia y hay un deseo de esforzarse.

Este constructo estaría formado por tres componentes. En primer lugar el componente físico (vigor), definido por altos niveles de energía física y predisposición para invertir esfuerzos. En segundo lugar el componente emocional (dedicación), expresado en altos niveles de entusiasmo, orgullo e inspiración en lo que se hace. Por último el componente cognitivo (absorción), que incluye la concentración y la sensación de que el tiempo pasa rápido (Schaufeli, Salanova, González-Romá y Bakker, 2002).

Como cabe esperar, el grado de implicación teniendo en cuenta estos tres componentes, se puede ver afectado por diversas variables, tanto internas como externas al trabajador. Según Schaufeli y Salanova (2011), cuando el empleado percibe un desequilibrio entre lo que él aporta a la empresa con su trabajo y lo que obtiene a cambio, el vigor puede convertirse en agotamiento, la dedicación en cinismo 
y la absorción en ineficacia profesional. Identificar estos déficits a tiempo permitiría realizar intervenciones para que no se vean afectadas la productividad de la empresa y el bienestar de sus trabajadores.

Luthans, Youssef y Avolio (2007) hablan del capital psicológico como un recurso con que cuenta la persona y que predice el bienestar laboral. Dentro del capital psicológico se encuentran: la creencia de autoeficacia, el optimismo, la esperanza y la resiliencia (capacidad de permanecer fuerte en momentos difíciles). En este estudio nos centraremos exclusivamente en la autoeficacia como predictora del grado de implicación laboral.

El autor más influyente en el estudio de la autoeficacia ha sido Albert Bandura. Este autor define dicho concepto como "los juicios de cada individuo sobre sus capacidades, con base a los cuales organizará y ejecutará sus actos, para alcanzar el rendimiento deseado" (Bandura, 2002). En realidad este concepto no hace referencia a los recursos con que cuenta objetivamente la persona, sino a la opinión que tenga sobre ellos, su percepción subjetiva acerca de si son suficientes y útiles para hacer frente a los problemas y alcanzar sus objetivos.

Si las creencias de autoeficacia son altas, es más probable que la persona esté motivada y comprometida, desempeñándose eficazmente en sus actividades, y afectando por lo tanto a su bienestar laboral de manera positiva.

Según Martínez y Salanova (2006), las personas que se consideran poco eficaces en el afrontamiento de las demandas del entorno exageran sus deficiencias y las dificultades potenciales del medio. Esta percepción negativa de sí mismos genera estrés y distrae la atención, y dificulta la utilización de los recursos disponibles (ya que no los perciben). Por el contrario, las personas que se perciben eficaces centran sus esfuerzos en las demandas que la situación les pueda plantear.

Por otro lado, Bandura sostiene que la autoeficacia también determina la manera en cómo consideramos a los obstáculos. Las personas con alta autoeficacia los ven como impedimentos u obstáculos superables, aumentando su nivel de esfuerzo y perseverancia. Las personas con baja autoeficacia, por otra parte, se convencen a sí mismas que es inútil esforzarse ya que no lograrán su objetivo, y acaban abandonando.

Teniendo en cuenta todo lo mencionado anteriormente, en este estudio se plantea analizar la relación existente entre las creencias de autoeficacia y la implicación laboral de un grupo de trabajadores. Para esto hemos averiguado en primer lugar cuál es el nivel de las creencias de autoeficacia de los participantes. En segundo lugar, necesitamos conocer su nivel de implicación en el trabajo (Work engagement). Por último, analizar si realmente existe una relación entre ambos constructos. Es decir, si las creencias de autoeficacia pueden influir en el nivel de engagement en el trabajo.

Si esto es así, el conocimiento de dicha relación tendría importantes aplicaciones prácticas para las empresas, ya que podrían aplicar programas para incrementar las creencias de autoeficacia de sus trabajadores, y así conseguir maximizar su desempeño, logrando una mayor implicación y satisfacción laboral.

\section{Hipótesis:}

$\mathrm{H} 1$ : Las creencias de eficacia se asocian positivamente con el engagement, es decir, existirá una relación positiva entre las variables engagement y autoeficacia de manera que a mayor autoeficacia generalizada (en el trabajo) mayor engagement laboral. 
H2: La media de las puntuaciones de las mujeres en todas las dimensiones del engagement será equiparable a la media de puntuaciones la de los hombres.

H3: Los participantes pertenecientes al ámbito laboral privado tendrán medias más altas en todas las dimensiones del engagement que los del ámbito público.

H4: Los participantes con estudios universitarios tendrán unas puntuaciones medias en las dimensiones del engagement mayores a las de los participantes sin estudios universitarios.

\section{METODOLOGÍA}

\section{Participantes:}

Para esta investigación se contó con la participación voluntaria y anónima de 105 trabajadores de la provincia de Granada, seleccionados al azar de diferentes empresas y sectores, entre otros: hostelería, educación y funcionarios públicos. La media de edad de los participantes es de 39,0667 años (DT=11,40198), siendo de 20 años la edad mínima y 65 años la edad máxima de los participantes.

La muestra estaba compuesta por 42 hombres (40\%) y 63 mujeres $(60 \%)$.

La media del tiempo trabajado de la muestra es de 12,2499 años (DT=9,59318), siendo el mínimo tiempo trabajado 0,20 años y el máximo 38 años.

Se dividió el ámbito laboral de los participantes en dos grupos: público (administraciones públicas, funcionariado) y privado.

Se contempló tres valores de la variable nivel de estudios siendo estos: básicos (hasta EGB o educación elemental), medios (BUP/COU/FP/ESO/Bachiller) y universitarios (Diplomaturas, Licenciaturas e Ingenierías).

\section{Instrumentos:}

Se construyó un cuestionario que incluía las siguientes medidas:

- Datos sociodemográficos: edad, sexo, sector de la empresa, nombre de la empresa, tiempo trabajado en la empresa, puesto que desempeña en la empresa, nivel de estudios.

- Escala de Work Engagement de Utrecht (Utrecht Work Engagement Scale, UWES), (Shaufeli et al., 2002), en la adaptación española de Salanova et al. (2000). Esta escala está compuesta por 17 ítems y comprende tres dimensiones: Vigor, Dedicación y Absorción. Para el vigor se dispone de 6 ítems (un ejemplo de ítem sería "soy fuerte y vigoroso en mi trabajo"), para la dedicación 5 (un ejemplo sería "estoy orgulloso del trabajo que hago"), y para absorción 6 (un ejemplo sería "estoy inmerso en mi trabajo"). Estos ítems se responden por medio de siete opciones de respuesta en una escala Likert de 0 a 6 . Se han obtenido los siguientes coeficientes alpha de Cronbach para las dimesiones: Vigor, $\alpha=.803$; Absorción, $\alpha=.80$; Dedicación $\alpha=.85$.

- Escala de Autoeficacia General (General Self Efficacy Scale, GSE), de Jerusalem y Schwarzer (1992). Esta prueba evalúa el sentido general de la creencia de autoeficacia, principalmente en cuanto a su capacidad de enfrentar problemas diarios. 
Contiene 10 ítems para los que los participantes deben responder su grado de acuerdo con cada enunciado en una escala tipo Likert con 4 alternativas de respuesta (1= "Falso" a 4= "Cierto"), logrando una puntuación mínima de 10 y un máxima de 40 puntos. Sus propiedades psicométricas han sido ampliamente establecidas tanto en población no española como española. Algunos ejemplos de ítems son: "Tengo confianza en que podría manejar eficazmente acontecimientos inesperados"; "Puedo encontrar la manera de obtener lo que quiero aunque alguien se me oponga". Se ha obtenido un alpha de Cronbach de .816 .

\section{Procedimiento:}

Se pidió la colaboración voluntaria y anónima a los participantes. Una vez que éstos accedieron, se les administró el cuadernillo que contiene los cuestionarios. Sólo se respondió a aquellas preguntas formuladas acerca de los datos sociodemográficos, no a las formuladas acerca de las escalas. Los participantes rellenaron el cuestionario y posteriormente fueron recogidos dándoles las gracias por su colaboración.

\section{Análisis de datos:}

Los análisis realizados fueron en primer lugar análisis descriptivos de las diferentes variables a analizar, como medias, desviaciones típicas y consistencias internas (alpha de Cronbach). Posteriormente se calculó los índices de correlación de Pearson entre las distintas dimensiones del engagement y la autoeficacia generalizada. Por último, para corroborar las hipótesis $\mathrm{H} 2, \mathrm{H} 3$ y H4, se realizó las diferencias de medias tStudent. Para realizar estos análisis se utilizó el paquete estadístico IBM SPSS Statistics versión 21 de prueba de 14 días.

\section{RESULTADOS}

Los porcentajes en cuanto al ámbito laboral de los participantes, público $(\mathrm{N}=50$, $47,6 \%)$ o privado $(\mathrm{N}=55,52,4 \%)$, quedan reflejados en el siguiente gráfico:

Gráfico 1: Porcentaje de participantes según el ámbito laboral.

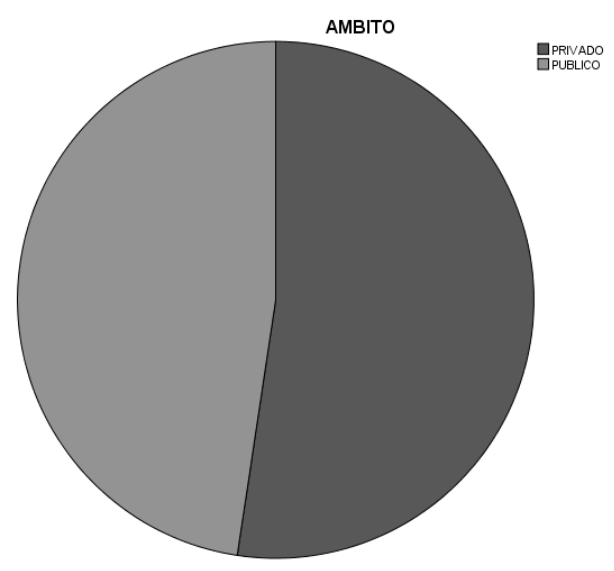

La distribución de participantes atendiendo a la variable nivel de estudios siendo es la siguiente: básicos $(\mathrm{N}=6,5,7 \%)$, medios $(\mathrm{N}=35,33,3 \%)$ y universitarios $(\mathrm{N}=64,61 \%)$ 


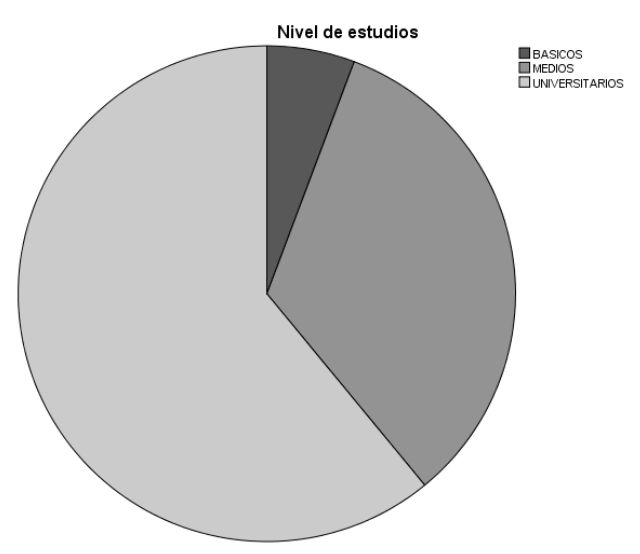

Gráfica 2: Porcentaje de participantes según nivel de estudios.

Los estadísticos descriptivos de los datos sociodemográficos tales como edad y tiempo trabajado (indicados ambos en unidades de tiempo anuales) son recogidos en la siguiente tabla:

Tabla 1. Estadísticos descriptivos de las variables de edad y tiempo trabajado.

\begin{tabular}{|c|c|c|c|c|c|c|}
\hline & \multirow{2}{*}{$\begin{array}{c}\mathrm{N} \\
\text { Estadístico }\end{array}$} & \multirow{2}{*}{$\begin{array}{l}\text { Mínimo } \\
\text { Estadístic } \\
\text { o }\end{array}$} & \multirow{2}{*}{$\begin{array}{l}\text { Máximo } \\
\text { Estadístic } \\
0\end{array}$} & \multicolumn{2}{|c|}{ Media } & \multirow{2}{*}{$\begin{array}{l}\text { Desv. típ. } \\
\text { Estadístic } \\
0\end{array}$} \\
\hline & & & & Estadístico & $\begin{array}{l}\text { Error } \\
\text { típico }\end{array}$ & \\
\hline Edad & 105 & 20,00 & 65,00 & 39,0667 & 1,11272 & 11,40198 \\
\hline $\begin{array}{l}\text { Tiempo } \\
\text { trabajado }\end{array}$ & 105 & ,20 & 38,00 & 12,2499 & ,93620 & 9,59318 \\
\hline
\end{tabular}

Las puntuaciones mínimas y máximas, medias y desviación típica en las diferentes dimensiones del engagement (vigor, absorción y dedicación) se detallan en la tabla 2:

Tabla 2. Estadísticos descriptivos de las dimensiones de vigor, absorción y dedicación del engagement.

\begin{tabular}{lccccc} 
& N & Mínimo & Máximo & Media & Desv. típ. \\
\hline VIGOR & 105 & 2,00 & 36,00 & 24,9333 & 5,73831 \\
ABSORCION & 105 & 4,00 & 36,00 & 22,4762 & 5,85579 \\
DEDICACION & 105 & 5,00 & 30,00 & 19,5238 & 6,22201 \\
\hline
\end{tabular}


Para el caso de la autoeficacia generalizada, los estadísticos descriptivos obtenidos son los siguientes:

Tabla 3. Estadísticos descriptivos de Autoeficacia generalizada.

\begin{tabular}{lccccc} 
& N & Mínimo & Máximo & Media & Desv. típ. \\
\hline GSE & 105 & 20,00 & 40,00 & 32,9238 & 3,83229
\end{tabular}

Para analizar la relación entre las diferentes dimensiones del engagement y con respecto a la variable de autoeficacia generalizada, se realizó un análisis de correlación de Pearson bivariada. En la Tabla 4 se pueden observar los resultados del análisis. Tal y como cabría esperar, las diferentes dimensiones del engagement correlacionan positivamente entre sí de forma bilateral; así VIGOR-ABSORCION tiene un coeficiente de correlación de $.768(p<.001)$, ABSORCION-DEDICACION, $r=.716$ $(p<.001)$ y DEDICACION-VIGOR, $r=.724(p<.001)$.

Por otro lado también existe una correlación positiva, aunque menos sólida que intradimensionalmente, entre la variable de autoeficacia generalizada y las distintas dimensiones del engagement, de forma bilateral, AUTOEFICACIA-VIGOR $r=.476$ $(p<.001), \quad$ AUTOEFICACIA-ABSORCION, $\quad r=.471 \quad(p<.001)$ y AUTOEFICACIADEDICACION, $r=.418,(p<.001)$.

Tabla 4. Coeficiente de correlación Pearson

\begin{tabular}{lrrrr} 
& GSE & VIGOR & ABSORCION & DEDICACION \\
\hline GSE & -- & & & \\
VIGOR &, $476^{* *}$ & -- & & \\
ABSORCION &, $471^{* *}$ &, $768^{* *}$ & -- & - \\
DEDICACION &, $418^{* *}$ &, $724^{* *}$ &, $716^{* *}$ & - \\
\hline
\end{tabular}

Nota: ${ }^{* *} p<.001$

\section{GSE= AUTOEFICACIA GENERALIZADA}

Los resultados de los componentes del engagement según el sexo del participante, el ámbito de la empresa y el nivel de estudios son los siguientes:

Tabla 5. Medias y desviaciones típicas de las dimensiones del engagement según el sexo de los participantes.

\begin{tabular}{|c|c|c|c|c|c|c|c|c|c|c|c|}
\hline \multicolumn{12}{|c|}{ SEGÚN EL SEXO } \\
\hline \multicolumn{4}{|c|}{ VIGOR } & \multicolumn{4}{|c|}{ ABSORCIÓN } & \multicolumn{4}{|c|}{ DEDICACIÓN } \\
\hline \multicolumn{2}{|c|}{$\mathrm{H}$} & \multicolumn{2}{|c|}{$M$} & \multicolumn{2}{|c|}{$\mathrm{H}$} & \multicolumn{2}{|c|}{ M } & \multicolumn{2}{|c|}{$\mathrm{H}$} & \multicolumn{2}{|c|}{ M } \\
\hline Media & DT & Media & DT & Media & DT & Media & DT & Media & DT & Media & $\mathrm{DT}$ \\
\hline 26 & 5.98 & 24.22 & 5.49 & 23.35 & 6.15 & 21.88 & 5.62 & 21,09 & 6,18 & 18,47 & 6,07 \\
\hline
\end{tabular}




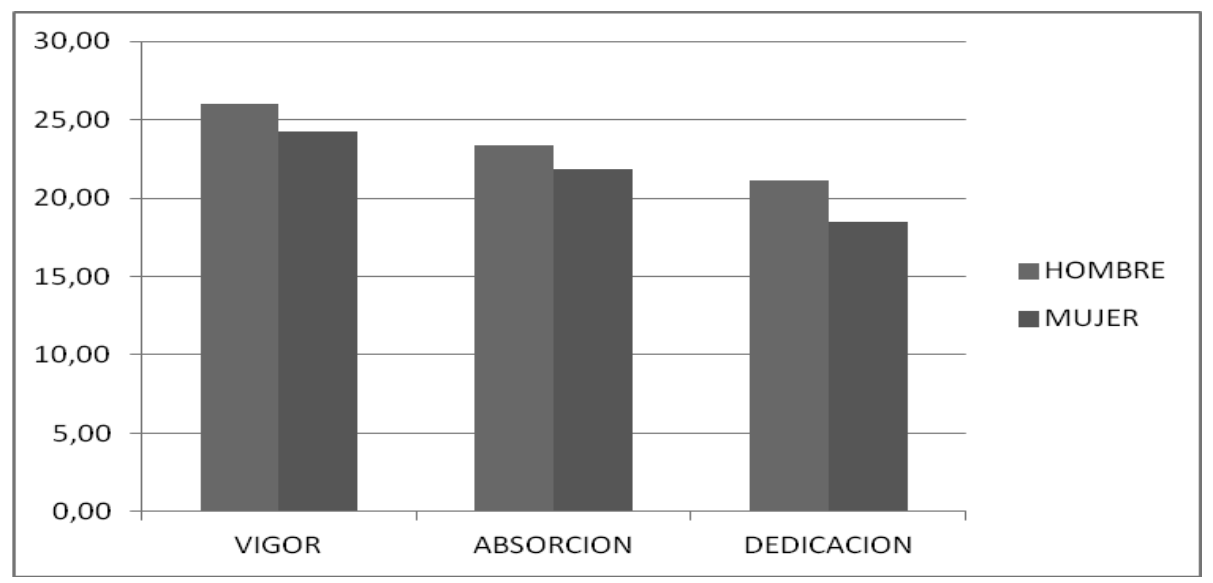

Gráfica 3. Comparativa de las medias de las dimensiones del engagement según el sexo.

Realizada la prueba $\mathrm{t}$ de Student para comparar las medias de las dimensiones del engagement teniendo en cuenta el sexo hemos obtenido los siguientes resultados. Para la dimensión VIGOR, se obtuvo un $\mathrm{t}(103)=1.566, \mathrm{p}=.120$, al ser éste mayor que 0.05 , no hay diferencia estadística entre las medias de los grupos de hombres y mujeres con respecto a esta dimensión. Para la dimensión ABSORCION, se obtuvo un $t(103)=1.262, p=.210$, al ser éste mayor que 0.05 , no hay diferencia estadística entre las medias de los grupos de hombres y mujeres con respecto a ABSORCION. Por último, para la dimensión DEDICACIÓN hemos obtenido un $t(103)=2.15, p=.034$, a diferencia de los casos anteriores, sí existe diferencia estadística entre las medias, con lo que éstas no serían equiparables.

Tabla 6. Medias y desviaciones típicas de las dimensiones del engagement según el ámbito laboral (público o privado) de los participantes.

\begin{tabular}{|c|c|c|c|c|c|c|c|c|c|c|c|}
\hline \multicolumn{12}{|c|}{ SEGÚN EL ÁMBITO } \\
\hline \multicolumn{4}{|c|}{ VIGOR } & \multicolumn{4}{|c|}{ ABSORCIÓN } & \multicolumn{4}{|c|}{ DEDICACIÓN } \\
\hline \multicolumn{2}{|c|}{ PÚBLICO } & \multicolumn{2}{|c|}{ PRIVADO } & \multicolumn{2}{|c|}{ PÚBLICO } & \multicolumn{2}{|c|}{ PRIVADO } & \multicolumn{2}{|c|}{ PÚBLICO } & \multicolumn{2}{|c|}{ PRIVADO } \\
\hline Media & DT & Media & DT & Media & DT & Media & DT & Media & DT & Media & DT \\
\hline 23,70 & 6,34 & 26,05 & 4,91 & 22,18 & 5,98 & 22,74 & 5,78 & 18,46 & 5,98 & 20,49 & 6,32 \\
\hline
\end{tabular}




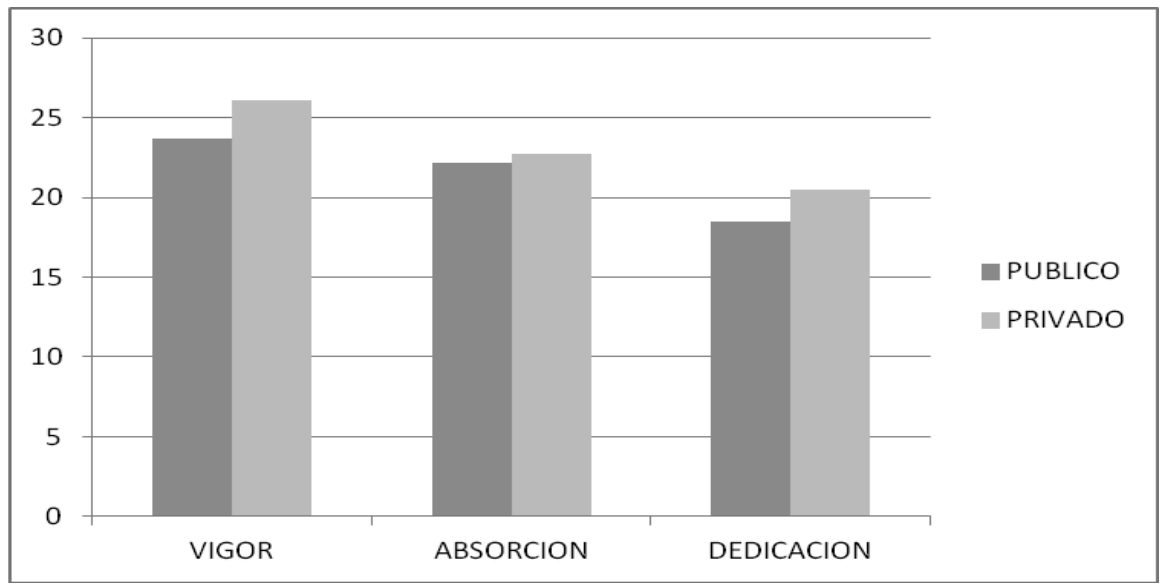

Gráfica 4. Comparativa de las medias de las dimensiones del engagement según el ámbito.

Realizada la prueba $t$ de Student para comparar las medias de las dimensiones del engagement teniendo en cuenta el ámbito laboral de los participantes (público o privado) hemos obtenido los siguientes resultados. Para la dimensión VIGOR, se obtuvo un $t(103)=-2.136, p=.035$, al ser éste menor que 0.05 , existe diferencia estadística entre las medias de los grupos público y privado a favor de este último. Para la dimensión ABSORCION, se obtuvo un $t(103)=-.492, p=.624$, al ser éste mayor que 0.05 , no hay diferencia estadística entre las medias de los grupos público y privado con respecto a $A B S O R C I O N$. Por último, para la dimensión DEDICACIÓN hemos obtenido un $t(103)=-1.685, p=.095$, en este caso no existe diferencia significativa de medias entre los grupos público y privado.

Tabla 7. Medias y desviaciones típicas de las dimensiones del engagement según el nivel de estudios de los participantes.

\begin{tabular}{|c|c|c|c|c|c|c|c|c|c|c|c|c|c|c|c|c|c|}
\hline \multicolumn{18}{|c|}{ SEGÚN NIVEL DE ESTUDIOS } \\
\hline \multicolumn{6}{|c|}{ VIGOR } & \multicolumn{6}{|c|}{ ABSORCION } & \multicolumn{6}{|c|}{ DEDICACION } \\
\hline \multicolumn{2}{|c|}{ BAS } & \multicolumn{2}{|c|}{ MED } & \multicolumn{2}{|c|}{ UNIV } & \multicolumn{2}{|c|}{ BAS } & \multicolumn{2}{|c|}{ MED } & \multicolumn{2}{|c|}{ UNIV } & \multicolumn{2}{|c|}{ BAS } & \multicolumn{2}{|c|}{ MED } & \multicolumn{2}{|c|}{ UNIV } \\
\hline M & DT & M & DT & $M$ & DT & M & DT & M & DT & M & DT & $\mathrm{M}$ & DT & $M$ & DT & M & DT \\
\hline $\begin{array}{c}25, \\
8\end{array}$ & $\begin{array}{c}3.3 \\
1\end{array}$ & $\begin{array}{c}24 \\
7\end{array}$ & $\begin{array}{c}6,4 \\
8\end{array}$ & $\begin{array}{c}24 \\
9\end{array}$ & $\begin{array}{c}5,5 \\
4\end{array}$ & $\begin{array}{c}22 \\
1\end{array}$ & $\begin{array}{c}5,2 \\
7\end{array}$ & $\begin{array}{c}21 \\
7\end{array}$ & $\begin{array}{c}6,3 \\
0\end{array}$ & $\begin{array}{c}22 \\
9\end{array}$ & $\begin{array}{c}5,6 \\
9\end{array}$ & $\begin{array}{c}19 \\
5\end{array}$ & $\begin{array}{c}5,5 \\
7\end{array}$ & $\begin{array}{c}19 \\
9\end{array}$ & $\begin{array}{c}5,9 \\
3\end{array}$ & $\begin{array}{c}19 \\
3\end{array}$ & 6,5 \\
\hline
\end{tabular}




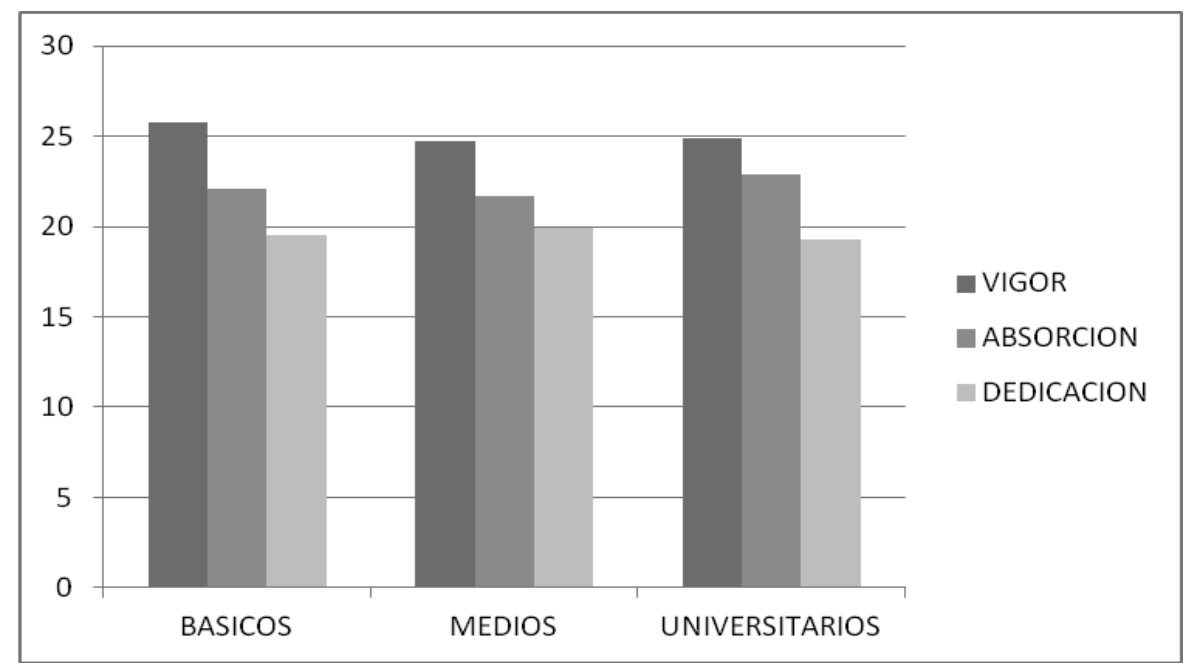

Gráfica 5. Comparativa de las medias de las dimensiones del engagement según el nivel de estudios.

Agrupando el nivel de estudios en universitario o no universitario, obtenemos los siguientes resultados para las dimensiones del engagement:

Tabla 8. Medias y desviaciones típicas de las dimensiones del engagement según si se tienen o no estudios universitarios.

\begin{tabular}{lllcc} 
& \multicolumn{1}{c}{ UNINO } & N & Media & Desviación típ. \\
\hline \multirow{2}{*}{ VIGOR } & NOUNIVERSITARIO & 41 & 24,9268 & 6,10488 \\
& UNIVERSITARIO & 64 & 24,9375 & 5,54026 \\
\hline \multirow{2}{*}{ ABSORCION } & NOUNIVERSITARIO & 41 & 21,7805 & 6,10538 \\
& UNIVERSITARIO & 64 & 22,9219 & 5,69406 \\
\hline \multirow{2}{*}{ DEDICACION } & NOUNIVERSITARIO & 41 & 19,8537 & 5,81619 \\
& UNIVERSITARIO & 64 & 19,3125 & 6,50488 \\
\hline
\end{tabular}

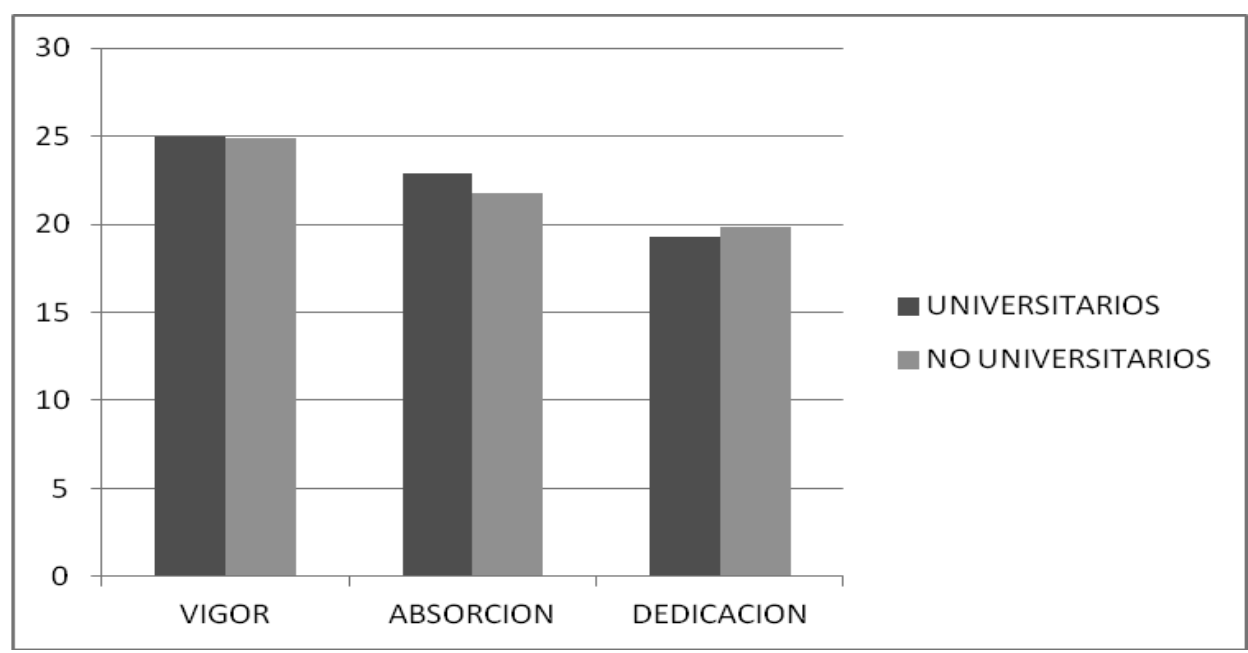

Gráfica 6. Comparativas de las medias de cada una de las dimensiones del engagement en población universitaria y no universitaria. 
Se realizó la prueba t de Student para comparar las medias de las dimensiones del engagement teniendo en cuenta si se tenían o no estudios universitarios obteniendo los siguientes resultados: para la dimensión VIGOR, se obtuvo un t $(103)=-.009, p=$ .993, lo que indica que no existen diferencias significativas entre las medias de los grupos con estudios universitarios y sin estudios universitarios. Para la dimensión ABSORCION, se obtuvo un $\mathrm{t}(103)=-.974, \mathrm{p}=.332$, de nuevo no hay diferencia estadística entre las medias de los grupos. Por último, para la dimensión DEDICACIÓN hemos obtenido un $\mathrm{t}(103)=.433, \mathrm{p}=.666$, tampoco existe diferencia significativa de medias entre los grupos con estudios universitarios y sin ellos.

\section{DISCUSIÓN}

En el presente estudio intentamos determinar si existe relación entre la Autoeficacia percibida y el compromiso organizacional (engagement) de un individuo con su contexto laboral, además de la dirección de esta relación (directa o inversa). A su vez, hemos intentado determinar si este nivel de Engagement se ve condicionado por variables como sexo, ámbito laboral y nivel de estudios.

Tras analizar los resultados comprobamos que existe una correlación positiva entre "Autoeficacia" y "Engagement", como planteábamos en nuestra primera hipótesis. Existe correlación positiva entre las dimensiones de "Engagement" (VIGOR, ABSORCIÓN y DEDICACIÓN) así como una correlación también positiva entre éstas y "Autoeficacia".

Tras realizar la comparación de datos entre hombres y mujeres observamos que las medias de las puntuaciones obtenidas en las dimensiones de VIGOR y ABSORCIÓN y DEDICACIÓN del engagement para el grupo de hombres fueron mayores que las de las mujeres. Sin embargo, la comparación de medias mediante la t-student arrojó los resultados de que en las dimensiones de VIGOR y ABSORCION, las diferencias no eran significativas, con lo que no existiría diferencia y se cumple nuestra hipótesis $\mathrm{H} 2$ para esas dimensiones. Sin embargo no ocurre así para la dimensión de DEDICACIÓN, en la que la diferencia de medias es significativa a favor del grupo de hombres.

Una posible explicación a esta diferencia se podría atribuir a diferencias de roles entre sexos aún presentes en nuestra sociedad. Por lo general, el hombre no tiene tantas responsabilidades fuera del ámbito laboral como la mujer, quien aparte de su puesto de trabajo, debe atender a labores domésticas o de educación. Esta menor carga de responsabilidad permitirían al hombre mayor focalización e inversión de esfuerzo en el puesto de trabajo.

Otra de las posibles variables que creímos que pudiera causar diferencias en cuanto a Engagement es el ámbito laboral, distinguiendo entre puestos públicos y privados. Los resultados obtenidos muestran que las medias de todas las dimensiones del engagemetn son más altas para el ámbito privado que para el público, sin embargo, sólo son significativas en la dimensión de VIGOR a favor del ámbito privado. Esto implica que nuestra hipótesis H3 no se cumpliría o sólo se cumpliría en la dimensión de VIGOR.

Mayor vigor en el sector privado lo asociamos a mayor responsabilidad por parte del trabajador, mayor exigencia y rendimiento en el puesto de trabajo.

Nuestra hipótesis respecto a la variable nivel de estudios, $\mathrm{H} 4$, apostaba por valores de 
Engagement más elevados para personas con niveles de estudios superiores, por encima de aquellos que no hubieran obtenido formación universitaria. Sin embargo, los resultados muestran que nuestra hipótesis no se cumple, en ninguna de las dimensiones del Engagement, al no existir diferencias significativas respecto a las medias de "universitarios" frente a "no universitarios".

Una posible explicación a estos resultados puede deberse a que muchos "universitarios" de nuestro estudio realizan trabajos que no se corresponden al nivel de las competencias adquiridas. Consideramos que si los empleos de los sujetos universitarios estuvieran relacionados con sus competencias académicas, la diferencia de medias hubiera sido significativamente mayor a favor de éstos.

Aunque los resultados obtenidos y su posterior interpretación confirman nuestra primera hipótesis $(\mathrm{H} 1)$ y parcialmente alguna de las demás, este estudio no está exento de limitaciones. Tal y como dicen las teorías organizacionales y diversos estudios, en nuestra muestra se puede aceptar que la "Autoeficacia" funciona como variable mediadora de "Engagement" ya que los datos muestran una correlación positiva entre ambos constructos. Sin embargo, la influencia de variables como sexo, nivel de estudios y ámbito laborales casi inexistente en la muestra de nuestro estudio.

Una de las limitaciones que nos hemos encontrado en la elaboración de este estudio es conseguir una muestra adecuada para el mismo. Uno de los requisitos de nuestra muestra debía consistir en personas que se encontraran trabajando actualmente y que estuvieran dispuestas a participar voluntariamente. En los tiempos de crisis que corren, no es tan fácil encontrar a gente con empleo, y aun encontrando a personas con estas características, algunas de ellas eran reticentes a la hora de participar, por si los datos se les suministraban a sus superiores.

Con respecto a la variable "ámbito laboral", se han seleccionado puestos de trabajo muy distintos entre sí. Si los empleos hubieran sido más homogéneos dentro de cada sector, quizá las diferencias en cuanto a la variable "ámbito laboral" habrían sido significativas en todas las dimensiones.

En cuanto a la variable "nivel de estudios" hay que tener en cuenta que los datos no sugieren ninguna diferencia entre "universitarios" y "no universitarios" respecto a puntuaciones en Engagement. Con un tamaño mayor de muestra, quizá estos resultados hubieran sido distintos a los obtenidos.

Por último y refiriéndonos a la variable "sexo", recordar que la muestra fue aleatoria y es posible que los empleos desempeñados por hombres tuvieran más capacidad de generar Engagement que aquellos realizados por mujeres, lo que explicaría mayores puntuaciones en la dimensión "dedicación" para el sector masculino.

Pensamos que en el ámbito laboral es muy importante conseguir que los trabajadores se encuentren comprometidos con la organización, es decir, conseguir un alto nivel de Engagement, ya que esto asegurará trabajadores más realizados con sus puestos de trabajo y al mismo tiempo más productivos y eficaces. Por ello es importante estudiar todas aquellas variables que puedan ayudar a favorecer esta situación y se abre un nuevo campo de investigación.

En este caso, se han estudiado variables como Autoeficacia, sexo, ámbito o nivel de estudios. En un futuro, se podrían estudiar otras variables susceptibles de mediar en el Engagement tales y como autoestima, clima laboral, condiciones laborales... 


\section{REFERENCIAS BIBLIOGRÁFICAS}

Bakker, A. y Oerlemans, W. (2011). Subjective well-being in organizations. En K. Cameron Y G. Spreitzer (Eds), Handbook of positive organizational scholarship. New York: Oxford University Press.

Bandura, A. (2002). Social cognitive theory in cultural context. Journal of applied Psychology: An International Review, 51, 269-290.

Bandura, A. (2004). Health promotion by social cognitive means. Health, Education \& Behavior, 31 (2), 143-164

Cherniss , C. (1980). Role of professional self-efficacy in the etiology and amelioration of burnout. En W.B. Schaufeli, C. Maslach y T. Marek (Eds.), Professional burnout: Recent developments in theory and research (pp, 135-150). Washington, DC: Taylor \& Francis.

Cherniss , C. (1993). Role of professional self-efficacy in the etiology and amelioration of burnout. En W.B. Schaufeli, C. Maslach y T. Marek (Eds.), Professional burnout: Recent developments in theory and research. Series in applied psychology: Social issues and questions (pp, 135-149). Washington, DC: Taylor \& Francis.

Luthans, F., Youssef, C. y Avolio, B. (2007). Psychological capital: Developing the human competitive edge. Oxford, United Kingdom: Oxford University Press.

Manzano, G. (2002). Burnout y engagement en un colectivo profesional. Boletín de Psicología, 74, 79-102.

Macey, W. y Schneider, B. (2008). The meaning of employee engagement. Industrial and Organizational Psychology: Perspectives on Science and Practice, 1, 3-30.

Martínez, I. y Salanova, M. (2006). Autoeficacia en el trabajo: el poder de creer que tú puedes. EstudiosFinancieros, 279 (45), 175-202.

Salanova, M., Martínez, I. M., Llorens, S. (2006). Psicología Organizacional Positiva. In F.J. Palací (Coord.).Psicología de la Organización (349-376). Madrid: Prentice Hall.

Salanova, M. y Schaufeli, M. (2009). El engagement en el trabajo. Cuando el trabajo se convierte en pasión. Anales de psicología, 25 (2).

Salanova, M., Schaufeli, W.B., Llorens, S., Peiro, J.M., Grau, R. (2000). Desde el "burnout" al "engagement": ¿una nueva perspectiva?. Revista de Psicología del Trabajo y las Organizaciones. 16 (2) 117-134.

Schaufeli W. y Salanova M. (2011). Commentary work engagement: On how to better catch a slippery concept. European Journal of Work and Organizational Psychology, 20 (1), 39-46.

Schaufeli W., Salanova M., González-Romá, M., y Bakker A. (2002). The measurement of burnout and engagement: A confirmatory factor analytic approach. Journal of Happiness Studies, 3, 71-92.

Seligman, M., Steen, T., Park, N., y Peterson, C. (2005). Positive psychology practice: Empirical validation of interventions. American Psychologist, 60, 410-421.

Ventura, M., Llorens, S., Salanova, M .El rol de la autoeficacia en el estudio del engagement. Jornades de Foment de la Investigació. Universitat Jaume I. Extraída el 5 
de abril de 2013 de http://www.uji.es/bin/publ/edicions/jfi12/4.pdf. 


\title{
¿LÍDERES SEXISTAS? UN ESTUDIO SOBRE LA INFLUENCIA DEL SEXISMO EN LOS ESTILOS DE LIDERAZGO
}

\section{SEXIST LEADERS? A STUDY ON THE INFLUENCE OF SEXISM IN LEADERSHIP STYLES}

Carolina Garzón Bello, Dolores Jiménez Domínguez, Inmaculada Juan Moreno, Cristina Luque Oliva, Rosa María Navío García, Mireia Pacheco Arco, María José Pérez Páez. Universidad de Granada

\section{Resumen}

Dos fenómenos psicosociales como son el sexismo y el estilo de liderazgo podrían estar más relacionados de lo que parece a priori. El objeto de este estudio es analizar cómo se relacionan ambas variables. Se espera que se revelen algunas de las diferencias existentes entre los distintos tipos de sexismo y su relación con los distintos tipos de liderazgo. Para ver la relación entre ambas variables se contó con una muestra de 140 participantes (70 mujeres y 70 hombres), de edades comprendidas entre 18 y 30 años. Los instrumentos empleados fueron el Test de Liderazgo de Kurt Lewin (1940) y la Escala de Sexismo Ambivalente (ASI) de Expósito, Moya y Glick (1998). Los resultados obtenidos mostraron una correlación entre el sexismo hostil con el liderazgo autoritario, y que las diferencias de género en cuanto al sexismo hostil eran mayores en hombres, no mostrando diferencias en el sexismo benévolo.

Palabras clave: estilo de liderazgo, autoritarismo, sexismo

\begin{abstract}
Two psychosocial topics such as sexism and leadership style may be more related than it seems a priori. The purpose of this study is to analyze how they relate both variables. It is expected that this study will reveal some of the differences between the different types of sexism and its relation to the different types of leadership. To see the relationship between both variables had a sample of 140 participants (70 women and 70 men), aged between 18 and 30. The instruments used were the Leadership Test of Kurt Lewin (1940), and Ambivalent Sexism Inventory (ASI) of Expósito, Moya and Glick (1998). The results showed a correlation between hostile sexism authoritarian leadership, and gender differences regarding hostile sexism were higher in men, showing no differences in benevolent sexism.
\end{abstract}

Key words: leadership style, authoritarism, sexism

\section{INTRODUCCIÓN}

"Imaginemos, por ejemplo, a un empresario que tuviera a dos aspirantes a la dirección de su empresa: un hombre y una mujer, ambos con una larga trayectoria en la organización y con un currículum semejante. "Elegiré al hombre porque estos son mejores líderes" o "elegiré a la mujer porque ellas tienen más mano izquierda y saben tratar mejor a los subordinados". Posiblemente, realizaría una mejor decisión si analizara más detenidamente las características idiosincrásicas de cada uno de los dos candidatos, los requisitos del puesto de dirección de que se trata, el tipo de empresa, las peculiaridades de los empleados a los que hay que dirigir, etcétera. (Moya, 2003, p. 322). 
En las últimas décadas se han atribuido características específicas a las personas que desempeñan el papel de líder en cualquier organización. Estas están influenciadas por factores biológicos, psicológicos y sociales que moldean a la persona y a la sociedad ejerciendo una relación bidireccional. Pero, ¿qué se entiende por liderazgo? Según Molero (2004) es un proceso de influencia entre el líder y sus seguidores que persigue conseguir las metas de un grupo, organización o sociedad.

Existen tres estilos de liderazgo, según Lewin (1939): estilo autoritario (caracterizado por ser directivo y hacer énfasis en el distanciamiento social, la determinación y control del trabajo a realizar), estilo democrático (hace énfasis en el trabajo grupal, donde se tiene en cuenta la aprobación y participación de todos en la toma de decisiones) y estilo laissez-faire (estilo no directivo, se basa en la otorgación de libertad de acción y la no participación e implicación en actividades del grupo que lidera).

Tradicionalmente se ha destacado el estilo de liderazgo autoritario, asociado a las características de personalidad típicas masculinas: se presenta al hombre (más que la mujer) como figura prototípica de líder. Un estudio de García-Retamero y López-Zafra (2006) concluyó que se manifiesta un mayor prejuicio hacia las mujeres líderes cuando estas desempeñan tareas tradicionalmente masculinas. Sus éxitos se atribuyen a factores externos (suerte), mientras que los fracasos se asocian a factores internos (falta de capacidad). En cambio, los éxitos masculinos son atribuidos a factores internos y los fracasos a factores externos. Estos prejuicios se mantienen cuando no cumplen con la expectativa del rol de líder esperado: en mujeres se espera que sean relacionales por ser una expectativa inherente al rol femenino, e instrumentales, por ser una característica propia de líder (Limón y Rocha, 2012).

Existen diferencias en la atribución del estilo de liderazgo según el género. Al estilo de liderazgo masculino se atribuyen características competitivas, control detallado, razonamiento analítico y con el objetivo de triunfar en las tareas. En cambio, a las mujeres se atribuyen características cooperativas, empatía, menor control de la situación y orientación hacia la calidad de las relaciones (Arteaga y Ramón, 2009).

Esta desigualdad entre sexos se conoce como sexismo, definido como el conjunto de creencias, actitudes y comportamientos perjudiciales hacia un individuo derivado de la percepción negativa del mismo por pertenecer a un sexo determinado (Moya, Glick, Expósito, De Lemus y Hart, 2007). Define dos tipos de sexismo: benévolo y hostil. El primero hace referencia a un conjunto de actitudes dirigidas hacia las mujeres, considerándolas un ser delicado al que hay que proteger y cuidar (tono afectivo positivo) pero limita la capacidad de autonomía en ciertas tareas. El segundo se define como un prejuicio de subordinación de la mujer, antipatía y/o rechazo explícito hacia ella.

Limón y Rocha (2011) encontraron que se atribuyen características de machismo, abuso y acoso hacia la mujer (sexismo hostil) a líderes con estilo autoritario. Ello implica aspectos comunes entre ambos: este tipo de líderes no aceptan las opiniones de los demás, creen estar en una posición de superioridad y no tienen en cuenta puntos de vista ajenos, imponiendo los propios.

Por ello, nuestro objetivo será establecer si existe relación entre el sexismo y los estilos de liderazgo, mediante las siguientes hipótesis:

1) A mayor sexismo mayor estilo de liderazgo autoritario, existiendo una relación mayor con el sexismo hostil que con el benévolo.

2) A menor sexismo mayor estilo de liderazgo democrático.

3) Existen diferencias de género en sexismo y estilos de liderazgo. 


\section{MÉTODO}

\section{Participantes}

Se contó con una muestra escogida al azar de 140 participantes (70 hombres y 70 mujeres), de edades comprendidas entre 18 y 30 años. La muestra procede de Granada, Córdoba y Jaén.

\section{Procedimiento}

Se administraron los cuadernillos a los participantes de forma individual, en un ambiente controlado, con adecuada iluminación, sin ruidos y sin ningún tipo de distractores. Después, se realizó un análisis de datos utilizando el paquete estadístico SPSS.

\section{Instrumentos}

Las pruebas utilizadas han sido el Test de Liderazgo de Kurt Lewin (1939) y la Escala de Sexismo Ambivalente de Expósito, Moya y Glick (1998). El primero evalúa los estilos de liderazgo que pueden presentar los sujetos ante un rol de mando (autoritario, democrático y laissez-faire). Consta de 33 ítems con respuestas de tipo dicotómico (de acuerdo/en desacuerdo). En cuanto al ASI, se evalúa el nivel de sexismo hostil y sexismo benevolente. Este test consta de 22 ítems, que puntúan en una escala de tipo Likert de 0 a 5.

\section{RESULTADOS}

En la Tabla 1 se encuentran los estadísticos descriptivos para la variable "Sexismo". Se observa una media de 2.69 en Sexismo Hostil, con una desviación típica de 1.17. Por otra parte, la media de Sexismo Benévolo es de 2.62, con una desviación típica de 1,14 .

También se incluyen los estadísticos descriptivos para la variable "Estilos de Liderazgo". La media del estilo de liderazgo autoritario es de 0.43 , con una desviación típica de 0.33. La media del estilo democrático es de 0.73 , siendo la desviación típica de 0.20 . Por último, la media del estilo laissez-faire es de 0.46 , con una desviación típica de 0.18 .

Tabla 1. Estadísticos descriptivos del sexismo y estilos de liderazgo.

\begin{tabular}{lcc}
\hline & Media & $\begin{array}{c}\text { Desviación } \\
\text { Típica }\end{array}$ \\
\hline Sexismo Hostil & 2.69 & 1.17 \\
Sexismo Benevolente & 2.62 & 1.14 \\
Estilo Autoritario & .43 & .33 \\
Estilo Democrático & .73 & .20 \\
Estilo Laissez-faire & .46 & .18 \\
\end{tabular}


A continuación, se realiza el análisis de los datos para cada una de las hipótesis planteadas en el estudio:

1) A mayor sexismo mayor estilo de liderazgo autoritario, existiendo una relación mayor con el sexismo hostil que con el benévolo.

Tabla 2: Correlaciones de Pearson entre el sexismo hostil y benévolo y el estilo de liderazgo autoritario.

\begin{tabular}{lccc}
\hline \multicolumn{4}{c}{ Correlaciones de Pearson } \\
\hline & 1 & 2 & 3 \\
$\begin{array}{l}\text { 1. Sexismo } \\
\text { Hostil }\end{array}$ & - & $.242^{* *}$ & $.522^{* *}$ \\
$\begin{array}{l}\text { 2. Sexismo } \\
\text { Benévolo }\end{array}$ & $.242^{* *}$ & - & $.203^{*}$ \\
3. Estilo & & & - \\
Autoritario & $.522^{* *}$ & $.203^{*}$ & \\
\hline${ }^{* *} p<.01{ }^{*} p<.05$ & & &
\end{tabular}

Como podemos observar, existe una correlación positiva entre ambos tipos de sexismo y el estilo de liderazgo autoritario. Así, la correlación entre el sexismo hostil y el estilo autoritario es de 0.522 , siendo dicha relación significativa $(p<0.01)$.

Por otra parte, la correlación entre el sexismo benévolo y el estilo autoritario también es positiva (0.203), con una significación de $p=0.016$.

Tras estos resultados, se observa una mayor relación del estilo autoritario con el sexismo hostil en relación al Sexismo benévolo.

2) A menor sexismo mayor estilo de liderazgo democrático.

A través del análisis de los datos, se observa una correlación negativa significativa entre el sexismo hostil y el estilo democrático de -0.281. En cuanto al sexismo benévolo, no se ha encontrado una relación significativa con este estilo.

Tabla 3: Correlaciones de Pearson entre el sexismo hostil y benévolo y el estilo de liderazgo democrático.

\section{Correlaciones de Pearson}

\begin{tabular}{lccc}
\hline & 1 & 2 & 3 \\
1. Sexismo Hostil & - & $.242^{* *}$ & $-.281^{* *}$ \\
2. Sexismo Benévolo & $.242^{* *}$ & - & -.002 \\
3. Estilo Democrático & $-.281^{* *}$ & -.002 & - \\
\hline
\end{tabular}

${ }^{* *} p<.01$ 
3) Existen diferencias de género en sexismo y estilos de liderazgo.

En relación al sexismo, se observan diferencias estadísticamente significativas en el sexismo hostil $(p<.01)$, puntuando en mayor medida los hombres en comparación con las mujeres (ver gráfico 1). Sin embargo, no se observan diferencias en el sexismo benévolo (no hay diferencias).
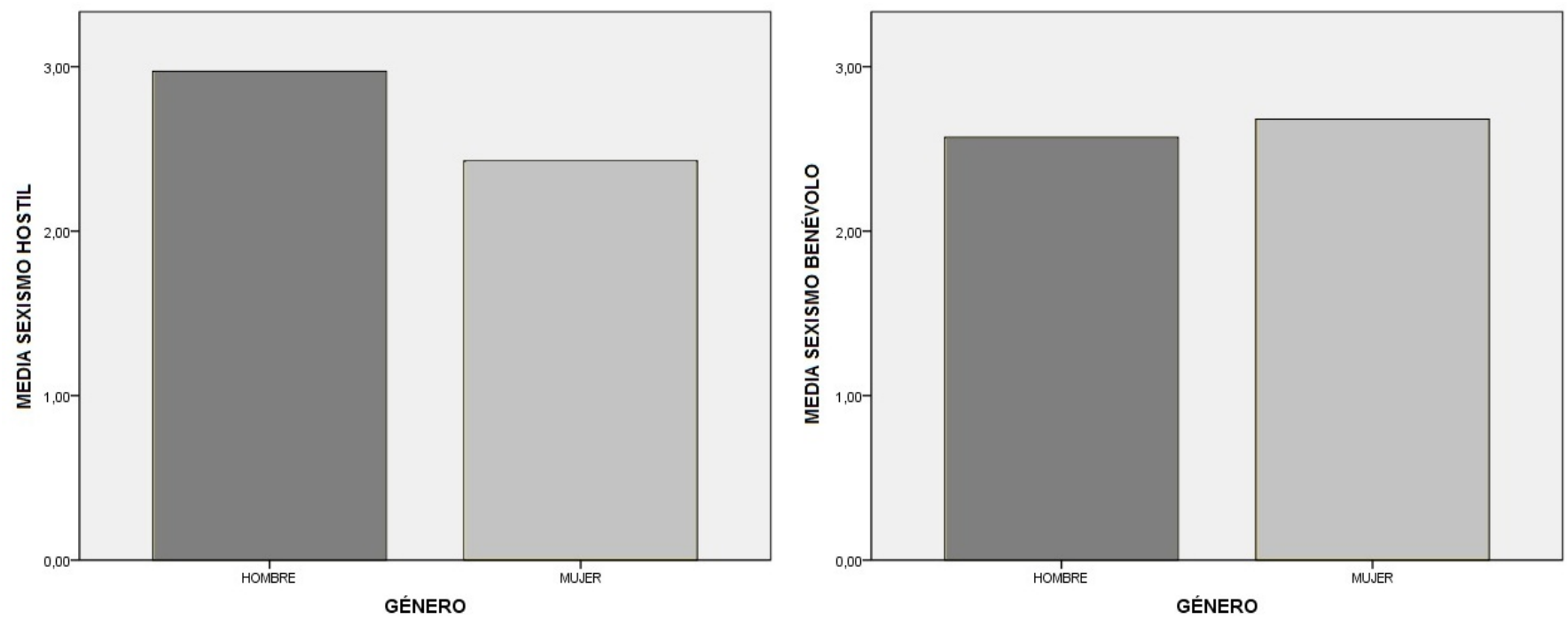

Prueba T para muestras independientes con la variable "Sexismo"

Gráfica 1: Prueba T para muestras independientes con las variables de Sexismo y Género.

Atendiendo a los diferentes estilos de liderazgo, existen diferencias estadísticamente significativas en el estilo de liderazgo autoritario $(p=0.36)$, observándose también una mayor puntuación en hombres que en mujeres. En este caso, no se observan diferencias en el estilo de liderazgo democrático.
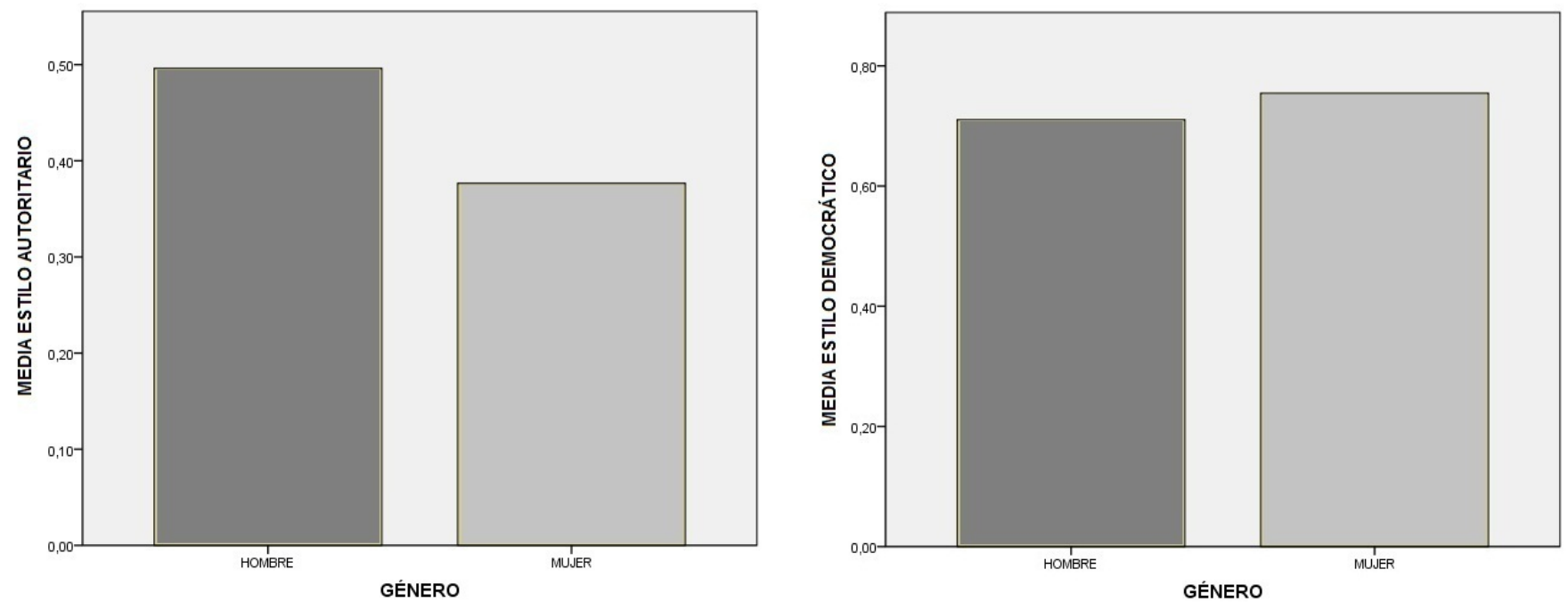

Prueba T para muestras independientes con la variable "Estilos de Liderazgo"

Gráfica 2: Prueba $T$ para muestras independientes con las variables Estilos de liderazgo autoritario y democrático 


\section{DISCUSIÓN}

En la actualidad, en las organizaciones, el rendimiento y satisfacción del empleado en la empresa depende del tipo de liderazgo que se ejerza y el nivel de sexismo que tenga el líder. Por ello, el estudio se centró en determinar si existía relación entre sexismo y liderazgo.

Tras el análisis de los resultados, podemos observar que las hipótesis planteadas se confirman. La primera hipótesis trata de ver la relación entre el sexismo y el estilo de liderazgo autoritario, obteniéndose una correlación positiva entre ambas variables. Este resultado se ve apoyado por Limón y Rocha (2011), defendiendo que el líder autoritario justifica la desigualdad entre sexos y la jerarquía en los puestos de trabajo.

Con respecto a la segunda hipótesis, "A menor sexismo mayor estilo de liderazgo democrático", se ha evidenciado que existe una relación inversa entre estilo de liderazgo democrático y sexismo hostil; sin embargo no se presenta relación con el sexismo benévolo.

El liderazgo democrático resalta valores de igualdad entre trabajadores y toma de decisiones grupal, considerando a todos por igual (Lewin, 1939). Estos valores son totalmente contradictorios al sexismo, que apoya la desigualdad de género y aporta características de superioridad-inferioridad.

Los resultados obtenidos confirmaron que "existen diferencias de género en sexismo y estilos de liderazgo". Los hombres presentan un mayor índice de sexismo hostil que las mujeres, y una media superior de estilo de liderazgo autoritario. Ello se ve respaldado por las características relacionadas al estereotipo del líder masculino, al cual se atribuyen éxitos a factores internos, y cuando actúan como líderes autoritarios se perciben congruentes a la expectativa del rol asumido (García-Retamero y LópezZafra, 2006).

Durante la investigación realizada se propuso una cuarta hipótesis que relacionaba el sexismo con el estilo de liderazgo laissez-faire. Sin embargo, no se pudo analizar ya que no encontramos justificación teórica para dicha hipótesis, lo que supuso una limitación al estudio. Otra limitación es la procedencia de la muestra, recogida en una sola región demográfica (Andalucía), pudiendo influir en los resultados obtenidos, así como la restricción de edad (muestra de población juvenil).

Sería interesante establecer futuros estudios donde se observe la relación entre el origen del estilo de liderazgo y la cultura, los rasgos de personalidad y el tipo de empresa. También podría estudiarse la influencia que tiene el puesto laboral en el estilo de liderazgo que presentan los empleados. Finalmente, podría realizarse otro estudio relacionando sexismo con el estilo de liderazgo laissez-faire.

\section{REFERENCIAS}

Arteaga, A. y Ramón, S. (2009). Liderazgo resonante según género. Multiciencias, 9(3), 289-295.

Expósito, F., Moya, M. y Glick, P. (1998) Sexismo ambivalente: medición y correlatos. Revista de Psicología Social, 13, 159-170.

García-Retamero, R. y López-Zafra, E. (2006). Congruencia de rol de género y liderazgo: El papel de las atribuciones causales sobre el éxito y el fracaso. Revista Latinoamericana de Psicología, 38(2), 245-257. 
Lewin, K. (1939). Experiments in social space. En D. Cartwright (Ed.), Field Theory in social science: selected theoretical papers by Kurt Lewin (pp. 71-83). Nueva York: Harper Torchbooks.

Limón, J. B. y Rocha, T. E. (2011). Creencias y actitudes sexistas de trabajadores en empresas mexicanas: un estudio exploratorio. Psicología Iberoamericana, 19(2), 55-66.

Limón, J. B. y Rocha, T. E. (2012). Prejuicio sexista y atribuciones de éxito o fracaso de líderes: importancia del contexto a evaluar. Enseñanza e investigación en Psicología, 17(2), 329-341.

Molero, F. (2004). El liderazgo. En C. Huici y J.F. Morales (Dir.): Psicología de grupos I. Estructura y procesos, 141-169. Madrid: UNED.

Moya, M. (2003). Sobre la existencia y el origen de las diferencias en el liderazgo entre hombres y mujeres. Revista de Psicología Social, 18(3), 321-325.

Moya, M., Glick, P., Expósito, F., De Lemus, S. \& Hart, J. (2007). It's for your own good: Benevolent Sexism and women's reactions to protectively justified restrictions. Personality and Social Psychology Bulletin, 33(10), 1421-1434. 


\section{TDAH Y SU RELACIÓN CON LA MOTIVACIÓN EN EL CONTEXTO EDUACTIVO}

Gómez Díaz, Isabel C.; Morán Alvarado, Verónica; Pereda Moral, Macarena; Pazos

Moreno, Eloísa. Universidad de Huelva

\section{Resumen}

Puesto que el objetivo de este trabajo es conocer la influencia de la motivación en los sujetos con Trastorno por Déficit de Atención con Hiperactividad (TDAH), se ha revisado la conceptualización del trastorno en la historia y su relación con la motivación, para determinar si tras el déficit atencional subyacen problemas motivacionales. El artículo señala las variables o factores más relevantes en el desarrollo del trastorno, éstas pueden ser genéticas, psicobiológicas y ambientales, desde una perspectiva más general. Tras analizar tanto la etiología del término como las variables que determinan el trastorno y la posible relación motivacional, se proponen una serie de estrategias educativas para fomentar el rendimiento académico de niños con TDAH. En definitiva, este trabajo manifiesta una posible relación directa entre atención y motivación, lo que marcará el desarrollo curricular de los alumnos en el contexto educativo.

Palabras claves: atención, aprendizaje activo, motivación, estrategias educativas.

\section{Introducción}

El Trastorno por Déficit de Atención e Hiperactividad (TDAH) se caracteriza por un patrón persistente de inatención, exceso de actividad e impulsividad como características definitorias. Según el Manual Diagnóstico y Estadístico de los Trastornos Mentales, DSM-IV-TR- ( 2002), este trastorno tiene una incidencia del 3-6\% en la población normal.

Desde que Still (1902) realizase la primera aproximación al trastorno, hablando de un déficit en el control moral, han sido distintas las aproximaciones que ha tenido el trastorno, como hiperkinesia, disfunción cerebral mínima (Clements, 1966), o más tarde Virginia Douglas (1972) argumentó que la deficiencia básica de los niños hiperactivos no era el excesivo grado de actividad, sino su incapacidad para mantener la atención y su impulsividad.

Así mismo, las consecuencias personales y sociales de la impulsividad son evidentes dado el alto índice de niños que cada día son diagnosticados bajo el TDAH, una manifestación extrema de las dificultades relacionadas con la autorregulación.

Aunque en las últimas décadas se ha conceptualizado el TDAH como un trastorno de las funciones ejecutivas, autores como Banaschewski, Hollis, Oosterlaan, Roeyers, Rubia, Willcutt y Taylor (2005), señalan que este trastorno podría estar más relacionado con anormalidades motivacionales, desorganización motriz y descontrol temporal. Otros autores, como Sonuga-Barke (2005) o Mclnerney y Kerns (2001), ven en la motivación un aspecto esencial para explicar y comprender el TDAH.

Sin embargo, las primeras aproximaciones al estudio de la motivación humana se basaban en términos como activación, instinto, impulso, energización; la necesidad de 
explicar por qué un individuo comenzaba, continuaba o terminaba una tarea, o sea, aquello que motiva o "empuja" a un sujeto a llevar a cabo determinadas acciones, su motivación (Douglas, 1972).

En este sentido, es importante diferenciar entre motivación extrínseca e intrínseca en el sujeto. La primera, vendrá determinada por refuerzos externos o recompensas que variarán su significación según los valores de cada persona. En cambio, la motivación intrínseca está impulsada por ganas e interés propio por involucrarse en una tarea por el simple hecho de participar, con tendencias hacia el aprendizaje y la creatividad. La motivación intrínseca es muy importante para el desarrollo cognitivo y social del niño; y además, según Romero Ayuso (2006), este correcto desarrollo motivacional es la principal fuente de exploración y curiosidad a lo largo de la vida.

Por todo ello, cada vez es mayor el interés por saber el papel que juega la motivación en los niños con TDAH. Es importante adoptar una visión global para la explicación del trastorno y deben incluirse factores afectivos, emocionales y sociales que inciden en su desarrollo. En esta línea, algunas investigaciones como las de Miranda (2002) o Keown y Woodward (2002), señalan que el contexto familiar tiene un papel fundamental en el curso del TDAH.

La disfunción familiar puede constituir un factor de riesgo que interactúa con la predisposición del niño, y exacerbar la presentación de los síntomas y su continuidad, (Miranda García, 2002). En este marco, los factores familiares no se consideran como la causa original del TDAH, pero sí se cree que mantienen e incluso amplifican la sintomatología de éste en el curso del desarrollo. En esta línea, Keown y Woodward, (2002), han tratado de analizar las variables predictoras de los problemas conductuales de los niños hiperactivos, a partir del análisis de las relaciones de los padres con sus hijos hiperactivos en edades tempranas en comparación con las relaciones padres-niños sin TDAH. Los resultados obtenidos de diversos estudios indican que los padres de los niños hiperactivos utilizan prácticas disciplinarias laxas, tienen menos comunicación con sus hijos y, además, hay una menor sincronía en las interacciones madre-hijo. Los hallazgos en el estudio de Miranda (2002), sugieren que la forma en que interactúan los padres con sus hijos hiperactivos en edades preescolares es precursora del desarrollo de dificultades de comportamiento experimentado por los niños hiperactivos en edades posteriores.

\section{Causas del TDAH}

\section{Factores genéticos}

Actualmente los niños empiezan a manifestar los síntomas de hiperactividad e inatención a partir de los 3-4 años, estos se reducen en la adolescencia y persisten en la edad adulta, (García, 2009). Como consecuencia de un deficiente desarrollo embrionario o genético, los niños con TDAH manifiestan una gran dificultad para guiar sus conductas mediante autoinstrucciones y para frenar sus propias conductas inapropiadas.

Para ello, existen estudios, como ejemplo el de Clements (1966), que demuestran que el hecho de que la madre fume en el embarazo multiplica por tres el riesgo de que el bebé desarrolle TDAH en sus primeros años de vida. Igual ocurre con el consumo de alcohol y de otras drogas durante la gestación, que también puede tener otras repercusiones cognoscitivas en el desarrollo del niño. 


\section{Factores psicobiológicos}

Los datos sugieren que la mayor pendiente del gradiente de refuerzo podría explicar la impulsividad y la hiperactividad. Sagvolden y Sergeant (1998) consideran que éstas son consecuencias de una alteración en el intervalo del gradiente de refuerzo (intervalo entre respuesta y refuerzo), que tiene una pendiente más pronunciada de lo normal.

El suceso de un estímulo gratificante puede reforzar la conducta que lo acaba de preceder. Los estímulos reforzantes son más eficaces si siguen inmediatamente a una conducta: cuanto mayor sea el aplazamiento, menos eficaz será el refuerzo. Sagvolden y Sergeant (1998), sugieren que ciertas deficiencias de la transmisión dopaminérgica en sujetos con TDAH aumenta la inclinación de la pendiente de gradiente de refuerzo, lo que significa que el refuerzo inmediato es aún más eficaz en estos niños.

La mayoría de investigaciones señalan que el TDAH se debe a anomalías de una red neural de regiones cerebrales que incluyen el estriado (núcleo caudal y putamen) y la corteza prefrontal (que tiene conexiones recíprocas con el estriado). Otra región también implicada en pruebas cognoscitivas en adultos es la corteza cingulada anterior. Según Sagvolden y Sergeant (1998), esta región modula la selección de estímulos y media la selección de respuesta, desempeñando un papel central en el proceso de atención; además encontraron hipoactivación de estas estructuras en el cerebro de personas con TDAH mientras realizaban tareas que precisaban atención minuciosa y capacidad de inhibir una respuesta.

\section{Factores ambientales}

No puede olvidarse las interacciones que operan entre los factores orgánicos y ambientales.

Según Miranda y Soriano (2010), la sociedad ha experimentado en este siglo cambios sociales radicales que han creado unas condiciones sociales que intensifican los síntomas del TDAH. Por ejemplo, el trabajo sedentario que exige una atención mental prolongada, la gratificación instantánea que proporciona la tecnología electrónica, las altas tasas de divorcios y familias no normativas, y el estrés que supone para las familias el ejercicio profesional de ambos padres, entre otros.

Por lo tanto, la calidad de las relaciones familiares y la competencia parental pueden jugar un papel importante, no sólo en la probabilidad de remisión clínica, sino también en la severidad y comorbilidad del desorden, la respuesta al tratamiento y el pronóstico.

\section{Características del TDAH manifestadas en la conducta}

Entre otras características presentes en el TDAH, se enumeran a continuación las más comunes manifiestas en la conducta diaria en niños diagnosticados de este trastorno (Kerns, Mclnerney y Wilde, 2001):

1. Muestran una incapacidad muy limitante para la inhibición de conductas.

2. Presentan una actividad motriz incesante, inadecuada e inoportuna, que resulta inadaptativa. 
3. Significativa dificultad en el control de la atención: dificultades en atención sostenida, en atención selectiva y en la atención dividida.

4. Impulsividad y déficit en procesos de análisis y síntesis, primero actúa y después piensa.

5. Memoria de trabajo: presentan menor eficacia en la codificación de los estímulos. Se les cataloga de "olvidadizos" y de que "sólo viven en el presente" sin prestar atención a las consecuencias futuras.

6. Autorregulación de la motivación y el afecto: muestran intereses numerosos y dispares, pero de muy corta duración.

7. Internalización del lenguaje: facilita la guía y el control de la conducta, los alumnos con TDAH poseen retraso en ese aspecto.

8. Dificultades en el aprendizaje e inadaptación escolar, familiar y social: aumenta la tensión en la clase, la ansiedad en los maestros y el rechazo a estos alumnos. También en el hogar y en otras situaciones su incapacidad para el control ejecutivo les acarrea inadaptación.

Todas estas características influyen significativamente en el desempeño académico y social de los niños que presentan el trastorno. Tan importante son las características impulsivas como las hiperactivas, así como las que se refieren al control y guía de la conducta (derivadas de su déficit de atención). El niño/a diagnosticado o no de esta alteración manifiesta una incapacidad sustancial para adaptarse a un normal y adecuado desarrollo, lo que aumenta la posibilidad de que se presenten anomalías asociadas (tensión en la clase, ansiedad en los maestros, etc.).

\section{Métodos y estrategias para trabajar la motivación en alumnos con TDAH}

Como alternativa o complemento a los tratamientos farmacológicos, las intervenciones psicosociales constituyen opciones útiles para el manejo de los síntomas centrales del TDAH, así como para abordar los múltiples problemas asociados que presentan los niños con este trastorno.

Frente a las demandas escolares que presentan los niños con TDAH en el aula, se presentan algunas estrategias didácticas para regular la motivación y las emociones en estos niños.

Una de estas demandas es el interés por el aprendizaje, en el que el problema del niño es la poca o nula motivación intrínseca. Para ello, se proponen algunas estrategias didácticas, tales como (Angrino, Panesso y Valencia, 2010):

1. Promover la participación del niño en el aula (ayudante de la instrucción, escribir palabras claves en la pizarra, recoger cuadernos, borrar la pizarra, realizar juegos de roles, etc.).

2. Explicitar los objetivos de aprendizaje de cada actividad.

3. Relacionar los contenidos con los intereses del alumno.

4. Proponer metas a corto plazo.

5. Modificar frecuentemente las características de la tarea.

6. Proponer actividades que garanticen el éxito, evitando la frustración y el abandono.

7. Utilizar programas de economía de fichas y/o contratos de contingencia. 
Otra de las demandas escolares es el autocontrol emocional, en la que el problema del niño con TDAH es el insuficiente control de las emociones. Las estrategias didácticas que se proponen son (Klimenko, 2011):

1. El entrenamiento en habilidades sociales.

2. Proponer tareas que se ajusten a sus intereses.

3. Proponer tareas que desarrollen su responsabilidad.

4. Brindar feedback sobre sus emociones para que reflexione sobre sí mismo y sus conductas consecuentes.

Por último, la demanda del locus de control interno, en la que el problema del niño es el sesgo atribucional. Se proponen diversas estrategias didácticas, como por ejemplo (Klimenko, 2011):

1. Dar claves para que pueda controlar su entorno.

2. Brindar información constructiva sobre sus errores.

3. Procurar interacciones satisfactorias.

En consecuencia, hay que evitar hacer comentarios sobre conductas indicativas de falta de atención como "estás en las nubes" o dar órdenes como "no te distraigas con el lápiz". Es mejor suministrar al alumno claves verbales discriminativas que le animen a reflexionar sobre su forma de comportarse, como "¿estás terminando ya tu trabajo?". Cuando se equivoque será conveniente dar al niño una oportunidad para que pueda intentarlo otra vez, procurar que tenga éxito proporcionándole las ayudas necesarias y alabarle por ello (Siegenthaler, Herrero y Muñoz, 2011).

\section{Conclusiones}

La dificultad de encontrar una relación firme entre el TDAH y la motivación radica en que la mayoría de los estudios, como los de Sonuga-Barke (2005) o Mclnerney y Kerns (2001), sostienen la intervención de otros factores como atribuciones, locus de control, feedback, refuerzos, etc., además también ha influido la escasa relevancia que se le ha otorgado a la motivación en el estudio del TDAH, junto con la carencia de estudios desde sus comienzos en las distintas investigaciones.

Todo ello, manifiesta la necesidad de incluir la dimensión motivacional en los estudios sobre el trastorno con el fin de mejorar las estrategias utilizadas en los sujetos con TDAH, posibilitando así el aumento o mejora en el rendimiento escolar.

En definitiva, este trabajo justifica la importancia de nuevas investigaciones que incluyan la motivación como factor primordial en el rendimiento académico de niños con TDAH, la necesidad de intervenciones psicosociales para la población afectada y su entorno inmediato, priorizar estrategias de autocontrol en los alumnos como alternativa y/o complemento valioso a los psicofármacos. Además, cualquier tipo de intervención con niños de TDAH debe incluir no sólo una valoración de los componentes cognitivos, sino también de los psicosociales como el entorno social, el tipo de feedback verbal que reciben, tipo de tareas, fomento de competencias necesarias, establecimiento de reglas, autocontrol e integración social. 


\section{Bibliografía}

Angrino, S. O., Panesso, I. C., y Valencia, Á. I. (2010). Las situaciones de resolución de problemas como estrategia de trabajo con niños diagnosticados con TDAH. Pensamiento Psicológico, 2(7).

Ayuso, D. M. R. (2006). La motivación y el rendimiento ocupacional en niños con trastorno por déficit de atención con hiperactividad. Revista electrónica de terapia ocupacional Galicia, TOG, $(4), 8$.

Banaschewski, T., Hollis, C., Oosterlaan, J., Roeyers, H., Rubia, K., Willcutt, E., y Taylor, E. (2005). Towards an understanding of unique and shared pathways in the psychopathophysiology of ADHD. Developmental Science,8(2), 132-140.

Clements, S. D. (1966). Minimal Brain Dysfunction in Children: Terminology and Identification: Phase One of a Three Phase Project. Washington DC: US Department of Health, Education and Welfare.

Douglas, V. I. (1972). Stop, look and listen: The problem of sustained attention and impulse control in hyperactive and normal children. Canadian Journal of Behavioural Science, 4(4), 259.

García-Castellar R., Miranda-Casas A., Siegenthaler-Hierro R. y Jara-Jiménez, P. (2006). Impacto familiar de los niños con trastorno por déficit de atención con Hiperactividad subtipo combinado: efecto de los problemas de conducta asociados. PREV NEUROL 42 (3), 137-143.

Keown L.J. y Woodward L.J. (2002). Early parent-child relations and family functioning of preschool boy with pervasive hyperactivity. J Abnorm Child Psychol, 30, 541-53.

Kerns, K. A., Mclnerney, R. J., y Wilde, N. J. (2001). Time reproduction, working memory, and behavioral inhibition in children with ADHD. Child Neuropsychology, 7(1), 21-31.

Klimenko, O. (2011). La enseñanza de las estrategias cognitivas y metacognitivas como una vía de apoyo para el aprendizaje autónomo en los niños con déficit de atención sostenida. Revista Virtual Universidad Católica del Norte, 1(27).

Manassero, M. y Vazquez A., (1998). Validación de una escala de motivación de logro. Psicothema, 10(2), 333-351.

Miranda A., García R., Presentación MJ. (2002): Factores moduladores de la eficacia de una intervención psicosocial en niños con trastorno por déficit de atención con hiperactividad. Rev Neurol 34 (Supl 1): S91-7.

Miranda Casas, A. y Soriano Ferrer, M. (2010). Tratamientos Psicosociales Eficaces para el Trastorno por Déficit de Atención con Hiperactividad. Información psicológica, (100), 100-114.

Oosterland, J., Logan, G.D y Sergeant, J.A (1998). Response inhibition in AD/HD, CD, comorbid $A D / H D+C D$, anxious, and control children: A meta-analysis of studies with the stop task. Journal of Child Psychology and Psychiatry, 3, 411-425.

Siegenthaler, R., Herrero, P. y Muñoz, J. (2011). Estrategias didácticas inclusivas en TDAH.

Sonuga-Barke, E. J. (2005). Causal models of attention-deficit/hyperactivity disorder: from common simple deficits to multiple developmental pathways. Biological psychiatry, 57(11), 1231-1238.

Still, G. F. (1902). Some abnormal psychical conditions in children. Lancet,1(1008), 1077-1082. 


\section{LA MOTIVACIÓN EN LOS DIFERENTES CONTEXTOS EDUCATIVOS EN ALUMNADO DE EDUCACIÓN SECUNDARIA OBLIGATORIA}

Ceciliano Gil, Mirian; Feria Acosta, Laura; González Caracuel, Jenny y Orta Torilo, Soraya. Universidad de Huelva

\section{RESUMEN}

En el presente artículo realiza una revisión teórica sobre la importancia que ejerce la motivación en el aprendizaje de los alumnos de Educación Secundaria Obligatoria. En primer lugar, se realizará un breve análisis sobre los cambios, tanto físicos como psicológicos, que influyen en los adolescentes y en su motivación para aprender los contenidos teóricos y prácticos durante su estancia en el instituto. Posteriormente, se realizará un análisis sobre los factores que más influyen en esta motivación, tales como el profesor, los iguales y el contenido que se pretende enseñarles. Las conclusiones extraídas indican que las últimas reformas educativas se han centrado en potenciar la motivación académica y las calificaciones escolares de los estudiantes, sin profundizar en el conocimiento de la influencia que pueden tener los factores sociales o contextuales sobre la motivación en el ámbito escolar.

PALABRAS CLAVE: motivación, adolescentes, profesorado de secundaria, grupo de iguales, contenido curricular.

\section{INTRODUCCIÓN}

En el presente artículo se pretende realizar una revisión teórica de las influencias del profesorado, de los iguales y del contenido/tarea respecto a la motivación del alumnado de Educación Secundaria Obligatoria (ESO).

Dichas influencias, unidas a los cambios que se producen en la adolescencia, merecen mención; por ejemplo, se destacan los que se dan a nivel físico (comienza a salir el vello púbico, crecen las mamas de las chicas, se ensanchan las caderas, crece vello en la cara de los varones...); en definitiva, se puede decir que sus cuerpos van madurando. Además, se deben destacar los cambios psicológicos que se dan en estos jóvenes (el sentido de la vergüenza se agudiza en la adolescencia, dan más importancia lo que otras personas piensen de ellos, etc.) ya que, debido a los requerimientos académicos, tienen que madurar cognitivamente, además de los cambios físicos mencionados anteriormente.

Así, se destaca a estas edades, sobre todo al inicio de la adolescencia, los cambios que se dan en las relaciones que mantienen con otras personas, puesto que antes eran más intensas con los familiares, y ahora comienzan a ser los amigos las personas más importantes para ellos y, por tanto, también son vitales las influencias que ejercen estos en el plano académico. Además, con el paso del colegio al instituto también se producen cambios en relación a los contenidos, puesto que éstos van siendo cada vez más y a la vez más complejos. Por otro lado, los profesores son diferentes y cada docente le da por lo general una asignatura, por lo que se deben adaptar a las exigencias y requerimientos de cada docente lo cual exige, por parte de los alumnos, una capacidad de adaptación considerable. 
Dichos profesores, puede ejercer alguna influencia en la motivación que tengan los alumnos sobre el contenido, ya que puede adaptar éste a las necesidades y preferencias de los adolescentes, en la medida de lo posible. Por ello, se parte de la idea de que dichos profesores deben tener ciertas habilidades para ejercer su práctica diaria y que ésta sea lo más efectiva posible. La mayoría de estas habilidades pueden adquirirse, a pesar de que no se debe olvidar la influencia de ciertas características de personalidad.

Los cambios que se dan en los adolescentes y que fueron nombrados anteriormente, influyen en el contenido, la relación con los iguales y la influencia del profesor puesto que, al variar el contenido y la forma de presentación del mismo, así como las habilidades que tiene el docente para hacer frente y los hábitos de sus iguales, se verá de forma diferente según si los alumnos han sufrido cambios tanto físicos como psíquicos.

\section{Influencia de profesores en la motivación de los alumnos}

Los profesores desempeñan un rol fundamental en la educación. Hoy en día, para ser un buen profesor, no basta con poseer determinados conocimientos y divulgarlos, sino que un buen profesional de la educación ha de saber aplicarlos. Además, ha de estar dotado de una serie de características personales (comunicación interpersonal, asertividad, técnicas de habilidades sociales, etc.) y de habilidades docentes (métodos o estrategias de enseñanza) que favorezcan el desarrollo de su trabajo (Román, 2008).

En definitiva, el profesor que posee cualidades humanas apropiadas para la enseñanza consigue que sus alumnos estén más motivados (Bernardo, 2004). Según Bernardo (2004), algunas de las habilidades y/o competencias del profesor que facilitan la motivación del alumno son las siguientes:

- La atmósfera interpersonal de comunicación en la que se desenvuelve la tarea ha de permitir al alumno sentirse apoyado cálida y honestamente, respetado como persona y capaz de dirigir y orientar su propia acción.

- Conviene utilizar, cuando sea necesario, la represión en privado, la conversación particular amistosa y los factores positivos que animen al alumno. Son más eficaces unas palabras de ánimo, la confianza en las posibilidades de rectificación y el reconocimiento de los aspectos positivos en la conducta y en el trabajo del alumno que los castigos.

- El profesor a de mostrar interés por cada alumno; por sus éxitos, dificultades, planes, etc., y hacer que él lo note.

- El elogio es útil si surge de un modo espontáneo y se dirige a un trabajo o esfuerzo concreto.

- Por otra parte, los alumnos declaran sentirse más motivados por el profesor que prepara cuidadosamente sus clases, sabe organizar el trabajo, exige de forma razonable un rendimiento proporcionado, revisa las tareas y corrige a tiempo los exámenes, etc..

En conclusión, es esencial la mejora y formación de las características personales y habilidades sociales del profesorado para que éstos puedan ejercer de forma adecuada su actividad como docente. 


\section{Motivación de los alumnos en función de sus iguales}

Por medio de la interacción social los niños aprenden normas de conducta, actitudes, comportamientos deseados por la sociedad y aquellos instrumentos culturales necesarios para una buena adaptación al escenario socio-cultural en el que el niño se halla inmerso (Rogoff, 2003). El desarrollo social se halla intrínsecamente relacionado con el desarrollo cognitivo a lo largo de todo el ciclo vital.

En este sentido, para los adultos la amistad no es una relación unilateral en la que una persona es atraída por otra, sino implica satisfacción psicológica mutua caracterizada por la comprensión de los sentimientos y pensamientos de ambas personas, por el cuidado físico y psíquico entre los seres humanos implicados en la relación, por una comunicación íntima y sincera, por tener unas expectativas de reciprocidad en relación a los valores fundamentales de las relaciones humanas y por una estabilidad a lo largo del tiempo que trasciende los conflictos ocasionales (Damon, 1977). Todos estos aspectos que constituyen lo que es una verdadera amistad, hacen que estas relaciones sean muy valoradas y gratificantes para los seres humanos, por lo que una ruptura podría incidir muy negativamente en el desarrollo social y personal del individuo.

Damon (1989) distingue tres tipos de aprendizaje entre iguales que se diferencian, a su vez, por el grado en el que se dan dos dimensiones de la interacción: igualdad y compromiso mutuo. La igualdad hace referencia al grado de simetría que se establece entre los participantes de una situación social. Sin embargo, el compromiso mutuo alude al grado de conexión, bidireccionalidad y profundidad de las conversaciones que se establecen en la participación. Tipos de aprendizaje según Damon (1989):

- Relación de tutoría. Lo esencial de esta relación es que un niño, que puede considerarse experto, instruye a otro que puede ser considerado un novato.

- Aprendizaje cooperativo. Este entorno se caracteriza porque el grupo es heterogéneo en habilidad y los niños pueden asumir diferentes papeles.

- Colaboración entre iguales. Existe un mayor grado de mutualidad e igualdad. Las relaciones que se establecen son, generalmente, simétricas y se caracterizan por una alta igualdad y mutualidad.

Actualmente, nadie duda que no sea posible comprender y analizar el desarrollo humano sin aludir al contexto social donde se desenvuelven los seres humanos.

\section{Influencia del contenido curricular sobre la motivación.}

El contenido curricular y su estudio son de vital importancia, puesto que se sabe que influye directamente en el rendimiento y resultados en los alumnos, al igual que en los resultados como educador del profesor. Por ello, se debe conocer cómo se da este proceso en la enseñanza-aprendizaje, en la relación de feedback entre profesor y alumno.

Así, Junco, (2010) se centra en las cualidades del contenido como modelador motivacional que dependerá de varios factores como:

- Si los contenidos curriculares en cantidad y nivel de dificultad son adecuados, lo que facilitará el sentimiento de control del alumno para la asimilación del contenido. 
- Si los contenidos curriculares están ubicados dentro de un contenido global o más amplio facilitará la activación y localización de conocimientos previos para un aprendizaje significativo.

- Si los contenidos son novedosos, sorprendentes y variados generará en el alumno un interés y curiosidad por el nuevo contenido.

- Si son contenidos curriculares sensorialmente atractivos y acordes a las características del aprendiz despertarán interés exploratorio y curiosidad por aprender.

- Relacionar las actividades con la vida diaria para que vean el por qué y la utilidad de su estudio. La mayor parte de los alumnos no entienden para qué se estudian la mayoría de los contenidos de una materia. Esto crea el desánimo y la falta de interés por aprenderlos. Para que el alumno se sienta motivado hacia el aprendizaje de estos contenidos se le deben presentar de manera atractiva y relacionada con situaciones de la vida cotidiana.

Por ello, si se tienen en cuenta estos factores influyentes en la motivación del alumnado, a través del contenido se conseguirá que estos tengan mejores resultados y que las técnicas del profesorado puedan mejorarse. Además, el aprendizaje será constructivo para su futuro personal, social o educativo y no una simple tarea de memorizar.

\section{CONCLUSIONES}

Es vital que tanto los contenidos curriculares dados en clase como la docencia que realiza el profesor estén encaminados a crear alumnos competentes, en el plano académico, y en otros ámbitos de su vida. En este sentido, los alumnos prosociales puntúan significativamente más alto en metas de aprendizaje y logro. Así, es enorme la influencia recíproca del ámbito escolar y socio-familiar donde Wentzel (2005) establece, que las metas académicas y sociales de los estudiantes están relacionadas y la coordinación de estas contribuye de manera significativa al éxito escolar.

En lo referente a la importancia de los docentes en la práctica educativa, todos estos deben dedicar tiempo y esfuerzo suficiente para que los alumnos de este nivel educativo empiecen a convertirse en hábiles estudiantes; se les facilite la adquisición de las estrategias básicas del estudio, que contribuyan al desarrollo de un adecuada motivación y estrategias de aprendizaje, antes de que su rendimiento potencial se vea mermado por el desconocimiento o la falta de aplicación de dichas estrategias y motivaciones (Maquillón, 2011).

Por otro lado, las sucesivas reformas educativas realizadas durante las últimas décadas se han centrado en la motivación académica y en las calificaciones escolares de los estudiantes de ESO sin profundizar en el conocimiento relativo a la influencia que pueden tener diversos factores sociales o contextuales sobre las mismas. La existencia de interrelaciones entre el comportamiento prosocial y la motivación escolar, (Cándido, 2010) confirma lo argumentado por otros autores, quienes indican que la comunidad educativa debería atender a una variedad de factores interpersonales, incluyendo el establecimiento de relaciones sociales positivas o prosociales con los iguales, además de seguir enfatizando sobre diversas variables intrapersonales como la motivación escolar y el rendimiento académico (Pintrich, 2003). Dichas reformas educativas están sometidas a la realidad que establezca en Espacio Europeo de Educación Superior (EEES). 
En conclusión, se puede decir que pretende crear alumnos competentes socialmente, y no alumnos reproductores de lo que hicieron otros en el pasado.

\section{BIBLIOGRAFÍA}

Alonso Tapia, J. (2012). Differences between Immigrant and NationalStudents in Motivational Variables and Classroom-Motivational-Climate Perception. The spanish journal of psychology, 15 (1), 61-74.

Bernardo Carrasco, J. y Basterretche Baignol (2004). Técnicas y recursos para motivar a los alumnos. Madrid: Rialp, S.A..

Blumen S. (2008). Motivación sobredotación y talento: un desafío para el éxito. Revista de Psicología, 21 (1).

Carbonero M.A.; Martín-Antón L.J.; Román, J.M. y Repyo, N. (2010). Efecto de un programa de entrenamiento al profesorado en la motivación, clima de aula y estrategias de aprendizaje de su alumnado. Revista Iberomamericana de psicología y salud, 1 (2), 117-138.

García Bacete F.J. y Doménche Betoret, F. (2002). Motivación, aprendizaje y rendimiento escolar. Revista electrónica de motivación y emoción, 1 (6).

Inglés, C.J.; Martínez-González, A.E.; Valle, A.; García-Fernández, J.M. y RuizEsteban, C. (2010). Conducta prosocial y motivación académica en estudiantes españoles de Educación Secundaria Obligatoria. Universidad psychology, 10 (2), 451465.

Junco Herrera, I. (2009). La motivación en el proceso enseñanza-aprendizaje. Revista digital para profesionales de la enseñanza, 9, Julio 2009.

López Muñoz, L. (2004). La motivación en el aula. Pulso, 27, 95-107.

Maquillón Sánchez, J.J. y Hernández Pina, F. (2011). Influencia de la motivación en el rendimiento académico de los estudiantes de formación profesional. REIFOP, 14 (1), 81-100.

Mingorance Muley, A. (2010). ¿Cómo motivar al alumnado?, Revista digital innovación y experiencias educativas, 4.

Navarrete Ruiz de Clavijo, B. (2009). La motivación en el aula. Funciones del profesor para mejorar la motivación en el aprendizaje. Revista digital innovación y experiencias educativas, 15.

Román, J.M. (2008). Psicología de la instrucción. Valladolid. Universidad de Valladolid: Departamento de Psicología. 


\title{
DISCRIMINACIÓN RACIAL DENTRO DEL ÁMBITO UNIVERSITARIO. UN ENFOQUE SOBRE LA DISCRIMINACIÓN SUTIL Y MANIFIESTA
}

\author{
Lara Guardia, Gracia Nacarí. Universidad de Granada
}

\section{RESUMEN}

El objetivo de este estudio es analizar el tipo de discriminación o prejuicio que se produce a nivel racial, en una muestra de 80 estudiantes universitarios de Granada de $5^{\circ}$ curso de psicopedagogía. Para ello utilizamos las escalas de prejuicio sutil y manifiesto de Pettigrew y Meertens, adaptadas al español por Rueda y Navas. Los resultados indican que el prejuicio racial que se produce a nivel sutil en este colectivo es superior (media $=258,2$ ), al prejuicio que se produce a nivel manifiesto (media= 231,2). Asimismo demuestran como el porcentaje de sujetos improbables (con unas puntuaciones altas en prejuicio manifiesto y bajas en prejuicio sutil) fue bajo (25\%), el porcentaje de sujetos sutiles (con unas puntuaciones altas en prejuicio sutil y bajas en prejuicio manifiesto) fue muy alto $(66,25 \%)$, y el porcentaje de sujetos igualitarios (con igual puntuación en el prejuicio sutil y manifiesto) fue muy bajo $(8,75 \%)$.

PALABRAS CLAVE: Discriminación; discriminación racial; prejuicio sutil; prejuicio manifiesto.

\section{INTRODUCCIÓN}

La palabra discriminación hace referencia a un término polisémico en el que se distingue una amplia variedad de significados, en función del aspecto discriminatorio al que se refiere (político, social, económico, racial, etc.), o del tipo de discriminación existente (positiva, negativa, directa, indirecta, etc.). Por ello se va a considerar, a nivel general, la definición de discriminación aportada en el año 2003 por la Ley Federal para Prevenir y Eliminar la Discriminación de los Estados Unidos Mexicanos, según la cual la discriminación hace referencia a toda distinción, exclusión o restricción que, basada en el origen étnico o nacional, sexo, edad, discapacidad, condición social o económica, condiciones de salud, embarazo, lengua, religión, opiniones, preferencias sexuales, estado civil, o cualquier otra, tenga por efecto impedir o anular el reconocimiento o ejercicio de los derechos, e igualdad de oportunidades de las personas. Y, a nivel más específico, se va a considerar la definición de discriminación de tipo racial, que nos ocupa lugar en esta investigación. Para ello, se va a tener en cuenta la definición aportada por la Convención Internacional sobre la Eliminación de todas las formas de Discriminación Racial de la ONU del año 1969, según la cual la discriminación racial se refiere a toda distinción, exclusión, restricción o preferencia basada en motivos de raza, color, linaje u origen nacional o étnico que tenga por objeto o por resultado anular o menoscabar el reconocimiento, goce o ejercicio, en condiciones de igualdad, de los derechos humanos y libertades fundamentales en la esfera política, económica, social, cultural, o cualquier otra esfera de la vida pública. Esta Convención, además, estableció el día 21 de Marzo, como el día Internacional de la eliminación de la discriminación racial.

No cabe duda, como afirma la directiva 2000/43/CE del consejo de 29 de Junio de 2000 relativa a la aplicación del principio de igualdad de trato de las personas independientemente de su origen racial o étnico, en el Diario Oficial de las 
comunidades Europeas, que para garantizar el desarrollo de unas sociedades democráticas y tolerantes en las que toda persona pueda participar, con independencia de su origen racial o étnico, la actuación específica en el ámbito de la discriminación por estos motivos debe ir más allá del acceso a la actividad por cuenta propia o ajena, y abarcar ámbitos como la educación, la protección social, incluida la seguridad social, y la asistencia sanitaria, las ventajas sociales, la oferta de bienes y servicios, y el acceso a los mismos.

España es un país que recibe un elevado número de inmigrantes y personas de distinta procedencia cada año, por lo que el tema de la multiculturalidad es muy común actualmente, en las instituciones tanto académicas como profesionales. La convivencia y el trabajo diario con personas que tienen distinta nacionalidad, cultura y/o religión, ha incrementado el porcentaje de casos de prejuicios, discriminación, y estereotipos, como consecuencia del gran número de conductas segregadoras y conflictos intergrupales que se originan entre las personas.

Un estudio realizado por el Consejo para la promoción de la igualdad de trato y no discriminación de personas por su origen racial o étnico, en el año 2012, para detectar los incidentes discriminatorios producidos en España, ha demostrado cómo en el año 2011 hubo un aumento del $67 \%$ en el número de casos de discriminación racial o étnica, en relación a los producidos en el año 2010. Además de demostrar cómo los incidentes discriminatorios que se producen a nivel individual, están dirigidos principalmente a personas de origen magrebí, etnia gitana, origen sudamericano andino, y subsahariano; mientras que los incidentes discriminatorios a nivel colectivo, están centrados en las personas de etnia gitana, personas de cualquier origen distinto al español, o de cualquier origen extranjero no comunitario. Por ello, es importante tener en cuenta la relación existente entre los estereotipos, los prejuicios, y la discriminación, defendida por Fiske (1998) y Huici (1999) a través de una concepción tripartita clásica sobre las actitudes, en la que se distinguen tres componentes básicos: el cognitivo, el afectivo y el conductual. De modo que, el conjunto de creencias sobre las características que se asignan a un grupo corresponde con la parte cognitiva 0 estereotipo; el afecto y/o la evaluación con el prejuicio; y el comportamiento con la discriminación.

Centrándonos en la discriminación que se produce en el ámbito universitario, como es la de tipo racial, producida por la presencia de pensamientos y numerosos actos infundados en una ideología racista, por cuestiones étnicas, de color de piel, lengua, o pertenencia a una minoría nacional, se puede decir, que es un hecho que queda al descubierto no sólo en la relación existente entre los alumnos/as, sino también en la relación entre el profesorado y los alumnos/as, o entre éstos y el personal de la institución, como afirma Anna Bermeo (2008) dentro de su blog Medio Ambiente y Periodismo. Esta autora habla, además, de discriminación en el alumnado cuando éstos son vulnerados en sus derechos por docentes prepotentes que tergiversan el contexto de observaciones críticas, y justifican sus acciones con libertad de cátedra; cuando éstos se ven en la necesidad de reclamar una ausencia de tutorías guiadas o una existencia de evaluaciones incongruentes; cuando éstos deben pedir algún tipo de información a unas coordinadoras prepotentes, y profesionales incompetentes; cuando éstos ven vulnerado su derecho de opinión y de expresión; cuando a éstos se le prohíbe su inscripción en alguna propuesta educativa de la institución, etc.

Dentro de la universidad también, según consta en algunas de las investigaciones realizadas sobre el racismo, tales como "Las escalas de prejuicio manifiesto y sutil: ¿una o dos dimensiones?" (2006), y "Actitudes de una muestra de estudiantes de la región de Murcia hacia los inmigrantes magrebíes" (2005), se ha demostrado cómo la 
discriminación que se realiza dentro de este ámbito, ha pasado de ser una forma de expresión directa y manifiesta de los prejuicios, a ser mucho más indirecta, sutil, y encubierta. Antonio Álvarez (2005), defiende que el racismo parece estar asumiendo formas más difíciles de identificar en lo que se ha dado en llamar nuevo racismo, racismo simbólico o criptorracismo, supuesto en el que el desprecio étnico y el desprecio racial opera de un modo implícito o inconsciente, según el cual el individuo trata de autojustificar su conducta discriminatoria negando expresamente su carácter racista. Los prejuicios basados en las características morfológicas se van sustituyendo por los más sutiles y asumibles argumentos culturales. De este modo se produce una cierta canalización del racismo socialmente inaceptable, al racismo socialmente permitido. Además, este tipo de discriminación, se caracteriza porque aún no procediendo de una práctica directamente prejuiciosa tiene como resultado una discriminación hacia un grupo concreto, como el que aquí presentamos, los grupos raciales. La directiva sobre Igualdad Racial (2000) defiende que este tipo de discriminación tiene lugar cuando una disposición, criterio, o práctica aparentemente neutro sitúe a personas de un origen racial o étnico concreto en desventaja particular con respecto a otras personas, salvo que dicha disposición, criterio o práctica pueda justificarse directamente con una finalidad legítima y salvo que los medios para la consecución de esta finalidad sean adecuados y necesarios.

\section{MÉTODO}

Este estudio se realizó durante el curso académico 2012/2013 en la Facultad de Ciencias de la Educación de la Universidad de Granada, con el objetivo de analizar el grado de discriminación racial, de tipo sutil y manifiesto, presente en el quinto curso de la licenciatura de psicopedagogía.

\section{Participantes}

En este estudio participaron voluntariamente 80 estudiantes (61 mujeres y 19 hombres) de $5^{\circ}$ curso de psicopedagogía de la Facultad de Ciencias de la Educación, de la Universidad de Granada. Se trata de una muestra bastante joven, cuyas edades oscilan entre 22 y los 35 años, con una media de 24,125 de edad.

\section{Instrumentos}

Para evaluar el grado de discriminación racial que, a nivel sutil y manifiesto, está presente en los estudiantes de quinto curso de psicopedagogía de la Universidad de Granada, se ha utilizado la escala de prejuicio manifiesto y sutil de Meertens y Pettigrew (1995), en la versión que Rueda y Navas (1996) han adaptado y validado al español. En nuestro estudio, hemos utilizado dos de los diferentes bloques de dicha escala. El primero permite obtener información de carácter general acerca de los sujetos de nuestra muestra (p.e., edad, sexo, estudios, y curso). El segundo presenta lo que constituye el núcleo central de la investigación: 20 ítems, de los cuales diez pretenden medir el prejuicio sutil (ítems $1,3,5,6,11,12,14,16,18$ y 19) y diez el prejuicio manifiesto (ítems $2,4,7,8,9,10,13,15,17$, y 20). Los sujetos evalúan cada ítem en una escala tipo Likert de 6 puntos, desde 1 (totalmente en desacuerdo) hasta 6 (totalmente de acuerdo).

Una de las modificaciones realizadas en este estudio, en relación a la escala de Meertens y Pettigrew, ha sido la sustitución de los conceptos de "magrebíes", "gitanos", y "negros", por el de "distinta raza", a nivel general. 


\section{Procedimiento}

Durante el curso académico 2012/2013 en la Facultad de Ciencias de la Educación (Granada), con el objetivo de analizar el grado de discriminación racial, a nivel manifiesto y sutil, se administró a los estudiantes de $5^{\circ}$ curso de la licenciatura de psicopedagogía, un cuestionario para que lo rellenaran de forma voluntaria. El mismo incluía las instrucciones específicas y necesarias para su adecuada cumplimentación.

\section{RESULTADO}

Para la presentación de los resultados que se han obtenido en esta investigación se ha utilizado el programa de Microsoft Excel. A través del mismo se ha recogido las respuestas de los 20 ítems, que cada uno de los 80 participantes ha otorgado, y se ha calculado, por un lado, la media de los ítems que evalúan el prejuicio sutil $(1,3,5,6$, $11,12,14,16,18$ y 19) y, por otro, la media de los ítems que evalúan el prejuicio manifiesto $(2,4,7,8,9,10,13,15,17$, y 20$)$.

Los resultados obtenidos demuestran como la media obtenida de aquellos ítems que evalúan el prejuicio de tipo sutil es algo superior $(258,2)$, a la media obtenida de los ítems que evalúan el prejuicio de tipo manifiesto $(231,2)$. Los resultados pueden observarse en la tabla de la media, y en el gráfico comparativo.
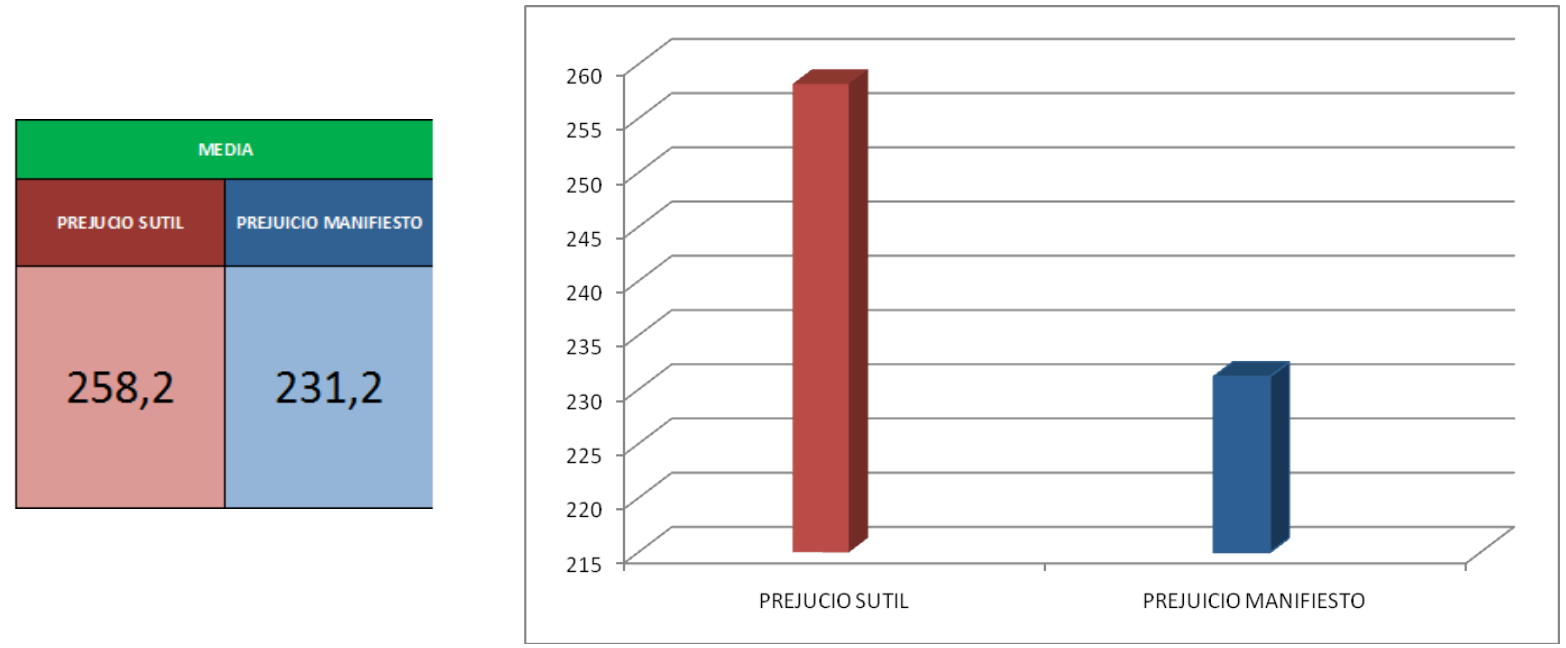

A través de la combinación de las puntuaciones de los sujetos en ambas escalas (altas o bajas), y siguiendo las directrices de Pettigrew y Meertens, construimos la tipología de sujetos. Como era de esperar, el porcentaje de sujetos improbables (puntuaciones altas en racismo manifiesto y bajas en racismo sutil) fue bajo, $25 \%$. Cabe destacar que el mayor grupo de sujetos $(66,25 \%)$ se sitúa en la casilla de sutiles. Los sujetos igualitarios constituyeron un $8,75 \%$. 


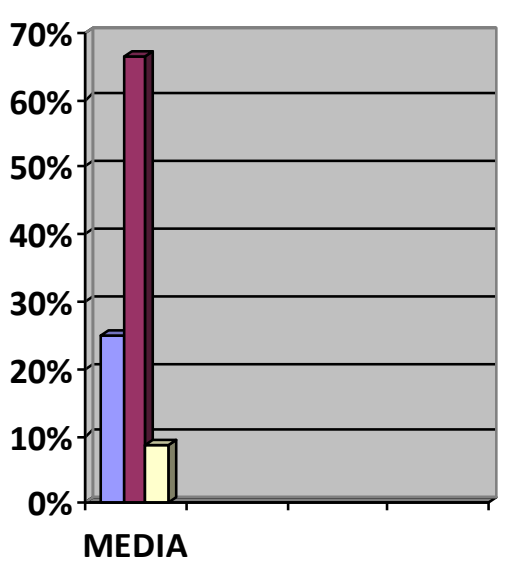

$\square$ Sujetos improbables

(puntuación alta en prejuicio manifiesto y baja en sutil)

$\square$ Sujetos sutiles (puntuación alta en prejuicio sutil y baja en manifiesto)

$\square$ Sujetos igualitarios (misma puntuación en prejuicio sutil y manifiesto)

\section{CONCLUSIONES}

Los resultados obtenidos en esta investigación han demostrado cómo el prejuicio o la discriminación racial que se produce a nivel sutil entre los estudiantes de $5^{\circ}$ curso de psicopedagogía es ligeramente superior a la que se produce a nivel manifiesto. Esto se debe, fundamentalmente, a que los estudiantes prefieren expresar sus creencias e ideas acerca de otras personas o colectivos, de una forma más suavizada, de manera que no se haga evidente su posición o concepción racista.

\section{REFERENCIAS BIBLIOGRÁFICAS}

Alonso, B. (2003). El principio de no discriminación por origen racial o étnico en la Unión Europea: su aplicación al empleo y a la política social. Revista de derecho de la Unión Europea, 5, 127-141.

Álvarez, A. (2005). Géneros o categorías humanas y discriminación racial en el trabajo. La igualdad ante la ley y la no discriminación en las relaciones laborales: XV Congreso Nacional de Derecho del Trabajo de la Seguridad Social, Lleida 28 y 29 de Mayo de 2004, págs. 87-112.

Blog Medio Ambiente y Periodismo (19 de Julio de 2008). Discriminación en las universidades. Revisado el día 30 de Abril de 2013 desde Internet: http://medioambienteyperiodismo.blogspot.com.es/2008/06/discriminacin-en-lasuniversidades.html

Convención Internacional sobre la eliminación de todas las formas de discriminación racial (4 de Enero de 1969). Revisado el día 5 de Mayo de 2013 desde Internet: http://www2.ohchr.org/spanish/law/cerd.htm

Diario oficial de la federación (11 de Junio de 2003). Ley federal para prevenir y eliminar la discriminación. Revisado el día 5 de Mayo de 2013 desde Internet: http://www.diputados.gob.mx/LeyesBiblio/pdf/262.pdf 
Diario oficial de las Comunidades Europeas (29 de Julio de 2000). Directiva 2000/43/CE del consejo de 29 de junio de 2000 relativa a la aplicación del principio de igualdad de trato de las personas independientemente de su origen racial o étnico. Revisado el día 28 de Abril de 2013 desde Internet: http://eurlex.europa.eu/LexUriServ/LexUriServ.do?uri=OJ:L:2000:180:0022:0026:es:PDF

Echeverría, R., y Flores, M. (2012). Diseño y evaluación de una escala de creencias estereotípicas sobre dos grupos estigmatizados socialmente. Enseñanza e investigación en psicología, 17, (2): 343-359.

Espelt, E., Javaloy, F., y Cornejo, J. M. (2006). Las escalas de prejuicio manifiesto y sutil: ¿una o dos dimensiones? Anales de psicología, 22 (1): 81-88.

Garganté, S., Pajares, M., Cachón, L., y Egenberger, V. (2003). La discriminación racial. Propuestas para una legislación antidiscriminatoria en España. Barcelona: Icaria Editorial, S. A.

Itxaro, J. (2011). Discriminación racial y de origen étnico en la Europa de los derechos. Revista de Derechos fundamentales, 6, 71-116.

Mesa, G. (2004). Estándares internacionales sobre no discriminación (conferencia), Bogotá.

Ministerio de Sanidad, Servicios Sociales, e Igualdad (20 de julio de 2012). Red de centros de asistencia a víctimas de discriminación por origen racial o étnico. Memoria anual de resultados 2011. Revisado el día 5 de Mayo de 2013 desde Internet: http://www.igualdadynodiscriminacion.org/recursos/publicaciones/2012/documentos/20 12_informe_red_11.pdf

Navas, M., García, M. C., Rojas, A. J., Pumares, P., y Cuadrado, I. (2006). Actitudes de aculturación y prejuicio: la perspectiva de autóctonos e inmigrantes. Psicothema, 18, (2): 187-193.

Pettigrew TF, Meertens RW. Subtle and Blatant prejudice in Western Europe. European Journal of Social Psychology 1995; 25: 57-75.

Rodríguez, J. (2005). Definición y concepto de la no discriminación. El cotidiano, 21, (134): 23-29.

Rueda JF, Navas M. Hacia una evaluación de las nuevas formas del prejuicio racial: las actitudes sutiles del racismo. Revista de Psicología Social 1996; 11 (2): 131-149.

Sánchez, M. M., Campillo, M. J., Illán, S., Llor, L., y Ruiz, J. A. (2005). Actitudes de una muestra de estudiantes de la región de Murcia hacia los inmigrantes magrebíes. Enfermería Global, 7, 1-9.

Viveros, M. (2007). Discriminación racial, intervención social, y subjetividad. Revista de estudios sociales, 27, 106-121. 


\section{EL PAPEL DE LA MUJER EN EL FRANQUISMO Y EN LA DEMOCRACIA. ANÁLISIS COMPARATIVO ENTRE ÉPOCAS}

Ma Pilar Garrido Cárdenas, Mª Lina Higueras Rodríguez. Universidad de Granada

\section{Resumen}

El papel de la mujer en España ha ido cambiando de una manera significativa a lo largo del siglo XX, sobre todo precedido por los cambios históricos que han ido sucediendo en este país durante dicho período. Nuestro trabajo se centra en la comparación entre dos épocas que han sido muy significativas en España como son el franquismo y la democracia. En estos períodos se pueden ver claramente el cambio del papel de la mujer con respecto a la sociedad. Se ha analizado para ello varios libros y manuales de distintas editoriales y autores de ambas épocas para proceder a un análisis comparativo. Las conclusiones nos llevan a afirmar que el papel de la mujer ha sido reconocido durante el período de la transición, ya que como se ha podido comprobar el papel de la misma durante el régimen franquista, era secundario y estaba ligado siempre a la figura del hombre.

Palabras Clave: Igualdad de oportunidades, Democracia, Libro de texto, Estereotipos.

\section{Introducción}

La igualdad de los derechos y deberes entre los ciudadanos es básica para un libre desarrollo personal basado en la equidad. Gracias a esto, la mujer puede introducirse en la sociedad con las mismas oportunidades que los hombres. Estos aspectos son tan básicos para el desarrollo de la sociedad, que aparecen reflejados en las leyes universales como por ejemplo la Declaración Universal de los Derechos Humanos.

La Declaración Universal de los Derechos Humanos adoptada por las Naciones Unidas en 1948, reúne que todos los derechos son considerados básicos para todas las personas. Los Derechos Humanos son considerados como las facultades, libertades y reivindicaciones inherentes a cada persona por el solo hecho de su condición humana. Esto quiere decir que se trata de derechos inalienables (nadie, bajo ningún concepto, puede privar de estos derechos a otro sujeto más allá del orden jurídico existente) e independientes de cualquier factor particular (raza, nacionalidad, religión, sexo, etc.).

En contraste con la actual legislación, nos encontramos con una serie de fueros y leyes proclamados por el dictador Francisco Franco, en los cuales excluía a la mujer de todo tipo de actividades, con el fin de mantenerlas en un papel sumiso donde eran las encargadas del mantenimiento de la casa y del cuidado de sus hijos. Como podemos comprobar, existían diferentes revistas donde se mostraban los pasos que debía de seguir una mujer para cumplir su rol: sumisión, estar guapa para el marido, saber comportarse, así como complacerlos en todo.

Durante el tiempo que duró la dictadura, a las mujeres se les fueron suprimiendo todos los derechos que habían conseguido con la constitución promulgada en 1931, en la cual a la mujer se le había otorgado un papel igualitario con respecto al hombre, así como el derecho al voto. Uno de los primeros fueros promulgados fue el de Trabajo en 
1938, donde a las mujeres casadas se les negaba el derecho al mercado laboral. Únicamente, podían trabajar las mujeres solteras o viudas sometidas a los varones.

Estas leyes se mantuvieron vigentes hasta 1976 con la Ley de las Relaciones Laborales, ya que con la muerte de Franco y el fin de la dictadura, surgió un gran avance en el papel que desempeñaba la mujer dentro de la sociedad. Según la Declaración Universal de Derechos Humanos dice que "cualquier persona puede prevalerse de todos los derechos y libertades proclamados en la presente Declaración sin distinción de sexo..."

El derecho de la mujer a no ser discriminada expone principios de igualdad de derechos y respeto de la dignidad humana. Lo que se pretende con esto, es que la mujer en las mismas condiciones que el hombre, participe en la vida política, social, económica, y cultural, lo cual constituye un elemento para el aumento del bienestar de la sociedad.

Existen muchos estudios sobre el papel de la mujer en la época franquista. La Sección Femenina desempeñaba un importante papel asistencial y educativo, difundiendo entre las mujeres normas de higiene y de puericultura y diversos oficios, por medio del Servicio Social, teóricamente obligatorio. También rescataba el folclore de todas las regiones, en trance de perderse por las modas modernas. Su máxima dirigente, Pilar Primo de Rivera, indicaba en una circular, apenas terminada la guerra, que "las mujeres van a ser más limpias, los niños más sanos, los pueblos más alegres y las casas más claras". Declaradamente anti feminista, la Sección Femenina propugnaba para la mujer el deporte, la profesionalización y la entrada en la universidad, tratando de hacerlo compatible con su función de madre y ama de casa. Creó Escuelas de Hogar, centros de divulgación sanitaria, cátedras ambulantes, etc. (Moa, 2007)

En la actualidad, numerosos autores afirman que no hemos logrado aún una equidad total en los roles entre hombres y mujeres. La actualidad en España adolece, como otros países de Europa y Norteamérica, de una reacción negativa contra el feminismo y la percepción errónea de que las mujeres han logrado la igualdad. (Cruz y Zecchi, 2004)

Si nos ubicamos en los actuales libros de texto, se puede observar un gran cambio con respecto a los publicados en la época franquista, ya que en la actualidad se centran mucho más en la definición de igualdad y equidad como se comprobará más adelante.

\section{Análisis comparativo de los libros de texto en ambas épocas}

Para el estudio comparativo entre ambas épocas se procedió a analizar varios libros y manuales de texto procedentes de uno y otro período. Los libros donde se pueden observar las diferencias más notorias en el rol de la mujer son, con respecto a la época franquista: La española cuando besa (Otero, 1999), Convivencia social (Werner, C. 1958) y Nociones de urbanidad para niñas (Pascual, 1937). Con respecto a la época que concierna a la Democracia, se hace referencia a libros de texto de distintas asignaturas y de distintas editoriales como son Educación para la ciudadanía (VVAA, Ed. Everest y Ed. laberinto), Lengua y Literatura (VVAA, Ed. Guadiel) e Historia y ciencias sociales (VVAA, Ed. Anaya) 
En primer lugar, se comprueba que se ha avanzado mucho en el trato igualitario hacia la mujer. La primera diferencia que se encuentra entre varias épocas es que tan solo en la portada de los libros analizados se puede observar que existe desde un principio el papel marginal de la mujer, por ejemplo el libro de "la española cuando besa" (Otero, 1999) muestra desde un principio lo que se trata en el libro, que son por ejemplo, actitudes y comportamientos que tiene que tener la mujer frente al hombre. Sin embargo, en los libros de la época actual, se observa cómo se pretende concienciar a la sociedad de hoy en día, que tanto la mujer como el hombre poseen los mismos derechos e igualdades en la sociedad. Un ejemplo de ello son los libros de educación para la ciudadanía, pues a partir del título se puede observar como la sociedad ha ido cambiando y como se debe de educar en igualdad.

En segundo lugar, se observa que los libros de la etapa franquista están divididos por lecciones, las cuales las niñas tenían que ir aprendiendo para comportarse de forma correcta según las condiciones de esta etapa. Sin embargo, en los libros actuales se fomenta la transversalidad a lo largo de todas las unidades didácticas aunque no se esté tratando de una forma directa el tema de la igualdad de oportunidades entre hombres y mujeres.

En tercer lugar, se encuentra otra diferencia en lo que respecta a las imágenes de los libros, pues en los manuales de la época franquista, se representa a la mujer como el ideal de familia, cuidando a la familia y realizando sus labores como ama de casa. Además en los pies de foto se utiliza la ironía, mostrando algún hombre haciendo las tareas de casa, cuidando a los niños, mujeres haciendo deporte, etc., mientras que en la etapa actual se puede observar hombres realizando las tareas que antiguamente sólo realizaban las mujeres, como por ejemplo planchar, limpiar, cocinar, etc. así como también, aparecen las mujeres ejerciendo trabajos propios del hombre como albañil, carpintera, informática, presidenta, etc.

Por último, en el lenguaje se halla desigualdad en la forma de expresión de ambas etapas. En la época franquista, los libros muestran un lenguaje estricto y severo, mostrándose en algunas ocasiones cómo las niñas debían de hablar a los mayores como si fuesen superiores, dirigiéndose a ellos por "usted" y hablándoles con mucho respeto. Sin embargo, los libros actuales no existen lenguaje discriminatorio ni sexista, tratando por igual tanto al hombre como a la mujer.

\section{Discusión tras el análisis}

El avance en el papel de la mujer a lo largo de estas décadas de democracia, ha sido más que notorio, ya que como se comprueba, en los libros de texto antiguos existía una gran diferenciación entre los manuales que estaban destinados para las mujeres y para los hombres, así como un lenguaje sexista en el que se daba importancia a la superioridad del hombre, dejando la figura de la mujer en un segundo plano.

Las imágenes que aparecían en estos manuales nos muestran al hombre como alguien luchador, valiente y fuerte que debía ser el encargado de sacar el país adelante. Mientras que la mujer aparecía en muchas fotos de espalda, o directamente no aparecía. Cuando lo hacía, siempre era acompañada de un hombre o realizando tareas del hogar, así como en el cuidado de sus hijos. En los libros de texto de la actualidad, sin embargo, se observa una gran evolución en el papel de la mujer. Aparecen por fin realizando tareas que antes estaban únicamente destinadas a los hombres, como por ejemplo, trabajos técnicos, estudios, tareas de bricolaje etc. 
Aunque este avance no es tan notorio como debería ser, ya que no en todas las materias aparece esta igualdad en el mismo grado, por lo que se puede afirmar que aún queda un largo camino por recorrer en el tema de la igualdad entre hombres y mujeres. En nuestra sociedad existe una serie de estereotipos falsos sobre la mujer, debido a que a lo largo de la historia, durante las guerras o en periodos de crisis, las mujeres han tenido un papel secundario en la sociedad de manera general y en el mundo del trabajo en particular. Desde los años veinte del pasado siglo, la mujer, poco a poco se ha ido introduciendo en la sociedad hasta ser un papel esencial en ésta. Pero en España, este avance, no se sucedió hasta la entrada de la democracia en el país, avanzando hacia la adquisición de una igualdad en el mundo cultural, jurídico y laboral con respecto al hombre. A pesar de todo esto, las mujeres saben que son capaces de valerse por ellas mismas, sin estar subordinadas a un hombre, y que existe una vida más allá de las tareas domésticas y del cuidado de los hijos.

\section{Referencias}

Arrufat, M. Grané, M. y Goméz, S (2002) Lengua y literatura. Ed. Guadiel. Barcelona. Baig, A.; Codina, S. (2007) Educación para la ciudadanía y los derechos humanos. Ed. Teide: Barcelona.

Bellido Cruz, L.; García Martín, S.; García Peña, J. (2007) Educación para la ciudadanía. Ed. Everest: León.

Burgos, M. Calvo, J. Jaramillo, M. Martín, S. (2006) Historia y ciencias sociales. ed. Anaya: Madrid.

Cruz, J y Zecchi, B (2004). La mujer en la España actual: ¿evolución o involución?. Ed. Icaria: Barcelona

Enciclopedia escolar en dibujos. Grado elemental (1945). Ed. Afrodísio Aguado: Madrid

Moreno, M. (1986) Cómo se enseña a ser niña: el sexismo en la escuela. Ed. Icaria: Barcelona.

Moa, P (2007) Años de hierro. ed. La esfera de los libros: Madrid.

Navarro Sustaeta, P.; Díaz Martínez, C. (2007) Educación para la ciudadanía. Madrid. Ed. Anaya.

Otero, L (1998) Mi mamá me mima. Ed. Plaza et Janés: Barcelona.

Otero, L (1999) La sección femenina. De cuando a la mujer española se le pedía ser hogareña, patriota, obediente, disciplinada, abnegada, diligente, religiosa, decidida, alegre, sufrida y leal. Ed. EDAF, S.A: Madrid

Otero, L (1999) La española cuando besa. Ed. Plaza et Janés: Barcelona.

Pascual, P. (1937) Nociones de urbanidad para las niñas. Ed. Hijos de Paluzíe: Barcelona. 
Perea Rodríguez, J; Gómez Rodríguez, E. Pagés Blanch, J. Muñoz García, F. (2007) Educación para la ciudadanía y los derechos humanos. Madrid. E. Laberinto.

Pérez Carrasco, J. Díaz Otero, C. Díaz Fleitas, J.M. (2007) Jóvenes ciudadanos. Educación para la ciudadanía y los derechos humanos. Ed. Pearson. Madrid.

Sánchez, D y Medina, R. (2007) Educación para la ciudadanía y los derechos humanos. Ed. Algaida: Sevilla

Serrano, A. (1952) Yo soy español. Ed. Escuela española: Madrid.

Werner, C. (1958) Convivencia social. Ed. Sección femenina: Madrid.

Villegas, S; Barranco, L y Fernández, J (2007) Educación para la ciudadanía. Ed Bruño: Madrid. 


\section{ESTUDIO CORRELACIONAL ENTRE LA IMAGINACIÓN CREATIVA Y HABILIDADES SOCIALES EN PSICOPEDAGOGOS}

González Rodríguez, Lucía; Marín Polo, Lorena; Ruiz Velasco, Ángela. Universidad de Granada

\section{RESUMEN}

El presente trabajo es el resultado de un análisis cuantitativo que trata de observar la relación que existe entre las habilidades sociales y la capacidad creativa en los estudiantes de Psicopedagogía. Los resultados obtenidos muestran una correlación inversa entre dos factores de ambas capacidades así como sus consecuencias en la práctica profesional de un psicopedagogos.

PALABRAS CLAVE: Capacidad creativa, habilidades sociales, autoexpresión, acción orientadora, competencia comunicativa.

\section{INTRODUCCIÓN}

El presente trabajo que abordamos surge de observar las nuevas corrientes pedagógicas y formativas así como la influencia que éstas tienen en la formación de los profesionales de la Educación. Son varias las leyes que han marcado nuestro Sistema Educativo y por las cuales podemos ver la evolución que ha sufrido la enseñanza así como, en consecuencia, la formación de los profesionales ligados al proceso enseñanza-aprendizaje. Dicho en otras palabras, se ha pasado de una pedagogía de corte intelectual donde prima la cantidad de conocimientos adquiridos, a una en la que aspectos como las emociones, las habilidades sociales y la creatividad forman parte de la misma. De esta manera se marca un punto de inflexión entre dos paradigmas educativos.

Por lo tanto, esto nos lleva a plantear la siguiente hipótesis: "los estudiantes de psicopedagogía que son socialmente inteligentes desarrollan un alto grado de creatividad."

De este modo, consideramos que estos profesionales interaccionan en su día a día con otras personas, y por ello, aspectos como las habilidades sociales, emocionales así como la creatividad y el pensamiento divergente, son recursos personales ineludibles para llevar a cabo su práctica profesional. Es decir, estos recursos repercuten de manera directa en la calidad de las relaciones establecidas o, como Goleman (2006) afirma que "cuando una persona vomita sobre otra sus sentimientos negativos -mediante explosiones de ira, amenazas u otras muestras de indignación o desprecio- activa en ella los mismos circuitos por los que discurren estas inquietantes emociones, un hecho cuya consecuencia neurológica consiste en el contagio de esas mismas emociones. (...) El subtexto emocional en el que se haya inserta cualquier interacción permite que, independientemente de lo que hagamos, el otro se sienta un poco (o un mucho) mejor o un poco (o un mucho) peor. (...) De este modo, las explosiones emocionales pueden convertir a un mero espectador en la víctima inocente del estado negativo de otra persona". 
Tras revisar la literatura existente en relación al tema que nos compete, hemos podido observar que no son muchas las investigaciones realizadas que hablan de la relación entre creatividad y habilidades sociales.

Por otra parte, podemos mencionar que desde Goleman $(1999,2006)$ son muchos los autores que han dedicado sus investigaciones a las habilidades sociales.

El concepto de habilidad social tiene como común denominador la conducta interactiva. Nos referimos a dicho concepto como la capacidad que toda persona posee en el momento de percibir, entender, descifrar y responder a estímulos sociales en general, y muy especialmente a aquellos que provienen de la interacción con los demás, entendiendo que la conducta socialmente habilidosa debe de situarse en un contexto social y cultural concreto. (Alsinet, 1997). En relación a esto debemos mencionar la significación positiva que adquiere el pensamiento divergente desde una visión social así como emocional. Esto supone una proyección en la manera de desenvolverse en la vida, tanto personal como profesional. Es decir, las personas que muestran un alto grado de pensamiento divergente son proactivas, autosuficientes, capaces de autorregularse, imaginativas, asertivas. Además serán capaces de aportar a la sociedad hitos innovadores disfrutando así de nuevos retos a los que enfrentarse.

Sin embargo y hasta el momento no existe en la literatura ninguna relación entre estos dos aspectos, siendo por ello este nuestro objeto de estudio.

De esta manera y antes de justificar la importancia de realizar esta correlación y el efecto de la misma en los psicopedagogos, nos parece trascendental comenzar aclarando la definición de los términos que estamos tratando.

"El concepto de inteligencia va ligado a la cultura y en occidente tradicionalmente se ha relacionado la inteligencia con competencias de índole cognitivo y metacognitivo, así como con otras habilidades de orden intelectual así como las habilidades de insight. Este concepto ha ido poco a poco cambiando y según al autor al que hagamos mención la inteligencia abarcaría desde dimensiones y habilidades creativas, afectivas, sociales, motivacionales, volitivas hasta de personalidad" (Hume y Sánchez, 2004). Por consiguiente y en nuestro caso, debemos considerar que la inteligencia así como el quehacer profesional abarca un concepto mucho más amplio, yendo más allá de aspectos que comprenden la cognición. Sin embargo, somos conscientes de que estos términos son argumentados por múltiples autores abriendo así un amplío abanico de definiciones. En esta línea nos parece relevante traer a colación la terminología delimitada por los test psicométricos utilizados en el estudio.

El test EHS, Escala de Habilidades Sociales, (Gismero, 2009) nos delimita seis factores: autoexpresión en situaciones sociales, el cual refleja la capacidad de expresarse uno mismo de forma espontánea, y sin ansiedad, en distintos tipos de situaciones sociales; defensa de los propios derechos como consumidor, implica la expresión de conductas asertivas frente a desconocidos en defensa de los propios derechos en situaciones de consumo; expresión de enfado o disconformidad, evita conflictos o confrontaciones con otras personas; decir no y cortar interacciones, refleja la habilidad para cortar interacciones que no se quieren mantener; hacer peticiones, esta dimensión refleja la expresión de peticione a otras personas de algo que deseamos, sea a un amigo o en situaciones de consumo e iniciar interacciones positivas con el sexo opuesto, se define por la habilidad para iniciar interacciones con el sexo opuesto pudiendo hacer de forma espontánea un cumplido, un halago, hablar con alguien que te resulta atractivo... 
Por último, el PIC-A, Prueba de Imaginación Creativa para Adultos (Artola et al., 2012) valora las siguientes escalas: la fantasía definida como la capacidad de ir más allá del estímulo que se presenta en la lámina, de imaginar cosas que no están presentes o que derivan del estímulo presentado; la fluidez, definida como la aptitud del sujeto para producir un gran número de ideas; la flexibilidad, como aptitud del sujeto para producir respuestas muy variadas, pertenecientes a categorías o temas muy diversos; la originalidad narrativa, aptitud del sujeto para producir ideas alejadas de lo evidente, habitual o establecido, caracterizándose por la rareza de las respuestas dadas; la originalidad gráfica, definida como la aptitud del sujeto para producir ideas alejadas de lo evidente, habitual o establecido pero mediante la producción gráfica; la elaboración como la aptitud del sujeto para desarrollar, ampliar o embellecer las ideas; detalles especiales, es la aptitud del sujeto para utilizar detalles llamativos y poco frecuentes en la mayoría de los sujetos; título, es la aptitud para proponer un título elaborando una frase adecuada para cada dibujo no quedándose en la mera descripción; creatividad narrativa es una media de pensamiento divergente cuando se aplica a la solución de un problema de contenido verbal y, por último, la creatividad gráfica, es la estimación del potencial creativo del sujeto, de su capacidad para transformar, combinar y establecer nuevas relaciones entre los elementos generando sus propias ideas.

Finalmente, a continuación se presentan los resultados obtenidos al correlacionar estos dos ámbitos, así como las consecuencias que tienen en los profesionales de la psicopedagogía.

\section{MÉTODO}

El objetivo de nuestra investigación es observar la relación que existe entre el nivel de creatividad en un estudiante y sus habilidades sociales.

Nos servimos para ello de un diseño meramente cuantitativo siendo la realización de pruebas estandarizadas el método fundamental que ha guiado el estudio.

\section{Participantes}

La población de estudio esta constituida por los estudiantes de $1^{\circ}$ y $2^{\circ}$ de Psicopedagogía de la Facultad de Ciencias de la Educación de la Universidad de Granada (UGR).

La selección de la muestra se realizó al azar entre los alumnos que comparten la asignatura de Psicología de los grupos.

El tamaño de la muestra fijada para el estudio fue 48 estudiantes de psicopedagogía

\section{Instrumentos}

Se seleccionaron dos cuestionarios psicométricos que se ajustaban a las variables que se pretendían medir y correlacionar en el estudio: PIC-A y EHS.

Para un nivel de confianza de 0,122 dado por la $r$ cuadrática y el Alfa de Cronbach es de 0,793 en la Escala de Habilidades Sociales y de 0,826 en la escala PIC-A. 
Las pruebas se realizaron durante una hora de la semana en la que los alumnos comparten la asignatura mencionada con anterioridad. Los alumnos/as contaron con una hora para llevar a cabo los tres cuestionarios.

Se les pidió que colocaran su nombre en los dos puesto que el objetivo del estudio es correlacionar variables que comprenden a un mismo sujeto.

En relación al EHS, categoriza las habilidades sociales a medir en seis subgrupos, teniendo una serie de ítems para cada uno de ellos. Éstos son autoexpresión en situaciones sociales, defensa de los propios derechos, expresión de disconformidad, decir no y cortar interacciones, hacer peticiones e iniciar interacciones positivas con el sexo opuesto.

Finalmente, se utilizó el PIC-A que presenta una serie de escalas que se exponen a continuación: fantasía, fluidez, flexibilidad, originalidad narrativa, originalidad gráfica, elaboración, detalles especiales y título; las cuales forman parte de dos grandes escalas denominadas creatividad gráfica y creatividad narrativa.

A partir de los datos obtenidos a través de los test psicométricos, se generó una base de datos que fue analizada con el software científico SPSS-20.

Tras la revisión y refinamiento de la matriz de datos, se utilizaron los recursos clásicos de la estadística inferencial como son el Alfa de Cronbach y la correlación entre los diferentes test.

\section{Procedimiento}

Los test se han pasado durante dos semanas en el mes de mayo de 2013 , entre las diez y las doce de la mañana, puesto que es el horario establecido para la asignatura de Psicología de los grupos en la Facultad de Ciencias de la Educación de la Universidad de Granada.

Primero se pasó el PIC-A, explicando a los estudiantes las correspondientes instrucciones para la elaboración del mismo. Posteriormente, y a la semana siguiente, la Escala de Habilidades Sociales.

Se pidió al alumnado que colocarán sus datos personales en cada test puesto que el fin del estudio es la correlación de los factores. Con ello se realizó especial mención a la protección de datos de los participantes.

Posteriormente, se unieron los test correspondientes al mimo alumno y se pasó a la corrección de datos de ambos test, así como a la introducción de los mismos en el programa informático.

\section{Resultados}

Una vez metidos los datos en el programa informático hemos hallado los siguientes resultados.

A través de SPSS-20 hemos calculado la fiabilidad, dada por el Alfa de Cronbach llegando a los siguientes resultados en ambos test: 
Fiabilidad de habilidades sociales

Alfa de Cronbach ,793

Fiabilidad de la creatividad

Alfa de Cronbach ,826

A través de la correlación de Pearson entre ambos test hayamos que las relaciones existentes son negativas, destacando el factor "autoexpresión", tendiendo a alejarse de la creatividad. Concretamente, observamos que se crea una correlación inversa a la hipótesis planteada en un inicio. Además destacar la relación significativa entre los factores "autoexpresión" y "Creatividad Narrativa de fluidez".

\begin{tabular}{|c|c|c|c|c|c|c|}
\hline orr & & $\Gamma$ & & & & \\
\hline \multirow{4}{*}{ Fantasia } & & $\mathrm{r}$ & CNF & & & CGO \\
\hline & Correlación de Pearson & 1 &, 541 &, 586 & ,396" & ,134 \\
\hline & Sig. (bilateral) & &, 000 &, 000 &, 006 &, 368 \\
\hline & $\mathrm{N}$ & 47 & 47 & 47 & 47 & 47 \\
\hline \multirow{3}{*}{ CNfluidez } & Correlación de Pearson &, $541^{\star *}$ & 1 &, $874 *$ &, $865^{* *}$ &, $330^{*}$ \\
\hline & Sig. (bilateral) &, 000 & & 000 &, 000 &, 023 \\
\hline & $\mathrm{N}$ & 47 & 47 & 47 & 47 & 47 \\
\hline \multirow{3}{*}{ CNflexibilidad } & Correlación de Pearson &, $586^{\mathrm{x}}$ & $874^{\mathrm{nx}}$ & 1 & ,908 & $321^{*}$ \\
\hline & Sig. (bilateral) & ,000 & ,000 & & ,000 & ,028 \\
\hline & $\mathrm{N}$ & 47 & 47 & 47 & 47 & 47 \\
\hline \multirow{3}{*}{ CNoriginalidad } & Correlación de Pearson &, $396^{* *}$ & $865^{* *}$ & $908^{* *}$ & 1 &, $373^{* * *}$ \\
\hline & Sig. (bilateral) & ,006 & ,000 & ,000 & &, 010 \\
\hline & $\mathrm{N}$ & 47 & 47 & 47 & 47 & 47 \\
\hline \multirow{3}{*}{ CGoriginalidad } & Correlación de Pearson & 134 &, $330^{*}$ & $321^{*}$ &, $373^{* *}$ & 1 \\
\hline & Siq (bilateral) & 368 & 023 & 028 & 010 & \\
\hline & $\mathrm{N}$ & 47 & 47 & 47 & 47 & 47 \\
\hline \multirow{4}{*}{ CGelaboracion } & Correlación de Pearson &, $312^{*}$ & ,265 &, $391^{* \star}$ &, $300^{*}$ & ,085 \\
\hline & & & & & & \\
\hline & Sig. (bilateral) & ,033 & ,072 & ,007 & 041 & ,571 \\
\hline & $\mathrm{N}$ & 47 & 47 & 47 & 47 & 47 \\
\hline \multirow{3}{*}{ CGdetalles } & Correlación de Pearson &, $357^{*}$ & 188 & 173 & ,152 & 177 \\
\hline & Siq (bilateral) & 014 & 206 & 244 & 306 & 233 \\
\hline & $\mathrm{N}$ & 47 & 47 & 47 & 47 & 47 \\
\hline \multirow{3}{*}{ CGtitulo } & Correlación de Pearson & ,224 & ,269 & $311^{*}$ & ,242 &, $297^{*}$ \\
\hline & Sig. (bilateral) & 131 & ,067 & ,033 & ,101 &, 042 \\
\hline & $\mathrm{N}$ & 47 & 47 & 47 & 47 & 47 \\
\hline \multirow{3}{*}{ Autoexpresion } & Correlación de Pearson &,$- 294^{*}$ &,$- 376^{* *}$ &,$- 320^{*}$ &,$- 365^{*}$ &,- 147 \\
\hline & Sig. (bilateral) & ,045 & 009 & ,028 & 012 &, 323 \\
\hline & $\mathrm{N}$ & 47 & 47 & 47 & 47 & 47 \\
\hline
\end{tabular}


Posteriormente y tras la observación de esa relación significativa entre ambos factores mencionados con anterioridad, a través de la regresión lineal jerarquizada por pasos, considerando como variable dependiente autoexpresión, y como variable independiente el factor fluidez, perteneciente a la escala de creatividad narrativa, hemos constatado que existe una correlación negativa muy significativa entre ambos factores, siendo la R cuadrado corregida de 0,122.

\begin{tabular}{|c|c|c|c|c|}
\hline \multicolumn{5}{|c|}{ Resumen del modelo } \\
\hline Modelo & $\mathrm{R}$ & R cuadrado & $\begin{array}{l}\text { R cuadrado } \\
\text { corregida }\end{array}$ & $\begin{array}{l}\text { Error típ. de la } \\
\text { estimación }\end{array}$ \\
\hline 1 &, $376^{a}$ & ,142 &, 122 & 27,288 \\
\hline
\end{tabular}

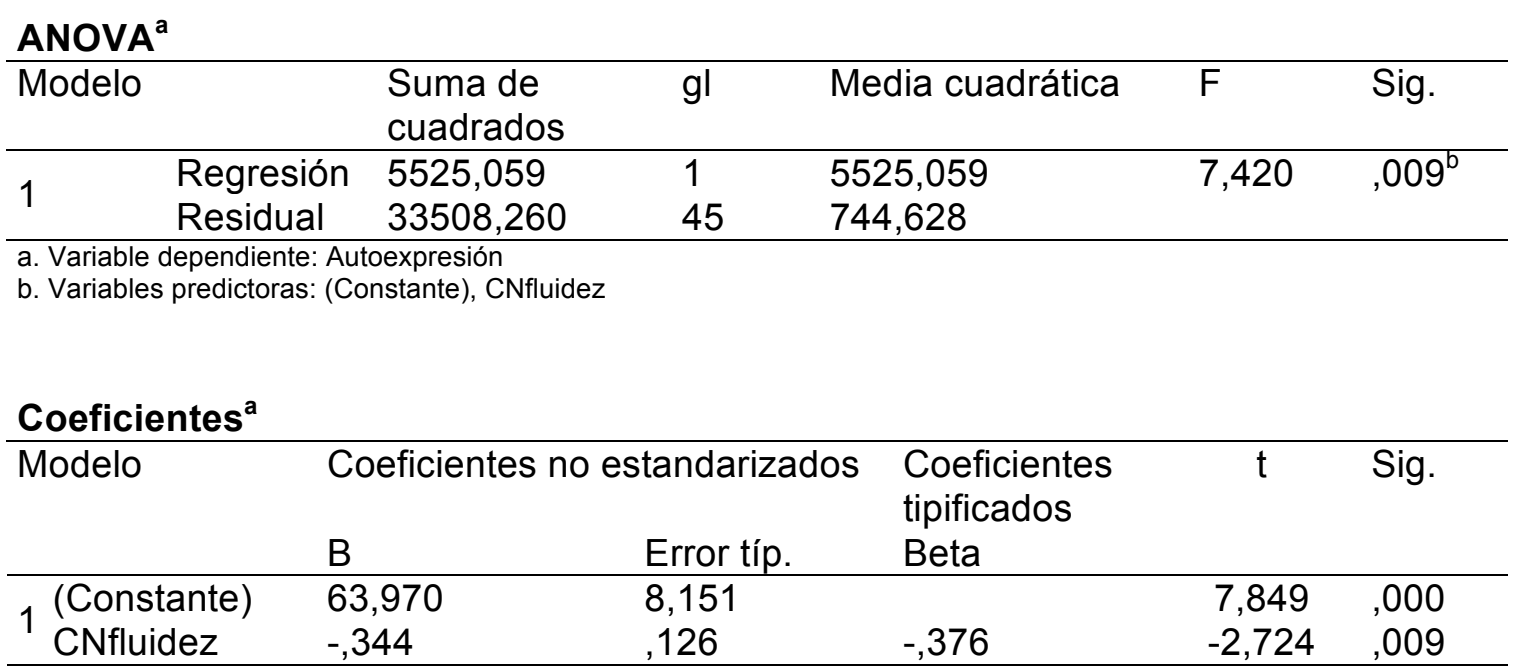

a. Variable dependiente: Autoexpresión

\section{DISCUSIÓN}

Tras el análisis de los datos obtenidos debemos destacar que nuestra hipótesis de partida es refutada. En un principio se planteó la relación directa que existe entre la capacidad creativa y la inteligencia social en un profesional debido a que el cambio de paradigma en los procesos de enseñanza, en términos generales, ha creado un vínculo muy estrecho entre estos términos, siendo parte de la formación integral de dicho profesional. Esto parece habernos llevado a dibujar una idea "tópica" de que las habilidades sociales y la creatividad son términos que se interrelacionan entre sí. Y por ello nos plantemos corroborar a través del método científico dicha ilación.

Las conclusiones halladas rompen con dicho nexo, demostrando que no solo no existe una correlación directa entre ambas sino que además dicha correlación es indirecta siendo significativa en dos factores; al contrario de lo planteado en una hipótesis inicial.

Dicho en otras palabras, los resultados obtenidos nos muestran que cuando una persona es capaz de expresarse espontáneamente con los demás, presenta menos aptitudes para responder ante un gran número de ideas a través del pensamiento divergente.

De esta manera, si aplicamos nuestros resultados al campo profesional de los psicopedagogos, la persona debe mostrar naturalidad en las prácticas profesionales y en las relaciones establecidas con los diferentes usuarios a través de la expresión 
personal, mostrándose tal y como es. Esto implica romper con la trivialidad de que para mejorar las practicas profesionales y la calidad de la relación que se establece entre orientador y orientado, es necesario potenciar en el profesional el pensamiento divergente. Puede considerarse como un habilidad más entre otras; sin embargo lo realmente importante es fortalecer las habilidades sociales, concretamente la autoexpresión. Esto se debe a que el orientador debe tomar conciencia de su autenticidad, lo que implica ser consciente de su responsabilidades, emociones, sus opiniones, necesidades e incluso de su propio cuerpo. Esta autenticidad propia debe ser asumida conllevando en sí misma la creencia de que la persona orientada también la posee, siendo el objetivo principal de la acción orientadora la ayuda o acompañamiento de la búsqueda de dicha autenticidad por parte del orientado.

Para ello consideramos relevante que las personas deben poner en concordancia las propias sensaciones, las emociones y los pensamientos ayudándose del diálogo intencional que se crea en la propia acción orientadora y entendiendo al orientador como un profesional de la comunicación. Esto se apoya en modelos como el de consejo, el cual "incide especialmente en la importancia de la comunicación entre le orientador y el orientado; dado que solo desde la colaboración y el compromiso del usuario es posible que la acción orientadora pueda alcanzar los objetivos previstos" (Arráiz y Sabirón, 2012, p. 144)

Por el contrario, debemos considerar que si el profesional no desarrolla esa autoexpresión y con ello esa búsqueda de autenticidad, corre el riesgo de llevar a cabo un mecanismo de proyección, lo que implica atribuir al orientado sentimientos y deseos propios que no se quieren atribuir como tales. Además implicaría que está eludiendo la responsabilidad de los propios sentimientos o deseos. Esto rompería con el objetivo principal de la acción orientadora, pues no daría respuesta a las necesidades reales del orientado sino a las suyas propias, trasgrediendo así la idea de autenticidad que mencionábamos con anterioridad.

En conclusión, consideramos que la formación óptima que debe recibir el orientador está encaminada a desarrollar habilidades sociales que potencien esa autoexpresión, focalizada en la búsqueda de la propia autenticidad. Esto conllevará a que la acción orientadora será un proceso de acompañamiento, a través de diálogo intencional donde el orientado descubra quién es y crea en su autenticidad para llegar a su propia autodeterminación, la cual es el eje vertebrador de cualquier acción orientadora.

\section{REFERENCIAS}

ALSINET MORA, CARLES. (1997). Un programa para mejorar las habilidades sociales en adolescentes. Intervención psicosocial. (Consultado en línea el día 25 de junio de 2013. http://www.copmadrid.org/webcopm/publicaciones/social/1997/vol2/arti6.htm)

ARRAIZ PEREZ, A. y SABIRON SIERRA, F. (2012) Orientación para el aprendizaje a lo largo de la vida: modelos y tendencias. Zaragoza. Prensas de la Universidad de Zaragoza.

ARTORA, T et al., (2012). PIC-A. Madrid. TEA

GISMERO, E. (2000) Escala de Habilidades Sociales. Madrid. TEA.

GOLEMAN, D. (1995) Inteligenia emocional. Barcelona. Kairós. 
GOLEMAN, D. (2006) Inteligenia social. Barcelona. Kairós.

HUME FIGUEROA, M. y SÁNCHEZ NÚÑEZ, M.T. Evaluación e intervención en inteligencia emocional y su importancia en el ámbito educativo. (Consultado el 04.06.2013. www.uclm.es/varios/revistas/docenciaeinvestigación/pdf/.../Trinidad.doc)

PETIT, M. (2009). La terapia Gestal. Barcelona. Kairós. 


\section{HOMOSEXUALIDAD, ¿QUÉ ACTITUD TIENEN LOS UNIVERSITARIOS AL RESPECTO?}

Baena Pérez, Daniel; Calvente Pérez, María del Rocío; Díaz Sánchez, Marina. Universidad de Granada

\section{RESUMEN}

El trato hacia los homosexuales siempre ha despertado mucha controversia, especialmente ahora que ha aumentado el interés por este fenómeno debido a que ha dejado de ser un tema tabú, al menos en la cultura occidental. Múltiples factores socioculturales han influido en este cambio de visión, factores como el uso de internet como medio libre de expresión o los cambios en las condiciones socio políticas del país (Ahmad, 2010). Estos cambios afectan tanto a jóvenes como a adultos quienes se están adaptando a esta visión de la sexualidad. El objetivo de esta investigación es analizar la actitud hacia personas homosexuales para ver si estos cambios socioculturales han ayudado a estrechar la diferencia entre hombres y mujeres (Cárdenas y Barrientos, 2008) o si por el contrario sigue presente, en cuyo caso será necesario crear nuevos planes de intervención que distingan entre hombres y mujeres.

Palabras clave: Homofobia, prejuicio, adaptación social, cambio de actitud

El 17 de mayo de 1990 marca un día histórico en la lucha contra la homofobia ya que fue en esta fecha cuando la Organización Mundial de la Salud retiró la homosexualidad de la lista de enfermedades mentales (OMS, 1990). 23 años más tarde, a pesar de lo que se ha luchado por erradicar esta discriminación ilógica e irracional, todavía queda mucho para que las parejas homosexuales puedan vivir con los mismos derechos sociales que las parejas heterosexuales y tengan las mismas oportunidades.

Las personas homosexuales son un grupo minoritario, lo que por desgracia hace que todo sea más novedoso, que sobresalga más y se vea como discordante. Esto hace que se produzcan ataques hacia ellos ya sea de manera directa en forma de agresiones físicas o un tipo de agresión más sutil en la que se incluirían aquellas conductas de discriminación hacia el colectivo que tienen como fin último marcarlos como un grupo social con menos derechos que el resto. Las conductas homófobas cumplen ciertas funciones para la persona que las realiza dotándolas de sentido y fomentando, además, que esta conducta se mantenga a lo largo del tiempo como ya propuso Katz (citado por Muchinik \& Seidmann, 1983) en su obra, dichas serían las siguientes:

Una función de adaptación en el sujeto el cual busca pertenecer a un grupo dentro de la sociedad, la pertenencia de una persona homosexual a este grupo perturbaría al sujeto lo que puede desembocar en conductas de evitación.

Una función de defensa del yo mediante la cual el sujeto expresa sus valores, en nuestro caso en particular puede usarse como un mecanismo de defensa. La persona por el mero hecho de ser hombre o mujer tiene unas ideas preconcebidas de cómo debe comportarse, un modelo a seguir. Nunca se plantearía la relación con personas del mismo sexo 
Una función de expresión de valores donde el sujeto expresa el tipo de persona que quiere llegar a ser, en nuestro caso, si el sujeto muestra una actitud positiva hacia la homosexualidad esto podría significar que quieren serlo y provoca rechazo.

Y una función de conocimiento que ayuda al sujeto a obtener una representación simplificada de la realidad que le rodea, la homofobia en este sentido permitiría una evaluación rápida, genérica y en la mayoría de los casos negativa, de todas las personas que formen parte de este colectivo Además de cumplir dichas funciones, consideramos una conducta como la manifestación de una actitud. Allport (1962) define la actitud como "Una disposición mental y neurológica, que se organiza a partir de la experiencia que ejerce una influencia directriz o dinámica sobre las reacciones del individuo respecto de todos los objetos y a todas las situaciones que les corresponden".

Krech, Crutchfield y Ballechey (1978) entran en más detalle definiendo la actitud como "una organización permanente de procesos emocionales, conceptuales y cognitivos con respecto a algún aspecto del mundo del individuo" lo que ha llevado a dividir esta en tres componentes: cognitivo, conductual y emocional. Según esta división la homofobia seria el componente emocional.

A su vez, Allport (1962) define al prejuicio como "una antipatía que se apoya en una generalización imperfecta e inflexible. Puede sentirse o expresarse. Puede estar dirigida hacia un grupo en general, o hacia un individuo por el hecho de ser miembro de ese grupo. El efecto final del prejuicio es colocar al objeto del mismo en una situación de desventaja no merecida por su propia conducta".

La mayor parte de las veces el prejuicio es negativo y acostumbra a incluir sentimientos de desprecio y desagrado hacia la persona o grupo al cual es dirigido. Billing (1975) define, en concordancia con Allport (1962), al prejuicio como un juicio previo, a priori, sin existencia de pruebas, como opiniones dogmáticas y desfavorables respecto a ciertos grupos y, por extensión, respecto a los miembros individuales que pertenecen a dicho grupo. Billing (1975) comprende al prejuicio como una actitud negativa y lo diferencia de la discriminación, que es comprendida por él como el prejuicio hecho conducta, es decir, la actitud sería el prejuicio y la discriminación sería la conducta.

Pero actualmente los cambios socioculturales mencionados anteriormente han dado lugar a la presencia de fuertes presiones normativas en favor de la igualdad y la tolerancia, haciendo que el prejuicio en lugar de desaparecer se haya adaptado a los tiempos transformándose en algo más sutil. En consecuencia actualmente se diferencia entre prejuicio sutil y manifiesto (Pettigrew y Meertens, 1995)

A toda conducta discriminatoria, le subyace un prejuicio, pero no todo prejuicio se transforma en conducta. Sin embargo, Allport (1962) afirma que toda actitud negativa tiende, de algún modo, a expresarse en acción en cierto momento. Plantea distintos grados en la acción negativa, desde la menos enérgica hasta la más enérgica:

- Hablar mal: Los sujetos efectúan comentarios con otras personas que no pertenecen a la minoría.

- Evitar el contacto: Intentan por todos los medios no acercarse o interactuar con sujetos de la minoría.

- Discriminación: No se les permite el acceso a ciertos grupos o instituciones.

- Ataque físico: El prejuicio llevado a actos de violencia física o psicológica.

- Exterminación: Linchamientos y matanzas. 
Aunque esta definición de prejuicio nos sirve como base para elaborar nuestra definición semántica del constructo, que no será otro que el prejuicio hacia la población homosexual, es necesario adaptarlo a nuestros tiempos y a nuestro tema de estudio en particular. Por ello, decidimos eliminar el apartado referente a matanzas y linchamientos y añadir nuevos indicadores que midan el prejuicio sutil. De esta forma nuestra definición semántica estará formada por los siguientes componentes:

- Realizar comentarios negativos o de desprecio sobre personas homosexuales

- Considerar a las personas homosexuales como inferiores y con menos derecho que los heterosexuales

- Evitar el contacto físico o intentar por todos los medios no acercarse/ interactuar con personas homosexuales

- Abstenerse de ir a lugares donde pueda haber personas homosexuales

- Sentir malestar fisiológico o cognitivo en presencia de personas homosexuales

- Discriminarles ante el acceso a ciertas actividades, grupos o instituciones

- Agredir o sentir el impulso de atacar a personas homosexuales de forma física o psicológica

- Sentir malestar ante pensamientos de atracción sexual hacia personas del mismo género o que una persona homosexual se sintiera atraída por la persona en cuestión.

Pero tal vez lo más interesante es que este prejuicio hacia personas homosexuales no se manifiesta de manera equitativa en hombres y mujeres, mostrándose estas últimas más tolerantes al respecto como ya nos informa la investigación llevada a cabo por Cárdenas y Barrientos con población universitaria (Cárdenas y Barrientos, 2008). Sin embargo estas investigaciones se realizaron acorde a la definición semántica de constructo anterior por lo que queremos comprobar si estas diferencias seguirán presentes al usar nuestra definición del constructo en la que se han contemplado aspectos más actuales.

Por tanto el objetivo de esta investigación es comprobar si existen diferencias de género respecto a la actitud hacia los homosexuales en la población universitaria. Para ello se evaluó la actitud hacia los homosexuales y se compararon las posibles diferencias entre hombres y mujeres controlando, además, variables como el tener personas homosexuales en el entorno con el objetivo de evaluar su posible influencia.

\section{MÉTODO}

\section{Participantes}

Se recogieron respuestas de 195 sujetos seleccionados al azar con edades comprendidas entre los 18 y los 30 años. De ellos, 55 fueron descartados por su condición sexual, es decir, si eran homosexuales o bisexuales ya que esto hubiera sesgado nuestra investigación. De los 140 restantes, 74 fueron mujeres y 66 fueron hombres, con una media de edad de 21'1 y desviación típica de 2'01. Todos ellos cursaban estudios universitarios.

\section{Instrumento}

Aplicamos la escala traducida del "Index of attitudes Toward homosexuals" (Hudson y Ricketts, 1980) cuyo objetivo original era medir la actitud hacia personas homosexuales acorde a la definición de homofobia de Weinberg (1972)La escala 
original cuenta con 25 ítems a ser respondidos por los sujetos mediante una escala tipo Likert de 1 a 5 (ver anexo 1).

La fiabilidad de la escala original, calculada mediante el coeficiente alfa de Cronbach, obtuvo una puntuación de $\alpha=0.90$ (Hudson y Ricketts, 1980). El alfa de Cronbach "de la IAH traducida al español fue de $\alpha=0.89$ (Caleb, 2005), lo que llevó al autor a concluir que con la traducción "no amenazo la validez construida por los autores".Para el cálculo de puntuaciones se invirtieron cierto número de ítems debido a su connotación negativa, es decir, donde el sujeto puntúa 1 se transforma en 5 , donde puntúa $2=4$, donde $4=2$ y donde $5=1$. La puntuación $=3$ se mantiene $\sin$ cambios. estos ítems son los siguientes: 3, 4, 6, 9, 10, 12, 13, 14, 15, 17, 19, 21 y 24 (anexo 1). Estos ítems se puntúan a la inversa porque son afirmaciones negativas, y si el sujeto responde la opción "1" de la escala Likert (totalmente de acuerdo) demuestra homofobia, entonces, se invierte la puntuación para mantener la idea inicial de los autores: "a mayor puntuación, mayor nivel de homofobia".

Dado que nuestro constructo incluye nuevos elementos realizamos un breve estudio para comprobar la validez de contenido. En dicho estudio le pedimos a un total de cinco expertos en la materia que valoraran el grado en que cada ítem representaba el constructo. Esta valoración se llevó a cabo mediante una escala Likert con tres alternativas de respuesta según el grado de acuerdo o desacuerdo con la asociación.

La valoración de los expertos nos demostró que los aspectos 1 y 7 de nuestra definición semántica no tenían ningún ítem asociado en la escala original por lo que decidimos añadir 5 ítems adicionales con el mismo formato de respuesta tipo Likert (ver anexo 2). También nos sugirieron eliminar el ítem número 11 de la escala traducida (Me sentiría cómodo/a sabiendo que mi sacerdote es homosexual) ya que la población universitaria actual es predominantemente no creyente como ya comprobaron España et al. (2001)

\section{Procedimiento}

En primer lugar, la escala traducida del "Index of attitudes Toward homosexuals" (Caleb, 2005), fue evaluada por un grupo de expertos que valoraron si los ítems estaban relacionados con los indicadores de la definición semántica que queríamos medir.

Una vez que los expertos aprobaron los ítems finales, adaptamos nuestro cuestionario a la aplicación electrónica LimeSurvey, un servicio de encuestas online que nos permitió aplicarlo vía Internet. La distribución del cuestionario se realizó por medio de cadena de correos electrónicos a estudiantes universitarios de carreras variadas y mediante la distribución de códigos QR impresos (ver anexo 3). Decidimos que este era el método más cómodo por ser rápido, fácil y sin limitaciones horarias, además aseguraba un nivel de anonimato mayor del que se hubiera conseguido pasándolo en persona.

Una vez que el participante accedía al enlace, en una página de bienvenida se le daban instrucciones y se le advertía del anonimato de la encuesta. Tras esto, se pasaba a la primera parte del cuestionario donde se registraban los datos sociodemográficos y por último se presentaban los 30 ítems de la escala, los cuales se contestaban mediante una escala tipo Likert con valores de 1 a 5 , siendo 1 totalmente en desacuerdo y 5 totalmente de acuerdo. Una vez finalizado, los resultados se añadían automáticamente a una base de datos que posteriormente exportamos al 
programa "Statistical Package for Social Sciences" (SPSS versión 21.0), con el cual realizamos los análisis estadísticos pertinentes.

\section{RESULTADOS}

Con el objetivo de agrupar a los participantes según sus puntuaciones creamos los siguientes grupos en base a la puntuación total obtenida: Grupo de baja tolerancia (30100), grupo de tolerancia media (101-125) y grupo de alta tolerancia (126-150). Una vez sumadas las puntuaciones obtenidas de cada participante se le asigna a uno de los tres grupos previamente descritos. En la Tabla 1 y Figura 1 se refleja dicha asignación así como las diferencias entre hombres y mujeres que en este caso fueron significativas (chi-cuadrado $<0,005$ ).

Tabla 1. Distribución en grupos según sexo y puntuación total obtenida

\begin{tabular}{|l|l|l|l|l|}
\hline Sexo & Baja tolerancia & $\begin{array}{l}\text { Tolerancia } \\
\text { media }\end{array}$ & Alta tolerancia & $\%$ \\
\hline Femenino & 0 & 25 & 49 & $52,86 \%$ \\
\hline Masculino & 11 & 27 & 28 & $47,14 \%$ \\
\hline$\%$ & F 0\% & F 33,78\% & F 16,21\% & \\
& M 16,6\% & M 40\% & M 42,42\% & \\
\hline
\end{tabular}

Figura 1. Distribución en grupos según sexo y puntuación total obtenida

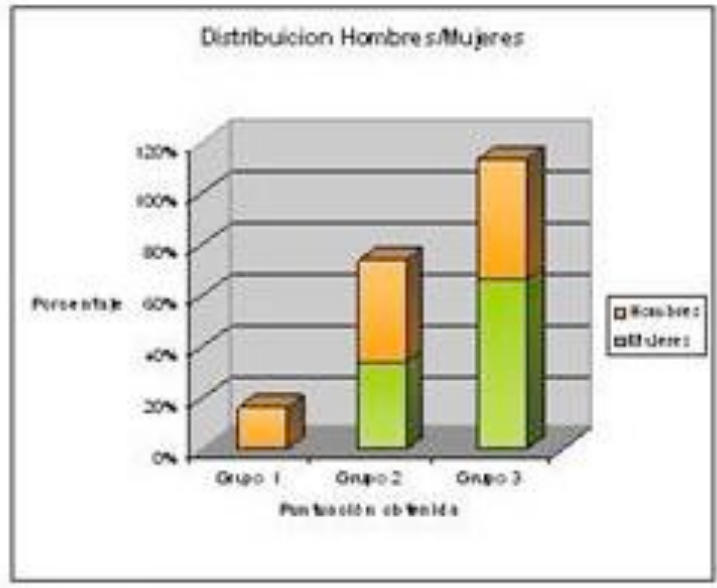

Figura 1.

Como muestra la Tabla 1 , en el grupo de baja tolerancia no hay ninguna mujer a diferencia de los hombres estando presentes en un 16'6\%. En el grupo de tolerancia media hay un $3778 \%$ de mujeres y un $40 \%$ de hombres, siendo este el grupo más igualado. $Y$ en el grupo de alta tolerancia hay casi el doble de mujeres que hombres.

Sumando las categorías que reflejan ausencia (grupos 2 y 3 ) y presencia (grupo 1) de niveles de homofobia se presentan los siguientes resultados: El 92'14\% de la muestra presentó un nivel bajo de homofobia y el $7^{\prime} 86 \%$ de la muestra presentó un nivel alto de homofobia estando este último grupo constituido exclusivamente por hombres.

En relación a las posibles diferencias entre participantes en función de la presencia de en su entorno, obtuvimos los siguientes resultados. 
Figura 2. Número de participantes con conocidos homosexuales en el entorno

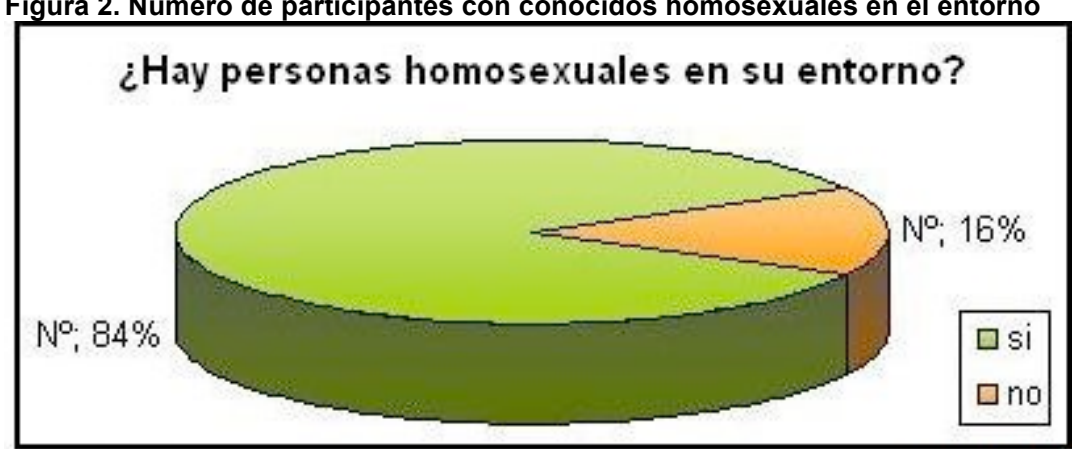

Como muestra la Figura 2, al haber tanta diferencia entre participantes con y sin personas homosexuales conocidas en el entorno, decidimos realizar el análisis con una submuestra compuesta por los 22 sujetos sin personas conocidas y otras 22 personas con conocidos elegidos al azar. Una vez obtenida la puntuación asignamos cada participante a uno de los tres grupos posibles, grupo de baja tolerancia (30-100), grupo de tolerancia media (101-125) y grupo de alta tolerancia (126-150). Los resultados de dicho subanálisis quedan recogidos en la tabla 2 .

Tabla 2. Distribución en grupos según conocidos en el entorno y puntuación total

\begin{tabular}{lllll}
\hline $\begin{array}{l}\text { ¿Hay personas } \\
\text { homosexuales } \\
\text { en su entorno? }\end{array}$ & Baja tolerancia & $\begin{array}{l}\text { Tolerancia } \\
\text { media }\end{array}$ & Alta tolerancia & Total \\
\hline Si & 2 & 7 & 13 & 22 \\
No & 3 & 13 & 6 & 22 \\
Total & 5 & 20 & 19 & 44 \\
\hline
\end{tabular}

Al realizar las pruebas de chi-cuadrado obtuvimos un valor de 0,101 lo que nos indica que las diferencias observadas no son significativas $(0,101>0,005)$ quedando descartada así nuestra segunda hipótesis según la cual el tener personas homosexuales en el entorno favorecería a tener una actitud más positiva hacia ellos. Por último, se realizó un análisis de fiabilidad del instrumento con el fin de comprobar la posible influencia de los ítems añadidos. Obtenemos evidencias de la fiabilidad del instrumento con un valor alfa de Cronbach de $\alpha=0,922$. Valor mayor que los obtenidos por la escala original y por la escala traducida. A pesar de esto tras un análisis más exhaustivo de los ítems añadidos observamos que si eliminamos los 4 últimos (ítems del 27 al 30) el coeficiente alfa seria aún mayor. Este hecho refleja que el aumento de longitud de la escala podría ser el factor responsable del aumento de fiabilidad.

\section{DISCUSIÓN Y CONCLUSIONES}

Respecto a nuestra primera hipótesis, el sexo femenino es más tolerante en el trato hacia la población homosexualidad, se ve confirmada, pues en el grupo de baja tolerancia no había presencia de ninguna mujer además de que en los grupos de tolerancia media y alta tolerancia obtuvieron mayores puntuaciones respecto a los hombres. La segunda hipótesis, tener en el ambiente cercano personas homosexuales hará que la persona sea más tolerante, queda rechazada.

Los resultados del estudio manifiestan que la muestra seleccionada presenta bajos niveles de homofobia. Tal como se comentó al principio, la homofobia representa al componente afectivo del prejuicio en lo referido al comportamiento respecto a los 
homosexuales, es decir, los sujetos tienden a actuar de un modo positivo hacia los sujetos homosexuales y en lo referido a lo cognitivo, los sujetos no tendrían una imagen negativa del grupo homosexual.

La media de la muestra fue muy superior a la de la muestra de la investigación realizada por los creadores de la escala (Hudson, y Ricketts, 1980). Lo interesante de esto es que a pesar de que pasaron, entre una aplicación y otra de la escala 30 años, la fiabilidad del test sigue siendo la misma. Esto hace pensar que las actitudes aprendidas culturalmente han cambiado con el paso del tiempo. La sociedad ha comenzado a realizar un cambio de actitud en torno a las personas homosexuales. Sin embargo es necesario mencionar la diferencia de resultados entre hombres y mujeres, lo que hace pensar que las mujeres son más tolerantes respecto a la introducción de los homosexuales en el panorama social. La mujer siempre ha presentado características de comprensión y sensibilidad respecto a la imagen de hombría del sexo masculino, quizás la homosexualidad para el hombre es un ataque a su rol social pues los hombres en presencia de hombres homosexuales se muestran más incómodos.

En cuanto a la conducta manifiesta de la homofobia presentada por la muestra pareciera que los sujetos optarían por alguno de los dos primeros grados propuestos por Allport (1962) en la definición semántica: hablar mal o evitar el contacto. Dado el bajo nivel de homofobia presentado por la muestra muy pocos sujetos optarían por la discriminación o el ataque físico y si alguno lo hiciera probablemente sería un hombre ya que son los sujetos que presentaron mayores niveles de homofobia.

En conclusión, a pesar de los grandes avances sociales, aún queda un largo camino por recorrer. Se deben inculcar valores de tolerancia y respeto para que llegue a existir una comunidad donde los homosexuales sean uno más del colectivo social, consiguiéndose así una sociedad en igualdad de derechos y oportunidades. No podemos olvidar que toda nuestra muestra de sujetos eran estudiantes universitarios por lo que el nivel cultural es más alto, factor que ayuda a mantener una actitud más tolerante en general y que explicaría nuestros resultados. La investigación futura tendrá que contemplar, además de este factor, la evolución de la homofobia hacia un tipo de prejuicio más sutil.

\section{REFERENCIAS}

Ahmad, S., y Bhugra, D. (2010). Homophobia: An updated review of the literature. sexual and relationship therapy, 25 (4), 447-455.

Allport, G. (1997). La naturaleza del prejuicio. Buenos Aires: Editorial Universitaria de Buenos Aires.

Billing, M. (1975). Racismo, prejuicios y discriminación: En Moscovici, S. (1980). Manual de Psicología Social. Capítulo 17, Tomo II. Buenos Aires: Amorrortu.

Caleb, J. (2005). Réplica de una escala de medición de actitudes hacia la homosexualidad. (Tesis inédita de doctorado). Facultad de Humanidades. Universidad de Belgrano. 
Cárdenas, M. y Barrientos, J. (2008). Actitudes explícitas e implícitas hacia los hombres homosexuales en una muestra de estudiantes universitarios en Chile. Psykhe, 17 (2), 17-25.

España, A., Guerrero, A., Farré, J.M., Canella-Soler, J., y Abós, R. (2001). La homofobia en el medio universitario. Un estudio empírico. Cuadernos de medicina psicosomática y psiquiatría de enlace, 57, 41-55.

Fiske, S., (1998). Stereotyping, Prejudice, and Discrimination. En Gilbert, D., Fiske, S., Lindzey, G. (Eds.), Handbook of psychology (pp. 357-392). Boston: McGraw-Hill.

IBM Corp. Released 2012. IBM SPSS Statistics for Windows, Version 21.0. Armonk, NY: IBM Corp.

Kawakami, K., Dunn, E., Karmali, F., y Dovidio, J. F. (2009). Mispredicting affective and behavioral responses to racism. Science, 323, 276-279.

Meertens, R.W., \& Pettigrew, T.F. (1997). Is subtle prejudice really prejudice? Public Opinion Quarterly, 61, 54-71

Muchinik, E. y Seidmann, S. (1983). Actitudes y Cambio Social. Buenos Aires. Departamento de Publicaciones, Facultad de Psicología de la Universidad de Buenos Aires.

Nadal, K. L. (2013). That's so gay!: microaggressions and the lesbian, gay, bisexual, and transgender community. Washington, DC: American Psychological Association.

Pratte, T. (1986 and 1991). A Comparative Study of Attitudes Toward Homosexuality. Journal of Homosexuality, 26 (1), 77 - 88.

Pettigrew, T.F., \& Meertens, R. (2001). In defense of the subtle prejudice concept: a report. European Journal of Social Psychology, 31, 299-309

Pettigrew, T.F., \& Meertens, R.W. (1995). Subtle and blatant prejudice in Western Europe. European Journal of Social Psychology, 25, 57-75.

Shelton, K., y Delgado-Romero, E. A. (2011). Sexual orientation microaggressions: The experience of lesbian, gay, bisexual, and queer clients in psychotherapy. Journal of Counseling Psychology, 58, 210-221. 


\section{AUTOCONCEPTO: FACTORES E INFLUENCIAS}

Ignacio Casado Lozano, Alberto Hernández Sande, Elena Manzano Bazaga. Universidad de Huelva

\section{Resumen}

En el presente artículo se ha realizado una revisión bibliográfica sobre el autoconcepto y las últimas investigaciones que aportan datos acerca de relaciones e influencias con diversas variables, así como los factores que podrían componer el constructo del autoconcepto. Las investigaciones han sido seleccionadas para disponer de una selección suficientemente reciente (a partir del año 2009 de publicaciones) para que pueda ayudar a dirigir otras futuras.

Palabras clave: autoconcepto, conducta prosocial, educación secundaria, adolescencia

El autoconcepto es un constructo de gran relevancia en la psicología. Aunque el hecho de haber sido sometido a un gran número de conceptualizaciones y revisiones por parte de numerosos autores a lo largo de décadas dificulta su universalización, sí hemos recogido aquí una serie de definiciones que permiten hacerse una acertada idea de su significado.

Según Nurius (1986) el autoconcepto se define como un sistema de estructuras cognitivas que media interpretaciones y respuestas de los individuos. El autoconcepto dirige la conducta de los individuos mediante el mecanismo de selección y procesamiento de la información y a través de la entrega de un marco interpretativo de las consecuencias de esas conductas (Núñez y González, 1994). Por lo tanto la información del autoconcepto de los individuos presenta un alto potencial para generar un cambio relevante en las actitudes de las personas (Marsh, 2006).

Algunas definiciones del concepto contemplan la existencia de, al menos, las cuatro siguientes dimensiones del autoconcepto (Goñi, A., 2000):

- El autoconcepto afectivo-emocional: Cómo se ve una persona a sí misma en cuanto a ajuste emocional o regulación de sus emociones.

- El autoconcepto ético/moral: Hasta qué punto una persona se considera a sí misma honrada.

- El autoconcepto de la autonomía: La percepción de hasta qué punto decide cada cual sobre su vida en función de su propio criterio.

- El autoconcepto de la autorrealización: Cómo se ve una persona a sí misma con respecto al logro de sus objetivos de vida.

Se considera necesaria, pues, una revisión bibliográfica que, no sólo dibuje una tímida silueta a un concepto problemático en su definición, sino que recoja algunas relaciones con otros conceptos, factores y variables según hallazgos de investigaciones anteriores. 


\section{LA INFLUENCIA DEL GÉNERO}

Así pues en un estudio publicado en 2009 (Inglés, C. Pastor, Y. Torregrosa, M. S.,Redondo, J. García-Fernández, J.M.) se estudió la relación entre género y autoconcepto en función del curso académico. Con una muestra de 2.267 estudiantes de Educación Secundaria Obligatoria de 24 centros de la Región de Murcia y la provincia de Alicante, se obtuvieron algunas relaciones significativas en una serie de subescalas del autoconcepto, medidas por la adaptación española del Self-Description Questionnaire (SDQ-II; Marsh, 1992a), realizada por García-Fernández et al. (2006). Los resultados mostraban que las chicas se autopercibían más honestas y sinceras, con mayores habilidades verbales, con una mayor satisfacción en las relaciones con los padres y también con mayores habilidades para hacer amigas y ser populares entre ellas. En contraste, como comentan los propios autores del artículo "los chicos se autoperciben con mayor interés y habilidades para las actividades físicas, más satisfechos con su apariencia y atractivo físico, más tranquilos, relajados y estables emocionalmente y con mayores habilidades para las matemáticas".

Para finalizar, los autores recalcan que las diferencias entre chicos y chicas son congruentes con los estereotipos de género socialmente instaurados, de forma que las chicas presentan un mayor autoconcepto en áreas sociales mientras que los chicos informan un mayor autoconcepto en áreas relacionadas con la fuerza y la racionalidad.

\section{EL IMPACTO DE LA CONDUCTA PROSOCIAL}

Por otro lado, siguiendo la línea de la investigación anterior, en un estudio de 2012 (Inglés, C. Torregrosa, M. S.,Redondo, J. García-Fernández, J.M., Ruiz-Esteban, C.) se analizó la relación entre conducta prosocial y dimensiones del autoconcepto en una muestra de 2022 estudiantes españoles de Educación Secundaria Obligatoria, en la zona geográfica de la Región de Murcia y la provincia de Alicante, justo como el estudio anterior. La conducta prosocial fue medida con el Inventario de Habilidades Sociales para Adolescentes (TISS, Teenage Inventory of Social Skills; Inderbitzen y Foster, 1992), mientras que el autoconcepto fue medido con el SDQ-II. El estudió concluyó que la puntuación en conducta prosocial influye positiva y significativamente sobre las altas puntuaciones en las dimensiones habilidades físicas, relaciones con los padres, relaciones con el mismo sexo, relaciones con el sexo opuesto, verbal, académica general, sinceridad y autoestima, tanto en varones como en mujeres y en todos los cursos de la ESO.

\section{VARIABLES FACILITADORAS DEL RENDIMIENTO ACADÉMICO}

En un artículo, publicado en Enero del 2012, se presentaron los resultados de un estudio cuyo objetivo fue estimar la asociación entre autoconcepto y talento académico de alumnos de contextos socioeconómicos vulnerables. Se utilizó una metodología cuantitativa con un diseño correlacional, y una muestra intencionada de 1411 alumnos. Se recolectaron los datos a través de un sistema de Evaluación del Progreso en el Aprendizaje (SEPA) de Lenguaje y Matemáticas, un test de inteligencia práctica, creativa y analítica y un cuestionario de autoconcepto académico (TAC). Una vez aplicadas las pruebas anteriormente mencionadas y llevado a cabo el análisis de los resultados, estos permiten identificar la relación entre expectativas académicas, autoconcepto y talento académico y cómo estos tres elementos conforman un círculo 
virtuoso. La relevancia del rol del autoconcepto radica en la posibilidad que tiene de potenciar al máximo las habilidades innatas de los estudiantes (Cross \& Swiatek, 2009; Morawska \& Sanders, 2009). Esta investigación evidencia que un alto autoconcepto académico en niños con talentos ayuda a actualizar sus habilidades y a obtener mejores resultados académicos. Pero, al mismo tiempo, demuestra que un autoconcepto alto en niños sin talentos académicos también podría asociarse con la obtención de buenos resultados académicos.

Por último, destacar que estos hallazgos se observan en el contexto chileno y en una población específica de niños que asisten a colegios municipales, por lo que su generalización a otros contextos es limitada.

\section{VARIABLES PREDICTORAS DEL RENDIMIENTO ACADÉMICO}

En un estudio publicado en Marzo del 2012, se marcaba como objetivo analizar cómo los resultados académicos se relacionan con el autoconcepto y la ansiedad social en los adolescentes con padres divorciados. Para ello se emplea una muestra formada por 342 adolescentes con edades comprendidas entre 14 y 18 años, la mitad de ellos son padres divorciados. Los participantes informaron del número de sobresalientes y suspensos obtenidos y completaron el Cuestionario de Autoconcepto y la Escala de Ansiedad Social para Adolescentes. Dicho estudio resalta dos importantes conclusiones. Por un lado, se confirma por primera vez con una muestra española que los adolescentes con padres divorciados tienen peor rendimiento académico que los que viven con ambos padres, y que su autoconcepto académico es también peor, probablemente como resultado de sus peores resultados académicos. Y por otro lado, se examina por primera vez el autoconcepto y la ansiedad social como variables predictoras de los suspensos en adolescentes con padres divorciados.

Finalmente, se sugiere la importancia de detectar lo antes posible, desde el ámbito educativo, problemas escolares en los adolescentes con padres divorciados para prevenir el fracaso escolar y otros problemas asociados como el bajo autoconcepto.

\section{DIFERENCIAS DE GÉNERO EN EL AUTOCONCEPTO GENERAL Y ACADÉMICO DE ESTUDIANTES DE $4^{\circ}$ DE ESO}

En una investigación fechada entre Mayo y Agosto de 2010, se pretendía determinar la existencia y naturaleza de las diferencias de género en una muestra extraída de alumnos de $4^{\mathrm{a}}$ de la ESO, y estableciendo si estas diferencias son sólo a nivel general o de sus facetas, ya citadas anteriormente. Aunque debido a la naturaleza del estudio no es muy extrapolable a la población, sí corrobora otros resultados, como los obtenidos por Amezcua y Pichardo (2000).

Los resultados obtenidos parecen beneficiar a los aspectos emocional y familiar, siendo también positiva en general en ambos sexos. Aunque se aprecian diferencias en entre géneros en otras facetas, generalmente éstas no alcanzan una verdadera relevancia estadística, como en la autoimagen física. Empero, los varones obtienen puntuaciones más altas en autoconcepto emocional y global, revelando una cierta propensión femenina a la ansiedad. Finalmente, probablemente la más importante correlación hallada sea la que se da entre el autoconcepto físico y el global 
(especialmente en las chicas), revelándose este aspecto del autoconcepto como el que tiene mayor incidencia en el general.

\section{EL AUTOCONCEPTO PERSONAL: DIFERENCIAS ASOCIADAS A LA EDAD Y AL SEXO}

En un estudio del 2011 se analizaron las diferencias entre hombres y mujeres de diferentes edades en el autoconcepto personal, utilizando el Cuestionario de Autoconcepto Personal (APE). La muestra constaba de 1135 sujetos, divididos en tres categorías de edad. Tras analizar los resultados, lo primero que se percibe es que no hay un único patrón que afecte al autoconcepto personal en todos sus aspectos, y a que deben considerarse conjuntamente las dos variables (sexo y edad) para discriminar los resultados de Iso grupos. De nuevo, nos encontramos con que la más baja puntuación de autoconcepto emocional se da en mujeres adolescentes, y de nuevo, posiblemente debido a la ansiedad, favoreciendo los resultados en este grupo a los varones en general, contrariamente a la autorealización, que favorecería a las mujeres de cualquier edad.

Otro dato extraído es que la adolescencia es la etapa más autocrítica: Comparado con cualquiera de los otros dos grupos de edad, en ella se dan los valores más negativos en todos los aspectos. En cuanto a las mujeres de mayor edad, compensan en cierto sentido su autopercepción en la adolescencia con una mayor puntuación en honradez y autonomía, que se hace más significativo con la edad, coincidiendo con la teoría de la madurez psicosocial de Greenberger (1984).

\section{BIBLIOGRAFÍA}

Amezcua, J. A. y Pichardo, M.C. (2000). Diferencias de género en autoconcepto en sujetos adolescentes. Anales de Psicología, 16 (2), 207-214.

Goñi, A., 2000 Psicología del individualismo

Goñi E., Fernández-Zabala A., Infante G., 2011 El autoconcepto personal: diferencias asociadas a la edad y al sexo, Aula Abierta, Vol. 40, n. 1, pp. 39-50

Greenberger, E. (1984). Defining psychosocial maturity in adolescence. Advances in Child Behavioral Analysis and Therapy, 3, 1-37.

Inglés, C. Pastor, Y. Torregrosa, M. S.,Redondo, J. García-Fernández, J.M., 2009, Diferencias en función del género y e curso académico en dimensiones del autoconepto: estudio con una muestra de adolescentes españoles, Anuario de Psicología, vol. 40, n², 271-288.

María de la Luz González L. y Daniella Leal V., 2012, Autoconcepto y Talento: Una Relación que Favorece el Logro Académico. Instituto de Sociología, Pontificia Universidad Católica de Chile, Santiago, Chile; Carolina Segovia A., Centro de Estudios Públicos, Santiago, Chile; Violeta Arancibia C., Escuela de Psicología, Pontificia Universidad Católica de Chile, Santiago, Chile. 
Mireia Orgilés, Blair T. Johnson, Tania B. Huedo - Medina, José P.Espada., 2012, Autoconcepto y ansiedad social como variables predictoras del rendimiento académico de los adolescentes españoles con padres divorciados Departamento de Psicología de la Salud, Universidad Miguel Hernández de Elche, Alicante, España.

Padilla Carmona, M.T., García Gómez, S, Suárez Ortega, M, 2010 Diferencias de género en el autoconcepto general y académico de estudiantes de $4^{\circ}$ de ESO, Revista de Educación $n^{\circ}$ 352, 495-515. 


\title{
LA DEPENDENCIA EMOCIONAL EN LAS RELACIONES INTERPERSONALES
}

\author{
Isabel Rodríguez de Medina Quevedo. Universidad de Granada
}

\section{Resumen}

En el presente ensayo detallaremos si la imagen social creada del dependiente emocional es la ofrecida por la cognición del grupo mayoritario. Revisáremos la visión ofrecida por la literatura empírica actual sobre su conceptualización. A su vez, se analizarán los factores sociales que la favorecen. Por último, se señalarán las características psicológicas - conductuales remarcadas en las últimas publicaciones empíricas y los efectos negativos/positivos en las relaciones interpersonales de los individuos dependientes emocionales.

Palabras clave: Apego ansioso, dependencia, relaciones interpersonales, afectividad.

\section{INTRODUCCIÓN}

"El instinto social de los hombres no se basa en el amor en la sociedad, sino en el miedo a la soledad" (Arthur Shopenhauer)

La sociedad actual viene caracterizada por una mayor influencia de adicciones que no solo conllevan el uso de sustancias psicotrópicas, sino otras propias de la sociedad post-industrial, como por ejemplo: la comida, el sexo, la televisión, Internet, etc. entre ellas las relacionadas con la dependencia emocional.

Goleman (1996) destacaba que existe un claro descenso de la competencia emocional en las últimas décadas. Los jóvenes actuales sufren de mayores problemas emocionales (aislamiento, insatisfacción o dependencia) y también de las enfermedades más comunes del siglo XXI, como la ansiedad o la depresión.

Todas las patologías vienen derivadas de un malestar del sujeto, de un yo interno inestable que se explota en las convicciones sociales, en una necesidad constante de cariño y en la importancia del reflejo hacía los demás. Individuos con miedo a la instropección que determinan a las otros como su fuente de gozo y de ser. Ellos son lo que los demás quieren y con miedo cubren los espejos con sábanas para no ver su reflejo. No saben estar consigo mismo y requieren de un contacto continuo social que le sirven como sábanas que tapan su reflejo en el espejo.

Si las drogas existen para desinhibir al individuo de su propio self, la dependencia emocional también. La sensación de sentirse amado (Jaak Panksepp, 1998) se asemeja al placer de los opiáceos. Es decir, toda relación amorosa positiva provoca en los circuitos cerebrales la misma sensación de placer que las drogas más sintéticas. La gratificación del drogadicto con su droga se reproduce de forma biológica igual que el placer de sentirnos conectados con las personas amadas.

El sentirse querido, deseado, mimado, preocupado por otro ser, no sólo es una función básica, la social, sino que representa una gran cuestión existencial en 
nuestras vidas. Sin embargo, el deseo a veces se transforma en una sensación demasiada dolorosa, apática y destructiva, transformando una acción racional y positiva en una emanación de sentimientos negativos y patología.

\section{DESARROLLO}

\section{Concepto}

Cuando hablamos de dependencia emocional, ¿Cuál es su imagen? Mayormente se imaginan que son personas pasivas y obedientes, intentando complacer a los demás. Individuos inseguros e indecisos que no pueden tomar cualquier idea racional sin el apoyo de los demás.

Primeramente, es importante destacar que la dependencia emocional es diferencial al trastorno de apego ansioso descrito por Bowlby (1958), el trastorno límite de personalidad, la adición al amor o la sociopatría.

Son variadas las definiciones que la literatura ofrece, a nuestro parecer, y la más sencilla a su vez, vendría derivada por la siguiente afirmación: son personas con un concepto del self paupérrimo e ineficaz buscándolo en los demás. La dependencia emocional se concibe como una sobredependencia en una relación interpersonal, afectando a la visión de uno mismo (self) y a la de los otros (Valor et al., 2009).

Otros autores destacan su carácter de enganche o adición. La dependencia emocional son comportamientos adictivos hacia otras personas produciendo asimetrías de rol (Villa \& Sirvent, 2009). Por último, Jorge Castelló (2010), el autor español que mayor revisión ha realizado sobre la temática, atiende a los componentes afectivos y conductuales, definiéndola como un "patrón persistentes de necesidades emocionales insatisfechas que se intentan cubrir desadaptativamente con otras personas".

\section{Desarrollo de la dependencia emocional}

La dependencia emocional se desarrolla en el individuo según diversos factores. La mayoría de los estudios (Bornstein, 1992; Schore, 1994; Castello, 2000; Goleman, 2006; Bornstein, 2011) lo asocian a la sobreprotección de los padres, sin importar la cultura. Es decir, el autoritarismo parental se vincula con la generación de dependencias en los niños, adolescentes y adultos. Si en las relaciones parentales no se ocasiona la capacidad de ofrecer al niño comportamientos independientes y autónomos, sobreprotegiendo y evitando todo acto de construcción de su ser por si mismo (en especial en la adolescencia), el individuo tiene una alta probabilidad de engendrar una dependencia emocional hacia los demás. Es decir, la incapacidad de que el infante se desarrolle autónomamente y aprenda por ensayo - error durante este período crítico.

Las modalidades de padres autoritarios se relacionan con el apego inseguro denominado por Bowlby (1958), donde el niño es muy dependiente de su figura paternal, teniendo una ansiedad y miedo constante de separación.

La teoría de Schore (1994) destaca la importancia de las relaciones interpersonales (como la anteriormente citada de los padres) en la remodelación del cerebro. A través de la afirmación, mundialmente reconocida, de la teoría de la 
neuroplasticidad, Schore (1994) nos muestra que el cerebro va moldeándose significativamente, movilizando circuitos neuronales, por personas cercanas y relaciones interpersonales, en especial las negativas. Así pues, una mala experiencia amorosa o familiar puede provocar una desconfiguración en nuestro sistema cerebral.

Una vez definido el estilo de apego durante la infancia se desarrolla similarmente en la edad adulta, manteniéndose estable e influyendo en nuestras relaciones interpersonales. Si se produce un apego inseguro florecerá incorrectamente la corteza orbifrontal (Goleman, 2006) limitando la capacidad de regulación de emociones inquietantes como: miedo, enfado, etc.

Las características del niño con apego inseguro son muy similares a las del dependiente emocional buscando la proximidad y con desasosiego a perderla. La dependencia emocional tiene una relación directa con el apego ansioso, pero a la viceversa no se produce (Castello, 2000).

Shaver (1999, citado en Goleman, 2006), aplica la teoría del apego de Bowlby (1958) a las relaciones interpersonales adultas, identificando variadas tipologías. Aproximadamente el $20 \%$ de las parejas caen en relaciones ansiosas, personas indignas de amor que se preocupan excesivamente por el paradero de su pareja y se encuentran en un vacío sin ellas. Tienen grandes sentimientos de sufrir abandonos y una obsesión ruminante excesiva. No solo se aplica a las parejas, sino que experimenta sensaciones similares en las relaciones amistosas y familiares. Esta preocupación excesiva en mantener la relación interpersonal produce un ausencia de felicidad y confianza proclive de una ruptura inmediata.

Por otro lado, el rechazo produce dependencia interpersonal. Todos esperamos conectar con las personas que intervienen en el transcurso de nuestra vida. Cuando en una relación no se presta la suficiente atención, un individuo no asume su parte de compromiso, se genera siempre un sentimiento de desamparación que puede favorecer dependencias emocionales. Este sentimiento negativo tiene un origen neuronal situado en la corteza cingulada anterior (CCA) siendo la misma región que se activa cuando se produce un daño físico (Goleman, 2006). Por lo tanto, cuando se produce el rechazo social se activan los mismos circuitos cerebrales que avispan de un posible daño físico. Por esta razón, el cerebro se ha modulado de tal forma que el dolor de la perdida de un ser querido o de la exclusión se asemeja cognitivamente al impacto físico: "me han partido el corazón", "se me fue la vida".

\section{Características de los dependientes emocionales}

Los dependientes emocionales son individuos muy motivados a complacer a otras personas para lograr protección y apoyo. Generalmente, reúnen un perfil psicológico donde se dejan influir, significativamente, por las opiniones de los demás para cumplir sus expectativas y deseos. Sin embargo, cuando el individuo adquiere el rol de complacer a un compañero o la figura de autoridad, normalmente, el dependiente optar por complacer a la autoridad (Bornstein, 1992), ya que es el personaje capaz de ofrecer mayor orientación, apoyo y protección. Por esta razón, podemos generalizar que presentan un déficit de habilidades sociales, con ausencia de asertividad, un alto índice de egoísmo y una exclusividad impuesta.

Los dependientes emocionales requieren de apoyo incondicional manifestando actitudes extrínsecas para poder recibir la búsqueda de ayuda. Su rol en la mayoría 
de las ocasiones es de subordinado o antidependiente, ejerciendo, a veces, un papel pseudoaltruistra o de rescatador.

El perfil diferencial, muestra que tienen un acusado anhelo de estar con las personas que quieren ("craving") experimentando emociones negativas cuando no sienten su cercanía, como el dependiente del tabaco cuando no tiene un cigarro (abstinencia). Esta razón de adherencia produce que los sujetos dependientes emocionales adquieran dificultad para romper las ataduras, produzcan una amplía gama de emociones negativas, sean hiperdependientes de las relaciones interpersonales, y finalmente, una pseudosimbiosis (estar incompleto sin el otro). A su vez, esa dependencia tan parasitaria, produce que tengan una gran claustrofobia hacia la soledad.

En consideración a las relaciones amorosas, presentan una acusada ilusión al principio, idealizando al compañero, siendo primordial en su vida (después de una relación buscan otra inmediatamente) y remarcando la exclusividad.

El dependiente emocional transforma el amor en dolor, el placer en disgusto. Su mayor defecto a nuestro parecer, es su escasa estima, la preocupación excesiva por los demás, obviando el ítem más relevante del ser, su persona. Ante la siguiente tesitura es fácil poder deducir que los sentimientos se encuentran a "flor de piel" en sus relaciones y que la indiferencia o la ruptura pueden llegar a ser más dañinas que para el resto de los individuos. El rechazo es la principal fuente de dependencia emocional en las relaciones interpersonales. A nadie le agrada la idea de ser repudiados $u$ alejados. En algunos casos para mitigar ese dolor, los dependientes acuden al alcohol u otras drogas permitiendo calmar químicamente su enojo, ansiedad o depresión, ayudando a sosegar cogniciones que le atormentan.

En resumen, Villa y Sirvent (2009) definen tres componentes generales: adictofílicos (relacionados con los comportamientos propios de las adicciones), vinculares (patologías en la relación), cognitivo - afectivo (mecanismos de negación/autoengaño, sentimientos negativos, integridad del yo).

En relación a la diferencia entre géneros. Las mujeres generan mayores niveles de dependencia emocional que los hombres sobre auto - informe, pero los hombres sobre medidas proyectivas (Bornstein, 1992). A su vez, la mayoría de víctimas de violencia de género suelen destacar como dependientes (Valor et al., 2009). Esta última tesitura puede ser explicada a través de las diferenciaciones de roles de género según la cultura.

Ninguno de estos problemas, si se consideran aisladamente, es lo bastante poderoso cómo para denominarlo patología o causar una gran problemática en el ser. Pero si se consideran en conjunto, es un indicador de unos cambios en la sociedad que está consiguiendo envenenarla y que conlleva la dependencia emocional.

Aunque, la dependencia interpersonal a menudo tiene un impacto negativo sobre las amistades, el amor e impide el éxito profesional es beneficiosa para: el cumplimiento de los regímenes de tratamiento (Bornstein, 2011), un rendimiento mayor en la tarea para complacer al superior, e inferir de un modo superior en la orientación y apoyo hacía los demás (Bornstein, 1992). 


\section{CONCLUSION}

La dependencia emocional es un trastorno emocional de los individuos que afecta, en especial, a su self y estima en las diferentes relaciones personales. La mayoría de estudios muestran como las relaciones primerizas son las generadoras de nuestras futuras actuaciones interpersonales, siendo la más relevante la paterno filial. Cuando se favorecen relaciones de apego ansioso el cerebro se modela y derivarán en un individuo con dependencia emocional. A su vez, el rechazo o discriminación puede producir una dependencia.

Aunque los diferentes manuales relevantes de la Psicología no recogen esta patología, los sujetos diagnosticados sufren de una gran dolencia psíquica. El amor y el cariño, uno de las afecciones más positivas, se convierte en una fuente de dolor y angustia, provocando una constante infelicidad y vacío existencial.

Es necesario, que los manuales que rigen la actual Psicología Clínica abarquen la dependencia emocional, buscando programas cognitivos - conductuales o de otra tipología que mejoren la calidad de vida de los seres que la padecen y medrando, a su vez, las relaciones interpersonales en todos los ámbitos.

\section{BIBLIOGRAFIA:}

Allan Schore (1994). Affect Regulation and the Origin of the Self: The Neurobiology of Emocional Development. Hillsdale (NJ): Lawrence Erblaum.

Bornstein, R. F. (1992). The dependent personality: Developmental, social, and clinical perspectives. Psychological Bulletin, 112(1), 3.

Bornstein, R. F. (2011). An interactionist perspective on interpersonal dependency. Psychological Science, 20, 124-128.

Bowlby, J. (1958). The nature of the child's tie to his mother. Internacional Journal of Psychoanalysis, 39, 350-373.

Castello, J. (2010). Dependencia emocional. Características y Tratamiento. Barcelona: Psicología Alianza Editorial.

Castello Blasco, J (2000). Análisis del concepto "dependencia emocional", Congreso Virtual de Psiquiatría.

Goleman D. (1996). Inteligencia emocional. Barcelona: Kairós

Goleman, D. (2006). Inteligencia social. Barcelona: Kairós.

Panksepp, P. (1998). Affective Neuroscience: The Foundations of Human and Animal Emotions. Nueva York: Universidad Oxford Press.

Villa Moral, M. y Sirvent, C. (2009). Dependencia Afectiva y Género: Perfil Sintomático Diferencial en Dependientes Afectivos Españoles. Interamerican Journal of Psychology, 43, 230-240. 
Valor-Segura, I., Expósito, F. y Moya, M. (2009). Desarrollo y validación de la versión española de la Spouse-Specific Dependency Scale (SSDS). International Journal of Clinical and Health Psychology, 9, 479-500.

Worchel, S., Cooper, J., Goethals, G.R. y Olson, J. (2002). Psicología Social. Madrid: Thomson. 


\section{UN CENTRO LÚDICO COMO REFUERZO EDUCATIVO EN PERÍODO VACACIONAL, DIRIGIDO A NIÑOS DE 5-12 AÑOS}

Alba Marín Santaolaya, José María Romero Rodríguez. Universidad de Granada

\section{Resumen}

Se expone un proyecto para la creación de una ludoteca como refuerzo educativo destinado a niños de entre 5 y 12 años durante el período vacacional, con el objetivo de servir como referencia a otras personas interesadas en actividades de este tipo.

En esta ludoteca se desarrollan actividades relacionadas con las diferentes materias transversales (coeducación, educación ambiental, educación afectivo-sexual, educación vial, educación para la salud) y otras actividades lúdicas, tradicionales (taller de actividades tradicionales, taller artístico).

El objetivo principal de este proyecto es crear una interrelación entre educación y ocio, consiguiendo así formar a los niños a través de un ambiente recreativo y un marco de respeto mutuo.

Palabras clave: Centro pedagógico, material didáctico, transmisión educativa, educación, ocio.

\section{INTRODUCCIÓN}

"El objetivo principal de la educación es crear personas capaces de hacer cosas nuevas, y no simplemente repetir lo que otras generaciones hicieron" Jean Piaget

Un centro lúdico es un lugar donde se desarrolla una importante labor educativa a través de un amplio programa de actividades y juegos.

Las ludotecas favorecen el desarrollo y el aprendizaje de los niños, ofreciendo no solo el material y el espacio adecuado sino también la orientación, ayuda y compañía que los niños requieren, con la guía de personal cualificado. Constituyen por tanto un recurso necesario y complementario a la escuela para el tiempo de ocio infantil, donde los niños hacen amigos, se divierten, aprenden, utilizan, respetan y comparten actividades, juguetes y juegos, a la vez que siguen afianzando los conocimientos que van adquiriendo en la escuela.

Con el desarrollo de la sociedad y las nuevas tecnologías los niños han ido perdiendo en relaciones sociales y ensimismándose en estas nuevas tecnologías haciendo un uso excesivo de ellas y creándose una dependencia innecesaria con todo lo que ello conlleva, como la pérdida de juegos y actividades tradicionales, hábitos sociales, disfrutar de la naturaleza...etc. 
Son múltiples los daños ocasionados por un uso irresponsable e inadecuado de las nuevas tecnologías, internet proporciona diversa información pero muchas veces esta información no es concisa en los temas fundamentales que los niños deben conocer, por lo que en el desarrollo del centro lúdico hemos tratado este tema con información precisa de los temas de interés que todo niño y niña debe conocer para desenvolverse mejor en la sociedad que les rodea (coeducación, educación ambiental, educación afectivo-sexual, educación vial, educación para la salud) a parte de numerosas actividades lúdicas, tradicionales (taller de actividades tradicionales, taller artístico) para que puedan aprender que hay más alternativas que jugar con el ordenador, videoconsolas, etc.

Con todo esto se quiere conseguir el objetivo de crear una dependencia menor hacia estas nuevas tecnologías con un modelo alternativo donde se potencien las habilidades sociales y grupales, despertando en estos niños el uso de su imaginación, el desarrollo de sus capacidades (ya sean artísticas, deportivas, creativas, etc.) y como culminación del proyecto un refuerzo de los contenidos aprendidos por los niños, dando charlas a los padres para que esos contenidos se refuercen y sean realmente de utilidad.

\section{"La inspiración existe, pero tiene que encontrarte trabajando" Pablo Ruiz Picasso}

Esta ludoteca está destinada a los más afectados y vulnerables a los cambios estos son niños que se encuentran en edades de entre 5 y 12 años.

Se desarrollaría durante el período vacacional, cuando el problema se agrava aún más.

Tras llevar a cabo un pequeño estudio hemos observado las siguientes causas que provocan este problema:

- Falta de un centro lúdico donde puedan pasar los meses de verano.

- Carecen de información y refuerzo de las materias transversales (educación ambiental, educación vial, afectivo-sexual...).

- Numerosas horas con las nuevas tecnologías, videoconsolas y otros juegos tecnológicos.

- Economía, debido a la situación económica que estamos atravesando los padres no disponen del dinero necesario para poder llevar a los niños a otros centros como por ejemplo academias.

Descubrimos que todas estas causas tienen a su vez una serie de consecuencias:

- Falta de tiempo por parte de los padres, debido a los horarios de trabajo que tienen los padres no pueden hacerse cargo del niño durante todo el día.

- Falta de cultura e información.

- Pérdida de valores tradicionales, uno de los factores desencadenantes son las nuevas tecnologías.

- Falta de creatividad y de motivación. 
Detectadas todas estas necesidades, creamos un orden de prioridades, ordenándolas de mayor a menor importancia:

- Economía: debido a las dificultades económicas y generalmente el trabajo de los padres los niños necesitan un centro lúdico y recreativo donde puedan pasar los meses de verano.

- Valores tradicionales: estos valores se están perdiendo debido a las nuevas tecnologías lo que provoca a su vez un alejamiento de las relaciones sociales con cierta tendencia al aislamiento.

- Fomentar las relaciones sociales con la relación y convivencia en grupo.

- Aumento cultural a través de la transmisión de las materias transversales.

\section{Soluciones}

Tras realizar el estudio llegamos a la conclusión de que las soluciones que debemos aplicar para solucionar el problema son las siguientes:

- Creación de la ludoteca de carácter gratuito para los niños.

- Incentivar y enseñar a los niños los juegos tradicionales en grupos para que puedan ser aplicados con normalidad, dejando a un lado las nuevas tecnologías y el aislamiento que producen.

- Motivar a través de diversos juegos y actividades la convivencia en grupo.

- Aprender a través de juegos y actividades las materias transversales.

- Refuerzo de los contenidos con charlas informativas sobre los temas más relevantes a los padres.

Dependiendo de cada edad se desarrollarán unas actividades acordes con esas edades con la finalidad de que resulte útil y divertido tanto para niños de 5 años como de 12 años.

\section{PROBLEMAS, NECESIDADES Y OBJETIVOS}

Se plantean una serie de problemas a los que les damos respuesta proponiendo unos objetivos y unas actividades para alcanzarlos.

\begin{tabular}{|c|c|c|}
\hline PROBLEMAS & OBJETIVOS & ACTIVIDADES \\
\hline De tipo económico. & $\begin{array}{l}\text { Lograr la igualdad de oportunidades } \\
\text { en las familias. }\end{array}$ & Ludoteca gratuita. \\
\hline Pérdida de valores tradicionales. & $\begin{array}{l}\text { Alejar a los niños de las nuevas } \\
\text { tecnologías debido a su abuso. }\end{array}$ & $\begin{array}{l}\text { Juegos de carácter tradicional como } \\
\text { la comba, petanca, etc. }\end{array}$ \\
\hline $\begin{array}{l}\text { Aislamiento y pérdida de relaciones } \\
\text { sociales. }\end{array}$ & $\begin{array}{l}\text { Fomentar las relaciones sociales y } \\
\text { convivencia en grupo. }\end{array}$ & $\begin{array}{l}\text { Juegos en grupos de tipo ayuda y } \\
\text { confianza mutua. }\end{array}$ \\
\hline \multirow[t]{2}{*}{ Aprendizaje de materias transversales } & \multirow[t]{2}{*}{ Aumentar la cultura e información. } & $\begin{array}{l}\text { Juegos de } \\
\begin{array}{l}\text { diversos tipos } \\
\text { dependiendo de la educación } \\
\text { requerida. }\end{array}\end{array}$ \\
\hline & & $\begin{array}{l}\text { Refuerzo de los contenidos con } \\
\text { charlas a los padres sobre las } \\
\text { materias transversales. }\end{array}$ \\
\hline
\end{tabular}


Tras una vista general de los problemas, objetivos y necesidades nos centramos en aquellos aspectos singulares y específicos de cada taller a desarrollar:

\section{Taller de actividades tradicionales:}

\begin{tabular}{|l|l|l|}
\hline Necesidades & Objetivos & Actividades \\
\hline $\begin{array}{l}\text { Uso excesivo de las nuevas } \\
\text { tecnologías que desencadena la falta } \\
\text { de relaciones sociales y amistades. }\end{array}$ & $\begin{array}{l}\text { Desarrollar sus capacidades afectivas } \\
\text { en todos sus ámbitos, personalidad y } \\
\text { en sus relaciones con los demás. }\end{array}$ & Juego del pilla-pilla. \\
\cline { 3 - 4 } & & Juego del parchís y la oca. \\
\cline { 3 - 4 } Pérdida de valores como la compasión & $\begin{array}{l}\text { Valorar la actividad física como algo } \\
\text { agradable, conocer las posibilidades } \\
\text { y solidaridad. }\end{array}$ & $\begin{array}{l}\text { Juego de la goma. } \\
\text { diferencias individuales y jugar sin } \\
\text { discriminación alguna. }\end{array}$ \\
\cline { 3 - 4 } & & Juego del relojito. \\
\hline
\end{tabular}

\section{Taller de educación artística:}

\begin{tabular}{|c|c|c|}
\hline Necesidades & Objetivos & Actividades \\
\hline $\begin{array}{l}\text { Ausencia de creatividad debido a las } \\
\text { nuevas tecnologías. }\end{array}$ & $\begin{array}{l}\text { Desarrollar la imaginación y la } \\
\text { creatividad. }\end{array}$ & Plantear un proyecto a dibujar. \\
\hline \multirow[t]{2}{*}{ Pérdida de habilidades sociales. } & \multirow[t]{2}{*}{$\begin{array}{l}\text { Fomentar el trabajo respetuoso y } \\
\text { cooperativo entre los compañeros. }\end{array}$} & $\begin{array}{l}\text { Realización de una máscara de su } \\
\text { propia cara. }\end{array}$ \\
\hline & & $\begin{array}{l}\text { Elaboración de un cuadro en grupos } \\
\text { de } 2,3 \text { personas. }\end{array}$ \\
\hline
\end{tabular}

\section{Taller de educación para la salud:}

\begin{tabular}{|c|c|c|}
\hline Necesidades & Objetivos & Actividades \\
\hline \multirow{2}{*}{$\begin{array}{l}\text { Problemas como la obesidad, cada vez } \\
\text { más presentes en los niños de estas } \\
\text { edades. }\end{array}$} & \multirow{2}{*}{$\begin{array}{l}\text { Conocer y aprender una serie de } \\
\text { dietas que favorezcan a un estilo de } \\
\text { vida sano. }\end{array}$} & $\begin{array}{l}\text { Explicar a los niños la pirámide } \\
\text { alimenticia y hacer una pirámide. }\end{array}$ \\
\hline & & $\begin{array}{l}\text { Explicación con power point sobre } \\
\text { problemas alimenticios. }\end{array}$ \\
\hline \multirow{2}{*}{$\begin{array}{l}\text { Desconocimiento de } \text { sustancias } \\
\text { nocivas para el organismo. }\end{array}$} & \multirow{2}{*}{$\begin{array}{l}\text { Conocer y comprender de forma crítica } \\
\text { los efectos malignos de sustancias } \\
\text { nocivas para nuestro organismo. }\end{array}$} & Explicación con power point. \\
\hline & & $\begin{array}{l}\text { Identificar mediante láminas las } \\
\text { sustancias nocivas de las que no lo } \\
\text { son. }\end{array}$ \\
\hline
\end{tabular}

\section{Taller de educación ambiental:}

\begin{tabular}{|l|l|l|}
\hline Necesidades & Objetivos & Actividades \\
\hline Falta de conciencia sobre el reciclaje. & $\begin{array}{l}\text { Utilizar el reciclaje como } \\
\text { medida preventiva. }\end{array}$ & $\begin{array}{l}\text { Rehusando material de desecho, los niños } \\
\text { construirán un juguete o un objeto con una utilidad } \\
\text { funcional o decorativa. }\end{array}$ \\
\hline $\begin{array}{l}\text { Aumento de la contaminación del } \\
\text { medio ambiente. }\end{array}$ & $\begin{array}{l}\text { Conseguir que los niños } \\
\text { respeten y valoren el medio } \\
\text { ambiente. }\end{array}$ & $\begin{array}{l}\text { A través de salidas al campo sealizaran juegos } \\
\text { (como el escondite) y plantaciones de árboles y } \\
\text { semillas. }\end{array}$ \\
\hline
\end{tabular}




\section{Taller de coeducación:}

\begin{tabular}{|l|l|l|}
\hline Necesidades & Objetivos & Actividades \\
\hline Falta de información y recursos. & $\begin{array}{l}\text { Educar en igualdad y oportunidades de } \\
\text { género. Dar a conocer la importancia } \\
\text { de la mujer a lo largo de la historia. }\end{array}$ & $\begin{array}{l}\text { Intercambio de roles establecidos } \\
\text { sobre hombres y mujeres por medio de } \\
\text { la inversión de papeles. }\end{array}$ \\
\hline $\begin{array}{l}\text { Estereotipos presentes en la sociedad } \\
\text { que categorizan a los géneros. }\end{array}$ & Eliminar estereotipos y prejuicios. & $\begin{array}{l}\text { Enseñar a utilizar los juguetes } \\
\text { indistintamente, sin pensar en el } \\
\text { género }\end{array}$ \\
\cline { 2 - 3 } & & $\begin{array}{l}\text { Ejercicios verbales y escritos sobre los } \\
\text { estereotipos presentes. }\end{array}$ \\
\hline
\end{tabular}

\section{Taller de educación vial:}

\begin{tabular}{|l|l|l|l|}
\hline Necesidades & Objetivos & Actividades \\
\hline Desconocimiento de las señales. & $\begin{array}{l}\text { Conocer las señales básicas de } \\
\text { circulación. }\end{array}$ & $\begin{array}{l}\text { Enseñarles las señales y su } \\
\text { funcionalidad. }\end{array}$ \\
\hline $\begin{array}{l}\text { No respeto de las normas de } \\
\text { circulación que puede ocasionar } \\
\text { accidentes graves. }\end{array}$ & $\begin{array}{l}\text { Alcanzar la comprensión y yonarar de circuito que } \\
\text { cumplimiento de las normas viales. }\end{array}$ & $\begin{array}{l}\text { Montar una especie de } \\
\text { contenga los aspectos básicos de la } \\
\text { calle. }\end{array}$ \\
\hline
\end{tabular}

\section{Taller de educación afectivo-sexual:}

\begin{tabular}{|l|l|l|}
\hline Necesidades & Objetivos & Actividades \\
\hline Construcción de la propia identidad. & Conocer su propio cuerpo y aceptarlo. & $\begin{array}{l}\text { Entre todos dibujarán la silueta de un } \\
\text { niño a tamaño real y lo completarán } \\
\text { con todas sus partes. A continuación } \\
\text { realizarán lo mismo con el sexo } \\
\text { opuesto. }\end{array}$ \\
\hline Construcción de la moralidad. & Valorar el sexo opuesto. & $\begin{array}{l}\text { Organización de un "debate", durante } \\
\text { un tiempo los niños serán } \\
\text { considerados superiores a las niñas, } \\
\text { pasado este tiempo consideraremos a } \\
\text { las niñas superiores respecto a los } \\
\text { niños. Una vez finalizada la actividad } \\
\text { pondremos en común los aspectos } \\
\text { negativos, opiniones, sentimientos... }\end{array}$ \\
\hline
\end{tabular}

\section{MATERIAS TRANSVERSALES}

Los Ejes transversales han sido definidos por González Lucini en su obra Educación en valores y Diseño Curricular (1992) como "contenidos de enseñanza y de aprendizaje (...) que afectan a todas las áreas y deben ser desarrollados a lo largo de toda la escolaridad".

Los aprendizajes relacionados con los temas transversales contribuyen a la educación en valores morales y cívicos, a la formación integral de los estudiantes y a su proceso de sociabilización.

Los temas transversales al igual que la educación, son de carácter abierto, siempre se puede indagar e innovar en ellos, no son inamovibles.

Tratan temas de gran importancia como el deterioro del medio ambiente, la violencia de género, discriminación de la mujer, consumo de sustancias nocivas, equilibrio y estabilidad personal. Señalan y recogen determinados aspectos problemáticos y/o 
controvertidos de la realidad con el fin de informar sobre ellos para que cada uno tome consciencia y cartas en el asunto y no permanezca ajeno a una realidad social (la cual nos incluye a todos).

Por tanto es necesario dar a conocer estas materias ¿Y qué mejor momento? Que en período vacacional donde los niños "no tienen nada que hacer, entre otras muchas cosas".

Cada taller tiene una finalidad explícita:

- Taller de actividades tradicionales: Desarrollado con la finalidad de controlar el uso excesivo de las nuevas tecnologías y aumentar la sociabilización de los niños.

- Taller de educación artística: Con el objetivo de fomentar el desarrollo de la expresividad y creatividad de los niños.

- Taller de educación para la salud: Destinado a la promoción y prevención de hábitos saludables y prácticas deportivas.

- Taller de educación ambiental: Con la finalidad de concienciar a los más jóvenes sobre la importancia del cuidado del medio ambiente y el reciclado.

- Taller de coeducación: Con el objetivo de tratar cuanto antes temas sobre igualdad y eliminar estereotipos de género. Coeducar nos corresponde a todos.

- Taller de educación vial: Con la intención de que los niños conozcan las normas y señales de circulación para prevenir accidentes ocasionados por su desconocimiento.

- Taller de educación afectivo-sexual: Con la finalidad de descubrir y aceptar su cuerpo así como la valoración del sexo opuesto.

\section{REFUERZO DE LOS CONTENIDOS}

Todo contenido que no lleve consigo un refuerzo, es como si quedara "a medias", incompleto.

Es vital un refuerzo y más aun tratándose de contenidos que afectan a la socialización y desarrollo de los niños. Se trata así, de no centrarse solo en la parte del desarrollo de la ludoteca con sus múltiples actividades, sino de poder ampliarse más allá reforzando dichos contenidos con charlas a los padres sobre las diversas cuestiones explicadas.

Temas a tratar como:

- Reducir el uso de las videoconsolas y ordenadores en los niños.

- Fomento de los juegos tradicionales como recurso educativo, para así lograr una mayor comunicación con nuestros hijos a la vez que desarrollan ellos su inteligencia.

- Cómo crear hábitos saludables en los niños.

- La importancia de hacer deporte en la salud.

- El deporte como elemento socializador.

- Uso adecuado de los recursos medioambientales.

- La importancia de un reciclaje adecuado. 
- Salidas al campo y contemplación de la naturaleza como recurso educativo.

- La eliminación de estereotipos y prejuicios.

- El desarrollo de la afectividad y la oposición a la violencia.

- El reconocimiento de la diferencia entre sexos.

- La práctica del diálogo como medio de resolución de conflictos.

- Conocimiento y aceptación del propio cuerpo.

- El desarrollo de la afectividad y prevención de la violencia y el género.

- Establecimiento de las diferencias entre sexos.

- Construcción del autoconcepto y la autoestima.

- Prevención de enfermedades y métodos anticonceptivos.

Siempre al terminar las charlas, los padres que estén más interesados en el tema podrán apuntar su correo en una hoja donde se les enviará más información sobre los temas que estén más interesados.

\section{CONCLUSIONES}

Tras el estudio y análisis de las necesidades encontradas durante la realización del proyecto concluimos con una serie de argumentos desprendidos del estudio realizado, dándole respuesta a estos problemas con la creación del centro lúdico.

La falta de un centro lúdico donde poder invertir el tiempo libre durante los meses de verano no solo beneficia a niños y padres sino a la comunidad en general, integrando valores sociales y pautas de comportamiento básicas. La ludoteca se crea con el objetivo de llevar a cabo el aprendizaje de las diferentes materias transversales y por otra parte lograr una menor implicación de las nuevas tecnologías en la vida diaria de los niños.

Creemos muy importante llevar a cabo este tipo de proyectos, pues hay que invertir en las nuevas generaciones, ya que ellos serán nuestro mañana.

Para finalizar animamos a todo el mundo a llevar a cabo nuevos proyectos de intervención educativa.

\section{REFERENCIAS BIBLIOGRÁFICAS}

Arriaza Mayas, J.C. (2006). "Cuentos para la Educación vial": cuentos para que niños y niñas aprendan normas básicas de seguridad vial y primeros años (Educación Infantil y primeros cursos de Primaria). Madrid: Ciencias de la Educación, Preescolar y Especial.

Bonal, Xavier. (1997). Las actitudes del profesorado ante la coeducación: Propuestas de intervención. Barcelona: Graó.

Cabrera Plazuelo, MC. (2009). Programa Coeducación: "Conozco a los demás", Hekademos, 3, 17-50. 
Casares García, P. (2012). Teoría de la Educación, guía de estudio 2012-2013. Granada.

Giráldez, A. y Pimentel, L. (2011). Educación artística, cultura y ciudadanía, de la teoría a la práctica. Educación Artística. Madrid: Organización de Estados Iberoamericanos para la Educación, la Ciencia y la Cultura (OEI).

Gladhys, M.R. (2009). Educación Física y su contribución al desarrollo integral de los niños en la primera infancia, Revista Iberoamericana de educación, 50 (7).

Lillo, Juan. (2006). Educación para la igualdad de género: de las grandes declaraciones a las buenas prácticas. Ponencia Jornadas para la Educación en Igualdad de Género, Baeza, marzo.

López, S. (2003). “Curso de Educación Afectivo-Sexual”, Madrid: Netbiblo.

Marín Viadel, R. (2011), "La Investigación en Educación Artística”, Educatio siglo XXI, 29, 1, 211-230.

Martí y Garbayo, M. y Sanz, I. (2003). "Medio ambiente”: actividades creativas para la educación infantil. Barcelona: Parramón.

Philip Rice, F. (1997). Desarrollo humano, estudio del ciclo vital. Madrid: Pearson Educación.

Ballarin, Pilar. (1993). El mito de la coeducación. En J. Ramos García (Comp.), El camino hacia una escuela coeducativa (119-128). Sevilla: M.C.E.P.

Subirats Martori, M. (1994). Conquistar la igualdad: la coeducación hoy. Revista Iberoamericana de Educación. 6, 49-78.

\section{«Fuentes electrónicas»}

www.educacionparalasalud.es (Consulta: 11/12/2012). Página web que contiene información acerca de temas y actividades relacionados con la promoción de la salud.

http://juegostradicionales.org/ (Consulta: 11/12/2012). Página web donde resalta algunos juegos tradicionales y populares de la infancia. 


\title{
VOLUNTARIADO. PERSPECTIVAS DE LOS ESTUDIANTES DE DESARROLLO INTERNACIONAL \\ VOLUNTEERISM. PERSPECTIVES FROM INTERNATIONAL DEVELOPMENT STUDIES STUDENTS
}

Jory Bolton (jorybolton@trentu.ca). Trent University

\begin{abstract}
Resumen
Este artículo examina las perspectivas variadas del 'voluntariado' a través de un enfoque de investigación. Para terminar esta investigación, un grupo de estudiantes de los estudios de desarrollo internacional (EDI) en la Universidad de Trent funcionó como participantes de investigación. El campo de EDI es muy interdisciplinario y muchas veces hay discrepancias entre perspectivas porque los estudiantes vienen de diferentes antecedentes académicos, por lo que los estudiantes de EDI son candidatos excelentes para una investigación como ésta. A cada estudiante se le pidió a crear un 'mapa mental' para expresar su propia definición del voluntariado. Los datos recogidos se utilizó para ilustrar cómo las percepciones del voluntariado comparan y contrastan, particularmente a las opiniones de la autora. Esta investigación se amplió aún más, examinando cómo factores como la edad y el género afectan las percepciones del voluntariado.
\end{abstract}

Palabras clave: voluntariado, altruismo, enfoques interdisciplinarios, mapas mentales

\begin{abstract}
This paper examines the varying perspectives of 'volunteerism' through an investigative approach. In order to complete the investigation, a small class of international development studies (IDS) students at Trent University acted as research participants. Because IDS is so interdisciplinary, there are often discrepancies between perspectives as students hail from different academic backgrounds, thus making IDS students prime candidates for such an experiment. Each student was asked to create a 'mind map' to convey their personal definition(s) of volunteerism. The data collected was used to illustrate how different perceptions of volunteerism compare and contrast, particularly to the author's own perceptions. This investigation was expanded further, examining how factors such as age and gender affect perceptions.
\end{abstract}

Key Words: volunteerism, altruism, interdisciplinary approaches, mind maps 


\section{Introducción}

En los estudios de desarrollo internacional (EDI) los estudiantes aprenden la razón por la que el mundo es tan desigual y por la que un pequeño por ciento de la población del mundo vive en la riqueza extrema mientras que otra gente vive en la pobreza extrema. Los estudiantes examinan las causas de las desigualdades globales además estudian las soluciones potenciales para derrotar esas desigualdades empobrecedores. Una solución discutida rutinariamente es el voluntariado.

El voluntariado se practica en todas partes y en general es conocido como "haciendo el bien" para ayudar a los necesitados; sin embargo, ¿el voluntariado se compone solamente de esas cosas? $\mathrm{O}$, ¿es el voluntariado más complejo, afectando la gente a través de una variedad de factores en una variedad de niveles? ¿Hay única definición aceptada, o una persona puede generar su propia definición, basado en sus experiencias? Creo que cómo definimos el voluntariado está basado en el segundo y por eso 'el voluntariado' puede referir a varios tipos del voluntariado y también a los efectos que tiene en la vida de la gente.

Mis percepciones son mezcladas. En la superficie relaciono el voluntariado con aspectos positivos - "haciendo el bien", ayudar a otros, haciendo la diferencia; pero ¿qué significan esas palabras? Cuando pienso en el voluntariado en un nivel más profundo, tengo conclusiones diferentes. La primera es la conexión entre el voluntariado y el altruismo. El altruismo es una idea filosófica de ayudar a otros sin tener en cuenta sus propios intereses (Haski-Leventhal, 2009). El altruismo representa el sacrificio de sí mismo para beneficiar a otro, incluso lo que significa dañarse a sí mismo durante el proceso. Debido a esa idea, se puede discutir que las ideas de altruismo están muy unidas con el voluntariado. No intento discutir que todas las formas del voluntariado son ejemplos del altruismo, tampoco no deseo discutir que todas las acciones del altruismo son ejemplos del voluntariado - quiero abordar simplemente la correlación fuerte entre los dos y que cuando usamos una perspectiva del altruismo, podemos aumentar nuestro conocimiento del voluntariado. Otra característica del altruismo es el sentido del deber (Haski-Leventhal, 2009). Creo que esto es importante porque las motivaciones de mucha gente están basadas en un sentido del deber a ayudar a otros. Este sentido puede ser derivado a partir de una variedad de razones, pero una razón prominente es la diferencia entre los estatus económicos. Mucha gente se ofrece como voluntario para ayudar a otros que son menos afortunados. Este deseo está relacionado con la característica socio-biológico del altruismo - que ayudando a otros es arraigado en nuestra composición genética y por eso naturalmente nos sentimos que sea nuestro sentido del deber y nuestro propósito a ayudar a otros. Creo que hay mucha gente que se ofrece como voluntario para hacer la diferencia, usando un enfoque altruista; sin embargo, creo que el voluntariado es asociado con más cosas y que el voluntariado tiene efectos negativos, algunos que causan más daño que beneficio.

Una razón principal por la que estoy escéptica del voluntariado es que pregunto las motivaciones de los voluntarios. ¿Se ofrecen como voluntario para tener beneficio propio? ¿Participan para lograr la autoestima? Todo el tiempo encuentro que estoy preguntando esas preguntas. A veces, cuando los voluntarios participan sin motivaciones buenas, hacen más daño que beneficio. También, si los participantes voluntariados tienen un conocimiento restringido de las comunidades donde están trabajando, problemas pueden ocurrir, muchas veces una consecuencia de la falta de la sensibilidad cultural. Un ejemplo es la falta de la sensibilidad cultural en relación con los atuendos apropiados. En comunidades conservadoras podría ser una expectación que la gente lleva puesta la ropa menos reveladora. Un voluntario 
que no está consciente de las normas culturales puede llevar puesta la ropa considerada inaceptable, creando problemas entre los voluntarios y la comunidad.

Otro ejemplo es los problemas asociados con 'volunturismo', los programas que mezclan el voluntariado con el turismo. Se podría argumentar que estos programas pueden hacer el bien; sin embargo, como una escéptica, me inclino ver los aspectos negativos. Las experiencias del volunturismo están manejadas para las compañías, es una empresa. Por eso, pregunto si este tipo del voluntariado es para beneficiar los pobres y la gente desfavorecida o para ganar dinero para las compañías. También pregunto si la gente participa en estos programas para ofrecerse como voluntario o para viajar a otros países a precio bajo. Estos programas son una mezcla del voluntariado y el turismo y por esto, me siento que haya potencial para enfocar en las necesidades de los participantes más que las necesidades de las comunidades que necesitan ayuda. No estoy argumentando que estos programas son negativos en entero; sin embargo, se debe examinarlos con un enfoque crítico. Creo que el voluntariado tiene ambos los beneficios y las desventajas y me sentí que sea importante descubrir si otros en mi campo académico comparten la misma actitud.

\section{El Propósito}

Debido a las discrepancias entre las opiniones en el campo de EDI, particularmente en relación con el voluntariado, decidí hacer un proyecto de investigación para descubrir cómo las perspectivas de los estudiantes de EDI difieren. La idea de dar ayuda a otros domina el campo de los estudios de desarrollo internacional y por eso decidí examinar las perspectivas variadas del voluntariado. Quise ver cómo mis propias opiniones compararon y contrastaron a las perspectivas de otros estudiantes. No quise ver solamente las similitudes y las diferencias entre las opiniones, quise examinar también cómo los factores como la edad y el género afectan las percepciones.

El voluntariado se está volviendo más prevalente mientras el mundo globaliza. Desafortunadamente el debate del voluntariado está aumentando también. ¿El voluntariado está ayudando a otros? ¿Es la motivación para ofrecerse como voluntario la satisfacción de sí mismo? ¿Es para ver el mundo? El debate es interminable. Es importante crear una definición colectiva si queremos tener un gran efecto en las comunidades. El propósito de esta investigación no es intento homogenizar el voluntariado. Tampoco no para crear una definición homogenizada. Mi propósito es para ilustrar que un concepto corriente principal puede tener perspectivas variadas, incluso en el mismo campo académico.

\section{La Metodología}

Para hacer esta investigación, una clase de los estudiantes de EDI en cuatro años funcionó como participantes de investigación. Había dieciséis estudiantes. Los estudiantes, de edades comprendidas entre veintiún y cuarenta y cinco años, consistieron en cuatro hombres y doce mujeres, una representación exacta de la Universidad de Trent en su conjunta. De estos estudiantes, solamente cinco decidieron participar en la investigación. Esas cinco estudiantes fueron mujeres, de las edades entre veintiún y treinta y uno. Durante toda la investigación, los participantes permanecieron anónimos.

3 ReiDoCrea. Revista electrónica de investigación Docencia Creativa. Volumen 2. Páginas 157-162 
Cada participante se le pidió a crear un mapa mental para ilustrar sus pensamientos. Los mapas mentales son diagramas que resumen la información, muchas veces se usa como herramienta de la tormenta de ideas. Las representaciones gráficas datan de muchos siglos; sin embargo, el concepto de los mapas mentales solamente ha desarrollado en los años sesenta y setenta por Tony y Barry Buzan (Whiting, 2012). Los mapas mentales tienen cuatro características importantes: (a) el sujeto del mapa tiene que estar en el centro, lo que le permite ser el punto focal; (b) los temas que tienen una relación con el sujeto se bifurcan de la palabra en el centro; (c) los temas más relevantes se bifurcan de la palabra en el centro, sin embargo, otros temas se bifurcan de esos temas; y (d) las ramas deben conectarse entre sí, creando una representación gráfica de las ideas y los conceptos mientras que están conectando las relaciones (Whiting, 2012). Los mapas mentales son buenas herramientas para conectar las relaciones estructurales y representacionales entre los conceptos y los subconceptos.

Para hacer esta investigación, los participantes usan los mapas mentales como una herramienta para ilustrar sus percepciones del voluntariado, lo que permite a los participantes a conectar los temas. Para hacer la recopilación de datos, los mapas mentales representaron claramente las similitudes y las diferencias entre los participantes, lo que permite un análisis fácil.

\section{Los Resultados}

Los resultados fueron sorprendentemente muy similares. Las variaciones fueron más pequeñas que anticipaba. Ochenta por ciento de los participantes creyeron que el voluntariado tiene ambas consecuencias positivas y negativas. Las consecuencias positivas se pueden dividir en dos categorías: (a) las consecuencias positivas para las comunidades que están recibiendo los servicios de los voluntarios; y (b) las consecuencias positivas para los voluntarios.

El voluntariado puede ser beneficial para las comunidades que están recibiendo la ayuda. Muchos de los participantes creían que el voluntariado es beneficial en las comunidades porque puede ocupar las grietas cuando los programas gubernamentales no tienen la capacidad. Por ejemplo, si el fondo de la educación en un país no tiene bastante dinero para construir una escuela, los voluntarios pueden construir la escuela sin cargo. La mayoría de los participantes también mencionaron la importancia de un aumento en conciencia - si la conciencia de problemas (económicos, sociales, políticos, de género) aumenta, el aumento de la atención puede generar en un aumento en la ayuda en esas comunidades. El voluntariado construye las comunidades. Esta idea fue una cosa en común entre los resultados de los participantes también. La ayuda mejora las comunidades, pero al mismo tiempo la ayuda crea salidas de comunicación entre los voluntarios y los miembros de las comunidades que es buena también. Un participante escribió algunas frases excelentes que tuvieron un gran impacto en mi percepción del voluntariado. Este participante escribió que el propósito del voluntariado es "to make an impact, not a difference" (para hacer un impacto, no la diferencia) y que el voluntariado es sobre "action rather than just talking" (la acción más que hablar). Me siento que sea muy importante considerar esas frases.

Los participantes creyeron que el voluntariado beneficia a los voluntarios también. Muchos participantes dijeron que la gente escoge ofrecerse como voluntario para participar en una cosa 
que les gusta, desarrollando una pasión. Esta pasión puede desarrollar en muchas oportunidades de empleo y al establecimiento de contactos. Si una persona tiene una pasión de una cosa, en general significa que esta persona ha obtenido un conocimiento más profundo de esa cosa. La mayoría de participantes se sintieron que el voluntariado es clave para obtener este conocimiento profundo. Cuando una persona se ofrece como voluntario, se vuelven a ciudadanos informados que están conscientes de lo que está ocurriendo en el mundo y cómo estos hechos afectan a la gente. La mayoría de los participantes también se sintieron que las oportunidades de viajar que crecen del voluntariado pueden llevar al aprendizaje de nuevas lenguas, que es ventaja; sin embargo, el turismo asociado con el voluntariado puede desarrollar en los problemas éticos, por ejemplo las motivaciones de los voluntarios para hacer el voluntariado.

Los problemas éticos no fueron las únicas consecuencias mencionadas. Como mí, muchos de los participantes mencionaron la negatividad que acompaña el 'volunturismo'. Los participantes creyeron que a diferencia de las organizaciones gubernamentales y las empresas, los voluntarios tienen poca ( $\mathrm{y}$ a veces nada) responsabilidad, lo que significa que la confiabilidad de los voluntarios está disputada. Muchos participantes usaron la frase "can do more harm than good" (puede causar más daño que beneficio) cuando hacen una referencia a las consecuencias negativas del voluntariado.

De los cinco participantes, solamente uno habló de la relación entre el altruismo y el voluntariado. Esto participante dijo que el voluntariado es una reacción natural que yo he mencionado también. El participante se sintió que el voluntariado sea un acto de bondad natural. Aunque los otros participantes no refirieron directamente al altruismo, todos los participantes refirieron a la necesidad del voluntariado, si había sacrificio de sí mismo o no. Un participante se usó el ejemplo de las horas obligatorias del voluntariado en la escuela secundaria canadiense para graduarse. Otro participante habló de cómo a veces el voluntariado está obligatorio en los cursos en la universidad también. En total, las respuestas de los participantes eran muy similares a mis propias percepciones.

Respecto a las comparaciones basadas en la diferencia entre las edades y los géneros, no podría hacer esta investigación con los participantes que yo tenía porque todos los participantes eran mujeres y de estas mujeres, ochenta por ciento tenían veintiún años. El otro participante tenía treinta y un años. Aunque no pudo comparar las percepciones basadas en la edad y el género, espero que pueda investigarlas en el futuro.

\section{La Conclusión}

El voluntariado es muy importante en los estudios de desarrollo internacional y por eso, me sentí que sea necesario investigar cómo los estudiantes de EDI lo perciben. También, quise comparar y contrastar esas percepciones a mis opiniones. El voluntariado es una palabra muy compleja y multidimensional. Al principio, creí que esta complexidad del voluntariado crearía discrepancias entre los resultados de los participantes y mis percepciones; sin embargo, yo estaba equivocada. Aunque había pequeñas discrepancias, parece que todos los participantes, incluyendo mío, están de acuerdo en muchos aspectos clave del voluntariado. Estos aspectos pueden estar en tres grupos - los beneficios para las comunidades, los beneficios para los voluntarios, y las consecuencias negativas que están asociadas con el voluntariado. Al principio, yo consideré que la creación de una definición aceptada del voluntariado en todas 
partes del mundo a ser casi imposible porque me sentí que su multidimensionalidad impediría que esto ocurra; sin embargo, después de la terminación del experimento, yo tengo esperanzas que una definición del voluntariado aceptada en todas partes puede existir y que esta definición llevará a una mejor comprensión de lo que significa el voluntariado.

\section{Bibliografía}

Haski-Leventhal, D. (2009). Altruism and Volunteerism: The perceptions of altruism in four disciplines and their impact on the study of volunteerism. Journal for the Theory of Social Behaviour, 39, 271-299.

Whiting, M. (2012). Mind Maps: establishing 'trustworthiness' in qualitative research. Nurse Researcher, 20, 21-27. 


\title{
MOTIVACIÓN DE LOGRO Y MOTIVACIÓN HACIA LA PRÁCTICA DE LA ACTIVIDAD FÍSICO- DEPORTIVA
}

\author{
María Almudena Carrasco Mantero, Rosario Lepe Pavón. Universidad de Huelva
}

\section{Resumen}

El tema de la motivación abarca diversidad de esferas en la vida, pero en este caso, parece interesante conocer las diferentes teorías de la motivación para la práctica deportiva así como los motivos que llevan a la realización de la actividad. Para ello se ha recurrido a recientes estudios en los que utilizan a muestras de estudiantes universitarios donde a través de cuestionarios y escalas se ha obtenido los diferentes factores que propician la práctica de la actividad físico-deportiva. Los resultados de dichos estudios señalan que el nivel de práctica físico-deportiva disminuye a medida que aumenta la edad de forma que las mayores tasas de práctica se registran en la etapa infantil continuando un descenso pronunciado hasta llegar a edad universitaria.

Palabras clave: actividad física-deportiva, motivación de logro, orientaciones de la motivación de logro.

\section{Introducción}

La siguiente revisión parte de una visión general sobre el concepto de motivación de logro y la motivación que lleva hacia la práctica físico-deportiva. Se estructura en cuatro apartados, partiendo desde un modelo cognitivo-social y la incidencia que tiene el clima motivador, con la importancia que ejerce el profesor de educación física en el alcance del mismo. Se destaca los dos tipos de orientación de la motivación; hacia la tarea y hacia el resultado. Seguidamente, se expone algunas teorias que tratan de explicar las motivaciones que inducen a los niños y adolescentes a la práctica físicodeportiva, destacando autores tales como Roberts, Kleiber y Duda (1981), Fox y Biddle (1988) y Coll y col. (1993). Y finalmente, se recogen los principales motivos que llevan a universitarios a practicar la actividad física-deportiva gracias a los datos que aportan diferentes estudios.

\section{Modelo cognitivo-social de la motivación de logro}

El modelo cognitivo-social de la motivación de logro asigna un papel central a los procesos interpretativos del individuo, considerando que diferentes creencias implícitas de habilidad van a orientar al sujeto hacia diferentes metas de logro, desarrollando consecuentemente, diferentes patrones motivacionales (González-Cutre, D., Sicilia, A., Moreno, J.A, 2008). Además, el clima motivacional percibido por el alumno determina sus creencias de habilidad y competencia percibida, puesto que estudios previos apuntan que la intervención del profesor era un factor importante en el desarrollo de estas variables.

El clima motivador se refiere al conjunto de estímulos presentes en el entorno que de manera directa o indirecta van a determinar o definir qué es éxito y qué es fracaso para el alumno (Ames, 1992). Según González-Cutre y cols. (2008) el profesor de 
educación física cobra un papel importante en la creación del clima motivador en clase. Aunque los compañeros también influyen en la percepción del clima motivador del alumno, hay que tener en cuenta que el profesor está influyendo al mismo tiempo sobre el clima de éstos.

Evidentemente, el alumno llega a clases de educación física con determinadas creencias de habilidad, metas de logro y motivación autodeterminada, adquiridas durante el proceso de socialización, y éstas pueden afectar a su percepción del clima motivacional, por lo que investigaciones apuntan que el profesor podía tener influencia sobre la motivación del alumno. En este sentido, el profesor puede transmitir dos tipos predominantes de climas motivadores: un clima motivador de ego (es decir, hacia el resultado) y un clima motivador hacia la tarea.

\section{Orientación de la motivación}

Se destaca un concepto esencial: hacia qué aspecto del logro -tarea o resultado- se dirige el esfuerzo de los alumnos. En quienes se orientan hacia la tarea prima del gusto por la ejecución en sí misma; en quienes lo hacen hacia el resultado predomina el afán de triunfo.

\section{- Orientación hacia la tarea}

Los alumnos orientados hacia la tarea tratan de mejorar sus propias competencias, evalúan el proceso, más que el resultado en sí y tratan de progresar en el dominio del deporte practicado. Están más protegidos frente a la decepción, frustración y la falta de motivación, eligen cometidos realistas o moderadamente difíciles, manifiestan una alta competencia percibida, no temen al fracaso, son más constantes y persistentes, tienden a sentirse bien consigo mismos y, en definitiva, suelen conseguir a la larga mejores resultados.

\section{- Orientación hacia el resultado}

Los alumnos orientados hacia el resultado juzgan el éxito más por comparación con los demás que por sus propias competencias, lo que los hace muy dependientes de su entorno en cuanto evaluar su propia eficacia y confianza, mostrando una fuerte tendencia competitiva. Sin embargo, al no controlar el modo en que los demás realizan sus ejecuciones tienen más dificultades en mantener una competencia percibida elevada.

\section{Teorías de motivación en la actividad físico-deportiva}

Existen varias teorías que tratan de explicar las motivaciones que inducen a los niños y adolescentes a la práctica físico-deportiva. A continuación se exponen algunas de ellas:

Roberts, Kleiber y Duda (1981) agrupan las motivaciones en tres tipos, en función de su orientación: 
- Motivaciones orientadas a la propia mejora: el objetivo principal del sujeto es mejorar su rendimiento.

- Motivaciones orientadas hacia la competencia: el sujeto se compara a sí mismo en relación con los demás.

- Motivaciones orientadas hacia la aprobación social: ganar premios, demostrar su capacidad a los demás, agradar a los padres.

Coll y col. (1993) afirman que las metas que los niños y adolescentes persiguen, y que determinan su modo de afrontar las actividades escolares y deportivas, se pueden clasificar en cuatro categorías:

- Metas relacionadas con la tarea o metas centradas en el aprendizaje.

- Metas relacionadas con el "yo" o metas centradas en la ejecución.

- Metas relacionadas con la valoración social.

- Metas relacionadas con la consecución de recompensas externas.

\section{Motivación hacia la práctica de la actividad físico-deportivo}

La práctica de actividad físico-deportiva (AFD) regular y adecuada conlleva numerosos beneficios para la salud de los sujetos, los cuales han quedado ampliamente demostrados y han sido muy difundidos en los últimos años (Darren, Crystal y Shannon, 2006; Castillo y Sáenz-Lopez, 2008; Pieron, Ruíz y García, 2009).

Sin embargo, el nivel de práctica de AFD disminuye a medida que aumenta la edad (Trost, Kerr, Ward y Rate, 2001; García, 2006; Van der Host, Paw, Twisk y Van Mechelen, 2007), de forma que las mayores tasas de práctica que se registran en la etapa infantil comienzan a decaer con la adolescencia, continuando ese descenso al llegar a la edad universitaria (Sánchez-Barrera, Pérez y Godoy, 1995; García, 2001; López y González, 2001; Pavón y Moreno, 2006).

Si se considera la motivación hacia la AFD como el producto de un conjunto de variables de diversa índole (sociales, ambientales e individuales) que determinan aspectos de la práctica como la elección de una o varias actividades, la frecuencia, la intensidad, la persistencia en la actividad e incluso el rendimiento (Escarti y Cervelló, 1994), el estudio de la misma puede ser un factor clave para favorecer la iniciación a la práctica, la adherencia a la misma y evitar el abandono, pues permite conocer por qué los sujetos eligen una actividad y los factores determinantes de la permanencia 0 abandono en esa elección (Moreno, Cervelló y Martínez, 2007). De este modo, si desde las instituciones universitarias se pretende, tal y como se expone en la Ley Orgánica 6/2001, de 21 de diciembre, de Universidades y en la Ley Orgánica 4/2007, de 12 de abril, favorecer y promocionar la práctica de AFD como parte de la formación del alumnado, será interesante conocer las motivaciones que llevan a los estudiantes a practicar AFD.

Según estudios recientes que se han llevado a cabo, se observa que la diversión y el pasatiempo aparecen como uno de los motivos más valorados en todos los estudios contemplados. En segundo lugar, el estar en forma aparece en cuatro de las cinco investigaciones, seguido de la mejora y/o mantenimiento de la salud y el hacer ejercicio, que aparecen en tres de los cinco estudios, aunque ninguno de ellos forma parte de los motivos más valorados por los estudiantes de la Facultad de Ciencias de la Educación. Otros motivos como la evasión, la relajación, el mantenimiento o el 
cuidado de la línea y la estética son también parte de esta constante de motivaciones para la práctica de los universitarios.

En cuanto a las motivaciones aducidas por el alumnado para no haber practicado nunca AFD, se observan de nuevo coincidencias entre los resultados de presente investigación y los obtenidos en otros estudios sobre universitarios. En la siguiente tabla puede observarse que la falta de tiempo aparece valorado en las cuatro investigaciones contempladas, y en tres de ellas, como el principal motivo por el que el alumnado no ha practicado nunca AFD. La flojera y/o pereza también aparece en todas las investigaciones como otro de los motivos más valorados, así como la falta de instalaciones, ya sean cercanas o adecuadas, se contempla en todos los estudios excepto en el de Sanz (2005). De este modo encontramos de nuevo una serie de motivaciones comunes en los universitarios por las que no han practicado nunca AFD, pudiendo considerar como las más importantes la falta de tiempo y la pereza o desgana. Siendo la falta de tiempo el motivo más valorado por los estudiantes de la Facultad de Ciencias de la Educación.

\section{Conclusión}

En los últimos tiempos, desde el ámbito de la psicología, el término "motivación" ha cobrado mucha relevancia. Este término aplicado a la práctica deportiva responde a muchos de los motivos por los que los jóvenes deciden practicar una actividad físicodeportiva y porqué no. El motivo principal por el que deciden practicarla es por mantenerse en forma, mientras que el motivo que les lleva a no practicarla, es la falta de tiempo. Con esto, no solo se busca informar de los motivos que llevan a muchos jóvenes a llevar una vida sedentaria, sin ninguna motivación deportiva, sino se invita a realizar una labor de conciencia en la que desde las universidades, se ofrezcan a todas las titulaciones facilidades para la práctica de estas actividades tan beneficiosas para la salud psíquica y física, así como refuercen en estos, valores tan positivos como la motivación de logro, termino tan vinculado al desarrollo positivo en los últimos tiempos.

\section{REFERENCIAS BIBLIOGRÁFICAS}

Ames, C. (1991). The relationship of achievement goals to student motivation in classroom settings. En G.C. Roberts (Ed.): Motivation in sport and exercise. Champaign, IL: Human Kinetics.

Castillo, E., y Sáenz-López, P. (2008). Práctica de actividad física y estilo de vida del alumnado de la Universidad de Huelva. España: Servicio de Publicaciones de la Universidad de Huelva.

Coll, C., Palacios, J y Marchesi, A. (1993). Desarrollo psicológico y educación, II. Madrid. Alianza Editorial.

Darren, E. R., Crystal, N., y Shannon, B. (2006). Health benefits of physical activity: the evidence. Canadian Medical Association Journal, 174(6), 801-809. 
Escartí, A., y Cervelló, E. (1994). La motivación en el deporte. En I. Balaguer (Ed.), Entrenamiento psicológico en deporte: Principios y aplicaciones (pp. 61-90). Valencia: Albatros Educación.

García, M. (2001). Los españoles y el deporte. Prácticas y comportamientos de la última década del siglo XX. Encuesta sobre los hábitos deportivos de los españoles, 2000. Madrid: Ministerio de Educación y Cultura. Consejo Superior de Deportes.

García, M. (2006). Postmodernidad y Deporte: Entre la individualización y la masificación. Encuesta sobre los hábitos deportivos de los españoles 2005. Madrid: CSD/CIS.

González-Cutre, D., Sicilia, A., y Moreno, J.A. (2008). Modelo cognitivo-social de la motivación de logro en Educación física. Psicothema, 20, 642-651.

González-Cutre, D., Sicilia, A., y Moreno, J.A. (2008). Un estudio cuasi-experimental de los efectos del clima motivador tarea en las clases de Educación Física. Revista de Educación, 365, pp. 677-700.

López, A., \& González, V. (2001). Niveles de satisfacción por la clase de Educación Física. Lecturas: Educación Física y Deporte, Revista Digital, 32. Recuperado de http://www.efdeportes.com/efd32/ satisf.htm

Moreno, J. A., Cervelló, E., y Martínez Camacho, A. (2007). Validación de la Escala de Medida de los Motivos para la Actividad Física-Revisada en españoles: Diferencias por motivos de participación. Anales de Psicología, 23, 167-176.

Pavón, A., \& Moreno, J. A. (2006). Opinión De los universitarios sobre la EF y el deporte. Revista de Ciencias de la Actividad Física, UCM, 8(8), 25-34.

Pieron, M., Ruíz, J., \& García, M. A. (2009). Actividad física y estilos de vida saludables. Wanceulen: Sevilla

Roberts, G. C., Kleiber, D. A. y Duda, J. L. (1981). An analysis of motivation in children's sport: The role of perceived competence in participation. Journal of Sport Psychology, 3, 206-216.

Sánchez-Barrera, M.; Pérez, M., y Godoy, J. (1995). Patrones de actividad física de una muestra española. Revista de Psicología del Deporte, 7-8, 51-71.

Sanz, E. (2005). La práctica físico-deportiva de tiempo libre en universitarios. Análisis y propuesta de mejora. Logroño: Servicio de Publicaciones de la Universidad de La Rioja.

Torres, G., Carrasco, L., y Medina, J. (2000). Investigación sobre los motivos por los que los estudiantes universitarios practican deporte. El caso de la Universidad de Granada. Motricidad, 6, 95-106.

Trost, S. G., Kerr, L. M., Ward, D. S., y Pate, R. R. (2001). Physical activity and determinants of physical activity in obese and non obese children. International Journal of Obesity, 25, 812-829. 
Van der Host, K., Paw, M. S., Twisk, J. W., \& Van Mechelen, W. (2007). A Brief Review on Correlates of Physical Activity and Sedentariness in Youth. Medicine and Science in Sporte Exercise, 39(8), 1241-1250. 


\section{LA INFLUENCIA DEL AUTOCONCEPTO EN EL RENDIMIENTO ACADÉMICO: UNA REVISIÓN TEÒRICA}

Bella del Rocío Aguilar Prieto, Ana María Navarro Domínguez, Rocío Rodríguez Jara, Virginia de la Cinta Trillo Fernández. Universidad de Huelva

\section{RESUMEN}

Existen investigaciones que confirman la relación existente entre el autoconcepto y la autoestima con respecto al rendimiento académico. En este sentido, el objetivo principal de este estudio se centra en revisar y exponer el nivel de influencia de ambos constructos con el rendimiento académico, en estudiantes que se encuentran en proceso de formación. Para ello, primeramente, se definirán los conceptos claves para posteriormente proceder a describir diferentes estudios sobre esta temática. En segundo lugar, se plasmarán diversos programas sobre intervención en autoconcepto y autoestima con la finalidad de conocer, informar y aplicar dichos programas en los centros educativos y familia entre otros.

Palabras clave: autoconcepto, autoestima, rendimiento académico, programas de intervención educativa.

\section{INTRODUCCIÓN}

El autoconcepto y la autoestima son términos íntimamente ligados. De hecho, existen diversos autores que tienden a utilizar estos términos de forma indistinta, mientras que otros limitan el término autoconcepto a los aspectos cognitivos del "sí mismo" y utilizan la autoestima para los aspectos evaluativos-afectivos. No obstante, en líneas generales, se acepta que el autoconcepto engloba ambos aspectos.

Según Saura (1995), el autoconcepto hace referencia al "conjunto de imágenes, sentimientos y rasgos que la persona reconoce como parte de sí misma" (p.20).

Por otro lado, según Duclos (2011), el origen de la autoestima se sitúa en los primeros años de vida a partir de los mensajes e imágenes que los padres devuelven al niño con los que él forma su primer concepto de sí mismo, ya que sus padres son sus principales referentes. El niño se ve influido por esos mensajes y las personas de su entorno proyectan en él una imagen determinada a través de sus opiniones, actos y afectos en las interacciones que se establecen. De modo que las bases de la autoestima se conforman en los primeros años de vida ya que si un niño se siente aceptado por su familia le permite desarrollar sentimientos de aceptación, aprecio, valor personal y seguridad que constituye la base para un buen nivel de autoestima para el futuro.

Finalmente, en la actualidad, el rendimiento académico ha sido estudiado mediante un enfoque multidimensional, ya que se interrelaciona con múltiples variables, siendo los factores que influyen en él los socioeconómicos, la amplitud de los programas de estudio, las metodologías de enseñanza utilizadas, la dificultad de emplear una enseñanza personalizada, los conceptos previos que tienen los alumnos, así como el nivel de pensamiento formal de los mismos (Benítez, Giménez y Osicka, 2000). En definitiva, el rendimiento es definido como "la productividad del sujeto, el producto 
final de la aplicación de su esfuerzo, matizado por sus actividades, rasgos y la percepción más o menos correcta de los cometidos asignados" (Forteza, 1975, p.72).

\section{INVESTIGACIONES}

\section{En la siguiente tabla se muestra las investigaciones que se han llevado a cabo en los últimos años sobre la temática:}

\begin{tabular}{|c|c|c|c|c|}
\hline INVESTIGACIONES & OBJETIVO & MUESTRA & PRUEBAS & CONCLUSIONES \\
\hline $\begin{array}{l}\text { Autoconcepto académico y } \\
\text { rendimiento académico de los } \\
\text { estudiantes de Lengua y } \\
\text { Literatura de la Universidad } \\
\text { Nacional Pedro Ruíz Gallo, del } \\
\text { ciclo académico 2009-II. } \\
\text { (Alvarez Gonzaga, B. R., } \\
\text { 2009). }\end{array}$ & $\begin{array}{l}\text { Determinar el nivel de } \\
\text { autoconcepto académico de } \\
\text { los estudiantes; determinar si } \\
\text { existe una dependencia entre } \\
\text { el nivel de autoconcepto y el } \\
\text { rendimiento académico; } \\
\text { determinar si existe una } \\
\text { diferencia significativa entre el } \\
\text { autoconcepto académico de } \\
\text { los alumno/as; y, determinar } \\
\text { cuáles son los indicadores que } \\
\text { se encuentran a } \\
1 \text { desviación estándar con } \\
\text { respecto al promedio general } \\
\text { de los indicadores. }\end{array}$ & 26 sujetos & $\begin{array}{l}\text { Test } \\
\text { estandarizado de } \\
20 \text { ítems con } \\
\text { escala Likert de } 1 \\
\text { a } 5 \text { siendo } 1 \text { la } \\
\text { menos frecuencia } \\
\text { (nunca) y } 5 \text { la } \\
\text { mayor frecuencia } \\
\text { (siempre). }\end{array}$ & $\begin{array}{l}\text { No existen diferencias } \\
\text { significativas entre el } \\
\text { autoconcepto académico de } \\
\text { los alumno/as; se determinó } \\
\text { que no existe una } \\
\text { dependencia entre la } \\
\text { variable autoconcepto } \\
\text { académico y rendimiento } \\
\text { académico en los } \\
\text { estudiantes; y, se determinó } \\
\text { que el incremento del } \\
\text { rendimiento académico de } \\
\text { los estudiantes se deben a } \\
\text { un } 2 \% \text { al autoconcepto. }\end{array}$ \\
\hline $\begin{array}{l}\text { La influencia del autoconcepto } \\
\text { en el rendimiento académico } \\
\text { en estudiantes universitarios } \\
\text { (Gallardo López, B., Garfella } \\
\text { Esteban, P. R., Sánchez Peris, } \\
\text { F. y, Serra Carbonell, B. } \\
\text { 2009). }\end{array}$ & $\begin{array}{l}\text { Conocer si existe relación } \\
\text { entre los diversos tipos o } \\
\text { dimensiones del autoconcepto } \\
\text { y el rendimiento y si el } \\
\text { autoconcepto tiene o no valor } \\
\text { predictivo sobre dicho } \\
\text { rendimiento. }\end{array}$ & $\begin{array}{l}1298 \\
\text { sujetos }\end{array}$ & $\begin{array}{l}\text { Cuestionario } \\
\text { AF5. }\end{array}$ & $\begin{array}{l}\text { Los resultados de esta } \\
\text { investigación corroboraron } \\
\text { la relevancia del } \\
\text { autoconcepto sobre el } \\
\text { rendimiento académico. }\end{array}$ \\
\hline $\begin{array}{l}\text { El autoconcepto social y el } \\
\text { rendimiento académico en la } \\
\text { educación artística escolar del } \\
\text { alumnado preadolescente } \\
\text { (Lekue, P., 2010). }\end{array}$ & $\begin{array}{l}\text { Conocer si existe relación } \\
\text { entre el rendimiento } \\
\text { académico de los escolares } \\
\text { adolescentes y el } \\
\text { autoconcepto social. }\end{array}$ & $\begin{array}{l}606 \\
\text { sujetos. }\end{array}$ & $\begin{array}{l}\text { Cuestionario de } \\
\text { autoconcepto } \\
\text { social. }\end{array}$ & $\begin{array}{l}\text { Existen diferencias } \\
\text { significativas entre el } \\
\text { autoconcepto social y el } \\
\text { rendimiento académico. } \\
\text { También hay diferencias } \\
\text { negativas entre } \\
\text { autoconcepto y edad. }\end{array}$ \\
\hline $\begin{array}{l}\text { Diferencias de género en el } \\
\text { autoconcepto general y } \\
\text { académico de estudiantes de } \\
4^{\circ} \text { de ESO (Padilla Carmona, } \\
\text { M. T., García Gómez, S. y, } \\
\text { Suárez Ortega, M. 2010). }\end{array}$ & $\begin{array}{l}\text { Identificar si existen } \\
\text { diferencias de género entre } \\
\text { autoconcepto, rendimiento } \\
\text { académico y otras variables, } \\
\text { partiendo de la base de la } \\
\text { relación existente entre dichas } \\
\text { variables. }\end{array}$ & $\begin{array}{l}415 \\
\text { sujetos. }\end{array}$ & $\begin{array}{l}\text { Inventario A-1: } \\
\text { Exploración de la } \\
\text { autoimagen de } \\
\text { chicas y chicos; } \\
\text { compuesto por } \\
16 \text { ítems, a su } \\
\text { vez, agrupados } \\
\text { en } 4 \text { subescalas. }\end{array}$ & $\begin{array}{l}\text { No se encontraron } \\
\text { diferencias significativas } \\
\text { entre el autoconcepto y el } \\
\text { rendimiento académico } \\
\text { entre ambos sexos. }\end{array}$ \\
\hline $\begin{array}{l}\text { Relación entre autoeficacia, } \\
\text { autoestima, asertividad y } \\
\text { rendimiento académico, en } \\
\text { estudiantes que ingresaron a } \\
\text { terapia ocupacional, (Aluicio } \\
\text { G., A. y Revellino, M., 2010). }\end{array}$ & $\begin{array}{l}\text { Describir si existe relación } \\
\text { entre la autoestima, la } \\
\text { autoeficacia, la asertividad y el } \\
\text { rendimiento académico. }\end{array}$ & 43 sujetos. & $\begin{array}{l}\text { Inventario de } \\
\text { autoestima de } \\
\text { Coopersmith // } \\
\text { Escala de } \\
\text { asertividad de } \\
\text { Rathus // Escala } \\
\text { de autoeficacia } \\
\text { generalizada // } \\
\text { Promedio de } \\
\text { calificaciones del } \\
2010 \\
\text { (rendimiento } \\
\text { académico) }\end{array}$ & $\begin{array}{l}\text { Se rechazaron las hipótesis } \\
\text { de que a mayor autoestima, } \\
\text { mayor autoeficacia y mayor } \\
\text { asertividad } \rightarrow \text { mayor } \\
\text { rendimiento académico. }\end{array}$ \\
\hline
\end{tabular}




\section{PROGRAMAS DE INTERVENCIÓN}

Los programas de intervención en autoconcepto y autoestima se basan en un conjunto de acciones sistematizadas, planificadas y basadas en necesidades identificadas, en este caso la mejora de ambos constructos. Una de las principales limitaciones de estos programas es que, con frecuencia, no se encuentran apoyados en la investigación empírica y no se muestran evidencias acerca de cuáles son los factores que explican los resultados. (Rodríguez y Caño, 2012).

\section{A continuación, se realizará una síntesis de varios programas de intervención:}

\begin{tabular}{|c|c|c|}
\hline NOMBRE DEL PROGRAMA & ESTRATEGIAS DE INTERVENCIÓN & RESULTADOS \\
\hline $\begin{array}{l}\text { Mejora de la autoestima en el } \\
\text { aula (Mestre y Frías, 1996). }\end{array}$ & $\begin{array}{l}\text { 1. Evaluación de situaciones problemáticas en el } \\
\text { ámbito escolar. } \\
\text { 2. Reducción ansiedad ante situaciones } \\
\text { estresantes mediante técnicas de relajación y } \\
\text { autocontrol. } \\
\text { 3. Desarrollo de técnicas de solución de problemas } \\
\text { para mejorar la adaptación al entorno. } \\
\text { 4. Estrategias de aprendizaje afectivo- } \\
\text { emocionales. } \\
\text { 5. Cambio de actitudes ante situaciones } \\
\text { estresantes. }\end{array}$ & $\begin{array}{l}\text { Efectos significativos sobre autoestima, } \\
\text { efectos de factores principales y la } \\
\text { interacción. }\end{array}$ \\
\hline $\begin{array}{l}\text { Prevención de emociones } \\
\text { negativas (Olmedo, 1997). }\end{array}$ & $\begin{array}{l}\text { 1. Incremento de la autoestima mediante auto- } \\
\text { observación y reestructuración cognitiva. } \\
\text { 2. Enseñanza de habilidades de relajación físicas } \\
\text { (relajación progresiva o entrenamiento } \\
\text { autógeno) y mentales (basadas en } \\
\text { imaginación). } \\
\text { 3. Aprendizaje de habilidades sociales con énfasis } \\
\text { 4. Enducta asertiva. }\end{array}$ & $\begin{array}{l}\text { Se encuentran efectos significativos en la } \\
\text { medida de autoestima. }\end{array}$ \\
\hline $\begin{array}{l}\text { Galatea (Cava y Musito, } \\
\text { 1999). }\end{array}$ & $\begin{array}{l}\text { 1. Desarrollar un ambiente de confianza y apoyo } \\
\text { en el aula. } \\
\text { 2. Centrarse en los aspectos positivos que } \\
\text { potencialmente todos los alumnos tienen. } \\
\text { 1. 3.Profundizar en un mayor autoconocimiento } \\
\text { 2. 4.Reflexionar acerca de sus metas y } \\
\text { aspiraciones } \\
\text { 3. 5.Analizar los impedimentos que dificultan } \\
\text { 4. alcanzar los objetivos } \\
\text { 5. } \\
\text { 6.Potenciar relaciones con iguales y amistad } \\
\text { Potenciar relaciones de alumnos con sus } \\
\text { respectivas familias. }\end{array}$ & $\begin{array}{l}\text { El programa parece útil tanto para } \\
\text { aquellos niños con dificultades } \\
\text { socioafectivas, como para los niños bien } \\
\text { adaptados socialmente, lo cual lo } \\
\text { convierte en un programa con una } \\
\text { finalidad, terapéutico y preventivo. }\end{array}$ \\
\hline $\begin{array}{l}\text { Entrenamiento en autoestima } \\
\text { y habilidades cognitivas } \\
\text { (Barrett, Webster y Wallis, } \\
\text { 1999). }\end{array}$ & $\begin{array}{l}\text { 1. Entrenamiento en habilidades para generar un } \\
\text { estilo más positivo de pensamiento, } \\
\text { comunicación, percepción y solución de } \\
\text { problemas. } \\
\text { 2. Moldeamiento y refuerzo de nuevas habilidades } \\
\text { y mejorar las existentes. } \\
\text { 3. Uso de tareas para casa semanales para } \\
\text { reforzar habilidades desarrolladas en grupo e } \\
\text { incrementar generalización. }\end{array}$ & $\begin{array}{l}\text { Se encuentra un efecto principal de la fase } \\
\text { y una interacción del tratamiento por la } \\
\text { fase. Análisis más detallados mostraron } \\
\text { que los efectos de fase fueron sólo } \\
\text { significativos en el grupo de intervención, } \\
\text { y que en la segunda fase, el grupo de } \\
\text { intervención mostró mejores resultados en } \\
\text { autoestima que ambos grupos de control. }\end{array}$ \\
\hline
\end{tabular}




\begin{tabular}{|c|c|c|c|}
\hline $\begin{array}{l}\text { Intervención en conducta } \\
\text { social, relaciones intragrupo, } \\
\text { autoconcepto y cogniciones } \\
\text { prejuiciosas (Garaigordobil, } \\
2000 \text { ). }\end{array}$ & & $\begin{array}{l}\text { Mejora del autoconcepto. } \\
\text { Incremento de la comunicación intragrupo, } \\
\text { aceptación iguales e interacciones amistosas. } \\
\text { Desarrollo de conductas sociales positivas } \\
\text { (prosociales, liderazgo y autocontrol, etc.) y } \\
\text { reducción de conductas sociales negativas. } \\
\text { Identificación de percepciones y prejuicios y } \\
\text { análisis discriminativos. } \\
\text { Aprendizaje de técnicas para análisis y solución } \\
\text { de conflictos. }\end{array}$ & $\begin{array}{l}\text { MANOVA sobre conjunto de medidas de } \\
\text { autoconcepto mostró diferencias entre } \\
\text { grupos tratamiento y control en la fase } \\
\text { post y diferencia en las puntuaciones entre } \\
\text { fase post y pretratamiento. ANOVAS } \\
\text { sobre medidas autoconcepto mostraron } \\
\text { diferencias significativas para } \\
\text { autoconcepto social y tendencia a } \\
\text { significación para académico. Los } \\
\text { participantes con puntuaciones bajas en } \\
\text { autoconcepto social mostraron mayor } \\
\text { cambio que participantes con } \\
\text { puntuaciones medias y altas. }\end{array}$ \\
\hline
\end{tabular}

\section{CONCLUSIÓN}

Esta revisión analiza la relación entre el autoconcepto y la autoestima con respecto al rendimiento académico. Teniendo en cuenta los resultados obtenidos en las investigaciones analizadas se concluye que sí existe relación (Gallardo López, B., Garfella Esteban, P. R., Sánchez Peris, F. y, Serra Carbonell, B. (2009); Lekue, P., (2010); Padilla Carmona, M. T., García Gómez, S. y, Suárez Ortega, M. (2010))

No obstante, algunos resultados obtenidos en las investigaciones revisadas no son estadísticamente significativos (Aluicio G., A. y Revellino, M., (2010); Álvarez Gonzaga, B. R., (2009)). Esto puede ser debido a que la muestra no es representativa a la población, ya que los sujetos que han conformado dicha muestra son muy pocos en comparación con el número de sujetos de los estudios que sí resultaron estadísticamente significativos. Por ello, se concluye, que se ha podido generar sesgos muestrales.

Por otro lado, la relación entre autoconcepto y autoestima con el rendimiento académico no es estadísticamente significativa con respectos al sexo; asimismo, si existen diferencias entre estas variables y la edad (Padilla Carmona, M. T., García Gómez, S. y, Suárez Ortega, M. (2010)).

Con respecto a los programas de intervención dirigidos a mejorar el autoconcepto y la autoestima y, por ende, mejorar el rendimiento académico, se ha comprobado que las personas que participaron en la intervención han tenido una evolución favorable con respecto a los constructos trabajados en dichos programas, por lo cual, se puede concluir que han sido efectivos (Barrett, Webster y Wallis, (1999); Cava y Musito, (1999); Garaigordobil, (2000); Mestre y Frías, (1996); Olmedo, (1997)).

Para finalizar, se podría concluir que el alto rendimiento académico podría estar íntimamente relacionado con niveles elevados de autoestima y autoconcepto.

\section{BIBLIOGRAFÍA}

Aluicio G., A. y Revellino, M. (2010). Relación entre autoeficacia, autoestima, asertividad y rendimiento académico, en estudiantes que ingresaron a terapia ocupacional, el año 2010. 
Alvarez Gonzaga, B. R. (2009). Autoconcepto académico y rendimiento académico de los estudiantes de Lengua y Literatura de la Universidad Nacional Pedro Ruíz Gallo, del ciclo académico 2009-II. Estudiante de Lengua y Literatura de la Facultad de Ciencias Histórico Sociales y Educación de la Universidad Nacional Pedro Ruíz Gallo.

Benítez, M; Gimenez, M. y Osicka, R. (2000). Las asignaturas pendientes y el rendimiento académico: ¿existe alguna relación?. Universidad Nacional del Nordeste Comandante Fernandez. Argentina

Barrett PM, Webster HM y Wallis JR (1999). Adolescent self-esteem and cognitive skills training: A school-based intervention. Journal of Child and Family Studies, 8, 217227.

Cava, M. J.; Musitu, G. (1999). Evaluación de un programa de intervención para la potenciación de la autoestima. Intervención Psicosocial, 1999, Vol. 8, n³, 369- 383

Duclos, G. (2011). La autoestima, un pasaporte para la vida. Madrid: Edaf

Forteza, J. (1975). Modelo Instrumental de las Relaciones entre Variables Motivacionales y Rendimiento. Revista de Psicología Aplicada, 132, 75-91.

Gallardo López, B., Garfella Esteban, P. R., Sánchez Peris, F. y, Serra Carbonell, B. (2009). La influencia del autoconcepto en el rendimiento académico en estudiantes universitarios. REOP, Vol. 20, $\mathrm{N}^{\circ} 1,1^{\circ}$ Trimestre, pp. 16-28.

Garaigordobil M (2000). Intervención psicológica en adolescentes: un programa para el desarrollo de la personalidad y la educación en derechos humanos. Madrid: Pirámide.

Lekue, P. (2010). El autoconcepto social y el rendimiento académico en la educación artística escolar del alumnado preadolescente. Jornada de Psicodidáctica. Departamento de Didáctica de la expresión Musical, Plástica y Corporal: Euskal Herriko Unibertsitate.

Mestre V y Frías D (1996). La mejora de la autoestima en el aula. Aplicación de un programa para niños en edad escolar (11-14 años). Revista de Psicología General y Aplicada, 49, 279-290.

Olmedo M (1997). Aplicación y evaluación de un programa de afrontamiento de problemas emocionales en adolescentes. Servicio de Publicaciones Universidad de Jaén. Micropublicaciones ETD.

Padilla Carmona, M. T., García Gómez, S. y, Suárez Ortega, M. (2010). Diferencias de género en el autoconcepto general y académico de estudiantes de $4^{\circ}$ de ESO. Revista de Educación, 352. Mayo-Agosto, 2010, pp. 495-515.

Rodriguez, C.; Caño, A. (2012). Autoestima en la adolescencia: análisis y estrategias de intervención. International Journal of Psychology and Psychological Therapy, 12, $3,389-403$

Saura Calixto, P. (1995). La educación del autoconcepto: cuestiones y propuestas. Servicios de publicaciones, Universidad de Murcia. 


\section{INCIDENCIA DE LOS FACTORES PSICOSOCIALES EN EL TRABAJO. UN ESTUDIO EN DOCENTES UNIVERSITARIOS}

Ortega Domínguez, S.; Sánchez Díaz, C.

\section{RESUMEN}

El presente estudio se adentra en las características de la relación existente entre las condiciones del trabajo y su organización, y la salud de las personas. Este es el punto de partida para analizar y discutir mediante el método Istas21, la incidencia de los factores psicosociales relacionados con la organización del trabajo y sus consecuencias en la salud de los docentes de un centro universitario.

Palabras clave: factores psicosociales, organización del trabajo, trabajo, estrés, condiciones del trabajo.

\section{INTRODUCCIÓN}

El trabajo es una actividad dentro de la realidad social en la que vivimos, y como tal puede tener una repercusión sustancial en el bienestar o malestar en las personas. Estas repercusiones en el estado afectivo de los trabajadores, no implican la existencia de características inherentes al trabajo que nos definan este tipo de situaciones, sino que son los factores psicosociales que rodean la organización del trabajo los que inciden en estas consecuencias de bienestar o malestar. (Córdoba, 2008).

\section{Los factores psicosociales y el estrés laboral}

Podemos entrever una serie de características en las condiciones del trabajo y en su organización, que afectan a la salud de las personas (ISTAS, 2002) y que les expone a una serie de riesgos de origen laboral (Luceño y otros, 2005). Estos riesgos de origen laboral se manifiestan a través de una serie de mecanismos psicológicos y fisiológicos donde se identifica al estrés como precursor de la enfermedad. De acuerdo con esta orientación, el estrés como proceso psicológico es la base de la relación entre la organización del trabajo y la salud de los empleados. Delimitamos entonces esta relación entre factores psicosociales y salud como una fuente de estrés 0 de reacciones de índole emocional, cognitiva, fisiológica o del comportamiento a ciertos aspectos adversos de la organización o del entorno de trabajo (Comisión Europea, 1999), que generan una sensación de frustración, al no poder hacer frente la situación.

\section{Incidencia del problema}

La salud laboral de los trabajadores en los centros docentes públicos es un problema al que, desde hace varios años, se enfrenta la Administración pública. Estudios realizados por comisiones obreras (2006) en la provincia de Málaga nos muestra que trabajar como docente 
expone a una serie de riesgos, que según Rabada (2006), se relaciona con una serie de trastornos en la salud.

Los estudios, centrados en los problemas de salud causados por el trabajo en las enseñanzas no universitarias, no nos arrojaban datos válidos para observar la incidencia de los factores psicosociales en la salud de los docentes de centros universitarios, presentándose el objetivo de evaluar la incidencia de una serie de factores en la salud de los docentes de nuestra propia universidad.

\section{Evaluación de los riesgos psicosociales}

La importancia de la evaluación de riesgos psicosociales en la salud de los docentes, radica en servir de base para gestionar de manera activa la seguridad y la salud en el trabajo, pudiéndose evitar desde los centros que las situaciones del trabajo puedan ser causa de una enfermedad en sus trabajadores. (Ley 31/1995, de 8 de noviembre, de Prevención de Riesgos Laborales).

A diferencia de lo que ocurre con parte de los riesgos físicos y biológicos, que pueden ser evaluados mediante medidas fiables y válidas para evaluar la exposición al riesgo (Luceño y otros), los riesgos psicosociales en este estudio han sido evaluados de forma subjetiva mediante la colaboración de diez docentes de uno de los departamentos de una facultad de la Universidad de Granada. La dificultad de medir de forma objetiva las características del trabajo que se definen en el método Istas 21 , radica en la necesidad de evaluar estos factores teniendo en cuenta la percepción del trabajador sobre las mismas, es decir, mediante la medida subjetiva de los factores sobre las condiciones de trabajo y su organización.

Entendemos que identificar el nivel de exposición psicosocial más o menor favorable para la salud a la salud a la que están expuestos los trabajadores mediante las diversas cuestiones sobre dimensiones psicosociales del método ISTAS21, constituye el primer paso para poder intervenir y tomar medidas orientadas a su prevención. La evaluación de los factores psicosociales de riesgo y los problemas de salud en los trabajadores cobra una gran importancia en los centros educativos y nos invita, a través de este estudio, a contribuir a la discusión y el análisis acerca de los factores psicosociales en la organización del trabajo en un centro universitario, y sus consecuencias para la salud de los docentes.

\section{MÉTODO}

\section{Muestra}

Los diez docentes participantes en el estudio pertenecen a un departamento con menos de 25 trabajadores de un centro universitario. La selección de la muestra se ha realizado en función de la disponibilidad de los/las docentes, por lo que los resultados de este estudio no son representativos de la población ni pueden ser generalizables. La muestra consta de un número equiparado de hombres y mujeres, en su mayoría profesores titulares, ayudantes o sustitutos de Universidad. 


\section{Instrumento}

EI método ISTAS21 es una adaptación para la población española del Cuestionario Psicosocial de Copenhagen (CoPsoQ). Este instrumento fue seleccionado como la principal herramienta para la recogida de datos por su carácter individual, anónimo, confidencial y de respuesta voluntaria. Estos datos nos permitieron realizar un estudio cualitativo de la realidad objeto de evaluación en una población específica, en este caso docentes de centros universitarios como una medida de prevención orientada a favorecer la localización de determinados problemas y vías alternativas de cambio o mejora, con el fin de impulsar otras formas de organización laboral más saludables.

El método Istas21, versión corta, es un cuestionario de cuatro secciones, dos de ellas orientadas a identificar las condiciones sociales y de empleo, y las otras dos centradas en determinar aquellos daños o dimensiones psicosociales que tengan algún efecto sobre la salud. De manera más específica, en el test se analizan seis apartados o dimensiones psicosociales: (1) exigencias psicológicas, (2) trabajo activo y posibilidades de desarrollo, (3) inseguridad, (4) apoyo social y calidad de liderazgo, (5) doble presencia y (6) estima. Definimos a continuación cada uno de estas dimensiones (Istas21, 2002) a evaluar.

De las exigencias psicosociales se distingue por un lado, las de tipo cuantitativo referidas al volumen de trabajo solicitado respecto a la falta de tiempo para ejecutarlo adecuadamente; $y$ las exigencias cualitativas, determinado por las demandas emocionales (al tener que reprimir sentimientos y opiniones), cognitivas (precisando grandes esfuerzos intelectuales) y de tipo sensorial.

En cuanto al trabajo activo y las posibilidades de desarrollo, indica la influencia y control sobre el trabajo a realizar, su organización, horarios, decisiones y mejoras; que posibilitan la integración en la empresa y dan sentido al trabajo. Las posibilidades de desarrollo en el trabajo no deben verse sólo como una oportunidad para ascender, sino para generar expectativas de superación y progreso.

El Apoyo social hace referencia al tipo de relaciones y ayuda entre compañeros, es decir, el sentimiento de grupo y los refuerzos, que requieren de un buen flujo de información que evite el aislamiento y posibilite las relaciones sociales. La calidad de liderazgo entiende que se debe mantener bien definidos los puestos de trabajo (claridad de rol), no exigiendo tareas contrarias a los valores personales (conflicto de rol) y proporcionando la información necesaria para adaptarse a los cambios (previsibilidad).

La inseguridad laboral incide en aquellos aspectos relacionados con la estabilidad laboras, la posibilidad de un cambio de tareas o en relación a una posible promoción y los cambios imprevistos que perjudiquen al trabajador (turnos, días de la semana...).

La estima por su parte pone de relieve el reconocimiento al trabajo y el esfuerzo, recibiendo un adecuado apoyo social y un trato justo.

La doble presencia hace referencia a la incapacidad de compatibilizar las tareas familiares y laborales, aun cuando existe una normativa para la conciliación de la vida laboral y familiar. 


\section{Procedimiento}

Tras la presentación individual del objeto de estudio y el método a utilizar, en este caso el cuestionario Istas21, se pidió la colaboración de los docentes de un mismo departamento universitario. En el momento de la recogida del cuestionario, se solicitó una valoración personal que pudiera ayudar a la interpretación de los resultados del test, conduciéndonos las reflexiones del profesorado a un mejor análisis de los resultados.

\section{ANÁLISIS DE DATOS}

En el departamento evaluado han participado 10 docentes, de los cuales un profesor colaborador tres profesores titulares de universidad, un profesor sustituto interino, un catedráticos de universidad, un profesor ayudante doctor y dos profesores contratados doctor y un profesor asociado laboral, por lo que entendemos que el desarrollo de su funciones varía en relación al contrato al que están sujetos.

En la tabla que mostramos a continuación mostramos los grupos de dimensiones evaluador en el cuestionario "versión corta" Istas21 en relación al nivel de exposición de los docentes, remarcando aquellas cuestiones básicas que han tenido mayor incidencia en sus respuestas.

Tabla 1. Datos obtenidos del cuestionario Istas 21

\begin{tabular}{|c|c|c|}
\hline DIMENSIÓN & NIVEL DE EXPOSICIÓN & SITUACIÓN \\
\hline $\begin{array}{l}\text { Exigencias } \\
\text { Psicológicas }\end{array}$ & $\begin{array}{l}\text { Nivel rojo: } 80 \% \text { nivel de exposición psicosocial } \\
\text { más desfavorable. } \\
\text { Nivel amarillo: } 20 \% \text { nivel de exposición } \\
\text { psicosocial intermedio }\end{array}$ & $\begin{array}{l}\text { "Siempre" o "muchas veces" existen } \\
\text { dificultades para olvidar los problemas del } \\
\text { trabajo. } \\
\text { "Muchas veces" el trabajo, en general, es } \\
\text { desgastador emocionalmente. }\end{array}$ \\
\hline $\begin{array}{l}\text { Trabajo activo y posibilidades } \\
\text { de desarrollo }\end{array}$ & $\begin{array}{l}\text { Nivel verde: } 80 \% \text { nivel de exposición } \\
\text { psicosocial más favorable para la salud. } \\
\text { Nivel rojo: } 10 \% \text { nivel de exposición psicosocial } \\
\text { más desfavorable. }\end{array}$ & $\begin{array}{l}\text { "Siempre o casi siempre": El trabajo } \\
\text { requiere iniciativa } \\
\text { Permite aprender cosas nuevas } \\
\text { Compromiso con la profesión }\end{array}$ \\
\hline Inseguridad & $\begin{array}{l}\text { Nivel rojo: } 50 \% \text { nivel de exposición psicosocial } \\
\text { más desfavorable. } \\
\text { Nivel amarillo: } 40 \% \text { nivel de exposición } \\
\text { psicosocial intermedio }\end{array}$ & $\begin{array}{l}\text { "Muy preocupado por": Inseguridad por lo } \\
\text { difícil de encontrar trabajo en caso de } \\
\text { perderlo } \\
\text { Inseguridad por el salario } \\
\text { "Bastante preocupado por": Inseguridad } \\
\text { por el salario y el cambios de horario }\end{array}$ \\
\hline $\begin{array}{l}\text { Apoyo social y calidad de } \\
\text { liderazgo }\end{array}$ & $\begin{array}{l}\text { Nivel rojo: } 40 \% \text { nivel de exposición psicosocial } \\
\text { más favorable para la salud. } \\
\text { Nivel amarillo: } 30 \% \text { nivel de exposición } \\
\text { psicosocial intermedio }\end{array}$ & $\begin{array}{l}\text { Puntuaciones bajas en: Planificación del } \\
\text { trabajo por los jefes y la comunicación con } \\
\text { los trabajadores. }\end{array}$ \\
\hline
\end{tabular}




\begin{tabular}{|c|c|c|}
\hline Doble presencia & $\begin{array}{l}\text { No doble presencia: } 20 \% \\
\text { Nivel rojo: } 50 \% \text { nivel de exposición psicosocial } \\
\text { más desfavorable }\end{array}$ & $\begin{array}{l}\text { Realización de la mitad de las tareas en } \\
\text { casa. } \\
\text { Si falta algún día en casa, las tareas } \\
\text { "muchas veces" se quedan sin hacer. }\end{array}$ \\
\hline Estima & $\begin{array}{l}\text { Nivel rojo: } 50 \% \text { nivel de exposición psicosocial } \\
\text { más desfavorable. } \\
\text { Nivel amarillo: } 40 \% \text { nivel de exposición } \\
\text { psicosocial intermedio }\end{array}$ & $\begin{array}{l}\text { Mis superiores me dan el reconocimiento } \\
\text { que me merezco (solo alguna vez) } \\
\text { "Muchas veces" reciben el apoyo } \\
\text { necesario en situaciones difíciles } \\
\text { "Muchas veces" el reconocimiento en } \\
\text { relación al trabajo y esfuerzo es adecuado }\end{array}$ \\
\hline
\end{tabular}

\section{Discusión}

Sobre las exigencias psicosociales, los datos reflejan que existen altos niveles de exposición al riesgo por factores cualitativos, principalmente respecto a las demandas emocionales. Entendemos que estas demandas emocionales están estrechamente relacionadas con los resultados favorables para la salud (niveles altos, 80\%) en relación al compromiso ante el trabajo como docentes en la dimensión trabajo activo y posibilidades de desarrollo. Es decir, los docentes tienen dificultades para evitar olvidarse de los problemas del trabajo y entienden que es desgastador emocionalmente, lo que se relaciona con un alto nivel de compromiso con el trabajo, precisando de una gran iniciativa en la mayoría de los casos. En esta misma dimensión se observa la poca influencia de los docentes sobre el volumen de trabajo asignado, en ocasiones según los mismos docentes por tener que cubrir bajas o asignaturas no contempladas inicialmente en la planificación docente, y en otras muchas ocasiones, por el poco control en la asignación anual de investigaciones a al profesorado.

El Apoyo social entre los compañeros de departamento es, según sus impresiones, positivo en pequeño grupo, donde creen que siempre existe algún "colega" cercano que les apoyo en el trabajo. Pero generalmente el apoyo social a nivel de departamento es mejorable, y "muchas veces" el profesorado entiende su alto compromiso y esfuerzo no es reconocido por sus jefes inmediatos. Uno de los aspectos a remarcar sobre la calidad de liderazgo, es la poca previsión de los jefes del departamento o del mismo rectorado, para cubrir bajas o sustituir de manera inmediata una materia, sin proporcionarles la información necesaria (previsibilidad) para adaptarse al cambio y ofrecer al alumnado una educación de calidad.

Respecto a la inseguridad laboral, aunque el $60 \%$ del profesorado tiene un contrato laboral fijo, se observa la incertidumbre en relación a la estabilidad laboral. En otras ocasiones también se encuentran preocupados por la reestructuración académica que desde hace varios años se están produciendo derivados del "Plan Bolonia", y más aún, con la desaparición en este curso académico de determinadas licenciaturas relacionadas con este departamento, con los cambios que eso conlleva a nivel laboral.

La percepción de los trabajadores sobre la estima, pone de relieve el poco reconocimiento que conlleva su esfuerzo y trabajo por parte de los jefes inmediatos, pero que según algunos de ellos, es recompensado por el apoyo social y el trato justo por parte de sus compañeros. 
En cuanto a la conciliación de la vida laboral y familia, la doble presencia del personal laboral el que entiende que pasa "muchas horas" en el trabajo, le dificulta compatibilizar sus tareas en determinadas épocas del curso escolar, creando un sentimiento de desasosiego.

\section{CONCLUSIÓN}

El análisis y valoración de los datos obtenidos en este estudio, aunque entendemos que no son generalizables a toda la población docente universitaria ni representativa de la misma, puede servir de base para generar un proceso de reflexión interno y externo con el resto de compañeros docentes para propiciar en los centros universitarios estudios amplios y profundos para prevenir o reducir la aparición de riesgos relacionados con la salud y el trabajo. Entendemos así, dadas las dificultades de participación del profesorado en este estudio, que la implicación activa de los trabajadores y trabajadoras es básica, si se pretende una prevención eficaz, ya que son ellos y ellas quienes van a protagonizar los cambios, que se aceptarán y entenderán mejor si han sido copartícipes de su diseño. Estos estudios de evaluación no se presentan como un fin en sí mismo, sino como un instrumento de acción preventiva y cambio, que permita identificar y localizar los riesgos de las condiciones de trabajo a la que están sometidos los trabajadores para proponer medidas resolutivas que favorezcan la salud, todos los ámbitos, de los trabajadores.

\section{REFERENCIAS BIBLIOGRÁFICAS}

Collado, S. (2008). Prevención de riesgos laborales: principios y marco normativo. Revista de Dirección y Administración de Empresas, 15, 91-117.

Comisión Europea. (1999). Guía sobre el estrés relacionado con el trabajo. ¿La sal de la vida o el beso de la muerte? Bruselas: Comisión Europea, Dirección General de Empleo y Asuntos Sociales.

Córdoba, E. (2010). Factores psicosociales y su influencia en el bienestar laboral. Buenos aires.

Departamento de Educación, Universidades e Investigación. Evaluación de factores de riesgo laboral en centros educativos. Donostia-San Sebastián.

Instituto Sindical de Trabajo Ambiente y Salud, ISTAS (2002). Manual de la versión media del método ISTAS-21 (CoPsoQ) de evaluación de riesgos psicosociales. ISTAS.

Ley 31/1995, de 8 de noviembre, de Prevención de Riesgos Laborales.

Luceño, L. y otros (2005). Evaluación de factores psicosociales en el entorno laboral. EduPsykhé, 4 (1), 19-42.

Rabadà, I. y Artazcoz, L. (2002). Identificación de los factores de riesgo laboral en docentes: un estudio Delphi. Prevención de riesgos laborales, 5 (2), 53-61. 
Sandín, B. (2002). El estrés: un análisis basado en el papel de los factores sociales. Revista Internacional de Psicología Clínica y de la Salud, 3 (1), 141-157.

Sindicato de enseñanza de Comisiones Obreras. (2006). Estudio de los factores psicosociales de riesgo en el sector de la enseñanza pública de la provincia de Málaga, a través del método Istas-21.

Vázquez, J. A. y otros. (2010). Factores psicosociales motivacionales y estado de salud. Medicina y seguridad en el trabajo, 56 (218), 12-21. 


\section{RELACIÓN ENTRE EL AUTOCONCEPTO Y EL RENDIMIENTO ACADÉMICO EN ADOLESCENTES}

Marina Agapito Romero, Ana Calderón Callejo, Blanca Cobo Jarones y Laura Rodríguez Rodríguez. Universidad de Huelva

\section{RESUMEN}

El estudio presente se centra en las relaciones existentes entre el autoconcepto y el rendimiento académico. Se ha elegido una muestra aleatoria de 67 adolescentes entre 14 y 15 años. Mediante la prueba estandarizada "Autoconcepto resultante del entorno social: Cuestionarios SC1 de Brookover y SC2; SC3 y SC4 de Coopersmith (1982)", comparada con las notas obtenidas en el anterior trimestre, se ha podido observas cómo se correlaciona la opinión que tiene el adolescente de sí mismo y las notas que finalmente obtienen. Asimismo, apreciamos la influencia que ejerce sobre el autoconcepto de dichos adolescentes la opinión de padres y profesores.

Palabras clave: Autoconcepto, rendimiento académico, calificaciones, adolescentes

\section{INTRODUCCIÓN}

El autoconcepto juega un papel fundamental en el desarrollo de la personalidad. Un autoconcepto positivo está en la base del buen funcionamiento personal, social y profesional dependiendo de él, la satisfacción personal, el sentirse bien consigo mismo (Goñi, E.,2009), y como se pretende comprobar aquí, un buen rendimiento académico. De ahí que el logro de un equilibrio socioafectivo en el alumnado a partir de una imagen ajustada y positiva de sí mismo figure entre las finalidades tanto de la Educación Primaria como de la Educación Secundaria Obligatoria (Goñi, E.,2009).

A mediados de los años setenta, se produce un cambio en la forma de entender el autoconcepto, al ser reemplazada una visión unidimensional por una concepción jerárquica y multidimensional. El autoconcepto global vendría a ser el resultado de un conjunto de percepciones parciales del propio yo, que se estructuran en una organización jerárquica: el autoconcepto general se compondría del autoconcepto académico y del no-académico y este último, a su vez, incluiría tanto el autoconcepto social como el personal y el físico (Goñi, E.,2009). Aquí se intentará hacer una pequeña prueba de la correlación existente entre algunos aspectos del autoconcepto general.

En un estudio realizado en la universidad de Granada por María Tamara Polo Sánchez y María Dolores López-Justicia en el que vincularon autoconcepto académico y discapacidad en la universidad, obtuvieron resultados que confirmaron que la presencia de la discapacidad parece asociada con un nivel más bajo de autoconcepto académico y emocional, esto es, los estudiantes con discapacidad se perciben menos competentes en el ámbito académico (Polo, M.T. y López-Justicia, M.D., 2009). Aunque la discapacidad no es el tema de este estudio, parece interesante cómo la autopercepción influye de manera directa con el rendimiento.

Otro estudio realizado en la universidad Miguel Hernández de Elche, ha examinado las variables que se relacionan con el rendimiento académico en los adolescentes con

1 ReiDoCrea. Revista electrónica de investigación Docencia Creativa. Volumen 2. Páginas 181-187 
padres divorciados. Los adolescentes con padres divorciados obtienen más suspensos que los que tienen padres casados (Orgilés, M., Johnson, B.T., Huedo-Medina, T.B., Espada, J.P., 2012). Este hallazgo se relaciona con resultados de estudios previos que indican que los adolescentes con padres divorciados tienen peor rendimiento académico que aquellos cuyos padres viven juntos (e.g. Tillman, 2007). Los adolescentes con padres divorciados tienen también peor autoconcepto que el de aquellos que proceden de familias con padres casados (e.g., Sweeney y Bracken, 2000).

\section{MÉTODO}

\section{Hipótesis}

- Lo que los alumnos piensan sobre sí mismos influye sobre las notas. A mayor puntuación en las escala SC1 y SC2, mejores resultados académicos.

- Lo que padres y profesores opinan sobre los alumnos correlaciona directamente con lo que opinan los alumnos sobre sí mismos.

- De igual manera, las puntuaciones obtenidas en las escalas SC3 y SC4, correlacionan directamente con los resultados académicos. Es decir, lo que opinen padres y profesores también influye de forma directa con los resultados académicos de los alumnos.

- Las notas obtenidas están relacionadas directamente con el autoconcepto. Altas puntaciones en autoconcepto se correlacionan con buenos resultados académicos.

\section{Sujetos}

Los participantes de este estudio han sido 67 alumnos del Colegio Diocesano Sagrado Corazón de Jesús de Huelva, de tres clases diferentes del mismo curso, que se encuentran cursando $3^{\circ}$ de Educación Secundaria en el año 2013, y tienen edades comprendidas entre 14 y 15 años.

\section{Instrumentos}

Se ha utilizado el cuestionario Autoconcepto resultante del entorno social: Cuestionarios SC1 de Brookover y SC2; SC3 y SC4 de Coopersmith (1982), en el que han sido consideradas cuatro subvariables, para medir el autoconcepto, con cuatro puntuaciones independientes que corresponden a las siguientes variables $e$ instrumentos:

SC1 de autoconcepto general, bajo el título “¿Cómo soy?”, es la adaptación (Self Concept) de Rodríguez Espinar, S. del denominado S.E.I. (Self-Steem Inventory) de Stanley Coopersmith, en su forma reducida de 25 ítems. (Purkey, 1.968 en Rodríguez Espinar, S., 1.982, p.78) quien la confeccionó a partir de otras escalas más amplias de Rogers y Dymond con la que guarda una correlación de 0,86 . El sujeto responde con verdadero o falso de acuerdo con lo que el sujeto opina de sí mismo.

Fiabilidad: Coopersmith obtuvo valores de 0,88 para un intervalo de cinco semanas y de una muestra de alumnos de $5^{\circ}$ grado. Rodríguez Espinar obtuvo un valor de 0,86 con alumnos de $8^{\circ}$ de E.G.B. en el año 1.982 para un intervalo de un mes. 
SC2 de autoconcepto académico con el título “¿Qué opinas de ti mismo?”, adaptación de Rodríguez Espinar, S. para su investigación "Factores de Rendimiento Escolar"(1.982) de la escala Self-Concept of Hability General desarrollado por Brookover et al (1.967) para alumnos de los cursos $7^{\circ}-12^{\circ}$ del sistema educativo norteamericano y que consta de una serie de 7 ítems para cada individuo que opina de sí mismo en el presente y futuro en lo puramente académico. Mediante un valor categorizado de 1 a 5 en cada uno de ellos resultado de elegir una opción y que puede dar una puntuación máxima de 35 y mínima de 7.

Fiabilidad: Brookover et al (1.974), obtuvieron valores de 0,82 en género masculino y 0,77 en el femenino en $7^{\circ}$ curso y para grupos iguales de $8^{\circ}$ de 0,85 y 0,87 respectivamente. La adaptación de Rodríguez Espinar (1.982) obtuvo en una muestra combinada de alumnos de Segunda Etapa de un valor de 0,82.

EI SC3 de autoconcepto académico titulado “¿Qué opinan tus padres de ti?" y el SC4 de autoconcepto académico titulado “¿Qué opina tu profesor de ti?" corresponden a las variables del autoconcepto académico percibido en las personas de los padres y el profesor respectivamente. Asumidas por las escalas Perceived Parental Evaluations of Ability y Perceived Teachers' Evaluations of Ability, desarrolladas también por Brookover y colaboradores. Cada una de ellas posee cinco ítems y, como en el SC2, con el mismo tipo de aplicación y puntuación.

Fiabilidad: Brookover y sus colaboradores para una muestra de 500 alumnos norteamericanos de $8^{\circ}$ curso, obtuvieron unos valores de 0,84 y 0,92 respectivamente. Y Rodríguez Espinar para 100 alumnos de Segunda Etapa españoles, obtuvo valores análogos de 0,83 y 0.90. (Périz, J.A., 2007)

Además, se ha añadido un apartado, donde se preguntaba a los alumnos los resultados académicos que suelen obtener en cada una de las materias. Después, se ha hecho una media de las notas obtenidas entre todas las materias. Para posteriormente, poder hacer la correlación entre autoconcepto y resultado académico.

\section{Procedimiento}

Para realizar el cuestionario, nos pusimos en contacto con la directora del Colegio Diocesano Sagrado Corazón de Jesús de Huelva. Tras el consentimiento, se realizó el cuestionario a 67 alumnos, de los cuales 27 eran chicos (40.3\%) y 40 chicas $(59.7$ $\%)$.

\begin{tabular}{llllll} 
Sexo & & & & \\
\hline & & Frecuencia & Porcentaje & Porcentaje válido & $\begin{array}{l}\text { Porcentaje } \\
\text { acumulado }\end{array}$ \\
\hline \multirow{2}{*}{ Válidos } & Chico & 27 & 40,3 & 40,3 & 40,3 \\
& Chica & 40 & 59,7 & 59,7 & 100,0 \\
& Total & 67 & 100,0 & 100,0 & \\
\hline
\end{tabular}

\section{Análisis estadístico}

Con ayuda del programa estadístico SPSS 15.0, calculamos correlaciones no paramétricas. En primer lugar, se ha realizado un coeficiente de correlación de Spearman. Posteriormente, se han realizado otros cálculos para comprobar otros datos de interés que hayan podido pasar desapercibidos en una primera aproximación. Las pruebas realizadas han sido, correlaciones bivariadas y ANOVA de un factor. 


\section{RESULTADOS}

\section{Lo que los alumnos piensan sobre sí mismos influye sobre las notas.}

Para contrastar esta hipótesis se ha realizado el siguiente estadístico con el programa SPSS.

\begin{tabular}{|c|c|c|c|c|c|}
\hline \multicolumn{6}{|c|}{ Correlaciones } \\
\hline & & & SC1 & $\mathrm{SC} 2$ & Nota \\
\hline \multirow[t]{9}{*}{ Rho de Spearman } & $\mathrm{SC} 1$ & $\begin{array}{l}\text { Coeficiente de } \\
\text { correlación }\end{array}$ & 1,000 &, 153 &, 058 \\
\hline & & Sig. (bilateral) & . &, 215 & 639 \\
\hline & & $N$ & 67 & 67 & 67 \\
\hline & $\mathrm{SC} 2$ & $\begin{array}{l}\text { Coeficiente de } \\
\text { correlación }\end{array}$ & ,153 & 1,000 &, $664^{\prime \prime}$ \\
\hline & & Sig. (bilateral) &, 215 & . &, 000 \\
\hline & & $N$ & 67 & 67 & 67 \\
\hline & Nota & $\begin{array}{l}\text { Coeficiente de } \\
\text { correlación }\end{array}$ & ,058 &, $664^{\mathrm{n}}$ & 1,000 \\
\hline & & Sig. (bilateral) &, 639 &, 000 & . \\
\hline & & $N$ & 67 & 67 & 67 \\
\hline
\end{tabular}

Si observamos la tabla de la correlación de Spearman, observamos que no hay correlación significativa entre el SC1 (¿Cómo soy?) y las notas obtenidas. Sin embargo, si encontramos una relación bastante significativa entre lo que los alumnos opinan de sí mismos (SC2) y los resultados académicos. Es decir, mayores puntuaciones en el cuestionario SC1 no influyen sobre las notas obtenidas, pero a mayor puntuación obtenida en el cuestionario SC2, mejores resultados académicos obtendrá el alumno. Por tanto, se podría decir que nuestra hipótesis se cumple solo en parte, ya que, según estos resultados, sobre el resultado académico influye la percepción que tiene uno de sí mismo, pero no influye el cómo se es.

\section{Lo que padres y profesores opinan sobre los alumnos correlaciona directamente con lo que opinan los alumnos sobre sí mismos.}

Al igual que en el caso anterior, vemos que no existe una relación significativa entre los resultados obtenidos en el cuestionario SC1 y los otros cuestionarios. Sin embargo, si observamos las relaciones del SC2 (¿qué opinas de ti mismo?) con el SC3 (¿Qué opinan tus padres de ti?) y SC4 (¿qué opina tu profesor/a de ti?), observamos que existe una relación muy significativa. Es decir, se cumple nuestra hipótesis, la opinión de padres y profesores sobre el alumno, influye en la opinión de este sobre sí mismo. Otro dato curioso, obtenido al realizar estos estadísticos, es la relación entre SC3 y SC4, podríamos deducir, que existe una relación directamente proporcional entre la opinión de padres y profesores, es decir, a mejor opinión tengan los profesores sobre los alumnos, mejor opinión tienen los padres, y viceversa. 
Lo que opinen padres y profesores también influye de forma directa con los resultados académicos de los alumnos.

\begin{tabular}{|c|c|c|c|c|c|}
\hline \multicolumn{6}{|c|}{ Correlaciones } \\
\hline & & & $\mathrm{SC} 3$ & $\mathrm{SC} 4$ & Nota \\
\hline \multirow[t]{9}{*}{ Rho de Spearman } & $\mathrm{SC} 3$ & $\begin{array}{l}\text { Coeficiente de } \\
\text { correlación }\end{array}$ & 1,000 & $689^{\prime \prime}$ & $.623^{\prime \prime}$ \\
\hline & & Sig. (bilateral) & . &, 000 &, 000 \\
\hline & & $\mathrm{N}$ & 67 & 67 & 67 \\
\hline & $\mathrm{SC} 4$ & $\begin{array}{l}\text { Coeficiente de } \\
\text { correlación }\end{array}$ & $689^{m}$ & 1,000 &, $488^{11}$ \\
\hline & & Sig. (bilateral) & , 000 & & , 000 \\
\hline & & N & 67 & 67 & 67 \\
\hline & Nota & $\begin{array}{l}\text { Coeficiente de } \\
\text { correlación }\end{array}$ & $623^{\mathrm{n}}$ &, $488^{n \pi}$ & 1,000 \\
\hline & & Sig. (bilateral) &, 000 &, 000 & . \\
\hline & & $\mathrm{N}$ & 67 & 67 & 67 \\
\hline
\end{tabular}

De la misma manera, comprobamos que existe correlación muy significativa entre SC3 (opinión de los padres) y SC4 (opinión de los profesores) y las notas obtenidas. Es decir, a mejor opinión de padres y profesores, mejores notas obtienen los alumnos. Por tanto, también se verifica nuestra hipótesis.

\section{Las notas obtenidas están relacionadas directamente con el autoconcepto.}

Con los resultados obtenidos anteriormente, podemos concluir que se verifica nuestra hipótesis general. El autoconcepto se relaciona de forma directamente proporcional con el resultado académico. Es decir, a mejor autoconcepto, incluyendo lo que uno piensa sobre sí mismo, y lo que piensan padres y profesores, mejores resultados académicos obtendrán los alumnos.

\section{DISCUSIÓN}

El presente trabajo pretendía valorar la relación existente entre el autoconcepto y las notas obtenidas. El cuestionario se adecuó correctamente a los sujetos estudiados y los grupos y, al ser de la misma edad, pudieron ser comparados entre sí.

Se ha podido comprobar, tras realizar un análisis y verificar las hipótesis, que mayores puntuaciones en el cuestionario sobre cómo soy, no influyen sobre las notas obtenidas, pero a mayor puntuación en el cuestionario sobre la opinión de sí mismo, mejores resultados académicos. Esto podría abrir un nuevo tema de debate para futuras investigaciones. A su vez, la visión de sus padres y de sus profesores influye de forma significativa en la percepción que tienen. Esto es, la opinión que tienen los padres y profesores influye en la opinión sobre ellos mismos.

Es posible que las puntuaciones obtenidas en el SC1 no influyan en las calificaciones, debido a la distinción que se realiza en el cuestionario. ¿Cómo soy? y ¿Qué opinas de 
ti mismo? son dos ítems que tienen relación entre sí, pero no valoran lo mismo. El primer ítem está relacionado con la forma de ser de cada uno, de forma general, y el segundo se refiere a la opinión que se tiene de sí mismos, es decir, puedes ser inteligente (ítem 1) pero percibirlo de forma negativa (ítem 2, opinión de sí mismos).

Para experimentos posteriores, una propuesta podría ser no realizar esta última distinción, ya que puede llevar a confusión por la fina línea divisoria entre ambos conceptos.

Al realizar una ANOVA de un factor, se pudo observar otro dato que parece interesante, aunque no se presenta entre nuestras hipótesis. No se encuentra ninguna diferencia significativa en cuanto al sexo, en ninguna de las variables.

ANOVA de un factor

\begin{tabular}{|c|c|c|c|c|c|c|}
\hline & & $\begin{array}{l}\text { Suma de } \\
\text { cuadrados }\end{array}$ & $\mathrm{gl}$ & $\begin{array}{c}\text { Media } \\
\text { cuadrática }\end{array}$ & $\mathrm{F}$ & Sig. \\
\hline \multirow[t]{3}{*}{ SC1 } & Inter-grupos & 2,080 & 1 & 2,080 & 166 & 685 \\
\hline & Intra-grupos & 814,785 & 65 & 12,535 & & \\
\hline & Total & 816,866 & 66 & & & \\
\hline \multirow[t]{3}{*}{$\mathrm{SC} 2$} & Inter-grupos & 1,882 & 1 & 1,882 & 073 & 789 \\
\hline & Intra-grupos & 1686,775 & 65 & 25,950 & & \\
\hline & Total & 1688,657 & 66 & & & \\
\hline \multirow[t]{3}{*}{$\mathrm{SC} 3$} & Inter-grupos & 13,682 & 1 & 13,682 & 1,003 & 320 \\
\hline & Intra-grupos & 887,005 & 65 & 13,646 & & \\
\hline & Total & 900,687 & 66 & & & \\
\hline \multirow[t]{3}{*}{$\mathrm{SC} 4$} & Inter-grupos & 192 & 1 & 192 & ,016 & 901 \\
\hline & Intra-grupos & 794,285 & 65 & 12,220 & & \\
\hline & Total & 794,478 & 66 & & & \\
\hline
\end{tabular}

\begin{tabular}{|c|c|c|c|c|c|c|c|c|c|}
\hline \multicolumn{10}{|c|}{ Descriptivos } \\
\hline & & \multirow[b]{2}{*}{$\mathrm{N}$} & \multirow[b]{2}{*}{ Media } & \multirow[b]{2}{*}{$\begin{array}{l}\text { Desviación } \\
\text { típica }\end{array}$} & \multirow[b]{2}{*}{ Error típico } & \multicolumn{2}{|c|}{$\begin{array}{l}\text { Intervalo de confianza para la } \\
\text { media al } 95 \%\end{array}$} & \multirow[b]{2}{*}{ Mínimo } & \multirow[b]{2}{*}{ Máximo } \\
\hline & & & & & & Limite inferior & $\begin{array}{l}\text { Limite } \\
\text { superior }\end{array}$ & & \\
\hline \multirow[t]{3}{*}{$\mathrm{SC1}$} & Chico & 27 & 14,26 & 3,096 & .596 & 13,03 & 15,48 & 8 & 19 \\
\hline & Chica & 40 & 13,90 & 3,808 &, 602 & 12,68 & 15,12 & 6 & 21 \\
\hline & Total & 67 & 14,04 & 3,518 & ,430 & 13,19 & 14,90 & 6 & 21 \\
\hline \multirow[t]{3}{*}{$\mathrm{SC} 2$} & Chico & 27 & 23,33 & 5,870 & 1,130 & 21,01 & 25,66 & 14 & 35 \\
\hline & Chica & 40 & 23,68 & 4,503 &, 712 & 22,23 & 25,12 & 12 & 32 \\
\hline & Total & 67 & 23,54 & 5,058 &, 618 & 22,30 & 24,77 & 12 & 35 \\
\hline \multirow[t]{3}{*}{$\mathrm{SC} 3$} & Chico & 27 & 18,70 & 3,383 & .651 & 17,37 & 20,04 & 13 & 25 \\
\hline & Chica & 40 & 19,63 & 3,887 &, 615 & 18,38 & 20,87 & 6 & 25 \\
\hline & Total & 67 & 19,25 & 3,694 &, 451 & 18,35 & 20,15 & 6 & 25 \\
\hline \multirow[t]{3}{*}{$\mathrm{SC} 4$} & Chico & 27 & 18,26 & 3,938 & ,758 & 16,70 & 19,82 & 10 & 26 \\
\hline & Chica & 40 & 18,15 & 3,167 &, 501 & 17,14 & 19,16 & 12 & 25 \\
\hline & Total & 67 & 18,19 & 3,470 &, 424 & 17,35 & 19,04 & 10 & 26 \\
\hline
\end{tabular}

Esta investigación pone de manifiesto que en las instituciones es importante trabajar el autoconcepto, ya que como se ha comprobado, influye de forma significativa. En numerosas ocasiones, ante el fracaso escolar, se pretende disminuir este número de suspensos con clases particulares o refuerzos sin hacer mención o tener en cuenta la percepción que tienen los alumnos sobre sí mismos y cómo puede influir en sus calificaciones. Por ello, puede ser considerado necesario realizar intervenciones sobre este aspecto, e investigar si al realizar actividades que mejoren el autoconcepto, se mejora el rendimiento académico, sería un aspecto a valorar muy interesante que completaría este estudio. 


\section{REFERENCIAS}

Brookover, W.B. et al (1.974) "Self-concept of ability and school achievement". Sociology of Education $n^{\circ} 73$, pp. (271-278)

Goñi, E., Madariaga, J.M. (2009) "El autoconcepto personal: estructura interna, medida y variabilidad". Servicio Editorial de la Universidad del País Vasco Euskal Herriko Unibertsitateko Argitalpen Zerbitzua.

Orgilés, M., Johnson, B.T., Huedo-Medina, T.B., Espada,J.P., (2012). "Autoconcepto y ansiedad social como variables predictoras del rendimiento académico de los adolescentes españoles con padres divorciados." Electronic Journal of Research in Educational Psychology, 10 (1), 057-072.

Périz, J.A., Martínez, M.C., Generelo, E. (2007) "Influencia de las variables bio-psicosociales de salud en la adherencia a la práctica físico-deportiva en adolescentes (1316 años)". Departamento de Educación, Cultura y Deporte: Aragón.

Polo, M.T. y López-Justicia, M.D., (2009) "Autoconcepto de estudiantes universitarios con discapacidad visual, auditiva y motora." Revista Latinoamericana de Psicología 44 (2), 87-98

Purkey, W.W. (1.968). "The search for self: evaluating students self concept" en Research Bulletin. Florida: Educational Research and Development Council 4, $n^{\circ} 2$.

Sánchez García, M. y Carmona Márquez, J. (2010) "Análisis de datos con SPSS 12". Universidad de Huelva Publicaciones.

Santana Vega, L. E. y Feliciano, L. (2011). Percepción de apoyo de padres y profesores, autoconcepto y toma de decisiones en bachillerato Revista de Educación, 355, 493-519.

Sweeney, R.B., y Bracken, B.A. (2000). Influence of family structure on children's selfconcept development. Canadian Journal of School Psychology, 16(1), 39-52.

Tillman, K.H. (2007). Family structure pathways and academic disadvantage amogn adolescents in stepfamilies. Sociological Inquiry, 77, 383-424. 


\section{APLICACIONES DE LA INTELIGENCIA EMOCIONAL}

Christian Platero Ibañez. Universidad de Granada

\section{RESUMEN}

El objetivo de este artículo es desarrollar la importancia de la inteligencia emocional en la actualidad dentro de diferentes ámbitos como bien son la escuela o la educación familiar y a su vez indagar más profundamente en debates tales como la relación entre inteligencia emocional y el género, o la depresión y la felicidad en relación con el control de las emociones.

A lo largo del artículo expondré mis ideas sobre la inteligencia emocional, basándome en investigaciones realizadas por diversos autores y aportando mi juicio de valor sobre la importancia en la actualidad de una correcta educación emocional.

PALABRAS CLAVE: Inteligencia, Socialización, Adaptación del estudiante.

\section{INTRODUCCIÓN}

El término "inteligencia emocional" comenzó a tomar relevancia a partir de los años 90 gracias a autores como Peter Salovey, John Mayer o Daniel Goleman que difundieron la importancia de esta en la vida del ser humano. En este momento, se introdujeron dentro del término aquellas cualidades emocionales consideradas como importantes: La empatía, expresión y comprensión de sentimientos, la simpatía, la persistencia o la cordialidad eran algunas de ellas.

La inteligencia emocional (IE) ha tomado una gran importancia dentro de la sociedad actual. Desde las primeras investigaciones realizadas en España, se observa un crecimiento continuo de la preocupación por el tema a tratar. Es por ello que, de forma concisa, realizaré un repaso sobre la inteligencia emocional y sus aspectos más discutidos.

La IE no se centra en la inteligencia propia de cada sujeto (intelecto) sino va mas dirigida a las características de la personalidad (capacidades sociales y emocionales). Se defiende que, tener un CE (coeficiente emocional) elevado puede ser más importante para tener éxito en la vida que tener un $\mathrm{Cl}$ (coeficiente intelectual) elevado.

La discusión actual sobre la IE se centra en el planteamiento por parte de Mayer y Salovey (2007) y su modelo centrado en 4 habilidades emocionales básicas (La habilidad para percibir, expresar y valorar emociones con exactitud; la habilidad para acceder y/o generar sentimientos que faciliten el pensamiento; la habilidad para comprender emociones y el conocimiento emocional y la habilidad para regular las emociones promoviendo un crecimiento emocional e intelectual) y aquellos modelos basados en rasgos de la personalidad, defendidos por. Hoy en día, la complementariedad de estos modelos o la contraposición sigue discutiéndose.

A lo largo del artículo postularé diversos ámbitos donde se podrá ver la inclinación hacia un modelo, hacia otro o el trabajo conjunto de ambos. 
Goleman (2009) ha sido un pilar importante dentro de la inteligencia emocional. Entre otros afirma que, se puede observar la poca influencia del intelecto para conseguir el éxito $(20 \%)$ dejando un $80 \%$ a otro tipo de variables como por ejemplo la IE. De este modo, controlando la angustia, la empatía, el empeño frente a la frustración o la confianza, se puede alcanzar unos niveles de éxito óptimo, siendo "estímulos ideales para el éxito" (Goleman, 2009).

\section{DESARROLLO}

La gran mayoría de los científicos-as, están de acuerdo en establecer una serie de emociones básicas presentes en todos los seres vivos como el amor, el miedo, el dolor, el odio o la culpa. A partir de aquí se pueden abarcar diferentes grados emocionales siendo los humanos los capaces de interpretar e identificar una mayor variedad de estas.

\section{Inteligencia emocional en el entorno familiar}

La utilización de la IE en distintos ámbitos, da lugar a hablar de su importancia para educar a los niños y niñas.

Por norma general, los niños presentan un intento repetitivo para conseguir el éxito, con un gran empeño para lograr sus metas. Hoy en día, se cree que, muchos problemas de la infancia pueden explicarse por los cambios sociales, en este caso, las emociones pueden tratar de solucionarlos.

Diferentes estudios (Shapiro 1997) organizan la manera de educar a los niños en tres formas distintas: De forma autoritaria donde los padres tienden a desalentar a los niños a expresar sus opiniones y sentimientos; de forma permisiva caracterizada por aceptar las ideas del niño pero sin poner metas muy claras a sus hijos ni límites ante sus acciones; y de una forma autorizada donde se logra equilibrar límites claros con un ambiente estimulante en el hogar.

\section{El/la niño niña y sus emociones}

Los-as niños-as pueden rodearse de emociones positivas o negativas, y todo su entorno debe procurar conseguir las primeramente mencionadas.

La atención positiva genera en el niño-a una autoconfianza y optimismo para afrontar todos los retos que aparecen en su vida. Si les ayudamos a mostrar empatía hacia los demás, obtendremos unos logros mayores tanto en la escuela como en su futuro laboral, fortaleciendo entre otras cosas, la sinceridad.

Cabe destacar que la mayoría de los estudios, no muestran diferencias significativas en las conductas empáticas de niños y niñas (Rey, y Extremera. 2012). En cuanto al resto de emociones, si se aprecian diferencias de género que desarrollare más adelante.

Uno de los estados emocionales a los que se puede llegar a través de las emociones positivas es la felicidad. La correcta utilización de las emociones positivas y por consiguiente, la buena utilización y control de la IE, ayudan a conseguir una mejora personal y social en el sujeto y la sociedad, evitando de este modo conductas que podemos denominar como de riesgo y ayudando a mejorar y optimizar las relaciones 
sociales. Toda esta correcta utilización de nuestras emociones, va inevitablemente ligada a nuestra felicidad en la vida diaria (Fernandez-Berrocal y Extremera-Pacheco 2009).

Es importante destacar que, hasta el momento se afirma que de manera general, una sociedad más feliz esta instaurada sobre unas emociones positivas y de ahí el empeño por continuar las investigaciones en este rumbo (Maritza y Sanhueza 2012). Como toda teoría, nos encontramos con la parte debatiente la cual considera que la felicidad, estará determinada por tres aspectos: los genes causantes de reflejar las características de la personalidad; las circunstancias sociodemográficas y las actividades intencionales en las que cada individuo se implica de forma voluntaria.

Al igual que emociones positivas, pueden aparecer emociones negativas, tales como la vergüenza o la culpa. Estas pueden estar presentes en momentos determinados a lo largo de la vida.

La culpa puede ser neurótica, donde uno se castiga a sí mismo por razones injustificadas e irracionales, o culpa interpersonal, que surge del interés por la opinión del otro, y sirve para reducir la autocrítica y mejorar las relaciones personales de un niño-a. Esta última también es conocida como conciencia y es la manera más poderosa para controlar la conducta de los niños.

Es cierto que algunas emociones negativas como el miedo, el castigo, la vergüenza o la culpa pueden ayudar y motivar al niño-a a aprender y desarrollar conductas más adecuadas tras un previo aprendizaje y razonamiento, pero estas mismas, pueden desencadenar en un estado de depresión.

Según diversos estudios (Fernandez-Berrocal, Extremera y Ramos Diaz 2003), los momentos o estados de depresión pueden generarse por una mala regulación de las emociones. Es por ello que una buena instrucción y aprendizaje emocional, junto con un desarrollo de la inteligencia emocional positiva, puede ayudar a disminuir las posibilidades de depresión dentro de una persona consiguiendo el control de uno mismo y así poder desarrollar los aspectos positivos de las situaciones.

\section{Inteligencia emocional y el ámbito educativo}

La IE dentro del ámbito académico es otro de los puntos a destacar en mi artículo debido a su importancia en la actualidad.

Jiménez Morales y López Zafra (2009) relacionan la IE con el ajuste socio-escolar del alumnado, especialmente en lo referente al rendimiento escolar y a la aparición de estrés o ansiedad. La realización de programas centrados en habilidades de la inteligencia emocional se percibe en la actualidad como necesarios para el crecimiento personal, y como ayuda para la preparación al mundo laboral. Cada vez se defiende con mayor ímpetu que la inteligencia en el ámbito académico no es suficiente y se le da una mayor importancia a todo lo que mueve y motiva a las personas, es decir todos los aspectos emocionales y sociales. Estos aspectos deben ser tratados tanto por la familia como por la escuela para aumentar las expectativas de éxito en el futuro.

Salovey y Mayer (2007) defienden la utilización de las emociones para que el sujeto pueda solucionar los problemas que se le presenten adaptándose al medio lo más eficazmente posible. 
Para esta intervención dentro del ámbito educativo, es necesaria y oportuna la sensibilización por parte de los docentes. Mientras que en épocas anteriores no hacían especial atención a los sentimientos y las emociones, centrándose más en el control de los alumnos y alumnas, actualmente los-as educadores-as deben intentar conseguir que el alumnado consiga sentir inteligentemente, siendo conveniente la práctica de habilidades emocionales dentro del aula y el entrenamiento para, con el tiempo, ir tratando de educar la IE (Pena, Garrido y Repetto Talavera 2008)

Es importante que el/la docente no vea las emociones de forma individual sino que trate de crear un clima emocional adecuado en el colegio para recibir, interiorizar y controlar las emociones de los-as alumnos-as. Berrocal y Aranda (2008) postulan que se puede apreciar que los centros educativos y el profesorado tienen cada vez una mayor consideración a los aspectos emocionales dentro del aula para conseguir un mayor rendimiento del alumnado y un clima óptimo.

Tras esta exposición de razones, creo haber dejado clara mi postura a favor del contexto educativo para la educación emocional, pero siempre en colaboración con la familia de cada niño-a la cual desempeña un papel fundamental para que estos-as niños-as adquieran una inteligencia y valoración emocional mayor y, por consiguiente, aspiren en mayor medida al triunfo. Para conseguir estos cambios de forma sostenible, los padres deben ser en el hogar el espejo en el que se reflejen los comportamientos positivos aprendidos por el niño-a y su responsabilidad moral será fundamental en la generación de sus virtudes positivas y habilidades emocionales.

\section{Diferencias sexuales}

Por último, encuentro preciso hablar de uno de los temas más debatidos en la actualidad dentro de la inteligencia emocional, la diferenciación o no en cuanto al género.

Investigadores como Mestre, Guil y Lim (2004) coinciden en la existencia de rasgos o habilidades más desarrolladas dependiendo de sexo teniendo cada uno una serie de puntos fuertes y de puntos débiles. Se aprecia que, dependiendo del tipo de medida utilizada, aparecen diferencias de género.

En las medidas de autoinforme, los sujetos proporcionan información sobre su apreciación de su propia IE y la de una tercera persona mientras que la prueba de habilidad, los sujetos tienen que resolver determinados problemas emocionales, comparando los resultados con otros objetivos (Mayer 2001; Mayer Salovey y Caruso, 1999)

En las medidas de autoinforme hay una gran controversia ya que, aunque la mayoría de investigaciones no encuentran diferencias de género, otros encuentran una mayor capacidad de las mujeres para controlar y manejar sus emociones y las de los demás.

Por su parte, las pruebas de habilidad o ejecución, muestran claras diferencias respecto al sexo con una inteligencia emocional mayor en mujeres que en hombres. Los hombres perciben una IE mayor a la que posteriormente transmiten o realizan, y las mujeres son todo lo contrario. Es decir, las diferentes pruebas de ejecución dejan al descubierto una infravaloración de las mujeres frente a una sobrevaloración por parte de los hombres (Sánchez-Nuñez, Fernandez Berrocal, Montañes Rodriguez y Latorre-Postigo 2008; Petrides y Furnham, 2000) 
Los datos revelan que los estereotipos dificultan e impiden en cierto modo la inteligencia emocional, siendo las personas menos estereotipadas y ligadas a pensamientos sociales, las poseedoras de un mayor desarrollo de su inteligencia emocional, alejándose de este modo de los roles que, supuestamente, deben cumplir dependiendo del sexo (Aritzeta, Balluerka y Barberá 2012). La expresividad es un factor muy importante para desarrollar la IE y los hombres, en comparación con las mujeres, presentan una expresividad inferior que deben intentar trabajar.

\section{CONCLUSIÓN}

A modo de conclusión puedo garantizar y apoyar la importancia de la psicología emocional en la actualidad para lograr el éxito en la vida. Muchos científicos creen que nuestras emociones humanas han evolucionado fundamentalmente como un mecanismo de supervivencia.

Como bien adelantó Goleman y otros autores de renombre, la IE es muy importante, tanto es así que la educación en la infancia debe permanecer ligada a este término. De ahí la importancia de transmitir emociones positivas como la empatía, y tratar de evadir o aprender de las emociones negativas para poder crecer y crear una sociedad más feliz y propensa al éxito.

Entrelazada con la educación familiar, se encuentra la educación escolar donde se deben de construir espacios educativos que hagan crecer las fortalezas individuales del alumnado para su crecimiento personal y social.

Independientemente del género o la edad, la IE juega un factor importante a lo largo de la vida. Por ello es merecedora de atención, investigación, desarrollo y control, evitando así verdaderos desastres sociales y consiguiendo una sociedad más preparada para lograr el éxito individual y colectivo.

\section{REFERENCIA BIBLIOGRÁFICA}

Fernández-Berrocal, P., Extremera, N. y Ramos-Díaz, N. (2003). Inteligencia emocional y depresión. Encuentros en psicología social, 1, 251-254.

Fernández-Berrocal, P., Extremera-Pacheco, N. (2009). La inteligencia emocional y el estudio de la felicidad. Revista interuniversitaria de formación del profesorado, 66, 85108.

Fernández-Berrocal, P. y Extremera-Pacheco, N. La inteligencia emocional como una habilidad esencial en la escuela. Revista Iberoamericana de educación.

Fernández-Berrocal, P. y Ruiz-Aranda, D. (2008). La inteligencia emocional en la educación. Revista electrónica de investigación psicoeducativa. ISNN, 6, 421-436.

Gartzia, L., Aritzeta, A., Balluerka, N., Barberá, E. (2012). Inteligencia emocional y género: más alla de las diferencias sexuales. Anales de psicología, 28, 567-575.

Goleman, D. (2009). Inteligencia Emocional. Barcelona: Kairós. 
Jiménez-Morales, M. I. y López-Zafra, E. (2009). Inteligencia emocional y rendimiento escolar: estado actual de la cuestión. Revista latinoamericana de psicología, 41, 69-79.

Maritza-Espinoza, V., Sanhueza, A.O., (2012). Miedo a la muerte y su relación con la inteligencia emocional de estudiantes de enfermería de concepción. ACTA Paul Enferm, 4, 607-613.

Maye r, J. D., Caruso, D. y Salovey, P. (1999). "Emotional intelligence meets traditional standards for an intelligence". Intelligence, 27, 267-298.

Mayer, J.D. y Salovey, P. (2007). ¿Qué es inteligencia emocional? En Mestre, J.M. y Fernandez Berrocal, P. (Eds): Manual de inteligencia emocional, Madrid, Ed. Pirámide

Mestre, J. M., Guil, R. y Lim, N. (2004). Inteligencia emocional: ¿ A qué pueden deberse las diferencias respecto a la variable género? En E. Barberá, L. Mayor, M. Choliz, E. Cantón, E, Carbonell, C. Candela y C. Gómez (Eds,), Motivos emociones y procesos representacionales: De la teoría a la práctica. Valencia, ADEIT.

Pena-Garrido, M. y Repetto Talavera, E. (2008). Estado de la investigación en España sobre la inteligencia emocional en el ámbito educativo. Revista electrónica de investigación psicoeducativa, 6, 400-420.

Petrides, P. V. y Furnham, A. (2000). Gender Differences in measured and selfestimated trait emotional intelligence. Sex Roles, 449-46.

Rey, L., y Extremera, N. (2012). Inteligencia emocional percibida, felicidad y estrategias distractoras en adolescentes. Boletín de psicología,104, 87-101.

Sánchez-Nuñez, M. T., Fernandez-Berrocal, P., Montañes-Rodriguez, J. y

Latorre-Postigo, J.M. (2008). ¿Es la inteligencia emocional una cuestión de género? Socialización de las competencias emocionales en hombres y mujeres y sus implicaciones. Revista de investigación psicoeducativa, 6, 455-474.

Shapiro, L.E. (1997). La inteligencia emocional de los niños. México: Vergara editor. 


\section{PROPUESTAS DE MEJORA DE TRABAJO EN CASOS DE ABSENTISMO ESCOLAR EN EDUCACIÓN PRIMARIA}

Coronel Garrido, Raquel; Díaz García, Melody; Moreno Leal, Patricia. Universidad de Huelva

\section{RESUMEN}

Partiendo del concepto de absentismo escolar, de la normativa existente y de las responsabilidades que atañen a la familia y a los poderes públicos, se describen las características personales y sociales de niños absentistas. Además se hará un abordaje de la tipología más actual en la que se clasifica el absentismo y sus posibles causas, expuestas por diferentes autores. Derivado de esto, se proponen diferentes actuaciones para combatir el absentismo escolar en primaria, ya que este, es uno de los momentos claves en los comienza a darse este problema, por lo que es necesaria una mayor atención en este tramo escolar, centrada en la prevención.

Palabras claves: Absentismo escolar, familia, escuela, fracaso escolar.

\section{INTRODUCCIÓN}

Según Melendro (2008), "El absentismo escolar se entiende como la asistencia irregular, o las ausencias repetidas e injustificadas del centro educativo, de los menores en edad de escolarización obligatoria, o su no escolarización en este periodo."(p. 67). Este absentismo puede derivar en la salida anticipada del menor del sistema educativo, el denominado abandono escolar prematuro. $Y$ a su vez tener efectos sobre el rendimiento escolar, provocando retraso y, en las situaciones más graves, fracaso escolar. Una situación que supone dejar el sistema educativo antes de haber logrado adquirir un nivel apropiado de conocimientos. Por lo que el absentismo escolar, comienza siendo "un problema educativo que afecta a la comunidad escolar y pasa a ser un problema social, familiar y cultural". La no adquisición de los aprendizajes necesarios, requeridos para su futura inserción laboral y social por parte de los jóvenes que abandonaron prematuramente el sistema educativo, tiene efectos muy significativos a todos los niveles -social, emocional, competencial, económico- en el tipo de tránsito que estos realizan a la vida adulta. $Y$ genera situaciones de desigualdad y exclusión social.

A continuación, se exponen los diferentes tipos de absentismo escolar, además de sus posibles causas e intervenciones. Respecto a los distintos tipos de absentismo escolar según la clasificación que nos ofrece, Álvarez Castro (2009):

\section{TIPOS}

Injustificado:

El centro escolar no recibe ningún certificado en el que se exponga los motivas de la ausencia del alumno. 


\begin{tabular}{|l|l|}
\hline Puntual o esporádico: & $\begin{array}{l}\text { El alumno se ausenta de clase falta durante } \\
\text { un periodo de tiempo considerable pero } \\
\text { luego se reincorpora al centro sin volver a } \\
\text { repetirse tal ausencia. }\end{array}$ \\
\hline Intermitente: & $\begin{array}{l}\text { La asistencia se produce de forma alterna, } \\
\text { es decir, el alumno se ausenta por periodos } \\
\text { breves. }\end{array}$ \\
\hline Desescolarización: & $\begin{array}{l}\text { No estar escolarizado en la educación } \\
\text { obligatoria. }\end{array}$ \\
\hline Abandono prematuro: & $\begin{array}{l}\text { Alumno que cursa la educación obligatoria y } \\
\text { después de haber superado varias etapas } \\
\text { educativas decide dejar su formación } \\
\text { académica. }\end{array}$ \\
\hline
\end{tabular}

Tabla 1: Tipologías del Absentismo Escolar. (Álvarez Castro, 2009)

Por otro lado, se muestran las posibles causas del Absentismo escolar, conforme a distintos autores:

Según Melendro (2008), el absentismo escolar puede producirse por múltiples causas; se trata de un problema complejo que se focaliza en los centros educativos, aunque puede tener su origen en aspectos diferentes, como pueden ser desde el propio entorno escolar hasta el círculo familiar, el entorno social y cultural, las relaciones entre iguales..., por lo que se requiere de un abordaje interdisciplinar, complejo, donde los diferentes agentes sociales y educativos, como los padres, educadores, profesores, etc., deben trabajar en equipo para obtener resultados satisfactorios.

Además, se afirma que la escuela no es capaz, por sí misma, de solucionar los complejos problemas de la población infantil. Para ello propone que entre las posibles causas de absentismo escolar, se encuentra (Petrus; 2009):

- Ausencia de motivación hacia el estudio

- Entorno poco estimulado, en el que es frecuente el desinterés respecto al desarrollo escolar

- Dificultades económicas

- Carencia de recursos personales, sociales, competenciales,...

- Sensación de inutilidad, fracaso y desinterés hacia lo educativo que tiene lugar entre el grupo de iguales, etc.

- Modelos escolares poco flexibles

Asimismo, Racionero y Padrós (2010), no atribuye una única causa que afecte al absentismo; siendo, para estos autores, las más frecuentes:

- Pertenecer a etnia gitana

- Padre y madre trabajando fuera de casa

- Familias mono-parentales

- Bajo nivel cultural de los padres

- Conflicto entre las expectativas de los jóvenes para su futuro y lo que el sistema educativo les reporta para alcanzarlo

- Bajo nivel de comprensión de algunos alumnos con respecto a sus compañeros, por lo que se sienten mal en las aulas 
Por último, Aguado (2005) hace una clasificación de todas las posibles causas del absentismo en tres grandes grupos:

- Entre las causas familiares se destaca como una causa decisiva la situación familiar difícil (familias numerosas, mono-parentales, en situación desestructurada)

- Entre las causas sociales se acentúa la presencia de modelos absentistas en el entorno, falta de referentes académicos con éxito en la familia o entorno próximo, ausencia de recursos y estimulación para el estudio, etc.

- Entre las causas educativas se encuentra la escolarización tardía, así como la insuficiencia en ocasiones, de recursos organizativos, humanos y materiales.

En definitiva, derivado de todo lo anterior se puede decir que el absentismo escolar no cuenta con una única causa, puesto que son diversos los factores que influyen en esta problemática.

\section{PROPUESTA DE INTERVENCIÓN}

Debido a que el abandono escolar temprano tiene múltiples causas y se produce fruto de muy diferentes trayectorias, las medidas que lo previenen coinciden, en parte, con las estrategias que favorecen las expectativas positivas hacia el estudio, la autoestima, el éxito y el rendimiento escolar. (Consortium INCLUD-ED, 2009). Por lo que se procede a una revisión de algunas de las actuaciones que se han realizado respecto al tema.

El Plan Integral para la Prevención, Seguimiento y Control del Absentismo escolar (2003), recoge que el carácter integral de las actuaciones es una condición básica para mejorar las condiciones socioeconómicas y culturales que suelen estar en la base del absentismo escolar. Por ese motivo, se hace imprescindible el desarrollo de actuaciones no solo en el campo educativo y familiar sino también en el ámbito de los servicios sociales, la salud, el empleo y la formación y, en general, de cuantos aspectos mejoren las condiciones sociales y económicas del entorno. (Plan Integral para la Prevención, Seguimiento y Control del Absentismo Escolar, 2003)

De acuerdo a dicho Plan, las áreas de actuación en Absentismo escolar son (Plan Integral para la Prevención, Seguimiento y Control del Absentismo Escolar, 2003):

Prevención e Intervención en el ámbito escolar. Se pretende favorecer la adaptación del proceso de enseñanza a las necesidades e intereses de la población escolar que se encuentre en riesgo de iniciar o mantenerse en una situación de absentismo escolar. La implicación de los equipos directivos de los centros escolares, así como de los equipos y departamentos de orientación y del Servicio de Inspección constituye la pieza fundamental de las actuaciones que se desarrollen en esta área.

Atendiendo al modelo inclusivo, se potencia que diversos recursos humanos (profesorado, pero también diferentes especialistas, personas de la comunidad, etc.) estén en el aula favoreciendo que el alumnado con dificultades específicas participe en la actividad y potenciando las interacciones entre el alumnado con diferentes niveles de rendimiento, en la perspectiva de las actuales teorías de aprendizaje basadas en el diálogo y la interacción (Racionero y Padrós, 2010). 
Intervención en el ámbito social y familiar. Se recoge que las medidas programadas en esta área tenderán a lograr la intervención psicosocial con las familias en las que se detecte que sus condiciones de vida, costumbres y cultura se encuentran en el origen del absentismo de los menores con objeto de implicarlas y comprometerlas en la asistencia regular a los centros. La actuación de los Servicios Sociales Municipales dependientes de los Ayuntamientos y las Diputaciones constituyen el elemento clave de las medidas incluidas en esta área, sin olvidar el papel que en este ámbito corresponde a los Servicios Sociales Especializados.

La participación educativa, por tanto, consiste en la implicación de las familias y otros miembros de la comunidad bien en el proceso de aprendizaje de los alumnos, bien en su propia formación como personas adultas dentro del centro; de esta manera, se convierten en recursos humanos de apoyo al aprendizaje con un valor añadido como referentes positivos para sus propios hijos, o alumnado del mismo grupo social. (Martínez y Niemela, 2010).

Formación e Integración laboral. Las medidas incluidas en esta área tenderán a completar la formación de los jóvenes mediante acciones formativas ajustadas a sus necesidades e intereses, con objeto de facilitar su inserción social y laboral, tales como Programas de Cualificación Profesional e Inicia (PCPT), Escuelas Taller, Casas de Oficios y Cursos de Formación Ocupacional y programas o iniciativas europeas relacionadas con los objetivos del Plan.

Formación y Coordinación. Las medidas incluidas en esta área recogerán iniciativas tendentes a favorecer la formación y coordinación entre los diferentes profesionales implicados en el desarrollo del Plan. Igualmente en esta área se recogerán los dispositivos de coordinación de ámbito autonómico, provincial y local que se requieran para el desarrollo de las actuaciones con intervención de todas las Administraciones implicadas.

Por último, se proponen diferentes ejemplos de algunas de las actuaciones educativas de éxito que se llevan a cabo según distintos autores:

Las comisiones mixtas son una forma de organización básica y una manera de avanzar hacia la calidad educativa a través de la participación (Flecha y García, 2008). Se trata de comisiones formadas por personas de diferentes perfiles de la comunidad educativa: profesorado, familiares, alumnado, otros agentes; para cada una de los objetivos o cuestiones que se han considerado prioritarios se constituye una comisión mixta (Folch y Parents' Association, 2004)

Voluntariado: se consigue a través de personas a las que se invita a participar voluntariamente en la escuela. Estas personas son tan diversos como se pueda: en primer lugar, se valora la participación de las propias familias o personas del entorno inmediato; además, participan también - en diversos casos, a través de convenios con universidades o con entidades del entorno - estudiantes universitarios, profesionales y otros perfiles (Vieira, 2010).

El valor de este voluntariado no reside solamente en la posibilidad de contar con un mayor número de recursos humanos, sino en la riqueza de su pluralidad y la inteligencia cultural que se aporta (Ramis y Krastrina, 2010).

Bibliotecas tutorizadas: el alumnado, pero también otras personas del entorno, pueden utilizar la biblioteca para leer cuentos, para hacer deberes o resolver tareas escolares, buscar información en internet, etc.; la actividad propia de las bibliotecas, la 
lectura, queda potenciada en un sentido comunitario y colectivo. En ese espacio transformado, la lectura es algo a compartir con diferentes personas, en una práctica de lectura dialógica (Aguilar, Alonso, Padrós y Pulido, 2010).

\section{CONCLUSIÓN}

Haciendo referencia a todas las posibles causas descritas anteriormente, se puede decir que la problemática del absentismo está ligada a múltiples factores personales, sociales, familiares, económicos, así como también a otros de carácter educativo y relacionado con el funcionamiento y organización de los centros escolares; por lo que resultaría importante políticas destinadas a paliar el absentismo y abandono escolar.

Derivado del factor multidisciplinar que presenta el absentismo, cabe decir que su intervención debe recoger el carácter integral de todas las actuaciones que se lleven a cabo para paliar el problema; ya que esas actuaciones no sólo se limitan al campo educativo y familiar sino también al ámbito de los servicios sociales, la salud, el empleo y la formación y, en general, de cuantos aspectos mejoren las condiciones sociales y económicas del entorno.

\section{BIBLIOGRAFÍA}

Aguado, P. (2005). Programa de prevención y control del absentismo escolar en el Ayuntamiento de Madrid. Indivisa: Boletín de estudios e investigación, n 6, 249-257.

Aguilar, C., Alonso, J., Padrós, M., y Pulido, M. (2010). Lectura dialógica y transformación en las comunidades de aprendizaje. Revista Interuniversitaria de Formación del Profesorado, 67(24 (1)), 31-44.

Álvarez Castro, E. (2009). Absentismo escolar. Revista digital enfoques educativos. Pag 22-27.

Consortium INCLUD-ED. ( 2009). Actions for success in schools in Europe. Brussels: European Comission.

Flecha, R., y García, R. (2008). Garantizar el éxito con la incorporación de las familias. De la fiscalización y la descalificación a la colaboración. Organización y Gestión Educativa, 16(5), 23 - 26.

Folch, X., y Parents' Association. (2004). Romani families transforming the school. Networks: An on-Line Journal for Teacher Research, 7(1).

Martínez, B., y Niemela, R. (2010). Formas de participación de las familias y de la comunidad hacia el éxito educativo. Revista Educación y Pedagogía, 56, 69-78.

Melendro, M. (2008). Absentismo y fracaso escolar: la educación social como alternativa. Bordón. Revista de pedagogía. Vol. 60, nº 4, 65-77.

Plan Integral para la Prevención, Seguimiento y Control del Absentismo Escolar (2003). Acuerdo de 25 de Noviembre, por el que se aprueba el Plan Integral para la 
Prevención, Seguimiento y Control del Absentismo escolar. (Publicado en BOJA $n^{\circ}$ 235, de 5 de Diciembre de 2003).

Petrus, A. (2009). Nuevos ámbitos en educación social. En Romans, M.,Petrus, A. y Trilla, J. De profesión: educador social. Barcelona: Paidós, 63-147.

Racionero, S., y Padrós, M. (2010). The dialogic turn in educational psychology. Revista De Psicodidáctica, 15(2), 143-162.

Ramis, M., y Krastrina, L. (2010). Cultural intelligence in the school. Revista De Psicodidáctica, 15(2), 239-252.

Vieira, L. (2010). Voluntariado en la escuela: Un estudio de casos dentro del proyecto comunidades de aprendizaje. Tesis doctoral no publicada. Universidad de Barcelona. 


\section{La importancia de la creatividad en las aulas en alumnos y alumnas del primer ciclo de la Enseñanza Secundaria}

Carreño Santo Tomás, V.; Castillo Romero, I.; Falcón Cordero, C.; Romero López, M.L.; Rico Collantes, S. Universidad de Huelva

\section{RESUMEN}

La creatividad es una parte perteneciente a la naturaleza humana, aunque con los años puede no seguir creciendo con el ser humano, debido a que durante muchas décadas no ha sido contemplada como parte indispensable del desarrollo del adolescente. El presente artículo consiste en una revisión teórica partiendo de un recorrido por la historia de la creatividad y una revisión por su conceptualización, con el fin de promover la importancia de la creatividad a través de una serie de actividades y estrategias propuestas para su desarrollo.

PALABRAS CLAVES: joven, creatividad, enseñanza secundaria, desarrollo mental.

\section{Introducción}

A lo largo de las diferentes épocas, el concepto de "creatividad" no ha sido estimado del mismo modo, ni ha recibido la significación que actualmente posee.

Las civilizaciones griegas y romanas, según Tatarkiewicz (1997), carecían de términos en su vocabulario para designar la palabra "crear" y "creador". La Edad Media se caracterizaba por su mentalidad religiosa donde, el acto de crear era reservado únicamente para el poder divino de Dios. Se presenta la revolución del concepto creatividad al llegar el Renacimiento, donde los autores comienzan a mostrar su sello en obras se comienzan a expresar la sensualidad y subjetividad. En la llustración se experimenta la consolidación de la creatividad en la producción, asociando el arte a la imaginación. La nueva mentalidad acepta que los seres pueden ser creadores a partir de lo ya existente. Durante el siglo XIX el arte y las acciones innovadoras en la ciencia comienzan a extenderse. En el siguiente siglo, empieza a ser aplicada en la elaboración de productos y en la reproducción de ideas. Finalmente, en el siglo XXI, la creatividad vive su máximo esplendor y es aplicada en la vida cotidiana de las personas constantemente.

\section{Definición del término}

El proceso creativo aparece de forma innata entre las facultades del ser humano e implica habilidades para integrar los procesos cognitivos. Sin embargo, a pesar de ser un constructo innato, no ha logrado captar el interés por su estudio hasta hace pocos años. Entre la variedad de significados hemos creído importantes las siguientes definiciones:

- "Capacidad y actitud para generar ideas nuevas y comunicarlas" (De la Torre, 1995).

- "La creatividad sería la capacidad esencial del ser inteligente que le permite producir sus creaciones u obra creada". (Beltrán y Bueno, 1995). 
- La creatividad se conceptualiza mejor, no como un "rasgo" de la personalidad, ni una habilidad general, sino como la conducta resultante de una constelación particular de características personales, habilidades cognitivas e influencias ambientales. Esta conducta, que se pone de manifiesto en productos 0 respuestas, sólo se puede explicar de una forma completa mediante un modelo que abarque estos tres conjuntos de factores. (Amabile, 1983).

- Habilidad para responder de forma adaptativa a la necesidad de nuevos enfoques y productos. Lo nuevo es un producto, resultante de un proceso, iniciado por una persona. Tanto el producto, como el proceso como la persona se caracterizan por su originalidad, utilidad, validez y adecuación. Muchos productos son procesos y muchos procesos son productos, y la persona es tanto un producto como un proceso. (Barron, 1988).

\section{¿Cómo trabajar la creatividad en las aulas de $1^{\circ}$ y $2^{\circ}$ de la E.S.O.?}

\section{Evidencia empírica, estudios sobre la importancia de la creatividad.}

Varios estudios empíricos (entre ellos la teoría de la inversión de Stemberg y Lubart) han demostrado que el mayor nivel de enseñanza creativa se da en profesores de guardería (Sternberg y Lubart, 1997), poco a poco este talento creativo se va perdiendo y olvidando ya que como menciona Stenberg $<</ o$ normal es que creatividad resulte obvia en alumnos pequeños, pero puede ser más difícil encontrarla en estudiantes de mayor edad porque su potencial creativo ha sido suprimido por una sociedad que promueve la conformidad intelectual>> (Sternberg,2010; p. 412).

El interés en abordar este vínculo entre adolescencia y creatividad desde el punto de vista conceptual estriba en que existen escasas referencias bibliográficas en que se señalen su importancia en relación al desarrollo humano de los adolescentes, sus implicaciones en la atención integral de los mismos y en la Salud Pública de este grupo de población (Donas, 2000).

Piaget (1962) coincide con Vigotsky (1990) en que la transformación cualitativa de la actividad creativa del adolescente es necesaria debida al incremento de su capacidad de razonamiento y pensamiento abstracto. El desarrollo del pensamiento conceptual y abstracto permite el acceso a una intensa y rica actividad imaginativa que, lejos de traducirse en una mayor productividad, es puesta al servicio de la maduración personal, emocional y social, y del progresivo desarrollo del razonamiento y de la inteligencia (Garaigordobil, 1995).

Maslow (1959, 1973) y Rogers (1978) consideran que existe una tendencia a la creatividad vinculada al propio desarrollo personal, social y emocional. El progresivo desarrollo personal y el acceso a la autonomía y a la responsabilidad por parte del individuo que se autorrealiza, aseguran el acceso a ese pensamiento creativo maduro en la adultez.

Por otro lado Vigotsky (1986) diferenció entre dos tipos creatividad, una creatividad subjetiva permite la emergencia de una vida interior, el desarrollo psicoafectivo y la resolución de los conflictos de identidad propios de esta etapa, y una creatividad objetiva que se desarrolla paralelamente a la subjetiva, pero a través de la cual el adolescente crea imágenes, ideas, conceptos y esquemas nuevos para explicar la realidad y contribuye a la generación de nuevas formas de adaptación y al desarrollo intelectual. 
Por estas razones es preciso considerar la creatividad un ámbito importante de la vida de los adolescentes que no se pierde con los años sino que se integra con el desarrollo de habilidades cognitivas y en el ámbito social.

\section{Cuadro de actividades}

\begin{tabular}{|c|c|c|c|c|}
\hline ACTIVIDADES & & & PROFESOR & ALUMNO \\
\hline $\begin{array}{l}\text { Plantear } \\
\text { problemas y } \\
\text { resolverlos }\end{array}$ & ¿Qué pretende? & $\begin{array}{l}\text { Gracias a esta } \\
\text { actividad los niños } \\
\text { podrán plantearse } \\
\text { diferentes } \\
\text { problemáticas y las } \\
\text { posibles soluciones a } \\
\text { éstas, invitando al } \\
\text { alumnado a realizar } \\
\text { propuestas creativas } \\
\text { que den por resuelto } \\
\text { el problema. }\end{array}$ & $\begin{array}{l}\text { El profesor planteará } \\
\text { diferentes situaciones a la } \\
\text { clase y, en caso de que el } \\
\text { alumnado no sepa o pueda } \\
\text { proponer y expresar ideas, } \\
\text { éste, mediante preguntas, } \\
\text { intentará que dialoguen } \\
\text { hasta resolver el problema } \\
\text { planteado (¿Haríais esto o } \\
\text { lo otro?, ¿Qué creéis que } \\
\text { haríais?, ¿Llamaríais a } \\
\text { alguien?...). }\end{array}$ & $\begin{array}{l}\text { El alumnado, a través } \\
\text { del diálogo, deberá } \\
\text { resolver la } \\
\text { problemática. Con la } \\
\text { colaboración de toda } \\
\text { la clase se pretende } \\
\text { que todos los } \\
\text { alumnos (más o } \\
\text { menos creativos) } \\
\text { puedan poner en } \\
\text { común sus ideas, } \\
\text { enriqueciéndolas con } \\
\text { la de los demás. }\end{array}$ \\
\hline $\begin{array}{l}\text { Música y } \\
\text { emociones } \\
\text { ¿qué sugiere? }\end{array}$ & ¿Qué pretende? & $\begin{array}{l}\text { A través de la música } \\
\text { se pretenderá que el } \\
\text { alumnado proponga } \\
\text { aquello que ésta le } \\
\text { sugiere. }\end{array}$ & $\begin{array}{l}\text { El profesor será el } \\
\text { encargado de poner la } \\
\text { música e invitar al } \\
\text { alumnado a que participe } \\
\text { diciendo aquello que le } \\
\text { sugiere la música } \\
\text { (emociones, momentos, } \\
\text { sabores, sensaciones en } \\
\text { general...). }\end{array}$ & $\begin{array}{l}\text { El alumno deberá } \\
\text { cerrar los ojos, } \\
\text { escuchar la música y a } \\
\text { su vez pensar las } \\
\text { cosas que ésta le } \\
\text { sugiere. }\end{array}$ \\
\hline $\begin{array}{l}\text { Reflexión y } \\
\text { justificación } \\
\text { sobre un tema }\end{array}$ & Ejemplos & \multicolumn{3}{|c|}{$\begin{array}{l}\text { Se plantea un debate centrado en la diversidad cultural en las aulas, cada } \\
\text { alumno se posicionará sobre si está de acuerdo o no en compartir aula con } \\
\text { distintas culturas y justificar dicha postura. }\end{array}$} \\
\hline \multirow[t]{2}{*}{$\begin{array}{l}\text { Expresión } \\
\text { corporal }\end{array}$} & ¿Qué pretende? & $\begin{array}{l}\text { Expresar y reconocer } \\
\text { las distintas } \\
\text { emociones mediante } \\
\text { la expresión corporal. }\end{array}$ & $\begin{array}{l}\text { Presentará tarjetas con } \\
\text { distintas emociones, para } \\
\text { pedir al alumnado que } \\
\text { ejemplifique ésta con su } \\
\text { expresión corporal. }\end{array}$ & $\begin{array}{l}\text { Observará la imagen } \\
\text { presentada y después } \\
\text { tendrá que } \\
\text { representarlas. }\end{array}$ \\
\hline & Ejemplos & \multicolumn{3}{|c|}{$\begin{array}{l}\text { El profesor muestra una tarjeta donde aparezca un chico enfadado y los } \\
\text { alumnos expresarán mediante su cuerpo, dicha emoción. }\end{array}$} \\
\hline $\begin{array}{l}\text { Objeto: ¿qué } \\
\text { harías con él? }\end{array}$ & ¿Qué pretende? & $\begin{array}{l}\text { Sin tener información } \\
\text { previa sobre algo, el } \\
\text { alumno intentará } \\
\text { buscar la utilidad de } \\
\text { esa cosa. }\end{array}$ & $\begin{array}{l}\text { Su tarea se centrará en } \\
\text { buscar objetos no } \\
\text { conocidos por los alumnos } \\
\text { y presentárselos, sin } \\
\text { aportar información } \\
\text { adicional. }\end{array}$ & $\begin{array}{l}\text { Observará el objeto e } \\
\text { intentará averiguar } \\
\text { para qué sirve. }\end{array}$ \\
\hline
\end{tabular}




\begin{tabular}{|l|l|l|l|l|}
\hline & Ejemplos & \multicolumn{2}{|l|}{$\begin{array}{l}\text { El profesor mostrará a sus alumnos un metrónomo clásico y tendrán que } \\
\text { averiguar para qué sirve mediante el conocimiento previo que poseen. }\end{array}$} \\
\hline $\begin{array}{l}\text { Dibujos en las } \\
\text { nubes }\end{array}$ & ¿Qué pretende? & $\begin{array}{l}\text { Se pretende que los } \\
\text { alumnos identifiquen } \\
\text { figuras de la vida real, } \\
\text { representadas en las } \\
\text { nubes. }\end{array}$ & $\begin{array}{l}\text { El profesor explicará la } \\
\text { actividad e iniciará el juego } \\
\text { aportando la primera figura } \\
\text { al resto. }\end{array}$ & $\begin{array}{l}\text { El alumno debe } \\
\text { intentar imaginar } \\
\text { figuras de la vida real } \\
\text { en las nubes. }\end{array}$ \\
\cline { 2 - 4 } & Ejemplos & $\begin{array}{l}\text { Se indica que la clase se desarrollará al aire libre, en ella los alumnos se } \\
\text { tumbarán en el suelo para observar los dibujos que le sugieren las nubes. }\end{array}$ \\
\hline
\end{tabular}

Fuente: elaboración propia.

\section{Cuadro de estrategias}

\begin{tabular}{|c|c|c|c|c|c|}
\hline ESTRATEGIAS & & & PROFESOR & \multicolumn{2}{|c|}{ ALUMNO } \\
\hline \multirow[t]{2}{*}{ Rincones } & $\begin{array}{l}\text { ¿Qué } \\
\text { pretende? }\end{array}$ & $\begin{array}{l}\text { Diferenciar espacios en } \\
\text { el aula con diferente } \\
\text { temática y recursos. }\end{array}$ & $\begin{array}{l}\text { Organizará y elegirá } \\
\text { sobre que versan los } \\
\text { distintos rincones. }\end{array}$ & \multicolumn{2}{|c|}{$\begin{array}{l}\text { Empleando los recursos que se } \\
\text { ofrecen, el alumno pasará por } \\
\text { todos los rincones trabajando la } \\
\text { temática de cada uno de ellos. }\end{array}$} \\
\hline & Ejemplos & \multicolumn{4}{|c|}{$\begin{array}{l}\text { Se diferenciarán en el aula distintas zonas relacionadas con la expresión artística } \\
\text { (rincón de la literatura, rincón de la música, rincón de la pintura...) y el alumno visitará } \\
\text { cada uno de ellos, desempeñando una tarea relacionada y empleando los recursos } \\
\text { disponibles. }\end{array}$} \\
\hline \multirow[t]{2}{*}{$\begin{array}{l}\text { Trabajo en } \\
\text { grupo }\end{array}$} & $\begin{array}{l}\text { ¿Qué } \\
\text { pretende? }\end{array}$ & $\begin{array}{l}\text { Fomentar un clima de } \\
\text { trabajo grupal donde } \\
\text { todos los alumnos } \\
\text { expongan sus ideas y } \\
\text { unas enriquezcan a las } \\
\text { otras. }\end{array}$ & \multicolumn{2}{|c|}{$\begin{array}{l}\text { Organizará, guiará y formará } \\
\text { los grupos. }\end{array}$} & $\begin{array}{l}\text { Cooperan entre sí } \\
\text { aportando ideas. }\end{array}$ \\
\hline & Ejemplos & \multicolumn{4}{|c|}{$\begin{array}{l}\text { Se plantea como tema central "la diversidad"; se organizan diferentes grupos en los } \\
\text { que deberán organizar el trabajo y repartir las diferentes responsabilidades. El } \\
\text { profesor intervendrá para guiar a los grupos. }\end{array}$} \\
\hline \multirow[t]{2}{*}{ Talleres } & $\begin{array}{l}\text { ¿Qué } \\
\text { pretende? }\end{array}$ & $\begin{array}{l}\text { Centrarse en un interés } \\
\text { concreto que pueda } \\
\text { tener el alumnado para } \\
\text { ampliar y desarrollar los } \\
\text { contenidos acerca del } \\
\text { mismo. }\end{array}$ & \multicolumn{2}{|c|}{$\begin{array}{l}\text { Deberá conocer los intereses } \\
\text { del alumnado para poder } \\
\text { proponer, en base a ellos, los } \\
\text { diferentes talleres. }\end{array}$} & $\begin{array}{l}\text { Asistirán al taller que } \\
\text { sea de su interés, } \\
\text { desarrollando los } \\
\text { contenidos que desde } \\
\text { éste se proponen. }\end{array}$ \\
\hline & Ejemplos & \multicolumn{4}{|c|}{$\begin{array}{l}\text { El profesor planteará un taller de cocina en el que ofrecerá a los niños diferentes } \\
\text { ingredientes con los que deberán realizar una receta propia, empleando todos ellos. }\end{array}$} \\
\hline
\end{tabular}

Fuente: elaboración propia.

\section{Conclusiones}

Tras tantos años de lucha contra el desconocimiento de la creatividad y su verdadero valor en épocas pasadas, poseemos una nueva visión del concepto que recuerda la importancia que tiene conocer y aplicar en cualquier actividad diaria nuestras habilidades creativas; resulta crucial que la educación recibida desde pequeños sea flexible en cuanto a la expresión creativa, además de recordar la necesidad de fomentarla en la educación. Debemos aprovechar la oportunidad de aportar a la sociedad hasta donde la imaginación nos permita sin dejar que la aptitud creativa se abandone, como bien es recogida la idea por Sáenz (2012), "Nacemos creativos, capaces de imaginar y de inventar, de ver las cosas desde múltiples perspectivas. Poco a poco ese talento creativo se va durmiendo, se va bloqueando, y con ello vamos 
perdiendo la oportunidad de crecer cada día, de contribuir a la sociedad y de disfrutar de las inmensas posibilidades que nuestra creatividad nos ofrece".

\section{BIBLIOGRAFÍA}

Aguerrondo, I. (2008); La calidad de la Educación: Ejes para su definición y evaluación; http://www.oei.es/calidad2/aguerrondo.htm, (consultada dic. 2008)

Amabile, T. M. (1983). The social psychology of creativity: a componential conceptualization, Journal of Personality and Social Psychology, 1983, 45, 357-376, American Psychological Association, Inc.

Barron, F. (1988). Putting creativity to work, en Sternberg, R.J. (ed.). The nature of creativity, Cambridge University Press, Cambridge, New Rochelle, Melbourne, Sydney, 76-98.

Beltrán, J., Bueno, J.A. (1995). Psicología de la educación. Editorial Boixareu Universitaria. España.

De la Torre, S. (1995). Creatividad Aplicada. Recursos para una formación creativa. Madrid: Escuela Española.

Donas, S. (b) Creatividad. En antología del curso Básico de Salud Integral del Adolescente, Proyecto Sarem-Minsa, Nicaragua, 2000

Elisondo, R. Donolo, D. y Rianaudo, M. (2009): Contextos de educación en la universidad. Perspectivas de los alumnos potencialmente más creativos. Revista Iberoamericana de Educación. 49 (6) http://www.rieoei.org/2725.htm (10-03-10)

Esquivias, S. M. T. (2004). Creatividad: Definiciones, antecedentes y aportaciones. Vol. 5, Núm: 1. ISSN: 1067-6079. Universidad Anáhuac.

Garaigordobil Landazabal, M. (1995) Psicología para el desarrollo de la cooperación y de la creatividad. Bibao: Desclée de Brouwer. Biblioteca de Psicología.

Liminana Gras, Rosa María. Cuando crear es algo más que un juego: creatividad, fantasía e imaginación en los jóvenes. Cuad. Fac. Humanid. Cienc. Soc., Univ. Nac. Jujuy [online]. 2008, n.35 [citado 2013-05-11], pp. 39-43.

Maslow, A. (1959) Creativity in self actualizing people. En H. Anderson (Ed.) Creativity and its cultivation. New York. Harper \& Row.

Maslow, A. (1973) El hombre autorrealizado. Barcelona, Kairós.

Piaget, J. (1962) Play, Dreams and imitantion in childhood. New York. Morton.

Rogers, C. (1978) Hacia una teoría de la creatividad. En Th. Roberts (Ed) Cuatro psicologías aplicadas a la educación. Madrid, Narcea.

Romo, M. (2008) "La creatividad como propuesta para la calidad en la educación superior". En M. Vladez y S. Alaya.(eds.) La calidad de la educación superior y la 
investigación científica. Guadalajara (México): Editorial CUCSH-Universidad de Guadalajara, 2008

Sáenz, I. (2012). ¡Buenos días creatividad! Hacia una educación que despierte la capacidad de crear. Informe Fundación Botín.

Sternber, R. J. y Lubart, T. (1997) La creatividad en una cultura conformista. Un desafío a las masas. Barcelona: Paidós.

Tatarkiewicz W. (1997). Historia de Seis Ideas: Arte, Belleza, Forma, Creatividad, Mímesis y Experiencia estética.

Vigotsky, L. (1990). Imagination and creativity in childhood. Soviet Psychology, 28, 8496. 


\section{ACOSO ESCOLAR: SENSIBILIZACIÓN Y PERCEPCIÓN DE LOS ALUMNOS DE PSICOLOGÍA}

Cabello, F.; Gregorio, C.; Monge, M.; Suárez, G. Universidad de Huelva

\section{Resumen}

El objetivo de este estudio es conocer y comprobar cuál es la percepción sobre el tema del Bullying, entendido como el acoso escolar entre compañeros, en estudiantes del Grado de Psicología de la Universidad de Huelva. El instrumento utilizado ha sido un cuestionario de Ying-Hin, C. (2005) adaptado y traducido para la población española. En este sentido, el cuestionario se administró a 122 universitarios de tres cursos diferentes, debido a que el grado de Psicología en esta universidad solo está implantado hasta tercero. Los resultados extraídos de esta investigación muestran que no existen diferencias en cuanto a la edad y el curso académico en relación a la sensibilización y la percepción con respecto al acoso escolar.

Palabras claves: Acoso escolar, Percepción del acoso escolar, Sensibilización al acoso escolar.

\section{INTRODUCCION}

El acoso escolar (del inglés bullying) se ha convertido en un tópico internacional. Aunque no existe todavía un consenso en la comunidad científica sobre su conceptualización, muchos investigadores coinciden en señalar que se trata de un acto con la finalidad de provocar daño, que se realiza de forma sistemática y repetida, y con desigualdad de poder entre el agresor y la víctima (Farrington, 1993), donde se practica un abuso sistemático de poder (Rigby 2002).

El bullying, término acuñado por Dan Olweus lo definió como un "maltrato entre escolares intencionado y persistente de un alumno o grupo de ellos hacia otro alumno sin que media provocación ni posibilidad de respuesta". Estos agresores o bullies suelen actuar movidos por el deseo de poder, de intimidar, dominar, aunque en ocasiones reconocen estar motivados por simple diversión (Olweus, 1993). En esta diada la víctima está indefensa, sin posibilidad de respuesta ni apoyos. Las agresiones no necesariamente son físicas, quizá las de éste tipo sean las menos frecuentes, especialmente en edades de la Educación Secundaria (se aprecia entre el $7 \%$ y el $5 \%$ ). Las agresiones verbales son mucho más comunes, desde el insulto, las amenazas, el correr rumores que tratan de mermar la estima, etc. (por encima del $30 \%$ de las agresiones) e incluso la exclusión social y el aislamiento (situada en torno al $20 \%$ ), en mucho menor grado se aprecian las agresiones que atentan contra la propiedad $(7 \%)$ o el acoso sexual (2\%) (AA.VV, 2000).

Para distinguir el acoso escolar de otras acciones violentas, como por ejemplo, una pelea entre compañeros, es necesario reconocer dos características que identifican el acoso escolar. La primera es la existencia intrínseca de una relación de poder (dominio-sumisión) que tiene uno o varios agresores sobre otro que es el agredido o acosado. La segunda es que, en el acoso, las situaciones de agresión se presentan en forma reiterada. 
Entre los factores que inciden en el desarrollo de estas conductas destaca el modelo social que proporcionan los adultos en el medio familiar y escolar, donde, sin duda, el mayor exponente lo conforman las experiencias de maltrato, sufrido u observado, como señala Barudy (1998).

Dentro de los grupos de iguales, que es donde se manifiesta bullying, juega un papel transcendente las relaciones interpersonales que conforman los roles y estatus a cada uno de sus componentes, los grupos se estructuran en torno a determinados componentes afectivos y relacionales que actúan como elementos básicos en la asignación de determinadas pautas comportamentales (Roland y Galloway, 2002).

En el contexto escolar, la mayoría de las agresiones se producen en el patio de recreo, el aula y los pasillos. Los autoinformes de los alumnos revelan que la edad de padecer un acoso escolar oscila entre el período de los 8 a los 16 años. En cuanto al género, los hombres son más proclives a ser agresores, pero no existen diferencias de género en cuanto a las víctimas. En cuanto a las características de las agresiones, los hombres utilizan/reciben más las agresiones físicas, mientras que las mujeres utilizan más la forma indirecta y relacional del acoso (Olweus, 1993).

\section{MÉTODO}

\section{OBJETIVOS}

El principal objetivo de esta investigación es conocer la sensibilización y percepción sobre el bullying que tienen los alumnos de Grado de Psicología de la Universidad de Huelva.

\section{PARTICIPANTES}

En esta investigación se ha aplicado un cuestionario para cada sujeto. La muestra está compuesta por 122 alumnos/as de edad comprendida entre 18- 52 años que cursan $1^{\circ}, 2^{\circ}$ y $3^{\circ}$ de Grado de Psicología en la Universidad de Huelva. La media de edad de los participantes es de 35 .

\section{INSTRUMENTO}

Esta investigación se realizará mediante la aplicación de un cuestionario, de Ying-Hin, C. (2005) adaptado y traducido para la población española formado por 34 preguntas de cuatro opciones de respuestas acerca de cómo es percibido el bullying.

\section{ANALISIS ESTADISTICOS}

El diseño de investigación es correlacional. Este tipo de diseño tiene como propósito medir el grado de relación que exista entre dos o más conceptos o variables, es decir, saber cómo se puede comportar un concepto o variable conociendo el comportamiento de otra u otras variables relacionadas. En este sentido, el objetivo ha sido evaluar la percepción que tienen los alumnos perteneciente a primero, segundo y tercero de grado de psicología ya que en la Universidad de Huelva aún no está vigente el cuarto curso de dicha carrera profesional. 
Las variables implicadas en el estudio, han sido la percepción como variable dependiente, el número de sujetos por curso como variable independiente y por último algunas variables extrañas que no han sido controladas tales como la edad, el sexo, o el tiempo.

\section{RESULTADOS}

A continuación se muestran los resultados más representativos obtenidos en la administración de dicho cuestionario, destacando aquellos en los que hay un mayor número de acuerdo y un mayor desacuerdo.

Los resultados generales de esta investigación se centran principalmente en cuatro ítems $(4,11,30$ y 34$)$.

En relación al ítem 4 "Es divertido ver como se enfadan los chicos cuando se burlan de ellos", un $86,1 \%$ de la muestra total ha coincidido en la misma opción de respuesta (totalmente en desacuerdo).

Refiriéndonos al ítem 11 "Las víctimas del acoso escolar vienen de familias pobres", un $90{ }^{\prime} 16 \%$ de la muestra han coincidido en que no están de acuerdo con el ítem (uniendo totalmente en desacuerdo y desacuerdo)

Respecto al ítem 30 "La victima debería dejar de ser diferente", donde un 90'16\% de la muestra total ha coincidido en /elegido la opción de respuesta "totalmente en desacuerdo".

En relación al ítem 34 "Los acosadores tienen sentimientos de culpa (se dan cuenta de que está mal acosar a otros, se sienten mal)", no hay acuerdo en ningún grupo con respecto a alguna de las opciones.

Con respecto a los resultados específicos, los ítems más representativos han sido: 5 , 14 y 17. La información contenida en estos ítems se refiere a las percepciones que se tienen sobre las víctimas, y aspectos personales y psicosociales de los acosadores.

En primero de psicología el ítem 5, "Las víctimas del acoso escolar son normalmente delgadas", un $73^{\prime} 80 \%$ de la muestra se posiciona en la respuesta totalmente desacuerdo. Respecto al ítem 14, "Los acosadores quieren sentirse superiores", hay un $100 \%$ de la muestra que se posiciona en las respuestas que reflejan el acuerdo. En el ítem 17, "Los acosadores tienen problemas familiares", no ha habido un consenso en ninguna de las opciones de respuesta. Del $100 \%$ de las respuestas registradas, un $54,76 \%$ de este porcentaje se corresponde con las respuestas que reflejan el desacuerdo y el $45,23 \%$ restante se refiere a las respuestas que reflejan el acuerdo.

En segundo de psicología el ítem 5, "Las víctimas del acoso escolar son normalmente delgadas" un $92,1 \%$ de la muestra se posiciona en las respuestas que reflejan el desacuerdo. Respecto al ítem 14, "Los acosadores quieren sentirse superiores" hay un $97,34 \%$ de la muestra que se posiciona en las respuestas que reflejan el acuerdo. En el ítem 17, "Los acosadores tienen problemas familiares", no ha habido un consenso en ninguna de las opciones de respuesta. Del $100 \%$ de las respuestas registradas, un $50 \%$ de este porcentaje se corresponde con las respuestas que reflejan el desacuerdo y el $50 \%$ restante se refiere a las respuestas que reflejan el acuerdo.

3 ReiDoCrea. Revista electrónica de investigación Docencia Creativa. Volumen 2. Páginas 206-211 
En tercero de psicología el ítem 5, "Las víctimas del acoso escolar son normalmente delgadas", un $100 \%$ de la muestra se posiciona en las respuestas que reflejan el desacuerdo. Respecto al ítem 14, "Los acosadores quieren sentirse superiores", hay un $92,24 \%$ de la muestra que se posiciona en las respuestas que reflejan el acuerdo. En el ítem 17, "Los acosadores tienen problemas familiares", no ha habido un consenso en ninguna de las opciones de respuesta. Del $100 \%$ de las respuestas registradas, un $42,86 \%$ de este porcentaje se corresponde con las respuestas que reflejan el desacuerdo y el $57,14 \%$ restante se refiere a las respuestas que reflejan el acuerdo.

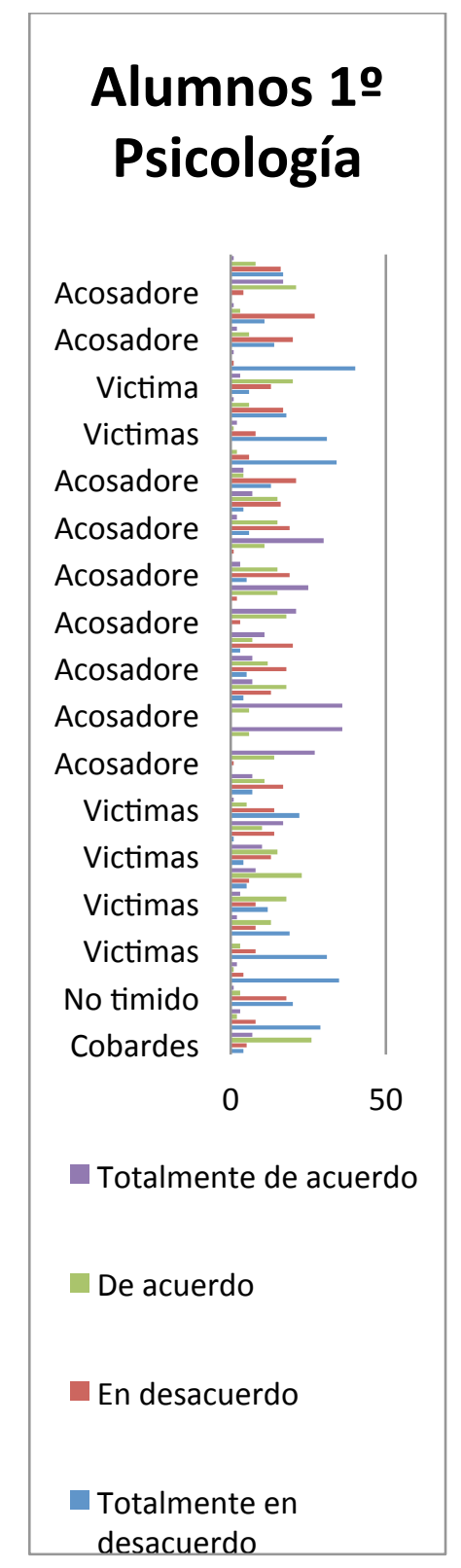

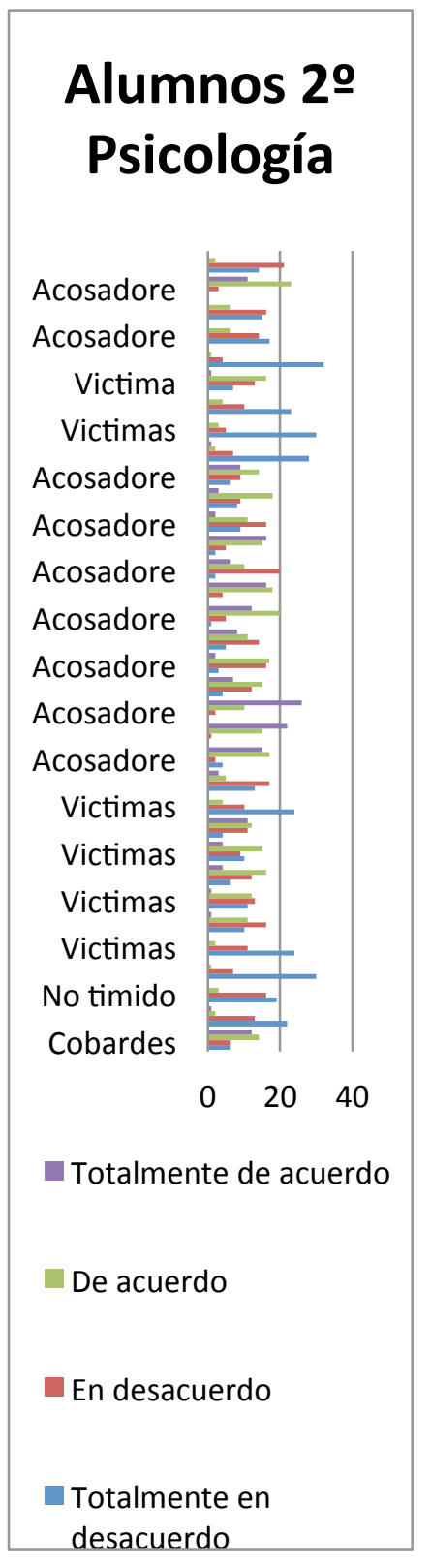

Alumnos 3ㅇ Psicología

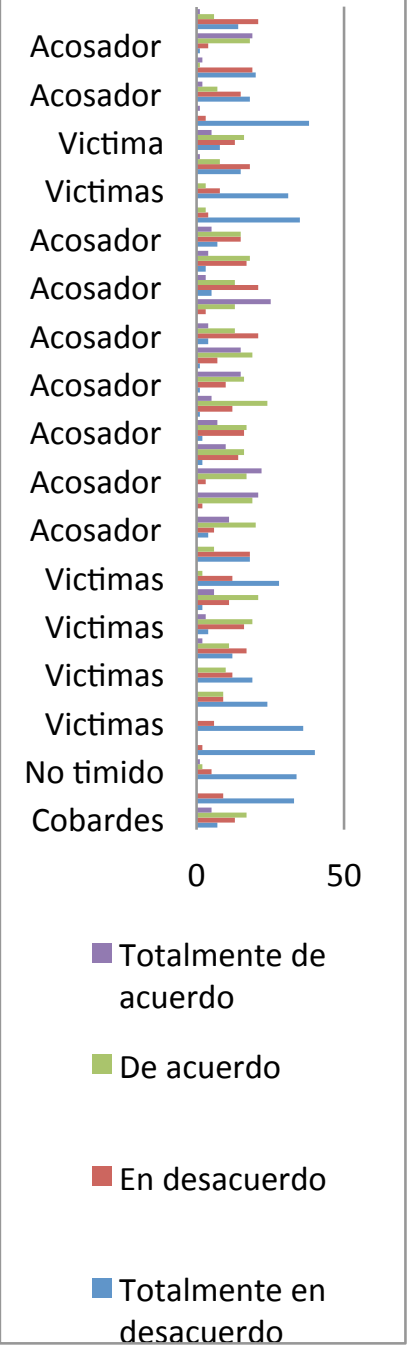




\section{DISCUSIÓN}

En este apartado, se ha analizado los resultados de los ítems 5, 14, 17 y 34 haciendo una comparativa entre los diversos cursos con el fin de comprobar si hay diferencias significativas.

\begin{tabular}{|l|l|l|l|}
\hline \multicolumn{2}{|l|}{ GENERALES } \\
\hline ITEM 4 (T. Desacuerdo) & ITEM 11 (Desacuerdo) & ITEM 30 (T. Desacuerdo) & ITEM 34 \\
\hline $86,1 \%$ & $90,16 \%$ & $90,16 \%$ & No consenso \\
\hline
\end{tabular}

\begin{tabular}{|c|c|c|c|}
\hline \multicolumn{4}{|l|}{ ESPECÍFICOS } \\
\hline & ITEM 5 (desacuerdo) & ITEM 14 (acuerdo) & ITEM 17(no consenso) \\
\hline $1^{\circ} \mathrm{PSICOLOGIA}$ & $73 ' 80 \%$ & $100 \%$ & $45,23 \%$ vs $54,76 \%$ \\
\hline $2^{\circ}$ PSICOLOGIA & $92 ' 1 \%$ & $97^{\prime} 34 \%$ & $50 \%$ vs $50 \%$ \\
\hline $3^{\circ}$ PSICOLOGIA & $100 \%$ & $92 ' 24 \%$ & $42,86 \%$ vs $57,14 \%$ \\
\hline
\end{tabular}

En $1^{\circ}$ de Psicología se puede ver que la mayoría de los encuestados no valora mucho el aspecto físico, es decir, no establecen relación entre el aspecto físico y el bullying. Sin embargo, hay un gran acuerdo en que necesitan acosar a otras personas para sentirse superiores y mejores consigo mismo. Por el contrario, entre los entrevistados, no existe consenso a la hora de relacionar algún tipo de problema desarrollado en el entorno familiar del acosador con el problema que causa éste en el aula.

Uno de los mitos acerca de bullying trata sobre la importancia que tiene el aspecto físico en nuestra cultura y lo que influye esta creencia en la socialización de los individuos. En este estudio se han obtenido resultados contradictorios, ya que los entrevistados no consideran que las personas menos atractivas o con alguna dificultad física sean más proclives a ser víctimas del acoso escolar.

En $2^{\circ}$ de Psicología no se encuentran muchas diferencias, respecto a los resultados, con los que se han obtenido en primero. De esto se puede deducir que ni el curso ni la edad influyen en el grado de sensibilización y de percepción sobre el bullying. No obstante, en relación al aspecto físico, aumenta el porcentaje de respuestas que reflejan desacuerdo, viéndose así una mayor sensibilización con respecto a $1^{\circ}$ en este tipo de creencias.

En $3^{\circ}$ de Psicología no se observan diferencias significativas ya que los resultados son similares a los obtenidos en $1^{\circ}$ y $2^{\circ}$.

En relación con estudios consultados, los resultados se muestran contradictorios. Según Frisen et al. (2007) un $40 \%$ de acoso se debe a la apariencia física. Sin embargo, nuestros resultados no son concluyentes con respecto a este factor.

Los resultados de Ying-Hin, C. (2005), muestran que un $47 \%$ de la muestra creía que los acosadores tienen problemas familiares. En nuestro estudio, estos resultados no muestran unanimidad con respecto a esta creencia. 


\section{CONCLUSIÓN}

A modo de conclusión, una vez analizados los datos, no se encuentra que haya una sensibilización total por parte de la muestra hacia el colectivo ya que los daños que se producen no son exclusivamente físicos.

En esta investigación se ha visto que las características, tanto de la víctima como del acosador, no sirven como factor clave para categorizar a una persona de acosadora 0 acosada, es decir, la muestra ha reflejado mayor grado de sensibilización y percepción en el mismo.

Por el contrario, a nivel psicológico y social, las evidencias empíricas no muestran que haya un nivel adecuado de sensibilización como reflejan los resultados antes expuestos.

\section{BIBLIOGRAFIA}

AA.VV. (2000). Violencia escolar: El maltrato entre iguales en la educación secundaria. Oficina del Defensor del Pueblo. Madrid.

Barudy, J. (1998). El dolor invisible. Una lectura ecosistémica del maltrato infantil. Barcelona: Paidós.

Cepeda, E., Pacheco, P. N., García, L., y Piraquive, C. J. (2008). Acoso escolar a estudiantes de educación básica y media. Revista de Salud Pública, 10(4), 517-528.

Cervero, J.A. (2010). 5 mitos sobre el acoso escolar.

Félix, V., Soriano, M., y Godoy, C. (2009). Un estudio descriptivo sobre el acoso y violencia escolar en la educación obligatoria. Escritos de Psicología (Internet), 2(2), 4351.

Franco, Y. (2011,30 de Junio). ¿En qué consisten los estudios correlacionales? Tesis de Investigación.

Guaita, C. (2012). Los mitos sobre el acoso escolar.

Olweus, D. (1993): Bullying at school: What we know and what we can do. Oxford. Black-well. Trad. Conductas de acoso y amenaza entre escolares. Madrid. Morata 1998.

Roland, E. y Galloway, D. (2002). Classroom influences on bullying. Educational Research, 44, 299-312

Santos, L. (2012). La violencia escolar. In The Second ISA Forum of Sociology (August 1-4, 2012). Isaconf.

Ying-Hin, C. (2005). Teachers' and students' perception of bullying. Tesis Doctoral. Sacramento, California. 


\section{LA INTELIGENCIA EMOCIONAL APLICADA AL MUNDO LABORAL EMOTIONAL}

Moreno Lucena, Álvaro. Universidad de Granada

\section{Resumen}

La inteligencia emocional es uno de los aspectos clave para desenvolverse en el mundo laboral y lograr el éxito en lo personal, académico y profesional, pero estas competencias y habilidades no son innatas, sino que se pueden trabajar y mejorar. En nuestro sistema educativo se está insertando en los últimos tiempos la educación emocional de los alumnos que ayude a desarrollar estas características en los estudiantes, pero todavía no es suficiente ya que sigue demasiado enfocada hacia el desarrollo de la inteligencia académica obviando otros aspectos muy importantes. Se requiere de una educación integral de los alumnos y a su vez, para conseguir ésta, se necesita una mayor formación de los docentes en la temática.

Palabras Clave: Inteligencia, educación, mercado de trabajo, competencias

\section{Introducción}

\section{Cómo definir la inteligencia emocional}

Tras revisar las distintas definiciones de inteligencia emocional que realizan Goleman (1996), Mayer, Salovey y Caruso (2000), Sterrett (2002) y FernándezBerrocal (2004); una definición de inteligencia emocional podría ser: "La inteligencia emocional sería la habilidad para manejar los sentimientos propios y de los demás, una forma de interactuar con el mundo, de controlar una serie de variables sobre nuestro comportamiento y de reaccionar adecuadamente con esa información para guiar el pensamiento y la acción de uno mismo y de los demás."

Esta inteligencia emocional es necesaria para el desarrollo de emociones que son imprescindibles para la supervivencia en la sociedad en la que el ser humano se encuentra inmerso, y del uso que se haga de ésta, dependerá el éxito o fracaso en distintos aspectos de nuestra vida.

\section{Inteligencia emocional y competencias sociales}

La inteligencia emocional tendría tres pilares básicos sobre la que se asienta: la capacidad de identificar y discriminar nuestras propias emociones y las de los demás; la capacidad de manejar y regular esas emociones; y la capacidad de utilizarlas de forma adaptativa (Bisquerra 2003).

El primero de los tres pilares, quedaría representado por las competencias emocionales de conciencia de uno mismo, como son el auto-conocimiento, la valoración emocional y la confianza en uno mismo; y la alfabetización emocional (refiriéndose a la honradez emocional, la energía, el conocimiento, el feedback, la intuición, la responsabilidad y la conexión). 
El segundo de los pilares se corresponde con las competencias emocionales de autorregulación y motivación. Aquí nos encontramos con las competencias relacionadas con la autorregulación, la integridad, responsabilidad, apertura, flexibilidad de ideas, innovación y creatividad; y con la agilidad emocional, la cual sirve para edificar nuestra autenticidad, nuestra credibilidad y nuestra flexibilidad, ampliando nuestro circulo de confianza y nuestra capacidad para escuchar, asumir conflictos y sacar el máximo partido posible del descontento positivo.

Con respecto al último de los pilares, se puede entender por medio de un conjunto de competencias emocionales relacionadas con la empatía y las habilidades sociales. En primer lugar, las competencias vinculadas a la empatía son la comprensión de los demás, el desarrollo de los demás, la orientación hacia el servicio y el optimismo. Además, existe un conjunto de competencias relacionadas con las habilidades sociales, como, por ejemplo, la influencia, comunicación, gestión de conflictos, liderazgo, catalización del cambio, colaboración y cooperación, y habilidades de equipo. Por otro lado también nos encontramos con la profundidad emocional y la alquimia emocional. Con la primera se trata de armonizar la vida y el trabajo con el potencial y las intenciones que le son peculiares, poniendo en ello su integridad, su empeño y su responsabilidad. En cambio, el segundo nos permite ampliar nuestro instinto y nuestra capacidad de creación aprendiendo a fluir con los problemas y las presiones, y a competir contra el futuro educando nuestras facultades para percibir mejor las soluciones y oportunidades ocultas (Bisquerra 2005).

\section{Desarrollo}

La inteligencia emocional en el mundo empresarial en situaciones laborales difíciles

Siguiendo a Gall, Grewal, Kadis, Lopes \& Salovey (2006), todas las competencias sociales son necesarias en el ámbito laboral, ya sea como directivo o como empleado de una empresa, ya que es esencial desarrollar las habilidades de interrelación personal. Estas habilidades de relación son imprescindibles tanto para acceder a un empleo, para prosperar en él, así como para conservar este empleo durante un largo periodo de tiempo. Aunque no todo son las habilidades de relación, ya que esto implica también además competencia profesional. En resumen, lo importante es ser valioso/a para la empresa o la organización, de forma que sea difícil prescindir del trabajador en cuestión. En esto juega un papel muy importante la relación que se establezca entre el jefe/a y el empleado/a, y el tipo de relación que se instaure se debe a la inteligencia emocional.

En cuanto a las distintas situaciones laborales que se pueden crear, pasaré a detallar la selección inteligente de personal y las distintas reacciones de la dirección de la empresa ante el personal improductivo. Antonio Valls (2000) nos explica que en cuanto a la selección de personal, el objetivo es la 
contratación oportuna de la persona adecuada, ya que con el equipo de empleados apropiado, la empresa puede avanzar con más celeridad y eficacia. Para ello, no se recomienda dejarse llevar por los datos que aparezcan en el currículum, sino darle una mayor importancia a la entrevista personal. En esta juegan un papel muy importante las emociones que el aspirante a empleado transmite, la primera impresión y la primera relación que se establece entre el jefe y el empleado. Con respecto a las reacciones de la empresa ante el empleado improductivo, hay que comentar previamente que siguiendo con Antonio Valls (2000), la mayor parte de las veces de rescisión de un contrato laboral, tiene sus raíces en el entorno o en las reestructuraciones que tienen que acometer las empresas para poder sobrevivir. Para la elección de la persona a despedir, los directivos tienen en cuenta en un gran número de ocasiones este tipo de competencias personales en el trabajador: motivación, relación jefe-empleado, capacitación, adaptación, delegación y trato adecuado; por lo que es necesario que este tipo de características estén presentes en el trabajador.

\section{Inteligencia emocional para lograr el éxito personal y profesional}

El éxito en cuanto a lo personal y social no tiene tanta relación con la inteligencia general, con el $\mathrm{Cl}$, ni con los resultados académicos obtenidos, puesto que una persona puede alcanzar el éxito personal si consigue tener buenas competencias en cuanto a habilidades sociales se refiere. Estas habilidades son múltiples, y siguiendo a Sterrett (2000), nos podemos encontrar con las siguientes destrezas sociales básicas: Reconocer la presencia de los demás, iniciar la conversación, mantener la conversación, sintonía, sincronización, Incorporación a la conversación de forma correcta, reciprocidad y contagiar a los demás el estado de ánimo.

Con respecto al trabajo, la inteligencia sí que se considera más relevante en un primer plano para conseguir el éxito, puesto que ésta te ayudará a conseguir los títulos, las credenciales necesarias para poder optar a determinados puestos de trabajo. A partir de esta obtención de títulos, entran en juego factores de tipo emocional, ya que nos encontramos en una sociedad donde abunda el personal altamente cualificado. Las empresas tienen más demandantes de empleo que ofertas de las que disponen, por lo que para elegir a los afortunados que pasarán a formar parte de la empresa se tendrán en cuenta estos factores de tipo emocional anteriormente mencionados.

Por otro lado, el famoso éxito es muy subjetivo, ya que depende de la concepción que tenga cada persona acerca de tener éxito en la vida personal y laboral. Cada persona puede considerar que tiene éxito en su trabajo sea éste del tipo que sea o requiera una mayor o menor inteligencia, depende de los objetivos que previamente se haya planteado esa persona y de si estos se han satisfecho positivamente.

\section{Cómo mejorar la inteligencia emocional}

Siguiendo a Sánchez, A. (2009), existen una serie de ámbitos de actuación para desarrollar la inteligencia emocional: 
- Detectar pensamientos, cambios fisiológicos y comportamientos erróneos para encauzarlos satisfactoriamente. Debemos aprender a comprender la importancia de conocer nuestras respuestas emocionales, adquirir posibilidades de actuar sobre ellas, manejar y superar emociones destructivas, desarrollar nuestra auto-confianza y auto-motivación y realizar una automodelación.

- La reestructuración cognitiva en las respuestas emocionales. Por ejemplo con la terapia racional emotiva de Albert Ellis que proporciona una toma de conciencia de tu auto-doctrinamiento en creencias irracionales y su sustitución activa por creencias más racionales, para aprender a resolver problemas.

- Técnicas de autocontrol emocional. Son necesarias en caso de conflicto y en aquellas situaciones en las que las emociones parecen tener un mayor peso que nuestras cogniciones.

- Estrategias para superar los problemas que se nos presentan en la vida. El uso de determinadas técnicas puede favorecer nuestro mundo emocional.

\section{La inteligencia emocional en la educación para el desarrollo integral de los alumnos}

Según Abarca \& Sala (2002), la inteligencia emocional posee una gran aplicabilidad, con lo que la educación es un campo de investigación donde existe gran cantidad de trabajos. Los estudios de investigación que se han realizado en este campo, se focalizan en analizar la evolución de la inteligencia emocional en los alumnos, su importancia en el aprendizaje, en el desarrollo intelectual y en la autorregulación. (Calero \& Espada 2012, García 2008).

Siguiendo a Cabello (2011) por otro lado es importante destacar el desarrollo de programas para el fomento de la inteligencia emocional en los niños, centrándose en aspectos tales como el reconocimiento de emociones, la empatía y las competencias emocionales. Estos programas surgen debido a que tradicionalmente se ha hecho un mayor hincapié en las funciones cognoscitivas que en el desarrollo de la competencia social y de Inteligencia Emocional, resaltando por este motivo la necesidad de educar en emociones en el futuro.

No es posible que solo fomentando la inteligencia académica se desarrolle integralmente un alumno, debido a que para que este sea posible, también deben desarrollarse otro tipo de inteligencias además de las cognitivas según Gardner (1998): las inteligencias personales. Estas, a su vez se podrían dividir en dos, en la inteligencia interpersonal y la inteligencia intrapsíquica. La inteligencia interpersonal consistiría en la capacidad de comprender a los demás, establecer contacto con los propios sentimientos, discernir entre ellos y aprovechar este conocimiento para orientar nuestra conducta. Mientras, por otra parte, la intrapsíquica sería la configuración de una imagen exacta y verdadera de nosotros mismos, que nos haga capaces de utilizar esa imagen para actuar en la vida de un modo más eficaz. 


\section{Conclusiones}

En nuestro actual sistema educativo no se tienen en cuenta con la misma importancia todos los ámbitos, ya que comúnmente se desea potenciar el desarrollo intelectual mediante la superación de pruebas académicas, las cuales miden tus conocimientos sobre distintas áreas. En la mayoría de los casos no se lleva a cabo una metodología en la que se intente favorecer el desarrollo de la inteligencia emocional de los alumnos, centrándose solo en el puro rendimiento académico. El desarrollo de este tipo de inteligencia no solo mejora las habilidades del alumno para interrelacionarse en los distintos contextos de su vida, sino que también nos ayuda a mejorar el clima en la clase, donde existirá un ambiente de trabajo más colaborativo, pudiendo utilizar la educación en valores de una forma más eficaz.

Se debería de realizar una enseñanza más individualizada, donde se tuviera en cuenta a la persona en su conjunto y no solo a sus resultados académicos, es decir, educar integralmente a los alumnos. Con un mayor acercamiento a nivel personal entre docentes y estudiantes la comunicación interpersonal sería más fluida, implicándose el profesor en mayor medida en los aspectos personales del estudiante. Esto favorecerá el desarrollo de las competencias y las características descritas en el desarrollo del trabajo, aumentando a su vez el desarrollo emocional de los alumnos.

Creo que a nivel administrativo e institucional sería de gran ayuda la inclusión en el curriculum de contenidos relacionados con la temática, es decir, que se imponga en cierta forma como obligatoria la educación emocional de los alumnos. También creo que sería de utilidad la asignación de un menor valor a las calificaciones obtenidas en determinadas pruebas, en aquellas en las que tras la realización se decide el futuro del alumno (selectividad, por ejemplo), y valorar en mayor grado el esfuerzo realizado durante todo el curso, es decir, llevar a cabo una evaluación más continua. Esto provocaría que los docentes no se preocupasen exclusivamente de preparar a los alumnos para que superen esas pruebas, sino que estarían más pendientes en otros aspectos de la educación de los estudiantes.

En nuestro sistema educativo se busca preparar al individuo para la vida laboral inculcándole una serie de contenidos que debe conocer, pero no las habilidades sociales para desenvolverse en ese futuro mundo laboral. Además, se busca una competitividad con respecto a los demás sistemas educativos, poseer a los alumnos más capacitados "intelectualmente", ya que lo más importante en nuestro sistema educativo es la calificación numérica obtenida y no el conocimiento aprendido.

Las consecuencias de este tipo de sistema, son la existencia de un gran número de personas, sobre todo jóvenes, excesivamente formados para desempeñar un puesto de trabajo. Al existir tanta demanda de empleo y tan poca oferta de trabajo, el aspirante que se hace finalmente con él, sería el que más habilidades sociales posee, el más estable emocionalmente, el que tenga un mayor control sobre las relaciones, en definitiva, el que mayor inteligencia emocional tenga. Además dependiendo de su inteligencia emocional (sin dejar 
de lado el resto de habilidades que el empleado posea), dependerá la evolución de la trayectoria que la persona tendrá en la empresa.

\section{Bibliografía}

Abarca, M. \& Sala, J. (2002). La educación emocional en el currículum. Ediciones Universidad de Salamanca. Teor. Educ. 13, pp. 209-232.

Bisquerra, R. (2003). Educación emocional y competencias básicas para la vida. Revista de investigación educativa. Vol 21, N 1, pp. 7-43.

Bisquerra, R. (2005). La educación emocional en la formación del profesorado. Revista interuniversitaria de formación del profesorado. Vol 19, №3, pp. 95114.

Cabello, M.J. (2011). Importancia de la inteligencia emocional como contribución al desarrollo integral de los niños/as de educación infantil. Pedagogía Magna, № 11, pp. 178-188.

Calero, J.C. \& Espada, M. (2012). La inteligencia emocional en el área de educación física. La peonza: Revista de educación física para la paz. № 7, pp. 65-69.

Fernández-Berrocal, P., Ruiz, D. (2008). La inteligencia emocional en la educación. Revista Electrónica de Investigación Psicoeducativa. Vol. 6 (2), № 15, pp. 421-436.

Gall, M., Grewal, D., Kadis, J., Lopes, P.N., \& Salovey, P. (2006). Evidence that emotional intelligence is related to job performance and affect and attitudes at work. Psicothema. Vol 18, supl., pp. 132-138.

García, V. (2008). La inteligencia emocional en la educación infantil. Educación y futuro, 19, 129-149.

Gardner, H. (1998). Inteligencias múltiples. La teoría en la práctica. Barcelona. Editorial Paidós.

Goleman, D. (1996). Inteligencia emocional. Barcelona. Editorial Kairós.

Mayer, J.D., Salovey, P. \& Caruso, D. (2000). Models of emotional intelligence. Handbook of intelligence. Cambridge, UK. Cambridge University.

Sánchez, A. (2009). El valor de la inteligencia emocional. Alcalá la real. Editorial Formación Alcalá.

Sterrett, E. A. (2000). Guía del directivo para la inteligencia emocional: de la gestión al liderazgo. Madrid. Editorial Centro de Estudios Ramón Areces. 
Valls, A. (2000). Inteligencia emocional en la empresa. Barcelona. Ediciones Gestión 2000. 


\section{ESTILOS DE ENSEÑANZA Y LAS NUEVAS TECNOLOGÍAS EN LA EDUCACIÓN}

García, D.M; Joaquín, M.; Torres, P. y Vázquez, I.R.. Universidad de Huelva

\section{Resumen}

El objetivo de este estudio es conocer la posible relación entre los estilos de enseñanza del profesor y la adaptación a la aplicación de las nuevas tecnologías en el aula. Los estilos de enseñanza son los comportamientos que el docente exhibe en su actividad profesional, éstos estarían basados en su conocimiento y experiencia pudiendo depender del contexto. La evolución dentro del sistema educativo español, ha dado lugar a diferentes estilos de enseñanza en el profesorado entre los que se encuentran el estilo autocrático, democrático, dominador o integrador, entre otros. Se considera la existencia de un continuo en los estilos de enseñanza donde los liberales o restrictivos, estarían situados en los extremos y los combinados en el centro del mismo. Con respecto a las nuevas tecnologías actualmente utilizadas en la enseñanza, hay que hacer referencia a las técnicas usadas en el tratamiento y transmisión de información, principalmente de informática y telecomunicaciones.

Palabras clave: Tecnología de la Información y de la Comunicación, estilo de enseñanza, educación primaria, educación superior

\section{Introducción}

El estilo de enseñanza se conceptualiza como aquellas categorías de comportamiento de enseñanza que el docente exhibe habitualmente en cada fase o momento de la actividad de enseñanza, que se fundamenta en actitudes personales que le son inherentes, que han sido abstraídas de su experiencia académica y profesional, que no depende de los contextos en los que se muestran, y que pueden aumentar o disminuir los desajustes entre la enseñanza y el aprendizaje (Martínez, 2007). Este mismo autor es partidario de que el estilo en la enseñanza está determinado y conformado de acuerdo con el enfoque de enseñanza y por el estilo de enseñanza del profesor; según tenga este último, criterios pedagógicos o personales. Hay un acuerdo generalizado en aceptar la existencia de diversos caracteres que definen a distintos educadores, en delimitar determinados tipos de profesores y en perfilar los avances y retrocesos de algunas formas de ejercer la docencia (Brincones, 1986; Rozada, 1985; Host, 1988; Escudero, 1981). En cuanto a los avances de la docencia, se puede encontrar signos de esta evolución si examinamos lo sucedido en el sistema educativo español en los últimos quince años. Han ido emergiendo diferentes tipos de profesores como por ejemplo, aquellos que utilizan estilos educativos innovadores para adaptarse a las variaciones del entorno educativo. Estas variaciones están asociadas a la asimilación de ciertas ideas referidas a la Tecnología de la Información y de la 
Comunicación (TIC) por parte del estamento docente (Fernández y Elortegui, 1996).

Según Cabero (2006), las TIC configuran nuevos entornos y escenarios para la formación con unas características significativas:

- Ampliar la oferta informativa y las posibilidades para la orientación y tutorización.

- Eliminar barreras espacio-temporales,

- Facilitar el trabajo colaborativo y el autoaprendizaje,

- Potenciar la interactividad y la flexibilidad en el aprendizaje.

A su vez, sobre las TIC, Marqués (2008) resalta que estas se añaden a los recursos que estábamos usando; por lo tanto, ahora las TIC son recursos más disponibles para los docentes. Además, tal como destaca Gairín (2010) las TIC facilitan la creación colectiva de conocimiento. De esta manera y destacando la importancia de las nuevas tecnologías en el ámbito educativo, el objetivo de este estudio es conocer si existe una posible relación entre los estilos de enseñanza del profesorado y la adaptación a la aplicación de las nuevas tecnologías en el aula.

\section{Clasificación de los estilos de enseñanza}

Uncala G. S (2008) recoge las diferentes clasificaciones de los estilos de enseñanza según diferentes autores, con el objetivo de agruparlas:

\begin{tabular}{|ll}
\hline \multirow{2}{*}{ Lippitt y White, (1938) } & Esificación de los Estilos de Entocrático \\
\hline & Esilo democrático \\
\cline { 2 - 2 } & Esilo laissez-faire \\
\hline Anderson, (1945) & Esilo dominador \\
\hline Esilo integrador \\
\hline Gordon (1959) & Esilo instrumental \\
\hline Esilo expresivo \\
\hline Elanders, (1984) & Esilo instrumental-expresivo directo \\
\hline Bennett, (1979) & Esilo indirecto \\
\hline & Esilo progresista o liberal \\
\hline & Esilo tradicional o formal \\
\hline
\end{tabular}

Lippitt y White, (1938) hacen referencia a tres estilos de enseñanza:

- El estilo autocrático: aquellos profesores/as que deciden por sí solos todas las actividades o tareas a realizar, es decir, ellos son quienes toman todas las decisiones, organizando y distribuyendo, incluso, las actividades, permaneciendo distantes al grupo en su realización y evaluando de forma individualizada.

- El estilo democrático: los profesores/as que planifican de acuerdo con los miembros del grupo, animando al grupo de alumnos/as a discutir, decidir, programar y distribuir las actividades: sugieren diversos procedimientos; participan como un miembro más y evalúan los resultados en función del grupo. 
- El estilo llamado laissez-faire: estos profesores/as se caracterizan por la falta de participación general, manteniéndose al margen lo más posible, dejando la iniciativa a los alumnos/as, y sólo cuando se requiere su opinión, interviene para dar su consejo.

Anderson, (1945) propone dos estilos:

- Dominador: que es fundamentalmente una persona autoritaria que recurre normalmente a mandatos y disposiciones exigentes, imponiendo las órdenes a la fuerza y que no acepta ni considera las decisiones autónomas de los alumnos/as.

- Integrador: es capaz de crear un clima social amistoso donde predomina el reconocimiento y el elogio, y no, la violencia; un ambiente donde la critica es constructiva y objetiva, y se toman en cuenta las iniciativas personales de los alumnos/as.

Gordon (1959), quién parte de la hipótesis de que un estilo de enseñanza está más condicionado por los grupos escolares y el sistema de enseñanza que por los profesores/as. Él distingue tres tipos de estilos de enseñanza:

- Instrumental: propio de los profesores/as que orientan su actividad docente a los objetivos de aprendizaje y centrados en la dirección y autoridad.

- Expresivo: orientado a satisfacer las necesidades afectivas de los alumnos/as; el profesor/a se preocupa, sobre todo, por satisfacer al alumno/a en lo referente a su rendimiento y a sus relaciones sociales.

- Instrumental expresivo: que es una mezcla de ambos y es propio de los profesores/as que pretenden combinar el interés por la enseñanza con su inquietud por las necesidades de los alumnos/as.

Flanders, (1984) investigador que al captar la influencia que genera el comportamiento verbal del profesor/a en el clima del aula y en el rendimiento del alumno/a establece los siguientes estilos:

- Directo: consistente en exponer las propias ideas, imponiendo su autoridad y competencia.

- Indirecto: propio de los profesores/as que tienen en cuenta las ideas de sus alumnos/as, promueven el diálogo e influyen en los sentimientos de los alumnos/as.

Bennett, (1979) comprueba que las tipologías anteriormente mencionadas tienen una serie de deficiencias, como parcialidad, ambigüedad y dicotomía. Este autor elabora una tipología, que a su juicio es global, precisa y completa.

- Progresistas o liberales: situados en un extremo, son los profesores/as considerados como serían aquellos cuyo comportamiento en el aula se reflejaría en características como integración disciplinar, motivación intrínseca, agrupamiento flexible, elección del trabajo por el alumno/a y cierta despreocupación por el control de la clase y el rendimiento. En relación con los aspectos directamente relacionados con los métodos de 
enseñanza aceptan las ventajas de los métodos formales para la adquisición de conocimientos básicos y la estructuración de entornos de aprendizaje que permitan una menor desorientación del alumno/a. Sin embargo, rechazan los métodos utilizados por sus compañeros/as con estilos formales para lograr la autodisciplina, el desarrollo personal del alumno/a, el equilibrio entre el trabajo individual y el colectivo y las mayores exigencias que conlleva el trabajo del profesorado.

- Tradicionales o formales: se sitúan en el otro extremo y tienen características completamente opuestas a las anteriores: motivación extrínseca, elección mínima del trabajo por el alumno/a, agrupamiento fijo (clase total y trabajo individual) y preocupación por el control del rendimiento.

- Estilos mixtos: se sitúan entre uno y otro extremo, son producto de la combinación de uno y otro estilo en grado diverso.

\section{Adaptación de la enseñanza a las nuevas tecnologías (TICs).}

Al hablar de nuevas tecnologías, se hace referencia a los elementos y técnicas usados en el tratamiento y transmisión de información, principalmente de informática, internet y telecomunicaciones. Este tipo de tecnologías son cada vez más usadas en el ámbito de la enseñanza, sobre todo, en la Educación Superior. Los ordenadores y las comunicaciones apropiadamente programadas e implementadas tienen el potencial de revolucionar la enseñanza y mejorar el aprendizaje con la misma profundidad que se ha revolucionado otros ámbitos (Dede, 2001). Además, el uso de la tecnología introduce nuevas formas de enseñanza y aprendizaje que implican cambios en qué aprender y en lo que hacen los estudiantes y profesores dentro y fuera de las aulas (Correa y Pablos, 2009). Se parte del supuesto de que la incorporación de las TICs a la educación, está produciendo una serie de cambios en las forma en la que se lleva a cabo los procesos de enseñanza y aprendizaje (Bustos y Coll, 2010).Estos cambios debidos al rápido desarrollo e influencia de las TICs ha generado dentro de la comunidad educativa tres perspectivas distintas hacia el aprendizaje electrónico, (Correa y Pablos, 2009):

- Una se preocupa casi exclusivamente de los aspectos técnicos.

- La segunda ve las TICs predominantemente como un medio de distribuir el contenido convencional, sin modificar, más rápido, más eficazmente y a una audiencia mayor.

- La tercera posición que adopta una postura más radical y considera los avances de las TICs, con su poderoso potencial para la democracia y diferenciación, un catalizador para una reconsideración fundamental de toda la empresa de la educación.

Por otro lado, la formación del profesorado no puede reducirse a la adquisición de competencias digitales o destrezas tecnológicas per se sino que debe basarse en su aplicación didáctica (Tejada, 2009). El docente ha de planificar, impartir, tutorizar y evaluar acciones formativas elaborando y utilizando medios y recursos didácticos, promoviendo la calidad de la formación y la actualización didáctica (Tejada, 2009). 


\section{Relación entre la clasificación de los estilos de enseñanzas y las Tics.}

A continuación, se expone una relación entre las diferentes clasificaciones de los estilos de enseñanza establecidas por los diferentes autores, y la aplicación de las nuevas tecnologías:

\begin{tabular}{|c|c|c|c|c|}
\hline & & Adaptablea Tics & $\begin{array}{l}\text { Adaptable } \\
\text { aunque } \\
\text { mejorable }\end{array}$ & $\begin{array}{l}\text { No adaptable } \\
\text { a Tics }\end{array}$ \\
\hline \multirow{3}{*}{$\begin{array}{l}\text { Lippitt y White } \\
\text { (1938) }\end{array}$} & Estilo autocrático & & & $\mathrm{x}$ \\
\hline & Estilo democrático & $\mathrm{X}$ & & \\
\hline & Estilo laissez-faire & & $\mathrm{x}$ & \\
\hline \multirow{2}{*}{$\begin{array}{l}\text { Anderson } \\
(1945)\end{array}$} & Estilo dominador & & & $\mathrm{x}$ \\
\hline & Estilo integrador & $\mathrm{x}$ & & \\
\hline \multirow[t]{3}{*}{ Gordon, (1959) } & Estilo instrumental & & & $\mathrm{x}$ \\
\hline & Estilo expresivo & & $\mathrm{x}$ & \\
\hline & $\begin{array}{l}\text { Estilo } \\
\text { instrumental- } \\
\text { expresivo }\end{array}$ & $\mathrm{x}$ & & \\
\hline \multirow[t]{2}{*}{ Flanders (1984) } & Estilo directo & & & $\mathrm{x}$ \\
\hline & Estilo indirecto & $\mathrm{x}$ & & \\
\hline \multirow[t]{3}{*}{ Bennet (1979): } & Estilo progresista & & & $\mathrm{X}$ \\
\hline & Estilo formal & & & $\mathrm{X}$ \\
\hline & Estilo mixto & $\mathrm{x}$ & & \\
\hline
\end{tabular}

Según Lippitt y White (1938):

- Estilo autocrático: presenta inconvenientes a la hora de adaptar la enseñanza a las nuevas tecnologías puesto que el profesor no tiene en cuenta la opinión ni la participación espontánea del alumno.

- Estilo laissez-faire se considera propicio para el uso de las nuevas tecnologías, pero puede que este uso no sea muy educativo dado que la intervención del profesor es muy escasa.

Por tanto, se considera que el estilo democrático es el más idóneo para la utilización de las TICs, ya que, el profesor tiene en cuenta la participación y la creatividad del alumno.

Según Anderson (1945):

- Estilo dominador: se considera el menos adecuado para la adaptación de la enseñanza a las nuevas tecnologías puesto que el profesor no considera la participación del alumno, ignorando su autonomía.

- Estilo integrador: permite la adaptación de las TICS puesto que se trata de un estilo en el que el profesor fomenta la creatividad del estudiante y realiza críticas constructivas.

Según Gordon, (1959):

- Estilo instrumental: el menos apropiado para la utilización de las TICs puesto que es el que menos permite la participación de los alumnos en clase. 
- Estilo expresivo: se considera que es demasiado liberal como para permitir la adaptación de las TIC a la enseñanza.

- Estilo instrumental-expresivo: es el más adecuado puesto que permite tanto la creatividad y la participación del alumno como la supervisión y dirección por parte del profesor.

Según Flanders (1984):

- Estilo directo: no se considera apropiada la inclusión de las TIC. EI profesor impone a los alumnos sus métodos.

- Estilo indirecto es el más propicio ya que, el profesor lo que valora es la participación del estudiante en clase y su creatividad.

Según Bennet (1979):

- Estilo progresista o liberal: Se refiere al profesor que está despreocupado por el control de la clase. En esta caso, la utilización de las TICs no es recomendable dada la elevada posibilidad de que el uso de las mismas se desvíen del objetivo educativo.

- Estilo formal no se considera apropiado para la utilización de las TICs puesto que los métodos son muy restrictivos.

- Estilo mixto se considera el más apropiado, ya que, sería un término medio entre ambos permitiendo así tanto la participación del alumno como la del profesor.

Realizando una valoración global de todos los estilos analizados anteriormente, se puede considerar que se enmarcan dentro de un continuo en el cual en los extremos se encuentran los estilos o muy liberales o muy restrictivos, donde la utilización de las TIC no se considera muy adecuada; estando en el punto intermedio los estilos más recomendados y donde la utilización de las TIC tiene su máxima cabida.

\section{CONCLUSIÓN}

Está aún por determinar la relación específica entre los estilos de enseñanza y las nuevas tecnologías en las aulas, debido a que la utilización de las mismas está en desarrollo. Para avanzar en este ámbito, es necesaria la adaptación del profesor y de los centros docentes a las nuevas tecnologías.

\section{Referencias bibliográficas.}

Aguilera, E. (2012). Los estilos de enseñanza, una necesidad para la atención de los estilos de aprendizaje en la educación universitaria. Revista estilos de aprendizaje, 10(10). 
Brincones, I.; Fuentes, A. ; Nieda, J. Palacios, M. (1986). Identificación del comportamiento y características deseables del profesorado de ciencias experimentales en bachillerato. Enseñanza de las Ciencias, 4(3) pp. 209-222.

Bustos, A. y Coll, C. (2010). Los entornos virtuales como espacios de enseñanza y aprendizaje. Una perspectiva psicoeducativa para su caracterización y análisis. Revista Mexicana de Investigación Educativa, 15(44).

Cabero, J. (2006). Bases pedagógicas para la integración de las TIC en Primaria y Secundaria. Universidad de Sevilla: Grupo de Tecnología Educativa.

Correa, J.M. y Pablos, J. (2009). Nuevas Tecnologías e Innovación Educativa. Revista de Psicodidáctica, 14(1), 133-145.

Dede, C. H. (2001). Aprendiendo con tecnología. Buenos Aires: Paidós.

Fernández, J. y Elortegui, N. (1996).Qué piensan los profesores acerca de cómo se debe enseñar. Enseñanza de las ciencias, 14 (3), 331-342.

Gairín, J. (2010). Gestión del conocimiento y escuela 2.0. DIMUAB, 16.

Marqués, P. (2008). Pizarra digital: las razones del éxito. Funcionalidades, ventajas, problemáticas. Barcelona: UAB.

Martínez, G.P. (2007). Aprender y enseñar. Los estilos de enseñanza y de aprendizaje: orientaciones para el aula. (3) Bilbao, España.

Tejada, J. (2009). Competencias docentes. Profesorado: Revista de Currículum y Formación de Profesorado, 13 (2), 1-15.

Uncala, G.S. (2008). Los estilos de enseñanza del profesor/a. Experiencias educativas, FETE-UGT Sevilla. 


\title{
LA GESTIÓN DEL CENTRO EDUCATIVO ANTE SITUACIONES DE ACOSO ESCOLAR: Estudio de caso de un centro de Educación Secundaria de Melilla
}

\author{
Boumadan Hamed, M; Vega Galiano, A. Universidad de Granada
}

\section{Resumen}

El acoso escolar es considerado uno de los problemas que más afecte el natural desarrollo de los vínculos sociales entre los alumnos, perjudicando el intercambio comunicativo de toda la institución educativa.

En la actualidad los espacios relacionales se han transformado en un intercambio comunicativo dirigido a través de las redes, con lo cual hay un cambio radical en la manera de interactuar entre los adolescentes, en la que también suceden casos de agresión.

El objetivo de esta investigación ha sido analizar la gestión del centro ante las situaciones de acoso, a través de la interpretación de los discursos de los agentes implicados en la comunidad educativa (profesorado, alumnado y padres).

Palabras clave: Institución educativa, comunicación, bullying, cyberbullying, gestión del centro.

\section{INTRODUCCIÓN}

La violencia que se localiza dentro de los centros educativos no es un tema actual, sino que existe desde hace décadas. Se puede considerar como un fenómeno particular que coexiste en todas las instituciones educativas de los distintos países del mundo (Debarbieux, 2003).

Dan Olweus, (1993). , fue el primero que dio forma a este concepto como una serie de conductas físicos y/o verbales que un sujeto o un grupo dirige contra otro/a con una frecuencia y una duración determinada y con el propósito de provocar daño y abusando de una desigualdad de un poder real o ficticio.

Para Avilés (1999) el bullying tiene como característica esencial la relación escolar basada en el dominio y la sumisión entre agresor/es y víctima, aparecen conductas tales como insultos, golpes, exclusión, amenazas, chantajes, etc., la aparición suele ser muy reiterada y la intención es la de causar daño físico, psicológico y o la separación del grupo.

Algunos autores distinguen tres roles implicados en el bullying: agresores, víctimas, y aquellos que son víctimas y agresores a la vez (Olweus, 1978 y Ortega y MoraMerchán, 2000).

A partir de las investigaciones de Ortega y Mora-Merchán (1996) aparece un nuevo rol: el espectador. El cometido de los espectadores puede variar dependiendo de su posición y conducta, él decide si prefiere que la situación de acoso se alargue en el tiempo o ponerle un fin 
El bullying puede aparecer como una agresión física, verbal y social o relacional, pero un mismo agresor puede aplicar los tres tipos a la vez, e incluso pueden estar dirigidas a la misma persona (Rigby, 2002).

Algunos autores consideran que el cyberbullying como un subtipo o una nueva forma de bullying con la diferencia de que ésta se usa a través de las nuevas tecnologías (Beran y Li, 2007; Erdur-Baker, 2010; Smith et al., 2008).

La violencia a través de las TICs está relacionada con las manifestaciones tradicionales de la exclusión social, la violencia física y la violencia verbal que pueden manifestarse también a través de las TICs. Así, un adolescente puede ser excluido, rechazado o ignorado en un programa de mensajería instantánea, foro o red social; la violencia física (como por ej., peleas o destrozos) puede ser grabada con un móvil y posteriormente difundida a través del propio móvil o de Internet; y la violencia verbal (insultos, motes molestos, amenazas, rumores,..) puede ocurrir a través de mensajes SMS, del correo electrónico o de las redes sociales, por ejemplo. (Álvarez-García et al. 2011).

\section{OBJETIVOS}

Como objetivo general nos propusimos conocer la gestión del centro educativo ante situaciones de acoso escolar. Bullying y cyberbullying a través del discurso de todas las personas que componen el centro educativo.

Como objetivos específicos nos planteamos:

Conocer las conductas agresivas que se dan en el centro educativo.

Conocer las características y las condiciones en las que se produce el maltrato entre iguales.

Describir los programas de prevención e intervención de bullying y cyberbullying que se trabajan en el centro.

Conocer la percepción de los profesores a cerca de la evolución sobre las conductas de maltrato en el centro educativo, a lo largo de su trayectoria profesional.

Conocer la influencia de las TIC en la conducta agresiva de los alumnos.

Conocer las medidas que toman los profesores ante la aparición de las conductas de maltrato entre iguales.

Conocer a través de qué medios es más propicio que se produzcan situaciones de cyberbullying.

\section{MÉTODO}

El presente estudio etnográfico se ha llevado a cabo en un centro de Secundaria Obligatoria de Melilla. Nuestros participantes han sido: 13 profesores/as de $1^{\circ}$ y $2^{\circ}$ de la Educación Secundaria Obligatoria (E.S.O.), una muestra de 19 alumnos/as de $1^{\circ} \mathrm{y}$ $2^{\circ}$ de la E.S.O. y un total de 19 padres/madres.

Las técnicas de recogida de datos han sido la entrevista en profundidad adaptada a los distintos grupos (padres, profesorado y alumnado) y el diario de campo que nos ha permitido triangular las informaciones recogidas. 
El discurso de las entrevistas fue organizado en las siguientes categorías consensuadas con otros investigadores que nos ayudaron a redactar los resultados:

- Tipos de agresiones.

- Clima de la clase.

- Espacios de desarrollo de una agresión.

- Causas por la que se desencadena una agresión.

- Evolución de los conflictos en el centro.

- Actividades y programas antibullying/cyberbullying.

- Influencia de las TICs en las conductas de los alumnos.

- Actuación de los docentes ante una agresión.

- Los medios más favorables para el cyberbullying.

\section{RESULTADOS}

Conductas agresivas que se dan en el centro educativo:

Los profesores/as estaban de acuerdo en que los casos violentos más frecuentes en el centro son las agresiones verbales, los insultos, los motes, las burlas,... y que las escasas agresiones físicas que se detectan, son fruto de una previa agresión verbal.

Muchos de los profesores/as no consideraron las agresiones verbales como algo alarmante.

Al analizar las respuestas de padres y alumnos/as, ellos si mantienen que las agresiones físicas están presentes en el día a día del centro educativo, y curiosamente en ambos grupos hay una opinión enfrentada sobre si contar con el profesor o no si estuvieran envueltos en un caso de violencia, tanto padres como alumnos piensan que contándolo al profesor podría empeorar la situación y algunos alumnos añaden que no lo contarían porque es un asunto exclusivamente de víctima y agresor.

Características y las condiciones en las que se produce el maltrato entre iguales:

La gran mayoría de los profesores/as padres y alumnos/as tiene muy claro que las agresiones suelen darse en ausencia de algún adulto.

Según los datos analizados, las causas que desencadenan una agresión suelen ser múltiples y muy variadas y las hemos agrupado en factores personales, factores familiares y factores del centro:

Según las causas personales, los profesores indican que las víctimas con diferencias físicas e intelectuales, pueden ser el blanco perfecto para burlarse de ellas.

Por otro lado los factores familiares que nos presentan los profesores son los relacionados con el ambiente familiar, especialmente contextos donde prima una excesiva permisividad por parte de los padres, pero también se señalan las diferencias socioeconómicas y religiosas como posible factor de riesgo para que suceda una agresión. 
Y por último, tanto padres y alumnos/as opinan que una de las causas es la poca vigilancia o los descuidos que puede haber por parte del centro educativo.

Percepción de los profesores a cerca de la evolución sobre las conductas de maltrato en el centro educativo, a lo largo de su trayectoria profesional.

Podemos decir que hay dos teorías enfrentadas. A pesar de que la mayoría de profesores/as afirme que la evolución ha ido mejorando y se han disminuido las agresiones físicas, dando lugar a un aumento de las agresiones verbales y psicológicas. Una minoría de profesores/as, sostienen que las agresiones han empeorado en los últimos años, y para justificarlo, los profesores/as aportan dos argumentos principales: por un lado, nos cuentan que ahora los alumnos son mucho más impulsivos y no controlan sus conductas y a consecuencia de ello se originan más casos de violencia; y por otro lado, se defiende que con la llegada de las TICs la violencia se ha masificado y los efectos son mucho más perjudiciales.

Al consultar el Plan de Convivencia del centro, hemos contrastado que realmente ha mejorado la convivencia y se ha reducido los índices de casos de violencia.

Una de las profesoras mantenía que la convivencia ha mejorado gracias al nuevo perfil de alumnos matriculados, cuyo nivel socioeconómico ha mejorado, y este mismo argumento ha sido apoyado por otra profesora que añade que las agresiones físicas han evolucionado a agresiones psicológicas y verbales.

Programas de prevención e intervención de bullying y cyberbullying que se trabajan en el centro:

En líneas generales todos los profesores conocían los programas que el centro lleva a cabo y estaban de acuerdo en que si aparecía un caso de violencia se trabajaría. Sólo la mitad de los alumnos entrevistados conocían el programa de las charlas informativas, la otra mitad del alumnado, al igual que la mayoría de padres afirmaban que el centro no organizaba actividades preventivas.

Podemos afirmar que en el centro se plantean muchas actividades como son: conferencias, el blog, las propuestas del Plan de Acción Tutorial y en el departamento de orientación también se trabaja de forma individual con los alumnos que lo requieran.

Influencia de las TIC en la conducta agresiva de los alumnos.

En este aspecto tanto padres, como profesores y alumnos comentan la cantidad de violencia que generan los videojuegos, la televisión o el cine y hay una idea compartida en que los jóvenes imitan esas conductas violentas.

Desde el centro se intenta promover la campaña de prevención mediante las conferencias sobre los riesgos que puede haber en internet, hay medidas tales como la prohibición de dispositivos móviles y los ordenadores del centro están protegidos e impiden el acceso a determinadas páginas.

Medidas que toman los profesores ante la aparición de las conductas de maltrato entre iguales.

Podemos afirmar que la inmensa mayoría de los profesores suele hablar directamente con los implicados e indagar sobre las causas que hayan podido desencadenar la 
agresión, y dependiendo de la gravedad del caso, algunos profesores deciden dar parte a la Jefatura de Estudio y avisar y hablar sobre el asunto con los padres y al Departamento de Orientación.

Padres y alumnos coinciden en que las actuaciones del profesor es hablar con los implicados y la medida más utilizada y menos efectiva es la de la expulsión.

Algunos profesores no dudan en comentar que las actuaciones que llevarían a cabo serían parecidas, hablar con los implicados y derivar a Jefatura de Estudios y en ese caso se pone en conocimiento de los padres.

Medios más propicios para que se produzcan situaciones de cyberbullying:

Hay una visión global por parte de alumnos/as, padres y profesores/as, que opinan que cualquier medio puede servir. Pero que como tuenti, Facebook y twitter son las redes sociales más utilizadas por los jóvenes pues posiblemente sería donde más casos de cyberbullying se produzcan.

\section{CONCLUSIONES}

Profesores/as padres y alumnos/as tiene muy claro que las agresiones suelen darse en ausencia de algún adulto. Este hecho nos lleva a pensar que realmente ni el profesorado ni la familia son conscientes del tipo de agresiones que están sucediendo tanto dentro como fuera del centro educativo.

Se repite la escena de padres versus profesores, en la que unos cargan sus responsabilidades sobre el otro, los padres acusan la poca vigilancia por parte del profesorado y éstos acusan a los padres de no ejercer un control sobres sus hijos. La solución está en que ambos tendrían que ponerse de acuerdo sobre "educar" bajo unos principios y valores de igualdad, para que el alumnado consiga ser empático, autosuficiente y sepa diferenciar lo que está bien de lo que está mal.

Afirmar que la convivencia ha mejorado gracias al nuevo perfil de alumnos matriculados con un nivel socioeconómico mejorado y que dichos alumnos ahora sólo utilizan agresiones verbales o psicológicas son dos argumentos poco fundados, y lo único que se consigue es minimizar la verdadera gravedad que esconde una agresión entre iguales.

Hay que romper con la errónea creencia de que las agresiones verbales y psicológicas son menos dañinas que las agresiones físicas, las agresiones verbales y psicológicas son mucho más peligrosas ya que una agresión física es más fácil de detectar y demostrar.

Se confirma que el centro plantea una gran variedad de propuestas y programas de prevención e intervención de bullying y cyberbullying, pero hay algo que falla, porque alumnos y padres manifiestan que en el centro no hay actividades o lo desconocen, con lo cual la difusión o publicación de las actividades no debe ser la adecuada.

Las Nuevas Tecnologías están muy presentes en el día a día de los adolescentes, y es normal afirmar que existe una influencia directa en su comportamiento y especialmente si tenemos en cuenta que a esa edad los adolescentes son más susceptibles. 
Estamos muy de acuerdo en que son las familias las que tengan que proteger a los alumnos de los innumerables peligros con los que se pueden encontrar los alumnos, mediante un seguimiento de los hábitos que se tengan con las TICs.

Cuando las agresiones ocurren en las Redes las dificultades para detectarlas por parte del docente se multiplican y en muchos casos se le hace imposible intervenir al profesor.

Queremos resaltar que los docentes no conocen o no aplican las medidas de actuación ante situaciones de acoso escolar y/o ciberacoso. Entre las causas encontramos por un lado el desconocimiento real de muchas situaciones de acoso que no son visibles para el profesorado al producirse estas conductas cuando nadie puede verlas. Otra de las causas por la que lo desconocen es porque las agresiones a las que tienen que hacer frente los docentes en su labor diaria, son de tipo puntual, pero aun así, las medidas de actuación que nos relatan, distan muchísimo de las actuaciones que el centro tiene recogido en su Plan de Convivencia. De hecho tanto padres como alumnos/as nos confirman que no se solucionan los conflictos que surgen y por esa razón no se lo contarían a los tutores.

Es triste que uno de los objetivos básicos que toda institución educativa debería tener muy bien organizado, como en este caso es la de afrontar el acoso escolar en la justa medida, y que tengamos que comprobar que en la teoría todo está muy bien anclado y que desde el campo de la práctica la visión que tenemos es turbia y con muchas lagunas.

\section{REFERENCIAS BIBLIOGRÁFICAS}

Álvarez-García D, Núñez Pérez J. C., Álvarez Pérez L., Dobarro González A., Rodríguez Pérez C., González-Castro P. (2011). Violencia a través de las tecnologías de la información y la comunicación en estudiantes de secundaria. Anales de Psicología. (27). 221-231.

Avilés, J. M. (2002). La intimidación y el maltrato en los centros escolares (Bullying). Lan Osasuna, 2, 1-13.

Avilés, J. M. (2009). Ciberbullying: Diferencias entre el alumnado de secundaria. Boletín de Psicología, (96), 79-96.

Olweus, D. (1998). Conductas de acoso y amenaza entre escolares. Madrid. Morata.

Olweus, D. (2005). Bullying en la escuela: datos e intervención. En J. Sanmartín (Ed.), Violencia y Escuela (pp. 13-30). Valencia: Centro Reina Sofía para el Estudio de la Violencia.

Ortega R., Mora-Merchán J. A., Jäger T. (2007). Actuando contra el bullying y la violencia escolar: El papel de los medios de comunicación, las autoridades locales y de Internet. Landau: Empirische Paedagogik e. V.

Ortega R. (2010). Agresividad injustificada, bullying y violencia escolar. Madrid: Alianza Editorial. 
Ortega R., Virginia Sánchez R. (2012). Nuevas dimensiones de la convivencia escolar: Ciberconducta y relaciones en la red. España. Ministerio de Educación, Cultura y Deporte.

Rigby, K. (2002). New Perspectives on Bullying. London: Jessica Kingsley Publishers.

Sharp, S. (1995). How much does bullying hurt? The effects of bullying on the personal well-being and educational progress of secondary-aged students. Educational and Child Psychology, 12(2), 81-88.

Smith P., Mahdavi J., Carvalho M., Fisher S., Russell S., Tippett N.. (2008). Cyberbullying: its nature and impact in secondary school pupils. Journal of Child Psychology and Psychiatry. (49:4). 376-385.

Smith P., Mahdavi J., Carvalho M., Tippett N. (2006). An investigation into cyberbullying, its forms, awareness and impact, and the relationship between age and gender in cyberbullying. Research brief. 


\section{PERCEPCIÓN DE LA INCLUSIÓN EDUCATIVA ENTRE EL PROFESORADO DE LA FACULTAD DE CIENCIAS DE LA EDUCACIÓN DE GRANADA: UN ESTUDIO EXPLORATORIO}

Conde Lacárcel, Alfonso. Universidad de Granada

\section{Resumen}

El presente artículo pretende concluir un análisis aproximativo respecto al grado de aplicación de la inclusión educativa en la Facultad de Ciencias de la Educación de la ciudad de Granada iniciado el curso anterior entre el estudiantado. Tras los datos obtenidos anteriormente, y a través en este caso de una entrevista con respuestas abiertas, se ha buscado conocer la percepción del profesorado respecto al alumnado universitario, con el fin de contrastar las percepciones de unos y otros.

¿Cuál es la percepción real de la comunidad universitaria en este centro respecto a la inclusión? ¿Coinciden las visiones entre el estudiantado y el profesorado? ¿Qué medidas deberían adoptarse en el futuro para que la inclusión universitaria sea más efectiva?

Palabras clave: educación universal, acceso a la educación, inclusión educativa, enseñanza superior.

\section{LA EDUCACIÓN INCLUSIVA UNIVERSITARIA}

Quisiéramos comenzar este artículo, con la última definición hecha por parte de la Unesco sobre la temática que nos atañe: La educación inclusiva y de calidad se basa en el derecho de todos los alumnos a recibir una educación de calidad que satisfaga sus necesidades básicas de aprendizaje y enriquezca sus vidas. Al prestar especial atención a los grupos marginados y vulnerables, la educación integradora y de calidad procura desarrollar todo el potencial de cada persona. Su objetivo final es terminar con todas las modalidades de discriminación y fomentar la cohesión social. (Unesco, 2012)

Debido a la brevedad de espacio, vamos a centrarnos en la educación inclusiva universitaria a la hora de establecer una breve introducción y marco teórico general. Para todo aquel lector que esté interesado en tener unas nociones sobre la evolución histórica que se ha producido hasta llegar a ella, les remitimos a la primera parte de este estudio inicial aproximativo que ha intentado modestamente dar una panorámica sobre el estado de esta cuestión en uno de los centros de la Universidad de Granada, que por pertenecer al área/ámbito de la educación se encuentra directamente implicado desde nuestro punto de vista.

En nuestro caso, coincidimos con Susinos y Parrilla $(2008,159)$ en la necesidad de abrir un amplio marco en el término de la inclusión que no haga referencia exclusivamente a personas con discapacidad, sino como está siendo tenido en cuenta por otros muchos autores e investigadores, que incluya todas las perspectivas en las cuales una persona

1 ReiDoCrea. Revista electrónica de investigación Docencia Creativa. Volumen 2. Páginas 233-238 
puede verse excluida y perjudicada en el acceso, calidad e igualdad en el derecho a la educación, en este caso, superior.

Nos referimos a los aspectos relacionados con el género, los grupos indígenas o minoritarios, inmigrantes; prestando atención al interesante artículo de investigación de Lebrero y Quicios (2010), debido a la importancia de esta población entre la comunidad universitaria; religión, capacidad económica, orientación sexual o ideológica, entre cualquier otra que genere procesos de discriminación.

Para conseguirlo es preciso seguir modificando la cultura, políticas y prácticas educativas del profesorado de los centros universitarios.

Otros autores como Echeita $(2008,11)$, citando a Castell (2004) nos advierten de determinadas prácticas de inserción o inclusión centradas en la ayuda inmediata, con el fin de evitar llevar a cabo políticas preventivas y sistemáticas eficaces. Según este autor, la inclusión educativa debe entenderse como: "un aprendizaje y rendimiento escolar de calidad y exigente con las capacidades de cada estudiante".

Países como por ejemplo, Reino Unido centran sus esfuerzos bajo la perspectiva de la detección e intervención oportuna, todo ello con la aspiración de evitar mayores niveles de desigualdad y exclusión producidas por algunos grupos mayoritarios y los condicionantes del contexto, que producen una clara diferencia en la calidad del aprendizaje, incluso en un mismo centro, como es el caso de las distintas iniciativas de los países Iberoamericanos sobre la actitud de los docentes universitarios sobre la inclusión de Martínez, Pineda y Saucedo (2010), comentado en el artículo anterior.

En nuestro país, España, podemos encontrar referencias a la inclusión educativa entre otras en el Art. 1(a. de la Ley Orgánica de Educación (LOE); así como en la exposición de motivos de la Ley Orgánica de Universidades (LOU); en el Prólogo de la Guía para la evaluación y mejora de la educación inclusiva realizada por el Consorcio Universitario para Educación Inclusiva, y a nivel práctico, destacamos la Guía para la elaboración de planes de acción para el alumnado con discapacidad (Cayo, 2010) y el estudio realizado por Fernández (2006) sobre las necesidades de los estudiantes universitarios en relación al Espacio Europeo de Educación Superior.

Las iniciativas en el contexto universitario parecen ir bien encaminadas, aunque presentan todavía múltiples deficiencias en su aplicación real. De ahí, la necesidad de la elaboración de un barómetro de la inclusión en la Universidad española surgida desde el CERMI y la Fundación Universia (noticia ofrecida por www.Europapress.es 2012), que desde nuestro punto de vista y ante la realidad social a la que nos enfrentamos en esta época de crisis a nivel mundial, debe ser ampliado a todos los posibles sectores de población en riesgo.

A modo de síntesis de este apartado, enumeraremos algunas de las distintas estrategias propuestas por los anteriores autores y organismos, así como a otros como Porter (2005) con el fin de favorecer la inclusión no solo universitaria, sino aplicable a todos los niveles educativos:

- Programas de Implicación de toda la comunidad universitaria.

- Programas de formación del profesorado (mentoring, adaptaciones al currículo y a las problemáticas planteadas, técnicas, contenidos...) 
- Programas de ingreso, permanencia y finalización de estudios universitarios.

- Programas de accesibilidad, recursos materiales, humanos y ayudas técnicas especializadas según el sector implicado (discapacidad, inmigración, problemas socio económicos...).

- Protocolos de atención y resolución de problemas a los grupos en riesgo de exclusión.

- Programas de información académica e inclusión laboral.

- Programas de I+D+i.

- Relaciones institucionales con el entorno.

Teniendo en cuenta todo, ¿Hasta qué punto el profesorado coincide en las percepciones de su alumnado respecto a la inclusión educativa en nuestro Centro? ¿Hay una auténtica cultura inclusiva reafirmada por acciones concretas?

\section{MÉTODO Y MATERIALES}

Hemos llevado a cabo una metodología con entrevistas semi-estructuradas vía on-line, sobre las distintas opiniones y valoraciones de la muestra seleccionada.

En la elaboración del instrumento utilizado se ha seguido la selección de ítems realizada a partir del "Cuestionario del Índice de Inclusión" del Programa de Educación Inclusiva con Calidad llevado a cabo por el Ministerio de Educación Nacional de Colombia, debido a su validez y fiabilidad comprobada.

La difusión de la misma y el tratamiento de los datos han sido facilitados por la plataforma encuestafacil.com que nos permite descargar en fichero csv y los formatos Excel y Access los datos cualitativos y trabajarlos con el programa Nvivo8 y las técnicas del discurso biográfico-narrativo.

El Universo teórico objeto del estudio está formada por el conjunto de los órganos directivos, de gestión, y el profesorado de los distintos departamentos (incluidos becarios FPU) de la Facultad de Ciencias de la Educación, siendo seleccionada de manera aleatoria para una mayor validez de los datos recogidos y evitar falseamientos de la información o posibles errores. Al tener un carácter voluntario, la muestra final ha sido la siguiente:

\begin{tabular}{lr}
\hline Cuestionarios entregados vía online: & 220 \\
Cuestionarios contestados: & 17 \\
Cuestionarios abandonados: & 2 \\
Cuestionarios finalizados: & 15 \\
\hline
\end{tabular}

En esta ocasión, hemos optado por una interpretación descriptiva e interpretativa de los datos para facilitar una información detallada de los aspectos de interés a destacar. Para ello, hemos identificado adecuadamente las entrevistas, configurándolas como casos para asignar rápidamente atributos y agilizar las búsquedas de información relevante. 
Igualmente, se ha procedido a diferenciar los distintos discursos, asignando distintos estilos de párrafo a cada pregunta, seleccionando el estilo de párrafo a codificar y asignando posteriormente los nodos donde se ubicarían. De esta manera, se ha facilitado enormemente el trabajo de análisis posterior de toda la información aportada. El resto de pasos seguidos no se explicitan por la falta de espacio, siguiendo el procedimiento habitual.

De todas formas, lamentablemente no se ha podido llegar a los niveles de saturación deseados, pero el estudio exploratorio realizado sigue ofreciéndonos información valiosa a tener en cuenta sobre la percepción del profesorado de la FCCE sobre la inclusión educativa.

\section{RESULTADOS}

En cuanto al índice de respuesta por departamentos en la FCCE, podemos encontrar los porcentajes siguientes:

\begin{tabular}{ll}
\hline Departamento de Didáctica y Organización Escolar: & 5 \\
Departamento de Didáctica de la Expresión Musical, Plástica y Corporal: & 2 \\
Departamento de Psicología Evolutiva y de la Educación: & 2 \\
Departamento de Didáctica de la Lengua y Literatura: & 2 \\
Departamento de Ciencias Experimentales: & 2 \\
Departamento de Pedagogía: & 2 \\
Departamento de Didáctica de la Matemática: & 1 \\
Departamento de Métodos de Investigación y Diagnóstico en Educación: & 1 \\
\hline
\end{tabular}

Nos hemos encontrado con unos índices de respuesta muy bajos, en cuanto a número de participantes, permitiéndonos un nivel nulo de generalización de los datos a nivel de comunidad universitaria, pero sí al menos, realizar una valoración de las respuestas ofrecidas por estos profesores/as, a los que les damos nuestro máximo agradecimiento por su tiempo dedicado.

Mayoritariamente, han respondido un $76^{\prime} 45 \%$ hombres y un $23^{\prime} 55 \%$ mujeres. De forma general, entre los entrevistados, se considera que la FCCE de Granada admite a toda la población sin ningún rechazo manifiesto, siempre que cumplan todos los requisitos administrativos (76'38\% afirmat. frente al $11^{\prime} 76 \%$ negativa.); igualmente creen que se recibe una atención que favorece el desarrollo del alumnado (64.67\% de media): "Sí, creo que el que ingresa en nuestra facultad recibe, en general, una importante atención que lo favorece [...] (Entrevista on-line 11. Prof. Depto. C. Experimentales).

La escucha y la atención personalizada a los estudiantes es un aspecto que genera más controversia, con porcentajes idénticos afirmativa y negativamente, tanto en género como en percepción (35'29\%): "En general digo que sí. Aunque quizás haya casos menos empáticos, pero que finalmente están "condenados a entenderse". (Entrevista on-line 16. Prof. Depto. Didáctica y Organización Escolar). 
Sin embargo es muy significativo que más del $50 \%$ del profesorado desconocen si existe un Plan de Mejora de la institución educativa, otro $17 \%$ creen que no; y además, piensan que no contempla acciones inclusivas: "Desconozco dicho plan. Pero pienso que la inclusión es un concepto imprescindible para cualquier plan de mejora" (Entrevista on-line 14.Prof. Depto. Expr. Corp. Plast. y Musical).

Por último, debido a la escasez de espacio, destacamos como puntos conflictivos el desconocimiento de la realización de actividades con las personas del sector para favorecer la inclusión en la comunidad educativa (35'29\% lo desconocen, $11^{\prime} 74 \%$ creen que sí se realizan, y el 17 '65\% no), así como la visualización de los resultados de las distintas iniciativas (52'94\% de media creen que no se visualizan y un 23 ' $53 \%$ lo desconocen): "Los resultados no los conozco, de lo cual debo derivar que no se hacen muy explícitos". (Entrevista on-line 12. Prof. Depto. Didáctica y Organización Escolar).

\section{DISCUSIÓN}

Teniendo en cuenta la dificultad a la hora de obtener los datos recopilados y la clara insuficiencia de éstos para realizar una visión general de la realidad percibida por el profesorado ante la inclusión universitaria, solo nos cabe reiterar la necesidad de ampliar la muestra de este sector para obtener una fiabilidad sobre las ideas y acciones que llevan a cabo diariamente y que se relacionan o no con la inclusión.

Aparentemente, podríamos decir al comparar las ideas obtenidas en sendos artículos (alumnado y profesorado) que se produce un desconocimiento y/o falta de impulso en la creación de una cultura inclusiva real en nuestra FCCE, o al menos, un mayor conocimiento e implicación por parte de toda la comunidad educativa.

En unos tiempos de crisis en que la satisfacción de las necesidades vitales y de desarrollo, sociales, personales, afectivas, laborales...se están convirtiendo lamentablemente en un lujo más que en un derecho, creemos firmemente en la necesidad de trabajar por todos aquellos colectivos de personas que se encuentran en mayor dificultad para llevar una vida lo más normalizada, desarrollada y feliz posible.

\section{REFERENCIAS BIBLIOGRÁFICAS}

Cayo, L. (2010). Guía para la elaboración de un plan de acción al alumnado con discapacidad en la universidad. La Cuestión Universitaria, 6. 103-116.

Echeita, G. (2008). Inclusión y Exclusión Educativa. Voz y Quebranto. Revista Electrónica Iberoamericana sobre Calidad, Eficacia y Cambio en Educación, 6(2), pp. 9-18. Extraído el 30-01-2012 de: http://www.rinace.net/arts/vol6num2/art1.pdf.

Fernández, M. J. (2006). Necesidad de los estudiantes universitarios ante la realidad de la Educación Superior Europea. Madrid: MEC. 
Lebrero Baena, Ma. P. y Quicios García, Ma del P. (2010). El estudiante inmigrante y su inclusión en la universidad española. Educación XX1. 13 (2), 241-262.

Ministerio de Educación Nacional. (2008). Índice de inclusión. Programa de Educación Inclusiva con calidad "Construyendo capacidad institucional para la atención a la Diversidad". Revolución Educativa Colombia aprende. Colombia.

Porter, G. (2005). Puesta en práctica de la educación Inclusiva. Material no publicado, preparado para el seminario "Levantar las barreras para el aprendizaje y la participación: construyendo una escuela inclusiva", organizado por el Departamento de Educación, Universidades e Investigación del gobierno Vasco.

Susinos, T. y Parrilla, A. (2008). Dar la Voz en la Investigación Inclusiva. Debates sobre Inclusión y Exclusión desde un Enfoque Biográfico-Narrativo. REICE. Revista Electrónica Iberoamericana sobre Calidad, Eficacia y Cambio en Educación 6(2),157-171. Extraído el 16-11-2012 de: http://www.rinace.net/arts/vol6num2/art11.pdf.

UNESCO (2012). Lucha contra la exclusión. [Website] Extraído el 1-12-2012 de: http://www.unesco.org/new/es/education/themes/strengthening-education systems/inclusive-education/

Vázquez Martínez, B., Méndez Pineda, J. y Mendoza Saucedo, F. (2010).Actitudes de Docentes Universitarios hacia los Procesos de Inclusión Educativa de Alumnos con Capacidades diferentes en la Universidad Autónoma de San Luís Potosí. En Primer Congreso Latinoamericano de Ciencias de la Educación. UABC México. 


\title{
COMPRENDIENDO LA AMENAZA DEL ESTEREOTIPO
}

\section{DEFINICIÓN, VARIABLES MEDIADORAS Y MODERADORAS, CONSECUENCIAS Y PROPUESTAS DE INTERVENCIÓN}

\author{
UNDERSTANDING STEREOTYPE THREAT \\ DEFINITION, MEDIATOR AND MODERATOR VARIABLES, CONSEQUENCES AND
PROPOSALS FOR INTERVENTION
}

Furrer Correa, Sofía E. (sofiefc@correo.ugr.es). Universidad de Granada

\section{RESUMEN}

Los estereotipos sobre determinadas capacidades de los miembros de un grupo en relación a características como la raza, sexo, estatus, religión, etc., pueden afectar a su rendimiento en tareas que evalúan esas capacidades, denominándose este fenómeno, amenaza del estereotipo. El presente trabajo pretende revisar los estudios clásicos y recientes sobre el tema con el objetivo de conocer en qué consiste, qué procesos psicológicos subyacen, qué factores situacionales y personales influyen y qué consecuencias se derivan del mismo. Para explicar el efecto de la amenaza del estereotipo se recurre a variables mediadoras relacionadas con el consumo excesivo de recursos cognitivos, y a variables moderadoras, como la creencia en el estereotipo, para explicar el tamaño de este efecto. Se plantean distintos tipos de amenaza dentro de un modelo multiamenaza basado en el objeto y la fuente del estereotipo. Finalmente, considerándose un fuerte marcador de desigualdad con implicaciones tanto a nivel personal como social, se presentan tres tipos de intervención: contacto, reentrenamiento de actitudes y estereotipos, y autoafirmación; y se recoge una serie de recomendaciones con el objetivo de contrarrestar su efecto.

Palabras clave: amenaza del estereotipo, rendimiento, grupos minoritarios, estigma social.

\begin{abstract}
Stereotypes about certain abilities of group's members in relation to characteristics such as race, sex, status, religion, etc., can affect performance on tasks that assess these skills, taking place a phenomenon called stereotype threat. The present work reviews classic and recent studies on the subject so as to know what it is, underlying psychological processes, influence from situational and personal factors, and consequences. In order to understand the effect of stereotype threat, mediator variables related to excessive consumption of cognitive resources are used. In addition, moderator variables such as belief in the stereotype are proposed to explain the size of this effect. Several types of threat are suggested within a multi-threat model based on the object and the source of the stereotype. Finally, considering stereotype threat as a strong marker of inequality with implications both personally and socially, three types of intervention are raised: contact, retraining attitudes and stereotypes, and self-affirmation, and some recommendations are proposed aimed to counteract its effects.
\end{abstract}

Keywords: stereotype threat, performance, minority groups, social stigma. 


\section{INTRODUCCIÓN}

Los seres humanos pertenecemos a diversos grupos sociales en función de distintas características como pueden ser la raza, el género, el estatus, etc. Basándonos en estas categorías, las personas solemos mantener determinadas creencias consensuadas que se conocen como estereotipos. Los estereotipos se han definido como imágenes mentales simplificadas sobre una persona, un grupo, una institución, etc., en sus características esenciales, como puede ser capacidad intelectual o aptitudes, y que de forma general, es compartida socialmente (Tajfel, 1984). Estas generalizaciones implican asignar características comunes a los miembros de un grupo de acuerdo con su apariencia, comportamientos o costumbres, y por lo tanto, van a marcar diferencias respecto a otros grupos sociales (Quin y McMahon, 1997).

Cabe esperar que dentro de un determinado grupo, ya sea una clase, un puesto de trabajo, un equipo deportivo, etc., existan diferencias individuales en el rendimiento de los sujetos las cuales se tienden a atribuir a habilidades personales. Sin embargo, los estereotipos sobre un grupo, sobre todo si son negativos, pueden llegar a condicionar el rendimiento de sus miembros en situaciones en las que son activados. Consideremos, por ejemplo, un grupo de hombres y mujeres a los cuales se les va a someter a una prueba de aptitud matemática. En consonancia con el estereotipo acerca de peores habilidades de las mujeres en matemáticas, éstas podrían mostrar un peor rendimiento que no se corresponde con su nivel real en esa habilidad. El hecho de que los sujetos puedan ser juzgados en función de su pertenencia a un determinado grupo y los estereotipos relacionados con el mismo, se denomina amenaza del estereotipo.

Este tipo de situaciones se viven diariamente y pocas veces se hace hincapié en reducir su efecto. Pero, ¿en qué consiste realmente la amenaza del estereotipo? ¿Sabemos cómo funciona? ¿Cuáles son sus efectos? ¿Cómo podemos reducir o eliminar estos efectos? Los estudios clásicos sobre el tema se han centrado en gran medida en la influencia de los estereotipos en el rendimiento escolar de los sujetos, fundamentalmente, en la capacidad intelectual de las personas de raza negra y las habilidades matemáticas de las mujeres. No obstante, el ámbito escolar no es el único contexto donde la amenaza del estereotipo puede ocurrir.

El objetivo del presente trabajo es, por tanto, intentar dar respuesta a las preguntas planteadas y ofrecer distintas alternativas de intervención para eliminar o reducir el efecto de la amenaza del estereotipo. Para ello, se deberá estudiar detenidamente ante qué nos encontramos por lo que se comenzará definiendo el constructo en profundidad. A continuación, se tratarán las variables que intervienen en el proceso y aquellos mecanismos psicológicos subyacentes que explicarían su efecto. El último apartado se dedica a las consecuencias de este hecho y como respuesta, se presentarán tres tipos de intervención y algunas pautas generales de actuación. 


\section{1. ¿Qué es la amenaza del estereotipo?}

Para ofrecer una definición clara y completa del concepto de amenaza del estereotipo se va a hacer referencia a los trabajos de distintos autores dentro de este campo a lo largo de las últimas décadas. En primer lugar, se han seleccionado algunos estudios clásicos como son los trabajos de Steele y Aronson (Steele y Aronson, 1995; Steele, 1997). En segundo lugar, dentro de este apartado, se va a complementar la definición con estudios más actuales sobre las distintas formas en que la amenaza del estereotipo puede ejercer su efecto.

\subsection{Considerando la amenaza del estereotipo. Los estudios clásicos.}

Los trabajos de Claude M. Steele sobre la amenaza del estereotipo tuvieron una gran repercusión en el estudio del rendimiento académico de estudiantes pertenecientes a grupos minoritarios. Para poder entender el concepto de amenaza del estereotipo de forma adecuada en un primer acercamiento, se considera necesario hacer referencia a los estudios realizados por este autor y colaboradores.

Los trabajos de Steele (Steele y Aronson, 1995; Steele, 1997) trataban de dar respuesta, en un primer momento, a las diferencias intelectuales de individuos afroamericanos y de mujeres, en Estados Unidos. La definición original que ofrece Steele sobre la amenaza del estereotipo se presenta a continuación:

"Cuando la existencia de un estereotipo negativo sobre un grupo al cual se pertenece llega a ser relevante para el sujeto, generalmente como interpretación de la acción que se está realizando, de la experiencia que se está viviendo o de la situación en la que se encuentra, será relevante para el concepto sobre uno mismo. Esto es lo que sucede cuando uno se encuentra en el campo del estereotipo, a lo que Cross (1991) se refería como "foco de ansiedad" (p. 195) donde el sujeto puede ser juzgado o tratado en términos de un estereotipo racial". P. 616

(Steele, 1997)

Steele observó en estos estudios que los miembros de grupos sociales sobre los que recaía un estereotipo negativo, reducían su rendimiento cuando se encontraban ante una prueba que activaba esos estereotipos, en este caso, un test de matemáticas que medía por un lado diferencias entre hombres y mujeres, y por otro, diferencias entre afroamericanos y blancos americanos. Por otra parte, en esta línea, Steele consideró que los estereotipos también afectaban al desarrollo de la identidad. Para que una persona muestre interés por su rendimiento en un determinado contexto, como puede ser la escuela, primero tiene que estar identificado con ese ámbito, es decir, éste debe formar parte de su definición personal. Esta identificación se vería influenciada por el logro obtenido en las tareas relacionadas con el ámbito. Así, si el rendimiento en estas tareas es negativo, se producirá un menor acercamiento del sujeto a ese contexto, llegando a producirse tras sucesivas experiencias similares, una desidentificación con el ámbito. Otros factores como la relevancia, el atractivo, la viabilidad y la receptibilidad del ámbito influirán también en la identificación con éste. Así, los estudiantes a través de una evaluación de sus perspectivas en ese campo, mostrarán interés en las actividades relacionadas si son favorables y las evitarán si encuentran inconvenientes en su desarrollo. Siendo así, se plantea que las personas que más se identifican con ese ámbito serán las más afectadas. Esto es, el efecto de la amenaza del estereotipo sería mayor porque interfiere en su rendimiento y ataca su autoconcepto, a diferencia de las personas que no muestran interés hacia estas tareas (no se identifican con el ámbito). 
Los resultados de estos estudios también ofrecieron algunas de las características principales que definen esta situación de amenaza (Tabla 1). Cabe destacar que la amenaza del estereotipo es un factor situacional y no disposicional. Por tanto, lo que afecta al rendimiento es una situación en la que los sujetos perciben que van a ser juzgados en función de su grupo de pertenencia (mujeres, personas de raza negra, asiáticos, etc.), al cual se han asociado determinados estereotipos negativos que temen confirmar.

Tabla 1. Características de la amenaza del estereotipo según Steele (1997).

1. La amenaza del estereotipo no supone una característica psicológica propia de un determinado grupo, sino que afecta a los miembros de cualquier grupo estigmatizado sobre el cual recaigan estereotipos negativos.

2. La interpretación del comportamiento de un miembro de un grupo en función de uno o varios estereotipos negativos se hará más relevante en situaciones donde más salientes sean esos estereotipos como es, ser minoría dentro un grupo.

3. Los miembros de diferentes grupos sufrirán la amenaza del estereotipo en distinta forma y grado dependiendo del contenido de los estereotipos y las situaciones donde se apliquen.

4. Para sufrir las consecuencias de la amenaza del estereotipo no es fundamental creer en él y en su veracidad sobre uno mismo.

5. Los intentos por no confirmar el estereotipo pueden resultar contraproducentes debido a la ansiedad que provoca la situación y la mediación cognitiva derivada del esfuerzo por evitar signos que validen esas creencias.

Elaboración propia a partir del artículo de Steele (1997).

Por lo tanto, partiendo de estos estudios, la amenaza del estereotipo se define en el presente trabajo como una situación de presión en la que la presencia de determinados estereotipos negativos sobre un grupo social minoritario afecta al rendimiento de sus miembros en una determinada tarea. Además, el grado del efecto de esta amenaza va a ser diferente para los miembros del grupo estigmatizado en función de su identificación con las tareas realizadas.

\subsection{Formas de la amenaza del estereotipo.}

Los estereotipos negativos sobre el propio grupo pueden llevar a experimentar distintas formas de amenaza en función de dos dimensiones: el objeto de amenaza y la fuente de estereotipos. Esta idea resulta de un enfoque múltiple propuesto por Shapiro y Neuberg (2007) en el que se plantean distintos tipos de amenaza que implican ciertas variables que es necesario conocer y que precisarán de distintas formas de intervención. 
Figura 1. Formas de la amenaza del estereotipo.

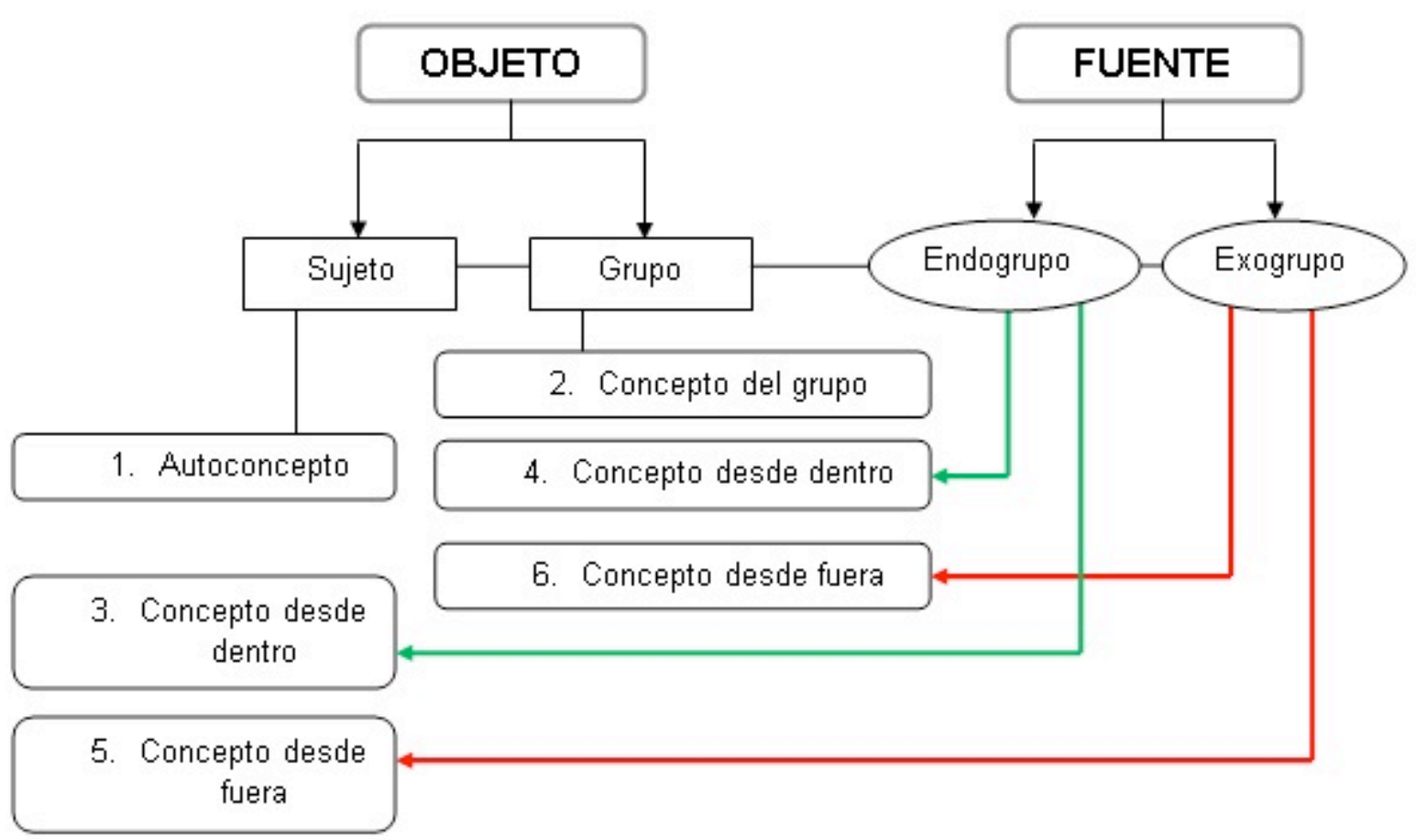

Elaboración propia a partir del artículo de Shapiro y Neuberg (2007).

El modelo representado en la Figura 1 parte de dos dimensiones dentro de la amenaza del estereotipo: el objeto ¿hacia quién va dirigida la amenaza? -puede ser el propio sujeto y/o el grupo al que pertenece- y la fuente ¿de dónde proviene el estereotipo? -puede tratarse del sujeto y/o de los que le rodean, los miembros de su grupo (endogrupo) y/o los miembros de otros grupos o grupo mayoritario (exogrupo). Partiendo de estos dos factores, se habla de seis posibles tipos de amenaza.

Para ilustrar mejor las diferentes amenazas que podrían tener lugar, pensemos en un caso concreto, el caso de Ismael y a la vez, consideremos el esquema de la Figura 1. Ismael tiene 28 años y ha sido diagnosticado de esquizofrenia hace aproximadamente cuatro años. Un estereotipo negativo sobre las personas con esquizofrenia podría ser, por ejemplo, su agresividad y conductas violentas. Esta creencia podría afectar a Ismael de la siguiente forma: Ismael podría sentir amenaza sobre su autoconcepto (1) ¿y si en realidad soy agresivo? o sobre el grupo al que se pertenece (2) ¿y si es verdad que las personas con esquizofrenia son agresivas? Asimismo, la reputación del sujeto vista desde dentro del grupo también puede verse afectada (3) preguntándose ¿y si las otras personas con esquizofrenia piensan que yo soy agresivo? y/o desde fuera (5), ¿y si los demás piensan que soy agresivo por tener esquizofrenia? Por último, también se encuentra amenazada la visión del grupo en su totalidad por el endogrupo (4) ¿y si las demás personas con esquizofrenia creen que en realidad somos agresivos? y desde fuera (6) ¿y si los demás en realidad piensan que las personas con esquizofrenia son agresivas y violentas? Cabe destacar que los distintos tipos de amenaza no son excluyentes, esto es, pueden estar presentes varios al mismo tiempo en la situación de amenaza.

Por lo tanto, la amenaza del estereotipo, desde un enfoque multiamenaza, afecta al sujeto de distinta forma dependiendo de la fuente y del objeto de amenaza, en función 
de si el estereotipo proviene de uno mismo, el propio grupo y/o los demás; y si recae sobre el sujeto y/o su grupo. A su vez, el tamaño de este efecto va a depender de una serie de variables como la creencia en el estereotipo entre otras, que se tratarán en el siguiente apartado (Véase punto 2.2 Variables moderadoras).

\section{Desarmando la amenaza del estereotipo. Variables mediadoras y variables moderadoras.}

Como puede observarse, la amenaza del estereotipo es un proceso complejo en el que pueden intervenir varios factores haciendo que su efecto sea mayor o menor. Como se ha mostrado previamente, este efecto se traduce en una disminución del potencial de cada persona que resulta en un menor rendimiento. Ahora cabe preguntarse, ¿por qué se produce esta disminución del rendimiento?, ¿el rendimiento de estos miembros del grupo siempre va a disminuir?, y si disminuye, ¿lo hará siempre de la misma forma?

Para responder a estas cuestiones, se va a recurrir en un principio a variables mediadoras que nos faciliten la comprensión de este efecto. En segundo lugar, se propone una serie de variables moderadoras que van a ayudar a entender cómo este efecto no siempre es igual, siendo diferente para unos miembros del grupo que para otros según características individuales y contextuales. A continuación se explicará de forma detallada, algunas de las más importantes.

\subsection{Variables mediadoras.}

Cuando un miembro de un determinado grupo se encuentra en una situación en la que percibe que va a ser juzgado en función de un estereotipo, se ponen en funcionamiento una serie de procesos psicológicos que desencadenan una disminución en el rendimiento. Este efecto en el rendimiento puede ser explicado por variables mediadoras asociadas al procesamiento de información como pueden ser el consumo excesivo de recursos cognitivos, alta vigilancia, sensibilidad a errores y alto grado de incertidumbre (Schmader, 2010).

Para poder entender mejor cómo se produce este efecto, pensemos de nuevo en un caso concreto. Por ejemplo, imaginemos la situación de Paula. Paula es una estudiante de bachillerato que ha escogido la modalidad tecnológica. Hay pocas chicas en su clase y sus padres en un principio, al igual que sus amigas, se sorprendieron de que eligiese esta opción. Asimismo, los profesores acostumbrados a la mayoría de chicos en el aula, en ocasiones muestran actitudes estereotipadas que hacen más partícipes a los chicos que a las chicas durante sus clases. Pronto va a tener lugar el primer examen de matemáticas del curso y Paula, que tiene gran interés en la materia, ha comenzado a prepararlo con bastante antelación. Además, piensa que es una buena oportunidad para demostrarles a todos que es tan capaz como sus compañeros de obtener buenos resultados. Por lo tanto, Paula tiene una alta motivación ante la tarea, sin embargo, al igual que quiere obtener una buena nota, también tiene miedo de no poder conseguirlo y que los demás "tengan razón". Por ello, el examen de matemáticas va a suponer para Paula un desafío que, como cualquier situación amenazante, aumentará su nivel de ansiedad. En este intento por evitar que los demás confirmen sus creencias, aumentará su control sobre los aspectos conductuales, fisiológicos y cognitivos que puedan denotar baja capacidad. Este hecho supone un gran consumo del sistema ejecutivo central, en concreto de la memoria de trabajo, el cual es necesario en su totalidad para realizar bien la tarea. Su atención estará dividida, es decir, los recursos cognitivos en lugar de centrarse en la resolución

6 ReiDoCrea. Revista electrónica de investigación Docencia Creativa. Volumen 2. Páginas 239-260 
de la tarea, tendrán en cuenta más aspectos que la tarea en sí. Además, para ella toda la información de la tarea será relevante y no seleccionará aquella que facilite su realización. En un intento por controlar todos aquellos indicios que puedan confirmar el estereotipo, Paula aumentará su vigilancia, prestando atención a sus pensamientos, su estado fisiológico, su conducta y la de los demás. En este proceso esta interpretación se hace de forma sesgada. La sensibilidad a los errores va a aumentar y evaluará su ansiedad ante la prueba como un signo de fallo o fracaso. Schmader explica este sesgo en la interpretación mediante la activación de pensamientos negativos que afectan a lo que uno está pensando, sintiendo y haciendo. Estas rumiaciones, que también absorben recursos cognitivos, supondrán también un esfuerzo para poder eliminarlos de la mente.

Por último, la situación de amenaza también puede crear incertidumbre sobre sus propias habilidades. En el momento de la realización del examen, Paula puede experimentar duda acerca de si puede hacer las tareas o no, a pesar de que anteriormente en otras asignaturas parecidas haya sido capaz de realizarlas correctamente obteniendo buenos resultados.

Cabe destacar que, como ya se ha planteado, la amenaza del estereotipo es una amenaza situacional y no ocurre únicamente en el momento en que el sujeto se someta a una evaluación. Las expectativas de que la prueba se realizará en un futuro, por ejemplo, durante la preparación para el examen en el caso de Paula, también supone un detrimento en el rendimiento (Steele, 1997).

Por lo tanto, la situación de amenaza va a suponer un aumento de los niveles de ansiedad. Los efectos perniciosos en el rendimiento debido a este tipo de suceso se pueden explicar principalmente por la carga cognitiva que experimentan los sujetos y que va a suponer un aumento de vigilancia y atención dividida hacia diferentes estímulos, conductas, emociones y cogniciones, sesgando su interpretación y prestando mayor atención a los errores. Como explicaremos a continuación, todas estas variables van a depender de diferencias individuales y situacionales que van a modificar el grado del efecto de la amenaza del estereotipo en el rendimiento.

\subsection{Variables moderadoras.}

Para poder entender las variables moderadoras que influyen en este efecto, Shapiro y Neuberg (Shapiro y Neuberg, 2007) proponen que cada una de estas variables consta de un umbral en el que superarlo a un nivel alto o bajo va a tener diferentes consecuencias en la intensidad del efecto. Esto es, dependiendo del nivel en estas variables, se va a producir un mayor o menor efecto, por lo tanto, una mayor o menor reducción del rendimiento de los sujetos.

Como se ha comentado anteriormente, los sujetos más afectados serán aquellos que se identifiquen más con una determinada tarea o ámbito en general. Tenemos, entonces, una variable moderadora muy importante la identificación para que este efecto se dé o no en los miembros del grupo, pero no va a ser la única.

Partiendo de los distintos tipos de amenaza que Shapiro y Neuberg proponían (Véase apartado Formas de la amenaza del estereotipo), se plantean distintas variables moderadoras en función de si es la propia persona (autoconcepto) o el grupo al que se pertenece el objeto de la amenaza y/o la fuente del estereotipo. Para representar mejor estas variables, retomemos el caso de Paula. Paula tiene ya una alta identificación con la modalidad de bachillerato elegida y por lo tanto, con la materia, por lo que el efecto de la situación de amenaza estará presente. ¿Qué variables 
influirán en la amenaza al autoconcepto? Una de estas variables puede ser la creencia de Paula en el estereotipo. Es decir, si ella cree en mayor medida que las mujeres tienen menos habilidades matemáticas o científicas en general, las situaciones de amenaza afectarán más a su autoconcepto que si esta creencia es menos fuerte. Otras variables relacionadas con la amenaza del autoconcepto podrían ser la necesidad de ser visto de manera positiva por los demás, la autoestima y la necesidad de pertenencia al grupo (Crocker y Wolfe, 2001; Kernis, Paradise Whitaker, Wheatman y Goldman, 2000; Leary, Kelly, Cottrell y Schreindorfer, 2006).

En cuanto a las variables que pueden afectar al concepto del grupo, se caracterizan por el deseo de la persona por que su grupo sea visto de manera positiva. Se considerarían dentro de esta categoría, contextos más o menos colectivistas y/o aquellos que exijan reconocimiento privado o público (Luhtanen y Crocker, 1992; Sellers, Rowley, Chavous, Shelton y Smith, 1997). Por ejemplo, para Paula podrían ser más amenazantes las tareas en grupo, como trabajos o ejercicios realizados y corregidos en clase, que cualquier tarea individual que pueda realizar en su habitación un día de estudio. Algo parecido ocurriría si la fuente del estereotipo es la propia persona, las situaciones privadas son las que menor efecto amenazante tendrían y más ventajas ofrecerían, tomando relevancia en este caso variables como la confianza y seguridad en uno mismo. En cambio, si consideramos que la fuente del estereotipo es el exogrupo, las situaciones públicas serían el contexto necesario para ofrecer una mejor visión de uno mismo y del grupo, estando presentes variables como el autocontrol y la confianza en el propio rendimiento. En relación con nuestro ejemplo, si Paula mantiene la creencia en el estereotipo, rendirá mejor en situaciones en las que no se cuente con la presencia de otros sujetos y su rendimiento dependerá de la confianza y seguridad en su capacidad, mientras que si la creencia viene de una fuente externa como pudieran ser familiares, profesores o compañeros, estas variables también serán importantes para demostrar ante ellos, en situaciones públicas, que el estereotipo sobre su grupo no se confirma.

Por lo tanto, la intensidad del efecto de la amenaza del estereotipo va a depender, en primer lugar, de la identificación con el ámbito y tareas relacionadas con él. En función del objeto de amenaza y la fuente de estereotipo, el efecto puede verse moderado por la creencia en el estereotipo, la necesidad de pertenencia y por la confianza y seguridad en uno mismo y el grupo. El tipo de situaciones, públicas o privadas, en el que tenga lugar la amenaza del estereotipo también moderarán su efecto.

\subsection{Una variable moderadora. El autocontrol como capacidad de resiliencia.}

A lo largo del estudio de la amenaza del estereotipo la literatura se ha centrado en mayor medida, en comprender el efecto nocivo en el rendimiento. Sin embargo, otros autores han mostrado mayor interés por aquellos miembros de grupos estigmatizados que superan las barreras y tienen éxito en estas áreas.

Inzlicht, Aronson, Good y McKay (2006) plantean las diferencias en el autocontrol como una variable moderadora. Estos autores parten de estudios que indican que las personas con altos niveles en autocontrol son sensibles a las demandas de las situaciones sociales, tienen habilidades para regular la expresión de su comportamiento, muestran una apariencia deseable socialmente y normalmente hacen más atribuciones externas de sus estados emocionales. Por otro lado, las personas con bajo autocontrol muestran poco interés por adecuar su comportamiento a las situaciones, tienden a regular y controlar menos la expresión de sus conductas y la presentación de sí mismos (Gangestad y Snyder, 2000; Snyder, 1974). 
Inzlicht y colaboradores pretendían estudiar si el autocontrol moderaba el efecto en el rendimiento de mujeres altamente identificadas con tareas matemáticas en situaciones de amenaza del estereotipo y, si este efecto, tenía lugar de forma directa o indirecta. Los resultados obtenidos mostraron que en ambientes en los que un grupo se encontraba en minoría, estereotipos negativos solían activarse y la magnitud del efecto dependía de las diferencias en autocontrol. Además, el autocontrol tenía una función indirecta, es decir, influía en la evaluación (appraisal) y en la atribución de significado de los estereotipos percibidos cambiando así la relación entre estereotipos y rendimiento. De esta forma, las personas con alto autocontrol interpretan las situaciones públicas como desafíos más que como amenazas. Este hecho no quiere decir que estos sujetos no perciban las situaciones de amenaza del estereotipo como tales, sino que el autocontrol funcionaría como capacidad de superación del estrés que supondría esa amenaza.

Por lo tanto, las personas con alto autocontrol mostrarían mayor capacidad para superar las situaciones de presión debido a que presentan altas habilidades adaptativas de afrontamiento y superación. Además, estos sujetos, emplearían mayores esfuerzos mentales para controlar su comportamiento, lograrían controlar la imagen que proyectan a los demás, siendo capaces de prevenir que los otros formen impresiones erróneas sobre ellos basadas en estereotipos negativos.

\section{Consecuencias de la amenaza del estereotipo. Propuesta de intervención.}

Hasta este punto se ha mostrado el efecto de la amenaza del estereotipo sobre el rendimiento de los individuos que pertenecen a grupos estigmatizados, sin embargo ¿qué consecuencias puede tener este efecto? De forma general, este tipo de amenaza va a tener repercusiones tanto sociales como personales, muchas de las cuales se han ido recopilando a lo largo de este trabajo. El presente apartado se dedica a las consecuencias principales de esta amenaza con mayor detenimiento, exponiéndose en el último punto diferentes propuestas de intervención y algunas recomendaciones generales para reducir su efecto.

\section{1 ¿Qué consecuencias tienen los efectos de la amenaza del estereotipo?}

Steele (1997) destacó la importancia de la identificación con el ámbito y cómo esta identificación se mantenía en función del rendimiento en el mismo (Véase apartado ¿Qué es la amenaza del estereotipo?). Así, en el caso de sujetos para los que el campo es relevante una de las primeras consecuencias tras una larga exposición a situaciones de amenaza del estereotipo sería desidentificación con el mismo, distanciamiento e incluso evitación de tareas relacionadas con el ámbito. Además, en un último momento los individuos pueden llegar a interiorizar dichos estereotipos, lo que crearía duda sobre sus propias capacidades, sentimientos de inferioridad, bajas expectativas de logro, baja eficacia personal y desmotivación. Todo esto, en suma, afectaría a la autoestima y al autoconcepto del sujeto. S. Steele (1990) se refiere a este efecto como vulnerabilidad racial. Una consecuencia importante derivada de este hecho en relación con el ámbito escolar es cómo afectaría a la elección de metas profesionales. Las actitudes hacia un ámbito influyen en la motivación para perseguir una meta concreta y deseada (Amodio y Devine, 2006) y la presencia de estereotipos puede sesgar esta persecución de metas dirigiendo la elección hacia opciones más estereotipadas como por ejemplo: mujeres enfermeras y profesoras, hombres médicos e ingenieros, etc. (Abrams, Thomas y Hogg, 1990).

A pesar de que los estudios sobre el efecto de la amenaza del estereotipo se han centrado en el rendimiento académico, es necesario tener en cuenta que cualquier 
actividad sobre la que se mantenga que un grupo obtendrá mejor resultados que otro, tendrá consecuencias para sus miembros. Así, esta amenaza se encuentra presente en tareas, ámbitos y grupos tan diversos como blancos y mujeres en el deporte (Stone, Lynch, Sjomerling y Darley, 1999; Stone y McWhinnie, 2008), mujeres en negocios (Kray, Galinsky y Thompson, 2002), homosexuales y cuidado de niños (Bossom, Haymovitz y Pinel, 2004), personas mayores y memoria (Levy, 1996), y mujeres y conducción (Yeung y Von Hippel, 2008).

A nivel social, es importante tener en cuenta que las repercusiones de este tipo de situaciones suponen evidencias a favor de los estereotipos, su confirmación y no cuestionamiento y por tanto, su mantenimiento, favoreciéndose su repetición en diferentes grupos y ámbitos.

Por lo tanto, los efectos de la amenaza del estereotipo muestran consecuencias importantes en las personas y en su desarrollo social que en muchas ocasiones van a determinar sus metas, objetivos y preferencias confirmando así y manteniendo los estereotipos a los que se son asociados por su grupo de pertenencia.

\subsection{Propuesta de intervención.}

La amenaza al estereotipo se considera un fuerte marcador de desigualdad para miembros de grupos sociales estigmatizados. Por esta razón, es necesario desarrollar formas de actuación para eliminar, o al menos reducir, su efecto. A continuación se desarrollarán tres tipos de intervención: contacto, reentrenamiento de actitudes y estereotipos, y autoafirmación. Se han considerado principalmente estas intervenciones porque presentan alto grado de efectividad y aplicabilidad. No obstante, en la literatura se pueden encontrar otras formas de intervención igualmente válidas.

\subsubsection{Contacto.}

Allport (1954) estudió el contacto entre miembros de diferentes grupos y bajo las condiciones adecuadas como una forma de reducción de la hostilidad y una mejora de las actitudes intergrupales. Desde entonces y hasta la actualidad, muchas de las intervenciones psicosociales que tienen como objetivo reducir el prejuicio y mejorar las relaciones entre grupos se basan en el contacto. ¿Podrían sus beneficios también ser aplicados al campo de la amenaza del estereotipo? Crisp y Abrams (2011) plantean un modelo integral en el que el contacto también es efectivo en la reducción de los efectos de los estereotipos en miembros de grupos estigmatizados.

El modelo planteado por estos autores establece un paralelismo entre los mecanismos psicológicos comunes del contacto y la amenaza del estereotipo: componente afectivo y cognitivo. El componente afectivo asociado al contacto se basa en la ansiedad intergrupal de los sujetos la mantener expectativas negativas, incertidumbre y miedo al rechazo del exogrupo. Los procesos cognitivos que tienen lugar durante el contacto y hacen de él una experiencia positiva se basan en la recategorización, esto es, la percepción de una identidad común más inclusiva que reduciría las diferencias entre los grupos. A través de la recategorización se favorece la percepción de variabilidad entre los miembros del exogrupo (Quattrone y Jones, 1980), se amplía la información empleada en la formación de impresiones (Ryan, Bogart y Vender, 2000), disminuye la tendencia a juzgar a los demás por su grupo de pertenencia (Ryan, Judd y Park, 1996) y disminuye la búsqueda de información congruente con los estereotipos (Pendry y Macrae, 1999). Por lo tanto, el contacto positivo mejoraría las actitudes por dos vías, afectiva -mayor contacto positivo, menos ansiedad intergrupal- y cognitiva -mayor contacto positivo, mayor percepción de una identidad común-. 
En cuanto a la amenaza del estereotipo, como ya se ha planteado, el estado de ansiedad durante una tarea relacionada con un determinado ámbito conlleva una disminución del rendimiento en esa tarea. La relación que se plantea en este estudio es que la ansiedad intergrupal en el contacto podría llegar a tomar la forma de la ansiedad experimentada durante la situación de amenaza, de manera que el miedo a ser juzgado negativamente en un encuentro intergrupal es similar al temor por ser evaluado como incompetente en un ámbito (miedo a confirmar el estereotipo negativo). El componente cognitivo en este caso se basa en la categorización, concretamente en la saliencia de categorías que, como se ha visto, es condición suficiente para que aparezca la amenaza (Steele, 1997). Por tanto, se plantea que una mayor experiencia de contacto llevaría a la percepción de una identidad común que supondría un menor acceso a estereotipos, reduciéndose así, el efecto nocivo en el rendimiento. Los diferentes estudios llevados a cabo en relación a estos dos componentes, afectivo y cognitivo se detallan a continuación.

Los efectos del contacto aplicados al campo de la amenaza del estereotipo, concretamente en relación a la ansiedad experimentada durante esta situación, fueron estudiados a través de un programa de investigación sobre el contacto intergeneracional en personas mayores (Abrams, Eller y Bryant, 2006). Se midió la calidad y cantidad de contacto directo, si tenían relación con el exogrupo; e indirecto, si tenían amigos con contactos en el exogrupo. Los resultados obtenidos apoyaron el planteamiento de que el contacto atenuaba el efecto de la amenaza del estereotipo disminuyendo la ansiedad que experimentaban los sujetos. Además, se observó que contar con al menos una forma de contacto, ya sea directo o indirecto, era suficiente para que se produjese este efecto.

Abrams y colaboradores $(2006 ; 2008)$ posteriormente mostraron que el contacto intrafamiliar, generalmente más accesible, tenía efectos más positivos. El conocimiento de este hecho es crucial para algunas intervenciones, pero presenta la limitación de que no todas las personas mayores tienen acceso a este contacto e incluso de ningún tipo. A raíz de esta limitación Crisp y Turner (2009), propusieron el estudio del contacto imaginado. El estudio de este efecto mostró que la activación de la representación de contacto positivo mitigaba la amenaza relacionada con la edad y devolvía el rendimiento al nivel normal. Esta técnica conseguía simular el efecto del contacto real simplemente imaginando una interacción intergrupal (Abrams, Crisp, Marques, Fagg, Bedford y Provias, 2008).

En esta línea, los trabajos sobre los efectos de la recategorización en el rendimiento durante la amenaza del estereotipo mostraron que a través de la generación de características compartidas por ambos grupos, el rendimiento en la tarea de los sujetos bajo amenaza mejoraba (Crisp y Beck, 2005). Como se mantiene, el contacto favorece la reducción del prejuicio y actitudes negativas lo cual implicaría la modificación de la percepción de uno mismo y los demás y a su vez, supondría una mejora de la autoestima, la confianza en uno mismo y la habilidad para manejar las situaciones de amenaza del estereotipo. Así, a través de esta recategorización las diferencias y los estereotipos sobre uno mismo disminuirían, existiendo así una menor susceptibilidad a pensar en ellos durante una determinada tarea (Cudder, Norton y Fiske, 2005).

Dentro de este tipo de intervención existen ciertas limitaciones que es necesario tener en cuenta previamente para evitar así posibles efectos contrarios a lo que se pretende. Los grupos minoritarios pueden resultar más desconfiados a la hora de establecer contacto con el exogrupo y por tanto, interpretar esta situación como una amenaza activándose otros estereotipos en detrimento de ambos grupos (Pinel, 2002). En este caso, se debe prestar especial atención a la relación intergrupal que se mantiene y a las condiciones en que se establece este contacto. También, cabe tener en cuenta que

11 ReiDoCrea. Revista electrónica de investigación Docencia Creativa. Volumen 2. Páginas 239-260 
la percepción de una identidad común puede suponer una amenaza a la identidad social de los sujetos, es decir, la diferenciación y las características de uno mismo y de su grupo de pertenencia. La sensación de pérdida de la identidad social podría acentuar las diferencias intergrupales (Brown y Abrams, 1986), sobre todo para sujetos altamente identificados con su endogrupo, favoreciéndose así el mantenimiento de los estereotipos tanto sobre uno mismo como sobre el exogrupo (Stone y Crisp, 2007).

Por otra parte, se debe tener en cuenta con qué grupos se va a trabajar y qué tareas se van a realizar y cómo. Por ejemplo, en pacientes con Alzheimer en los que se pretende medir la capacidad de memoria en relación a un grupo de jóvenes, se aconseja el uso de medidas indirectas (Helmes y Gee, 2000), ya que si se emplean tareas en las que esta capacidad está directamente implicada podría ser interpretado como una evaluación comparativa, resultando así, en un rendimiento aún menor (Schamder y Johns, 2003).

Por lo tanto, el contacto positivo entre dos grupos, bajo las condiciones adecuadas, reduce la ansiedad durante una situación de amenaza del estereotipo. Tiene importantes efectos en el aumento de autoestima que lleva a la evitación de activación de estereotipos sobre uno mismo y, por tanto, menor ansiedad ante una tarea relacionada con un ámbito estereotipado. En situaciones en las que el contacto directo no es accesible, el contacto imaginado puede llegar a mostrar efectos positivos similares.

\subsubsection{Reentrenamiento de actitudes y estereotipos.}

Forbes y Schmader (2010) estudiaron cómo el reentrenamiento de las actitudes y los estereotipos tenía un gran impacto en la reducción del efecto de la amenaza del estereotipo en el rendimiento. Los trabajos de estos autores para estudiar este efecto se basan en los estudios de Amodio y Devine (2006) sobre blancos americanos y afroamericanos en los cuales se mostraron que las actitudes y estereotipos tenían diferentes efectos en la realización de tareas. Las actitudes predecían la motivación para buscar, comprometerse y lograr una meta y evitar otras, mientras que los estereotipos, predecían la interpretación del procesamiento de información durante la persecución de un objetivo o realización de una tarea determinada.

Forbes y Schmader pretendían contrarrestar el efecto de la amenaza del estereotipo mediante la mejora de las actitudes hacia un ámbito determinado (por ejemplo, matemáticas), y desarmando los estereotipos asociados a ese grupo en ese ámbito ("las mujeres son peores en matemáticas"). Los resultados de sus trabajos mostraron que creando una actitud positiva hacia un ámbito, la motivación por perseguir ese ámbito aumentaba; y por otro lado, desafiando los estereotipos en ese campo se mejoraban las capacidades cognitivas de procesamiento necesarias para combatir el estereotipo. Por lo tanto, para estos autores el rendimiento es un proceso dual en el que la motivación es necesaria para alcanzar un objetivo y la capacidad cognitiva lo es para tener éxito en la tarea.

Como se ha revisado, la amenaza del estereotipo supone una reducción de los recursos cognitivos cuando se intenta controlar o suprimir signos que confirmen un estereotipo que ha sido activado, resultando así en un peor rendimiento. Además, esta disminución del rendimiento en una tarea llevaría al sujeto a esforzarse menos en la práctica y a distanciarse del ámbito posteriormente (Jamieson y Hankins, 2007). Cuando los individuos son entrenados con contraestereotipos sobre su grupo y un ámbito determinado, este procesamiento extra cesa, la memoria de trabajo mejora, se mitigan las dudas acerca de su propia capacidad y, por lo tanto, el rendimiento mejora. 
De esta forma, creando una asociación positiva con ese ámbito, la motivación para perseguir un mejor resultado en las tareas relacionadas aumentará.

Se considera conveniente tener en cuenta ciertas limitaciones a la hora de aplicar este tipo de intervención. En primer lugar, a pesar de que los estudios presentados plantean que los efectos de la inducción de una actitud positiva hacia un ámbito y la elaboración de contraestereotipos tienen una duración de numerosos días (Kawakami, Dovidio, Moll, hermsen y Russin, 2000), no se conocen por el momento datos acerca de la duración y estabilidad de estos resultados a largo plazo. Es necesario prestar atención también al grupo que se beneficia del estereotipo, puesto que al presuponer su éxito en la tarea, su motivación y esfuerzo por rendir bien en la misma, podría disminuir. En este caso, se debe trabajar la concepción de cada sujeto sobre sus habilidades como algo moldeable a través de la práctica (Dweck, Chiu y Hong, 1995).

Por otra parte, es importante considerar que estas medidas serán eficaces en mayor grado en sujetos con una motivación alta por el dominio, ante tareas de dificultad moderada y bajo situaciones en las que la amenaza del estereotipo ya esté presente 0 se cree que puede estarlo.

Por último, una pregunta permanece abierta en relación a si los efectos de este tipo de intervención producen un cambio de actitudes y estereotipos a nivel implícito o simplemente, explícito. Se mantiene que tras sucesivas experiencias empleando esta técnica, se podría conseguir una modificación de forma implícita, siempre y cuando el las tareas realizadas posteriormente se resuelvan con éxito.

Por lo tanto, las actitudes y estereotipos sobre un determinado ámbito afectan a la motivación y a la capacidad cognitiva para rendir de forma adecuada en las tareas relacionadas con ese ámbito. De esta forma, los cambios que se produzcan en relación a la mejora de las actitudes y la contradicción de los estereotipos van a tener un efecto positivo en el rendimiento del sujeto que se encuentre bajo una situación de amenaza del estereotipo.

\subsubsection{Autoafirmación.}

La sensación de una integridad personal dañada (conjunto de aptitudes personales) es una consecuencia importante de la amenaza del estereotipo, sobre todo para los individuos que más se identifican con un ámbito determinado. La autoafirmación es la fuente primaria de motivación humana y es definida como el logro y el mantenimiento de la integridad y valía personal y ha sido estudiada como una estrategia psicológica para reducir el efecto de la amenaza del estereotipo con resultados positivos (Steele, 1988; Steele y Liu, 1983).

En relación con el tema que nos ocupa, se plantea que los intentos por mantener la integridad personal a través de la afirmación de características propias que son valoradas y no relacionadas con la amenaza, permitirían enfrentar la situación de amenaza y mejorar el rendimiento (Martens, Johns, Greenberg y Schimel, 2006). Este estudio comparó dos grupos de mujeres, un grupo control y un grupo bajo condición de amenaza y autoafirmación. Ambos grupos debían completar una prueba que planteaba diferentes problemas (Graduate Management Test). La actividad de autoafirmación empleada consistía en ordenar una lista de 11 características y valores de importancia personal, tales como sentido del humor, creatividad, atractivo físico, habilidades sociales y relaciones con amigos/familia (Estudio 1). Posteriormente, los participantes en la condición de autoafirmación debían explicar por qué el primer valor en la lista era importante para ellos y describir algún momento en que así lo habían sentido. Los resultados encontrados no mostraron diferencias en el rendimiento entre las mujeres que realizaron el test bajo situación de amenaza y posteriormente, la 
actividad de autoafirmación; y las mujeres del grupo control, sin amenaza presente. Además, las mujeres que realizaron esta actividad consiguieron más ítems correctos. Dentro del mismo trabajo (Estudio 2), se comprobó que la autoafirmación se trataba realmente de una técnica para mitigar los efectos de la amenaza del estereotipo y no solo favorecía el rendimiento en general.

Una posible limitación dentro de este tipo de medida es la autonomía para llevar a cabo actividades de autoafirmación por parte de los sujetos. Se plantea si el resultado se mantendría si los sujetos conocen el objetivo de estas técnicas en la reducción de la amenaza del estereotipo. Además, si los sujetos no eran conscientes en un principio de que existe un determinado estereotipo, hacerlo saliente podría tener el efecto contrario que se está tratando evitar. Por último, en relación a la aplicabilidad es difícil que antes de una situación de evaluación exista tiempo y se dé el ambiente adecuado para poder realizar actividades de este tipo e incluso, llegar a tenerlas en cuenta.

Por lo tanto, como la amenaza del estereotipo supone un desafío para el autoconcepto de la persona y su grupo la autoafirmación sería efectiva eliminando y suprimiendo los pensamientos sobre estereotipos negativos. De esta forma, se liberarían recursos cognitivos lo que hace que mejore el rendimiento. Cabe destacar, que el ámbito debe ser relevante para la persona porque si no hay una identificación previa con éste, no supone amenaza para la integridad de la persona.

Las tres formas de intervención que se han presentado persiguen un mismo objetivo: reducir de los efectos de la amenaza del estereotipo, pero ¿cuál resultaría más eficaz? Para responder a esta pregunta se considera pertinente establecer una breve comparación entre las mismas ya que, como se ha podido observar, no son excluyentes pero la efectividad de cada una depende en gran medida de una serie de consideraciones y limitaciones.

La intervención basada en el contacto puede ser empleada como medida de prevención mientras que la eficacia de las dos restantes será mayor cuando la amenaza del estereotipo esté presente o se considere que puede estarlo. En este caso, las actividades de autoafirmación, por ejemplo autovaloración de características - capacidades personales que no se encuentran bajo amenaza, no supone un aumento del rendimiento general, es decir, si no existe amenaza, el efecto será casi imperceptible, pero tampoco perjudicial. Las actividades basadas en el contacto deben realizarse con grupos con un nivel de identificación bajo y también debe consideración de relación previa entre los grupos con los que se va a trabajar. Se debe tener en cuenta que no se debe tratar de eliminar diferencias, si no de crear una identidad común sin dejar de lado las características personales de cada grupo, por lo que es necesario trabajar también este aspecto. El reentrenamiento se recomienda en situaciones en que la amenaza del estereotipo pueda estar presente, en el uso de tareas que no son limitadas de tiempo y de dificultad moderada y considerando necesario reforzar la motivación del grupo que se beneficia del estereotipo. Algunos ejemplos de esta técnica son la presentación de miembros que hayan tenido éxito en tareas relacionadas, mayor consideración de aciertos y explicación de fallos, y de la mejora con la práctica.

\subsection{Algunas recomendaciones.}

Las técnicas de investigación que se han presentado en el apartado anterior no suponen una única forma de actuación para contrarrestar el efecto de los estereotipos negativos en el rendimiento. Existe una serie de factores que pueden ser controlados y diversas estrategias sencillas de gran aplicabilidad que también han demostrado ser 
efectivas. La mayoría de estas acciones han sido estudiadas concretamente para su aplicación en el contexto escolar, otras en cambio, presentan mayor generalización.

El efecto de la amenaza del estereotipo será menor si los sujetos ven las capacidades sobre las que recaen los estereotipos negativos como cambiantes a través de la experiencia y la práctica (Aronson, 2002). El hecho de atribuir los fallos en las tareas relacionadas con esas capacidades o habilidades a condiciones externas como pueden ser, presencia de ruido, hacinamiento, limitación de tiempo, etc., supone un alejamiento de la creencia negativa y a su vez, un aumento de la autoestima (Brown y Josephs, 1999; Stone, Lynch, Sjomeling, y Darley, 1999). Otra forma de intervención relacionada con la percepción de la amenaza, es la evaluación y valoración (reappraisal) de la ansiedad que supone la situación de presión. Por ejemplo, haciendo saber al sujeto que la ansiedad no perjudicará su rendimiento (Johns, Inzlicht, y Schmader, 2008) o normalizando este estado haciéndole saber que la tarea puede producir ansiedad por el contenido en sí de la misma (Schmader, Forbes, Zhang y Mendes, 2009) aliviará la carga del sistema ejecutivo central. Asimismo, hacer consciente a los sujetos del hecho en sí de la amenaza del estereotipo mostrándoles en qué consiste también tendrá efectos positivos en el rendimiento (Johns, Schmader y Martens, 2005).

La actitud del profesor hacia el alumno y la alumna debe ser optimista (Steele, 1997) y de confianza. No sólo el alumno o la alumna debe confiar en sus capacidades, sino que el profesor también debe creer en ellas. Las tareas encomendadas a los sujetos deben suponer un desafío más que facilidad en la resolución, ya que podría interpretarse como poca seguridad en sus capacidades. Los resultados de los alumnos y alumnas en las tareas siempre deben comentarse para explicar qué ha fallado haciendo hincapié en la mejora con la práctica y cuidando la forma de hablar y expresarse ya que podrían mostrarse actitudes estereotipadas.

Cabe destacar la diferenciación de este tipo de intervenciones según los sujetos estén identificados o no con el ámbito, ya que un sujeto que no está identificado con el mismo no va a mostrar interés de partida por cualquier actividad relacionada con él. En este caso, Steele (1997) propone que tanto el alumno y la alumna como el profesor, no deben centrar la atención en las respuestas correctas o incorrectas, sino emplear una estrategia socrática donde el sujeto vaya consiguiendo sus logros gradualmente. Así, poco a poco se construye la confianza de uno mismo en ese ámbito (Howard y Hammond, 1985). En cuanto a los alumnos y alumnas ya identificados, se debe afirmar esta relación con el ámbito destacando su habilidad en la resolución de los problemas y disipando cualquier duda sobre su propio potencial (por ejemplo, inteligencia maleable). Es conveniente que esto no se aplique únicamente a ese ámbito en concreto y se extienda a otros diferentes. Es importante además, que tengan conocimiento de aquellos miembros de su grupo de referencia que destacan o han destacado en esos ámbitos.

De forma general, se ha estudiado cómo llevar a cabo determinadas actividades unos minutos antes de la realización de un examen, test, prueba o situación de evaluación (no únicamente relacionada con el ámbito escolar) que pueda suponer la activación de ciertos estereotipos. Entre estas actividades se encuentran aquellas relacionadas con la autoafirmación, que ya se ha comentado en el apartado anterior. Un estudio reciente en relación a estas posibles actividades previas, propone tareas mindfulness (Weger, Hooper, Meier y Hopthrow, 2012). Esta técnica consiste en el desarrollo del autocontrol a través de la práctica de la detención del pensamiento y la concentración de la atención en una determinada tarea antes de la exposición a la situación.

Por lo tanto, se puede apreciar cómo a través de simples estrategias y el control de determinados factores se puede debilitar el efecto de la amenaza del estereotipo. 
Conocer estos tipos de intervención es importante puesto que su grado de aplicabilidad y efectividad es considerable. Además de esto, cualquier persona concienciada en su efecto y con interés por evitarlo, puede emplearlo con diferentes grupos y en diferentes ámbitos. 


\section{CONCLUSIÓN}

La amenaza del estereotipo es un fenómeno social importante que afecta en gran medida a los individuos que forman parte de grupos sociales estigmatizados. Estos grupos tienen asociados diferentes estereotipos negativos sobre sus capacidades en determinados ámbitos. Los estudios que han sido revisados en este trabajo están relacionados sobre todo con el ámbito escolar, sin embargo éste no es el único contexto en el que se pueden presentar situaciones de amenaza. Cualquier situación de la vida diaria que suponga la evaluación de un sujeto en función de la pertenencia a un grupo al cual se le asocian unas características negativas, va a producir los efectos de la amenaza del estereotipo. Desde un enfoque multiamenaza, se considera que la amenaza puede afectar al sujeto y/o al propio grupo dependiendo de la fuente del estereotipo y del objeto de amenaza.

Se ha revisado también, cómo funciona la amenaza del estereotipo. La situación de amenaza va a suponer un aumento de los niveles de ansiedad de los sujetos que se encuentran bajo esa situación que afecta a su rendimiento. El rendimiento disminuye principalmente por la carga cognitiva que experimentan los sujetos la cual supone un aumento de vigilancia y atención hacia diferentes estímulos, conductas, emociones y cogniciones, sesgando su interpretación y prestando mayor atención a los errores que cometen o podrían cometer. La intensidad de este efecto va a depender de diferencias individuales y situacionales que van a modificar el grado de efecto en el rendimiento. En este caso, la identificación con el ámbito y tareas relacionadas cobra gran importancia y es importante tenerlo presente durante todo este trabajo. Otras variables moderadoras del efecto dependen del objeto de amenaza y la fuente de estereotipo. Algunas de estas variables pueden ser la creencia en el estereotipo, necesidad de pertenencia a su grupo y confianza y seguridad en uno mismo y en su grupo. En cuanto a los factores situacionales que también influyen en el efecto, se encuentran las situaciones públicas o privadas en las que se encuentra el sujeto y tenga lugar la amenaza del estereotipo. Dentro de estas variables situacionales, se ha estudiado cómo las personas con alto autocontrol presentan habilidades adaptativas de afrontamiento y superación de situaciones de estrés, como puede ser la amenaza del estereotipo.

Los efectos de la amenaza del estereotipo van a tener unas consecuencias importantes en la persona y en su desarrollo social que determinan sus metas, objetivos y preferencias, y que no deben pasar desapercibidas. En este punto, es necesario concienciar a los profesores y profesoras, agentes educativos y de formación, de la existencia de este fenómeno y de cómo está en su mano controlar que no se produzcan este tipo de situaciones en el aula que pueden marcar en gran medida la percepción de los alumnos y alumnas de sí mismos. A nivel social, esta amenaza contribuye a la confirmación, y como consecuencia, al mantenimiento de los estereotipos sobre los miembros de un determinado grupo por lo que es importante que tanto los miembros de grupos estigmatizados como los de grupos mayoritarios sean conscientes de la fuerza de este efecto sobre determinadas capacidades. Por esta razón, se considera necesario desarrollar intervenciones efectivas para contrarrestar este efecto.

En el presente este trabajo se han presentado tres propuestas. El contacto positivo, tanto real como imaginado, ha mostrado tener importantes efectos en la disminución de la activación de estereotipos negativos y en la reducción de la ansiedad durante la situación de amenaza. Por otra parte, el reentrenamiento de las actitudes y estereotipos incrementa la motivación y la capacidad cognitiva facilitando un mejor rendimiento en las tareas relacionadas con un ámbito estereotipado. La autoafirmación también ha mostrado ser efectiva en la reducción del efecto de la amenaza del estereotipo. A través de la realización previa de actividades de afirmación de 
características valoradas personalmente, se puede reducir este efecto y favorecer un mejor rendimiento y resultados correctos.

Por último, se han presentado determinadas estrategias sencillas a través de las cuales, y junto al control de determinados factores, se puede debilitar este efecto nocivo en el rendimiento. De forma general, algunas de estas estrategias son la explicación de los resultados obtenidos por los sujetos haciendo hincapié en la plasticidad de las habilidades individuales. Según la identificación de estos alumnos y alumnas con el ámbito, estas estrategias van a ser distintas ya que el efecto no es el mismo en unos sujetos que en otros. Por ejemplo, para los alumnos y alumnas ya identificados es conveniente reforzar esa identificación, mientras que para aquellos que no muestran interés, se debe trabajar para crear ese vínculo. Conocer estos tipos de intervención es importante porque su grado de aplicabilidad y efectividad es considerable. La aplicación de estas técnicas y estrategias en un determinado colectivo o colectivos no requiere más que el interés por reducir los efectos de la amenaza del estereotipo. 


\section{REFERENCIAS}

Abrams, D., Crisp, R. J., Marques, S., Fagg, E., Bedford, L., \& Provias, D. (2008). Threat inoculation: Experienced and imagined intergenerational contact prevent stereotype threat effects on older people's math performance. Psychology and Aging, 23, 934-939.

Abrams, D., Eller, A., \& Bryant, J. (2006). An age apart: Effects of intergenerational contact and stereotype threat on performance and intergroup bias. Psychology and Aging, 2, 691-702.

Abrams, D., Thomas, J., \& Hogg. M. A. (1990). Numerical distinctiveness, social identity and gender salience. British Journal of social Psychology, 29, 87-92.

Allport, G. W. (1954). The nature of prejudice. New York: Doubleday Reading, MA: Addison-Wesley.

Amodio, D. M., \& Devine, P. G. (2006). Stereotyping and evaluation in implicit race bias: Evidence for independent constructs and unique effects on behavior. Journal of Personality and Social Psychology, 91, 652-661.

Aronson, J. (2002). Stereotype threat: Contending and coping with unnerving expectations. En J. Aronson (Ed.), Improving academic achievement: Impact of psychological factors on education. San Diego: Academic Press.

Bosson, J. K., Haymovitz, E. L., \& Pinel, E. C. (2004). When saying and doing diverge: The effects of stereotype threat on self-reported versus non-verbal anxiety. Journal of Experimental Social Psychology, 40, 247-255.

Brown, R., J., \& Abrams, D. (1986). The effects of intergroup similarity and goal interdependence on intergroup attitudes and task performance. Journal of Experimental Social Psychology, 22, 78-92.

Brown, R. P., \& Josephs, R. A. (1999). A burden of proof: Stereotype relevance and gender differences in math performance. Journal of Personality and Social Psychology, 76, 246-257.

Crisp, R. \& Abrams, D. (2011). Improving intergroup attitudes and reducing stereotype threat: An integrated contact model. European Review of Social Psychology, 19 (1), 242-284.

Crisp, R. J., \& Beck, S. R. (2005). Reducing intergroup bias: The moderating role of ingroup identification. Group Processes and Intergroup Relations, 8, 173-186.

Crisp, R. J., \& Turner, R. N. (2009). Can imagined interactions produce positive perceptions? Reducing prejudice through simulated social contact. American Psychologist, 64 (4), 231-240.

Crocker, J., \& Wolfe, C. T. (2001). Contingencies of self-worth. Psychological Review, 108, 593-623.

Cuddy, A. C., Norton, M. I., \& Fiske, S. T. (2005). This old stereotype: The pervasiveness and persistence of the elderly stereotype. Journal of Social Issues, 61, 267-285.

Dweck, C. S., Chiu, C., \& Hong, Y. (1995). Implicit theories and their role in judgments and reactions: A world from two perspectives. Psychological Inquiry, 6, 267-285. 
Forbes, C. E. \& Schmader, T. (2010). Retraining Attitudes and Stereotypes to Affect Motivation and Cognitive Capacity Under Stereotype Threat. Journal of Personality and Social Psychology, 99 (5), 740-754.

Gangestad, S. W., \& Snyder, M. (2000). Self-monitoring: Appraisal and reappraisal. Psychological Bulletin, 126, 530-555.

Helmes, E., \& Gee, S. (2000). Development of a training program in clinical geropsychology. Australian Journal on Ageing, 19, 113-117.

Howard, J., \& Hammond, R. (1985). Rumors of inferiority. New Republic, 72, 18-23.

Inzlicht, M., Aronson, J., Good, C. \& McKay, L. (2006). A particular resiliency to threatening environments. Journal of Experimental Social Psychology, 42, 323-336.

Jamieson, J. P., \& Harkins, S. G. (2007). Mere effort and stereotype threat performance effects. Journal of Personality and Social Psychology, 93, 544-564.

Johns, M., Inzlicht, M., \& Schmader, T. (2008) Stereotype threat and executive resource depletion: Examining the influence of Emotion regulation. Journal of Experimental Psychology: General, 137, 691-705.

Johns, M., Schmader, T. \& Martens, A. (2005). Knowing is half the battle: Teaching stereotype threat as a means of improving women's math performance. Psychological Science, 16, 175-179.

Kawakami, K., Dovidio, J. f., Moll. J., Hermsen, S., \& Russin, A. (2000). Just say no (to stereotyping): Effects of training in the negation of stereotypic associations on stereotype activation. Journal of Personality and Social Psychology, 78, 871-888.

Kernis, M. H., Paradise, A. W., Whitaker, D. J., Wheatman, S. R., \& Goldman, B. N. (2000). Master of one's psychological domain? Not likely if one's self-esteem is unstable. Personality and Social Psychology Bulletin, 26, 1297-1305.

Kray, L.J.,Reb,J., Galinsky, A., \& Thompson, L. (2004). Stereotype reactance at the bargaining table: The effect of stereotype activation and power on claiming and creating value. Personality and Social Psychology Bulletin, 30, 399-411.

Leary, M. R., Kelly, K. M., Cottrell, C. A., \& Schreindorfer, L. S. (2006). Individual differences in the need to belong: Mapping the nomological network. Unpublished manuscript, Wake Forest University.

Levy, B. (1996). Improving memory without awareness: Implicit self-stereotyping in old age. Journal of Personality and Social Psychology, 71, 1092-1107.

Luhtanen, R., \& Crocker, J. (1992). A collective self-esteem scale: Self- evaluation of one's social identity. Personality and social Psychology Bulletin, 18, 302-318.

Martens, A., Johns, M., Greenberg, J. \& Schimel, J. (2006). Combating stereotype threat: The effect of self-affirmation on women's intellectual performance. Journal of Experimental Social Psychology, 42, 236-243. 
Pendry, L. F., \& Macrae, C. N. (1999). Cognitive load and person memory: The role of perceived group variability. European Journal of Social Psychology, 29, 925-942.

Pinel, E. (2002). Stigma consciousness in intergroup contexts: The power of conviction. Journal of Experimental Social Psychology, 38, 178-185.

Quattrone, G. A., \& Jones, E. F. (1980). The perception of variability within in-groups and out-groups: Implications for the law of small numbers. Journal of Personality and Social Psychology, 38, 141-152.

Quin, R. \& McMahon, B. (1997). Historias y estereotipos. Madrid: Ediciones de la Torre.

Ryan, C. S., Bogart, L. M., \& Vender, J. P. (2000). Effects of perceived group variability on the gathering of information about individual group members. Journal of Experimental Social Psychology, 36, 90-101.

Ryan, C. S., Judd, C. M., \& Park, B. (1996). Effects of racial stereotypes on judgments of individuals: The moderating role of perceived group variability. Journal of Experimental Social Psychology, 32, 71-103.

Schmader, T. (2010). Stereotype Threat Deconstructed. Current Directions in Psychological Science, 19 (1), 14-18.

Schmader, T., Forbes, C. E., Zhang, S., \& Mendes, W. B. (2009). A mea-cognitive perspective on the cognitive deficits experienced in intellectually threatening environments. Personality and Social Psychology Bulletin, 35, 584-596.

Schmader, T., \& Johns, M. (2003). Converging evidence that stereotype threat reduces working memory capacity. Journal of Personality and Social Psychology, 85, 440-452.

Sellers, R., M., Rowley, S. A. J., Chavous, T. M., Shelton, J. N., \& Smith, M. (1997). Multidimensional inventory of black identity: Preliminary investigation of reliability and construct validity. Journal of Personality and Social Psychology, 73, 805-815.

Shapiro, J. R. \& Neuberg S. L. (2007). From Stereotype Threat to Stereotype Threats: Implications of a Multi-Threat Framework for causes Moderators. Personality and Social Psychology Review, 11 (2), 107-130.

Snyder, M. (1974). The self-monitoring of expressive behavior. Journal of Personality and Social Psychology, 30, 526-537.

Steele, C. M. (1988). The psychology of self-affirmation: Sustaining the integrity of the self. In L. Berkowitz (Ed.). Advances in experimental social psychology (Vol. 21, pp.261-302.). New York: Academic Press.

Steele, C. M. (1997). A threat in the air: How Stereotypes Shape the intellectual identities and performance of women and African Americans. American Psychologist, 52 (6), 613-629. 
Steele, C. M., \& Aronson, J. (1995). Stereotype threat and the intellectual test performance of African Americans. Journal of personality and social Psychology, 69, 797-811.

Steele, C. M., \& Liu, T. J. (1983). Dissonance processes as self-affirmation. Journal of Personality and Social Psychology, 45, 5-19.

Steele, S. (1990). The content of our character. New York: St. Martin`s Press.

Stone, C. h., \& Crisp, R. J. (2007). Superordinate and subgroup identification as predictors of intergroup evaluation in common ingroup contexts. Group Processes and Intergroup Relations, 10, 493-513.

Stone, J., Lynch, C. I., Sjomeling, M., \& Darley, J. M. (1999). Stereotype threat effects on Black and White athletic performance. Journal of Personality and social Psychology, $77,1213-1227$.

Stone, J., \& McWhinnie, C. (2008). Evidence that blatant versus subtle stereotype threat cues impact performance through dual processes. Journal of Experimental Social Psychology, 44(2), 445-452.

Tajfel, H. (1984). Grupos humanos y categorías sociales. Barcelona: Editorial Herder.

Weger, U.W., Hooper, N., Meier, B.P. \& Hopthrow. (2012). Mindful maths: Reducing the impact of stereotype threat through a mindfulness exercise. Consciousness and Cognition, 21, 471-475.

Yeung , N.C.J., \& Von Hippel, C. ( 2008 ). Stereotype threat increases the likelihood that female drivers in a simulator run over jaywalkers. Accident Analysis \& Prevention, $40,667-674$. 